\title{
Metabolic disturbances in mental illness
}

Citation for published version (APA):

Kucukgoncu, S. (2020). Metabolic disturbances in mental illness. [Doctoral Thesis, Maastricht University]. Digital Printing Partners. https://doi.org/10.26481/dis.20201214sk

Document status and date:

Published: 01/01/2020

DOI:

10.26481/dis.20201214sk

Document Version:

Publisher's PDF, also known as Version of record

\section{Please check the document version of this publication:}

- A submitted manuscript is the version of the article upon submission and before peer-review. There can be important differences between the submitted version and the official published version of record.

People interested in the research are advised to contact the author for the final version of the publication, or visit the DOI to the publisher's website.

- The final author version and the galley proof are versions of the publication after peer review.

- The final published version features the final layout of the paper including the volume, issue and page numbers.

Link to publication

\footnotetext{
General rights rights.

- You may freely distribute the URL identifying the publication in the public portal. please follow below link for the End User Agreement:

www.umlib.nl/taverne-license

Take down policy

If you believe that this document breaches copyright please contact us at:

repository@maastrichtuniversity.nl

providing details and we will investigate your claim.
}

Copyright and moral rights for the publications made accessible in the public portal are retained by the authors and/or other copyright owners and it is a condition of accessing publications that users recognise and abide by the legal requirements associated with these

- Users may download and print one copy of any publication from the public portal for the purpose of private study or research.

- You may not further distribute the material or use it for any profit-making activity or commercial gain

If the publication is distributed under the terms of Article $25 \mathrm{fa}$ of the Dutch Copyright Act, indicated by the "Taverne" license above, 


\section{Metabolic}

\section{Disturbances in \\ Mental IIIness}

Suat Kucukgoncu 
ISBN: 978-94-6423-042-0

Nur: 875

Cover Cover Image: Public Domain drawing by Suat Kucukgoncu Layout and printing: Digital Printing

@Suat Kucukgoncu, Istanbul 2020. All parts of this thesis may be reproduced, distributed, or transmitted in any form or by any means with the prior permission of the author. 


\title{
Metabolic Disturbances in Mental IIIness
}

\author{
DISSERTATION
}

to obtain the degree of Doctor at Maastricht

University, on the authority of the Rector Magnificus,

\author{
Prof. Dr. Rianne M. Letschert
}

in accordance with the decision of the Board of

\section{Deans,}

to be defended in public

on Monday 14 December 2020 at 10.00 hours

by

Suat Kucukgoncu

Born 1 April 1981 in Kayseri, Turkey

Approved after corrections

Prof. dr. Rianne M. Letschert

Rector Magnificus 


\section{Supervisor}

Prof. Dr. B.P.F. Rutten

\section{Co-supervisors}

Dr. S. Gülöksüz

\section{Assessment committee}

Prof. Dr. D.E.J Linden (Chair)

Prof. Dr. T.A.M.J. van Amelsvoort

Dr. M. Bak

Prof. Dr. J.J. van Os (Utrecht Medical Center)

Prof. Dr. L. de Haan (Amsterdam UMC)

The research presented in this thesis was performed at the School for Mental Health \& Neuroscience (MHeNS), department of Psychiatry \& Psychology, Maastricht University, the Netherlands, Yale University School of Medicine, Department of Psychiatry, New Haven, CT, and Bakırköy Research and Training Hospital for Psychiatry, Neurology, and Neurosurgery, Istanbul, Turkey 
Paranymphs

Cenk Tek

Ceren Ilkay Soylu 



\section{Table of Contents}

$\begin{array}{llr}\text { Chapter } 1 \text { Introduction } & \text { 1-25 }\end{array}$

Chapter 2 26-77

Glucose Metabolism Dysregulation at The Onset of

Mental Illness Is Not Limited to First Episode Psychosis:

A Systematic Review and Meta-Analysis

Chapter 3

78-115

Antipsychotic Induced Weight Gain in First Episode

Psychosis Patients: A Meta-Analysis of Differential

Effects of Antipsychotic Medications

Chapter 4

$116-138$

Alpha-Lipoic Acid (ALA) as a supplementation for weight loss:

Results from a Meta-Analysis of Randomized Controlled Trials

Chapter 5

139-181

Antipsychotic-exposure in pregnancy and the risk of gestational

diabetes: A Systematic Review and Meta-Analysis

\section{Chapter 6}

182-206

Clinical features of night eating syndrome among depressed patients

\section{Chapter 7}

207-216

Effects of Curcumin on cognitive functioning and inflammatory state in schizophrenia: A double-blind placebo-controlled pilot trial

$\begin{array}{lll}\text { Chapter } 8 & \text { Discussion } & \mathbf{2 1 7 - 2 3 4} \\ \text { Summary } & \mathbf{2 3 5 - 2 3 8} \\ \text { Impact } & \mathbf{2 3 9 - 2 4 1} \\ \text { Acknowledgment } & \mathbf{2 4 2} \\ \text { Curriculum Vitae } & \mathbf{2 4 3} \\ \text { List of publications } & \mathbf{2 4 4 - 2 4 9}\end{array}$


Chapter 1 
Chapter I. Introduction

\section{Introduction}


People with severe and persistent mental illnesses (SMI), such as schizophrenia spectrum disorders, bipolar disorder and major depression, die 10 to 20 years earlier than the general population (E. R. Walker, McGee, \& Druss, 2015). Although suicide partly explains the shortened life expectancy, most of this early mortality can be attributed to the premature cardiovascular disease (CVD) (Correll et al., 2017; Vancampfort et al., 2016; E. R. Walker et al., 2015). Several cross-sectional and longitudinal studies have shown that people with SMI have much higher risk of developing CVD compared to the general population (Correll et al., 2017; Saari et al., 2005). In a recent largescale meta-analysis, the pooled prevalence and cumulative incidence of CVD among SMI patients and general population were found to be $9.9 \%(\mathrm{Cl}=7.4-$ 13.3) and 3.6\% ( $\mathrm{Cl}=2.7-5.30)$, respectively (Correll et al., 2017). The same study also showed that people with SMI have 53\% higher risk of having CVD, a $78 \%$ higher risk of developing CVD, and an $85 \%$ higher risk of death from CVD compared to the matched general population. Taken together, these findings represent a challenging, but preventable, healthcare disparity among people with SMI (Mangurian, Newcomer, Modlin, \& Schillinger, 2016).

Type 2 diabetes mellitus (DM) is a major risk factor for CVD. Like CVD, people with SMI have increased risk for developing diabetes. The prevalence of diabetes mellitus in people with SMI is reported to be two to threefold higher than the age-matched general population samples (De Hert et al., 2010; Regenold, Thapar, Marano, Gavirneni, \& Kondapavuluru, 2002; van Winkel et al., 2008). A recent meta-analysis with a sample size of 438,245 people with SMI reported the pooled diabetes prevalence as $11.3 \%$ (Vancampfort et al., 2016). Similarly, another meta-analytic study showed an increased risk for diabetes by 1.70 fold in people with SMI (Osborn et al., 2008).

Several underlying mechanisms have been postulated to explain the relationship between diabetes and SMI (Perry, Mclntosh, Weich, Singh, \& Rees, 2016; Calkin, Gardner, Ransom, \& Alda, 2013; Vancampfort et al., 2016). One of the main contributors of the increased diabetes rate in SMI 
patients is related to the side effects of antipsychotic medications. Particularly, antipsychotic induced body weight gain and altered insulin metabolism are well-established factors contributing to the development of diabetes in SMI (D. B. Allison et al., 1999; Calkin et al., 2013; Ramaswamy, Masand, \& Nasrallah, 2006). In addition to the antipsychotic side effects, research from pre-antipsychotic era (Henneman, Altschule, \& Goncz, 1954), as well as findings from treatment-naïve, first episode psychosis (FEP), indicate impaired glucose metabolism, insulin resistance, and increased rates of diabetes before antipsychotic use (C. Garcia-Rizo, Kirkpatrick, FernandezEgea, Oliveira, \& Bernardo, 2016; Greenhalgh et al., 2016; Guha et al., 2014; Pillinger et al., 2017). Similar to the findings in patients with FEP, research with treatment-naïve, first episode patients with bipolar disorder and major depression also suggest altered glucose metabolism and increased rate of DM in people with SMI (Chang et al., 2013; Clemente Garcia-Rizo et al., 2013; Guha et al., 2014). While these findings suggest a pre-diabetic condition and biological vulnerability to the development of DM in SMI patients, we have still limited knowledge on the differences of glucose metabolism outcomes across different categories of SMIs.

At this background, Chapter 2 examines previous findings on glucose metabolism alterations in treatment-naïve, first episode patients with SMI. Additionally, this chapter also provides possible explanations regarding shared biological pathways that lead to increased diabetes rate in people with SMI.

\section{Antipsychotic Medications and Obesity}

Obesity is an important intersecting factor that contributes to the development of both CVD and diabetes. A multitude of studies demonstrated an alarming increase in the prevalence of obesity among people with SMI. Obesity rates in people with SMI is estimated to be two to three times higher than the general population (D. B. Allison et al., 1999; Annamalai, Kosir, \& Tek, 2017; Keck \& McElroy, 2003; Saari et al., 2005). For example, Allison et al. (D. B. Allison et al., 1999) showed that $42 \%$ of individuals with 
schizophrenia had a BMI of 27 or greater, compared to $27 \%$ in the general population. Similarly, a large number of research and meta-analyses confirmed the increased rates of obesity among patients with bipolar disorder and major depression (Jantaratnotai, Mosikanon, Lee, \& Mclntyre, 2017; Keck \& McElroy, 2003). It also appears that the impact of obesity is more dramatic in people with SMI than in the general population. Obesity in SMI is associated with significantly increased outpatient medical costs, stigma and discrimination at workplace and in society, and additional decline in quality of life (Annamalai et al., 2017; L. Chwastiak, Rosenheck, \& Leslie, 2006; L. A. Chwastiak et al., 2009; Kolotkin et al., 2008). These findings underscore the impact of obesity and urgency of the problem in this vulnerable population.

Obesity in people with SMI is multifactorial. Poor knowledge about nutrition, increased costs of, and lack of access to, healthy foods contribute to increased prevalence of obesity among SMI patients (Annamalai et al., 2017; Ratliff et al., 2012). However, the most important factor for the obesity epidemic in this population is the necessity for continuous antipsychotic treatment (D. B. Allison et al., 1999). Antipsychotic medications have been associated with increased body weight since their introduction in the 1950's (Mefferd, Labrosse, Gawienowski, \& Williams, 1958; Rockwell, Ellinwood, \& Trader, 1983). In a landmark study, Allison et al. (D. B. Allison et al., 1999) reviewed weight gain liabilities of various antipsychotic medications. This study found that almost all antipsychotic medications were associated with weight gain to a varying degree: patients on clozapine had a mean weight gain of $3.99 \mathrm{~kg}$, followed by a mean weight gain of $3.51 \mathrm{~kg}$ for olanzapine, $2.10 \mathrm{~kg}$ for chlorpromazine, $2.00 \mathrm{~kg}$ for risperidone, $0.48 \mathrm{~kg}$ for haloperidol, $0.43 \mathrm{~kg}$ for fluphenazine, and $0.04 \mathrm{~kg}$ for ziprasidone. Further studies of chronic SMI patients also showed differentiating weight gaining effects of antipsychotics, with second-generation antipsychotic medications (clozapine, olanzapine, risperidone etc.) having more impact on body weight than firstgeneration antipsychotics (haloperidol, fluphenazine etc.) (Lieberman et al., 2005; Newcomer \& Hennekens, 2007; Newcomer \& S., 2005). Although the 
exact mechanism of antipsychotic induced weight gain has yet to be elucidated, the effects of antipsychotics on appetite and energy metabolism through histamine $(\mathrm{H} 1)$, serotonin (5HT2A, 5HT2C), dopamine (D2) and muscarinic (M3) receptors has been linked to increased body weight (Casey \& Zorn, 2001; Dayabandara et al., 2017).

Given above-mentioned studies reported outcomes from chronic patients, weight gain liabilities for the use of individual antipsychotics might be somewhat different. Research suggests that rapid body weight gain is observed in the first few weeks after the initiation of antipsychotics, and it gradually decreases and flattens over the following months (Dayabandara et al., 2017; Rummel-Kluge et al., 2010). In line with these findings, a previous meta-analysis showed a more noticeable weight gain due to antipsychotic medications in patients with FEP compared to chronic patients (Parsons et al., 2009). The ideal way to explore the individual effects of antipsychotics on body weight is to study first-episode patients as weight outcomes are less likely to be influenced by previous antipsychotic exposure (Bak, Fransen, Janssen, van Os, \& Drukker, 2014). However, evaluating true effects of antipsychotic medications on body weight in patients with FEP is a challenging task. First onset of most mental disorders occurs in childhood or adolescence. First episode psychosis shows a marked increase in prevalence between ages 15-17 (Kessler et al., 2007). Therefore, most patients with FEP is still on body growth phase when antipsychotic medications are initiated. Lack of placebo-controlled studies, due to the ethical reasons, has limited our knowledge of the effect of antipsychotic medications on body weight, in addition to that of the continuing growth phase, in this population. Identifying individual weight gain liabilities of antipsychotic medications may help us develop better strategies for prevention of antipsychotic-related weight gain and consequent CVD risk. To this end, Chapter 3 explores the individual effects of antipsychotic medications on short-term ( $<12$ weeks) and long-term ( $>12$ weeks) body weight changes in patients with FEP. 
As mentioned above, obesity and related medical morbidity (i.e. diabetes, hypertension, ischemic heart disease) translate to higher mortality rates and shorter life expectancy for patients with SMI compared to the general population. Thus, there is an urgent need to develop solutions for obesity problem in patients with SMI.

Alpha lipoic acid (ALA), is a naturally occurring short chain fatty acid which is an essential cofactor for energy production in the mitochondria, a powerful antioxidant and a free radical scavenger (Bast \& Haenen, 2003; Deneke, 2000; Evans \& Goldfine, 2000). Several studies have shown that antipsychotic medications contribute to weight gain by stimulating hypothalamic adenosine monophosphate dependent protein kinase (AMPK) and blocking adipocyte hormone leptin's inhibition of hypothalamic AMPK (Carbonelli et al., 2010; Koh et al., 2011; Ansar, Mazloom, Kazemi, \& Hejazi, 2011; McNeilly et al., 2011). In animal studies, ALA has been shown to suppress hypothalamic AMPK activation independent of leptin pathways, thus decreasing appetite; while activating peripheral AMPK, and thus increasing peripheral catabolic activity (Prieto-Hontoria, Perez-Matute, Fernandez-Galilea, Alfredo Martinez, \& Moreno-Aliaga, 2013; PrietoHontoria et al., 2009). Limited number of clinical studies yielded mixed results on anti-obesity effects of ALA. Although, some clinical trials reported that ALA may help to lose body weight (Carbonelli et al., 2010; Koh et al., 2011), other studies failed to confirm this effect (Ansar et al., 2011; McNeilly et al., 2011). Chapter 4 will examine the effect of ALA on body weight through a systematic review and meta-analysis.

\section{Antipsychotic Exposure and Gestational Diabetes}

A common pregnancy complication, gestational diabetes, is a growing health concern (DeSisto, Kim, \& Sharma, 2014). Gestational diabetes is a form of diabetes, defined as glucose intolerance with onset or the initial diagnosis during pregnancy (Buchanan, Xiang, Kjos, \& Watanabe, 2007). Several maternal health consequences, including the development of diabetes and SMI later in life, have been associated with gestational diabetes 
(Bellamy, Casas, Hingorani, \& Williams, 2009; Buchanan et al., 2007; Van Lieshout \& Voruganti, 2008). In addition to well established risk factors (i.e. maternal age, obesity) (Buchanan et al., 2007), SMI is also associated with gestational diabetes (Nguyen et al., 2013).

Pregnant women with SMI represent a unique population regarding antipsychotic medication exposure. SMI usually peaks during the reproductive ages and has a significant impact on the physical health of female patients during pregnancy (Kulkarni et al., 2015; Park et al., 2018). It is estimated that more than $50 \%$ of women with SMI become pregnant (Coughlin et al., 2015; McCauley-Elsom, Gurvich, Elsom, \& Kulkarni, 2010). In most cases, these pregnancies are unwanted and not closely monitored. Hence, the management of SMI during pregnancy poses significant challenges to mothers and clinicians (Kulkarni et al., 2015; Park et al., 2018).

Glucose regulation during healthy pregnancy has a crucial role on supporting the demands of the growing fetus. Naturally, insulin sensitivity alters depending on the requirements of the mother and the fetus (Buchanan et al., 2007; Plows, Stanley, Baker, Reynolds, \& Vickers, 2018). While insulin sensitivity increases during early gestation, a surge of local and placental hormones (i.e. estrogen, progesterone, placental growth hormone) leads to insulin resistance during late gestational phases (Plows et al., 2018). On the other hand, research suggests that people with SMI have an innate vulnerability to develop glucose metabolism abnormalities and insulin resistance (C. Garcia-Rizo et al., 2016; Greenhalgh et al., 2016; Guha et al., 2014; Pillinger et al., 2017). An overlap of the innate vulnerability in SMI and the natural course of pregnancy may also increase the risk of GDM development.

Exposure to antipsychotics during pregnancy was also proposed as an additional risk factor for GDM. Antipsychotic use during pregnancy has increased over the years (Toh et al., 2013; Vigod, Gomes, Wilton, Taylor, \& Ray, 2015). Increased risk for relapse of SMI during pregnancy necessitates the use of antipsychotics during this period (Toh et al., 2013; Whitworth, 
2017). Exposure to antipsychotics during pregnancy also increased because of the "off-label" use of these medications (Kulkarni et al., 2015). Antipsychotic related adverse-effects, mainly weight gain and altered glucose metabolism, may increase risk of GDM for pregnant women on antipsychotics (Kulkarni et al., 2015; Park et al., 2018). However, limited number of studies have revealed inconsistent results on the relationship between pregnancyterm-antipsychotic-exposure and GDM (Bellet et al., 2015; Boden et al., 2012; McKenna et al., 2005; Reis \& Kallen, 2008). Given the deleterious health outcomes of GDM, it is critical to understand the risk of antipsychotic exposure related GDM in women. Accordingly, Chapter $\mathbf{5}$ evaluates previously published studies to improve our knowledge on the risk of GDM in pregnant women treated with antipsychotics.

Night Eating Syndrome: A Disorder with Impaired Health

\section{Outcomes}

Chapter 6 focuses on Night Eating Syndrome (NES), which is associated with impaired health outcomes and SMI. NES is mainly characterized by recurrent episodes of night eating, as manifested by excessive eating following the evening meal and/or by eating consciously after awakening from sleep (Kucukgoncu, Midura, \& Tek, 2015). NES has been investigated among various populations, including people with mental disorders, obesity, and diabetes mellitus (Calugi, Dalle Grave, \& Marchesini, 2009; Lundgren et al., 2006; Palmese et al., 2012). In the general population, the prevalence of NES was estimated to be between 1.1 to 1.5 (de Zwaan, Muller, Allison, Brahler, \& Hilbert, 2014; Lundgren et al., 2006; Rand, Macgregor, \& Stunkard, 1997). Compared to the general population, the reported prevalence of NES was higher in psychiatric patient populations, varying between $12.4 \%$ and $22.4 \%$ in psychiatric outpatients, and from $21.3 \%$ to $35.2 \%$ in patients with major depression, and between $15 \%$ and $44 \%$ in patients with binge eating disorder (Kucukgoncu et al., 2015). Although these findings suggest an alarmingly high comorbidity between NES and various 
mental disorders, NES has yet to be recognized by clinicians (K. C. Allison \& Tarves, 2011).

Research suggests a relationship between NES and major depression (K.C. Allison, Grilo, Masheb, \& Stunkard, 2005; de, Roerig, Crosby, Karaz, \& Mitchell, 2006; Kucukgoncu et al., 2015). Numerous studies reported increased rates of major depression and more frequent depressive symptoms in patients with NES (K.C. Allison et al., 2005; Calugi et al., 2009; de et al., 2006; Lundgren, Allison, O'Reardon, \& Stunkard, 2008). Similarly, the prevalence of NES was reported to be higher in patients with major depression compared to the general population (Kucukgoncu \& Bestepe, 2014; Orhan et al., 2011). Although the exact mechanism remains unexplained, research points to the disruption in serotonergic system as a possible underlying mechanism (Lundgren, Newberg, et al., 2008; O'Reardon et al., 2004; Stunkard et al., 2006). Limited number of clinical studies that reported improvement of NES symptoms with selective serotonin reuptake inhibitor treatments also provided support for the role of the serotonergic system in NES (K.C. Allison et al., 2013; O'Reardon et al., 2004; Stunkard et al., 2006).

NES was also associated with body weight gain ever since it was first described in people with obesity (Stunkard, Grace, \& Wolff, 1955). Altered serotonergic system functioning is a putative mechanism for weight gain in NES owing to the interaction between the serotonin system and appetite. While few cross-sectional studies confirmed the relationship between obesity and NES, others reported contrasting findings (Bruzas \& Allison, 2019; Kucukgoncu et al., 2015). Nevertheless, the interaction between obesity and NES remains to be elucidated.

Considering the comorbidity of NES and major depression, and their cumulative effects on health outcomes, it is important to evaluate the impact of NES in major depression. In this regard, Chapter 6 examines the clinical effects of NES in a sample of patients with major depression.

\section{Improving Cognitive Functioning in Patients with Schizophrenia}


Cognitive impairment is one of the core features of SMls (Bortolato, Miskowiak, Kohler, Vieta, \& Carvalho, 2015). Particularly in patients with schizophrenia, cognitive impairment has been recognized as an enduring problem over the course of the disease and is associated with poor overall functioning (Schulz \& Murray, 2016). Current research points to the role of aberrant immune system response in pathogenesis of schizophrenia as evidenced by association between pre-natal infection and schizophrenia, pro/anti- inflammatory cytokine imbalance, and association of immunerelated genes with schizophrenia (Fineberg \& Ellman, 2013; Miller, Buckley, Seabolt, Mellor, \& Kirkpatrick, 2011). A recent meta-analysis shows many of the pro-inflammatory cytokines are increased in schizophrenia; and IL-1 $\beta$, IL6 , and transforming growth factor (TGF)- $\beta$ emerge as state markers for acute psychosis, whereas others (IL-12, interferon (IFN)- $\gamma$, tumor necrosis factor (TNF)- $\alpha$, and soluble interleukin receptor (sIL-2R)) may be trait markers (Miller et al., 2011).

Immune activation has been associated with cognitive decline in the general population, people with Alzheimer's disease (AD), and, to a certain degree, in those with schizophrenia (Asevedo et al., 2013; Dickerson, Stallings, Origoni, Boronow, \& Yolken, 2007; Fineberg \& Ellman, 2013; McAfoose \& Baune, 2009). Peripheral CRP, IL-1 $\beta$, IL- 6 and TNF- $\alpha$ have been associated with cognitive decline and dementia in both cross-sectional and prospective population studies (Asevedo et al., 2013; Dickerson et al., 2007; Fineberg \& Ellman, 2013; McAfoose \& Baune, 2009). Cross-sectional studies in patients with schizophrenia indicate immune activation, which may lead to cognitive impairment (Asevedo et al., 2013; Dickerson et al., 2007).

Currently, there are no pharmacological agents that specifically aim to treat cognitive functioning in patients with SMI. Therefore, there is growing interest in the development of such effective treatments. There is limited research focused on the effects of anti-inflammatory medications, such as aspirin and $\mathrm{N}$-acetylcysteine, and cognitive functioning in patients with 
schizophrenia (Vreeker, van Bergen, \& Kahn, 2015). Although, the results of adjunctive anti-inflammatory medications trials in schizophrenia showed improvements in some of the symptoms in schizophrenia, this effect does not extend to cognition in most studies (Muller, Riedel, Schwarz, \& Engel, 2005; Nitta et al., 2013; Vreeker et al., 2015). However, recent studies show that minocycline (a tetracycline antibiotic), which has pleiotropic anti-inflammatory properties directed at several targets (e.g. reducing cyclooxygenase(COX)-2 expression, inhibiting TNF- $\alpha$ induced apoptosis by downregulation of proinflammatory cytokines, and nuclear factor kappa B (NF-kB) mediated microglial activation) and a neuroprotective profile, has a beneficial effect on negative symptoms and cognitive functioning, mainly in executive functions (e.g. working memory, cognitive set shifting, and cognitive planning) (Levkovitz et al., 2010; Liu et al., 2014).

Curcumin, derived from turmeric root, is a polyphenol with antioxidant and anti-inflammatory properties targeting multiple molecular targets, such as inflammatory mediators (chemokines, cytokines such as IL-1 $1 \beta$, IL-6, and TNF- $\alpha$, COX-2 inhibition), transcription factors (e.g. NF-KB), protein kinases, enzymes, growth factors, and anti-apoptotic proteins (Lee et al., 2013; Naksuriya, Okonogi, Schiffelers, \& Hennink, 2014). Indeed, this pleiotropic nature emerges curcumin as a distinguished and robust modulator of immune and cell-cycle pathways. Therefore, there is growing interest in curcumin for the treatment of inflammatory conditions, cancer, and $A D$. In vitro and in vivo studies showed that curcumin suppresses activated immune pathways, thereby promoting neuronal survival. The results of the pre-clinical trials are encouraging for the treatment of $A D$, however preliminary clinical trials failed to meet the robust effects observed in pre-clinical trials. To date, only limited number of trials have tested the effectiveness of add-on curcumin in patients with schizophrenia (Woodbury-Farina, 2012; Wynn et al., 2017). An open label study investigating curcumin in patients with schizophrenia with persistent negative symptoms (Scale for the Assessment of Negative Symptoms $>30)$ showed that both curcumin $1 \mathrm{~g} /$ day $(n=7)$ and $4 \mathrm{~g} /$ day $(n=$ 
8) improve negative symptoms over 12 weeks in both groups (WoodburyFarina, 2012). Furthermore, this study showed positive change in overall neurocognitive index in both groups without serious adverse events. However, a recent double blind, randomized, placebo-controlled study has failed to show any clinical or cognitive improvements with add-on curcumin treatment in patients with schizophrenia (Wynn et al., 2017). To analyze the interaction between inflammatory response and cognitive functioning, Chapter 7 presents an 8-week randomized, double-blind, placebo-controlled, parallel, fixed-dose add-on curcumin trial for the treatment of inflammatory response and cognitive impairment in schizophrenia.

\section{Aims of the thesis}

The overall aim of this thesis is to examine the factors that lead to the increased obesity rates and cardio-metabolic risk in people with SMIs. Obesity among people with SMI and preventive treatment options are still largely understudied issues that have major public health significance, leading to early mortality in SMI. Although several health care organizations, including the World Health Organization (WHO), the Surgeon General and the Institute of Medicine, and American Heart Association urged health care policy makers and clinicians to address the increased mortality gap among people with SMI (Mangurian et al., 2016), these efforts unfortunately provided limited achievement. Despite the increased risk of CVD and diabetes, people with SMI, even those diagnosed with chronic physical diseases, often do not receive recommended care and monitoring (McGinty, Baller, Azrin, JulianoBult, \& Daumit, 2015; Frayne et al., 2005). For instance, the Clinical Antipsychotic Trials of Intervention Effectiveness (CATIE) study with 1460 patients with chronic schizophrenia reported that $62 \%$ of those who had hypertension and $30 \%$ of those who had diabetes received no medications for these chronic medical problems (Nasrallah et al., 2006). Given the high burden of disease and suboptimal medical care, it is important to understand 
the factors that lead to increased cardio-metabolic problems in people with SMI.

The thesis aims to synthesize current knowledgebase by conducting systematic reviews and meta-analytic studies of cardio-metabolic problems and treatment options in psychiatric disorders. Meta-analysis is a powerful technique for research synthesis to answer clinical questions such as APinduced weight gain and to guide further research. Most importantly, metaanalyses are important for developing treatment guidelines, medical research, and clinical practice (Egger \& Smith, 1997; Lawrentschuk, McCall, \& Güller, 2009; E. Walker, Hernandez, \& Kattan, 2008). Although metaanalytic procedure may have some limititations (i.e. publication bias, poor data quality, outcome variability), a well conducted meta-analysis provides more objective evidence than traditional reviews and a better estimation of treatment effect (Egger \& Smith, 1997). Additionally, such meta-analysis may also help explain heterogeneity between individual study results, thus offers a better understanding of the subject matter (Egger \& Smith, 1997).

At this background, Chapter 2 aims to extend previous findings on glucose metabolism disturbance in patients with FEP by conducting a systematic review and a meta-analysis in first episode, treatment-naïve patients with FEP, as well as first episode, treatment-naïve patients with depression and bipolar disorder. The second aim of this chapter is to examine the differences of pooled results from glucose metabolism outcomes between three diagnostic categories. Chapter 3 aims to detect short-term ( $\leq 12$ weeks) and long-term (>12 weeks) weight gain liabilities of individual antipsychotic mediations in patients with FEP. Chapter 4 presents findings from a metaanalysis of alpha-lipoic acid, as a supplement for body weight management. Chapter $\mathbf{5}$ aims to perform a systematic review and meta-analysis to assess gestational diabetes mellitus risk associated with antipsychotic-exposure in pregnancy. Chapter 6 aims to investigate the frequency and clinical features of night eating syndrome (NES), a delayed pattern of food intake, in patients with depression, focusing on the differences in clinical features and on the 
Chapter I. Introduction

predictors of NES. Finally, Chapter 7 aims to test the effects of add-on curcumin treatment on inflammatory markers and cognitive functioning in patients with schizophrenia. 
References

Allison, D. B., Mentore, J. L., Heo, M., Chandler, L. P., Cappelleri, J. C., Infante, M. C., \& Weiden, P. J. (1999). Antipsychotic-induced weight gain: a comprehensive research synthesis. Am J Psychiatry, 156(11), 1686-1696. doi: 10.1176/ajp.156.11.1686

Allison, K. C., Grilo, C. M., Masheb, R. M., \& Stunkard, A. J. (2005). Binge eating disorder and night eating syndrome: a comparative study of disordered eating. J.Consult Clin.Psychol., 73(6), 1107-1115. doi: 2005-16405-012 [pii];10.1037/0022006X.73.6.1107 [doi]

Allison, K. C., Studt, S. K., Berkowitz, R. I., Hesson, L. A., Moore, R. H., Dubroff, J. G., . . . Stunkard, A. J. (2013). An open-label efficacy trial of escitalopram for night eating syndrome. Eat.Behav., 14(2), 199203. doi: S1471-0153(13)00017-2 [pii];10.1016/j.eatbeh.2013.02.001 [doi]

Allison, K. C., \& Tarves, E. P. (2011). Treatment of night eating syndrome. Psychiatr Clin North Am, 34(4), 785796. doi: 10.1016/j.psc.2011.08.002

Annamalai, A., Kosir, U., \& Tek, C. (2017). Prevalence of obesity and diabetes in patients with schizophrenia. World J Diabetes, 8(8), 390-396. doi: 10.4239/wjd.v8.i8.390

Ansar, H., Mazloom, Z., Kazemi, F., \& Hejazi, N. (2011). Effect of alphalipoic acid on blood glucose, insulin resistance and glutathione peroxidase of type 2 diabetic patients. Saudi Med J, 32(6), 584-588.

Asevedo, E., Gadelha, A., Noto, C., Mansur, R. B., Zugman, A.,
Belangero, S. I., . . . Brietzke, E. (2013). Impact of peripheral levels of chemokines, BDNF and oxidative markers on cognition in individuals with schizophrenia. J Psychiatr Res, 47(10), 1376-1382. doi: 10.1016/j.jpsychires.2013.05.032

Bak, M., Fransen, A., Janssen, J., van Os, J., \& Drukker, M. (2014). Almost all antipsychotics result in weight gain: a meta-analysis. PLoS One, 9(4), e94112. doi:

10.1371/journal.pone.0094112

Bast, A., \& Haenen, G. R. (2003). Lipoic acid: a multifunctional antioxidant. Biofactors, 17(1-4), 207213.

Bellamy, L., Casas, J. P., Hingorani, A. D., \& Williams, D. (2009). Type 2 diabetes mellitus after gestational diabetes: a systematic review and meta-analysis. Lancet, 373(9677), 1773-1779. doi: 10.1016/s01406736(09)60731-5

Bellet, F., Beyens, M.-N., Bernard, N., Beghin, D., Elefant, E., \& Vial, T. (2015). Exposure to aripiprazole during embryogenesis: a prospective multicenter cohort study. Pharmacoepidemiology and Drug Safety, 24(4), 368-380. doi: 10.1002/pds.3749

Boden, R., Lundgren, M., Brandt, L., Reutfors, J., Andersen, M., \& Kieler, H. (2012). Risks of adverse pregnancy and birth outcomes in women treated or not treated with mood stabilisers for bipolar disorder: population based cohort study. British Medical Journal, $345 . \quad$ doi: 10.1136/bmj.e7085 
Bortolato, B., Miskowiak, K. W., Kohler, C. A., Vieta, E., \& Carvalho, A. F. (2015). Cognitive dysfunction in bipolar disorder and schizophrenia: a systematic review of meta-analyses. Neuropsychiatr Dis Treat, 11, 31113125. doi: 10.2147/ndt.S76700

Bruzas, M. B., \& Allison, K. C. (2019). A Review of the Relationship between Night Eating Syndrome and Body Mass Index. Curr Obes Rep. doi: 10.1007/s13679-019-00331-7

Buchanan, T. A., Xiang, A., Kjos, S. L., \& Watanabe, R. (2007). What is gestational diabetes? Diabetes Care, 30 Suppl 2, S105-111. doi: 10.2337/dc07-s201

Calkin, C. V., Gardner, D. M., Ransom, T., \& Alda, M. (2013). The relationship between bipolar disorder and type 2 diabetes: more than just co-morbid disorders. Ann Med, 45(2), 171-181. doi: 10.3109/07853890.2012.687835

Calugi, S., Dalle Grave, R., \& Marchesini, G. (2009). Night eating syndrome in class II-III obesity: metabolic and psychopathological features. Int J Obes (Lond), 33(8), 899-904. doi: 10.1038/ijo.2009.105

Carbonelli, M. G., Di Renzo, L., Bigioni, M., Di Daniele, N., De Lorenzo, A., \& Fusco, M. A. (2010). Alpha-lipoic acid supplementation: a tool for obesity therapy? Curr Pharm Des, 16(7), 840-846.

Casey, D. E., \& Zorn, S. H. (2001). The pharmacology of weight gain with antipsychotics. J Clin Psychiatry, 62 Suppl 7, 4-10.

Chang, H. H., Chi, M. H., Lee, I. H., Tsai, H. C., Gean, P. W., Yang, Y. K., . . Chen, P. S. (2013). The change of insulin levels after six weeks antidepressant use in drug-naive major depressive patients. J Affect Disord, 150(2), 295-299. doi: 10.1016/j.jad.2013.04.008

Chwastiak, L., Rosenheck, R., \& Leslie, D. (2006). Impact of medical comorbidity on the quality of schizophrenia pharmacotherapy in a national VA sample. Med Care, 44(1), 55-61.

Chwastiak, L. A., Rosenheck, R. A., McEvoy, J. P., Stroup, T. S., Swartz, M. S., Davis, S. M., \& Lieberman, J. A. (2009). The impact of obesity on health care costs among persons with schizophrenia. Gen Hosp Psychiatry, 31(1), 1-7. doi: 10.1016/j.genhosppsych.2008.09.012 Correll, C. U., Solmi, M., Veronese, N., Bortolato, B., Rosson, S., Santonastaso, P., . . . Stubbs, B. (2017). Prevalence, incidence and mortality from cardiovascular disease in patients with pooled and specific severe mental illness: a large-scale meta-analysis of $3,211,768$ patients and 113,383,368 controls. World Psychiatry, 16(2), 163-180. doi: 10.1002/wps.20420

Coughlin, C. G., Blackwell, K. A., Bartley, C., Hay, M., Yonkers, K. A., \& Bloch, M. H. (2015). Obstetric and neonatal outcomes after antipsychotic medication exposure in pregnancy. Obstet Gynecol, 125(5), 1224-1235. doi: 10.1097/aog.0000000000000759

Dayabandara, M., Hanwella, R., Ratnatunga, S., Seneviratne, S., Suraweera, C., \& de Silva, V. A. (2017). Antipsychotic-associated weight gain: management strategies and impact on treatment adherence. 
Neuropsychiatr Dis Treat, 13, 22312241. doi: 10.2147/NDT.S113099

De Hert, M., Mauri, M., Shaw, K., Wetterling, T., Doble, A., Giudicelli, A., \& Falissard, B. (2010). The METEOR study of diabetes and other metabolic disorders in patients with schizophrenia treated with antipsychotic drugs. I. Methodology. Int J Methods Psychiatr Res, 19(4), 195-210. doi: 10.1002/mpr.322

de Zwaan, M., Roerig, D. B., Crosby, R. D., Karaz, S., \& Mitchell, J. E. (2006). Night time eating: a descriptive study. Int.J.Eat.Disord., 39(3), 224-232. doi: 10.1002/eat.20246 [doi]

de Zwaan, M., Muller, A., Allison, K. C., Brahler, E., \& Hilbert, A. (2014). Prevalence and correlates of night eating in the German general population. PLoS One, 9(5), e97667. doi: 10.1371/journal.pone.0097667

Deneke, S. M. (2000). Thiol-based antioxidants. Curr Top Cell Regul, 36, 151-180.

DeSisto, C. L., Kim, S. Y., \& Sharma, A. J. (2014). Prevalence estimates of gestational diabetes mellitus in the United States, Pregnancy Risk Assessment Monitoring System (PRAMS), 2007-2010. Prev Chronic Dis, 11, E104. doi: 10.5888/pcd11.130415

Dickerson, F., Stallings, C., Origoni, A., Boronow, J., \& Yolken, R. (2007). $\mathrm{C}$-reactive protein is associated with the severity of cognitive impairment but not of psychiatric symptoms in individuals with schizophrenia. Schizophr Res, 93(1-3), 261-265. doi: 10.1016/j.schres.2007.03.022
Egger, M., \& Smith, G. D. (1997). \&lt;em\&gt;Meta-analysis:\&lt;/em\&gt; Potentials and promise. BMJ, 315(7119), $1371 . \quad$ doi: 10.1136/bmj.315.7119.1371

Evans, J. L., \& Goldfine, I. D. (2000). Alpha-lipoic acid: a multifunctional antioxidant that improves insulin sensitivity in patients with type 2 diabetes. Diabetes Technol Ther, 2(3), 401-413. doi: 10.1089/15209150050194279

Fineberg, A. M., \& Ellman, L. M. (2013). Inflammatory cytokines and neurological and neurocognitive alterations in the course of schizophrenia. Biol Psychiatry, 73(10), 951-966. doi: 10.1016/j.biopsych.2013.01.001

Frayne, S. M., Halanych, J. H., Miller, D. R., Wang, F., Lin, H., Pogach, L., . . . Berlowitz, D. R. (2005). Disparities in diabetes care: impact of mental illness. Arch Intern Med, 165(22), 2631-2638. doi: 10.1001/archinte.165.22.2631

Garcia-Rizo, C., Fernandez-Egea, E., Miller, B. J., Oliveira, C., Justicia, A., Griffith, J. K., . . . Kirkpatrick, B. (2013). Abnormal glucose tolerance, white blood cell count, and telomere length in newly diagnosed, antidepressant-naïve patients with depression. Brain, Behavior, and Immunity, 28, 49-53. doi: http://dx.doi.org/10.1016/j.bbi.2012.1 1.009

Garcia-Rizo, C., Kirkpatrick, B., Fernandez-Egea, E., Oliveira, C., \& Bernardo, M. (2016). Abnormal glycemic homeostasis at the onset of serious mental illnesses: A common pathway. Psychoneuroendocrinology, 
67 ,

70-75.

10.1016/j.psyneuen.2016.02.001

Greenhalgh, A. M., Gonzalez-Blanco, L., Garcia-Rizo, C., Fernandez-Egea, E., Miller, B., Arroyo, M. B., \& Kirkpatrick, B. (2016). Meta-analysis of glucose tolerance, insulin, and insulin resistance in antipsychoticnaive patients with nonaffective psychosis. Schizophr Res. doi: 10.1016/j.schres.2016.09.026

Guha, P., Bhowmick, K., Mazumder, P., Ghosal, M., Chakraborty, I., \& Burman, P. (2014). Assessment of insulin resistance and metabolic syndrome in drug naive patients of bipolar disorder. Indian journal of clinical biochemistry : IJCB, 29(1), 5156. doi: 10.1007/s12291-012-0292-x

Henneman, D. H., Altschule, M. D., \& Goncz, R. M. (1954). Carbohydrate metabolism in brain disease. II. Glucose metabolism in Schizophrenic, manic-depressive, and involutional psychoses. AMA Arch Intern Med, 94(3), 402-416.

Jantaratnotai, N., Mosikanon, K., Lee, Y., \& Mclntyre, R. S. (2017). The interface of depression and obesity. Obes Res Clin Pract, 11(1), 1-10. doi: 10.1016/j.orcp.2016.07.003

Keck, P. E., \& McElroy, S. L. (2003). Bipolar disorder, obesity, and pharmacotherapy-associated weight gain. J Clin Psychiatry, 64(12), 14261435.

Kessler, R. C., Amminger, G. P., Aguilar-Gaxiola, S., Alonso, J., Lee, S., \& Ustün, T. B. (2007). Age of onset of mental disorders: a review of recent literature. Current Opinion in Psychiatry, 20(4), 359-364. doi: 10.1097/YCO.0b013e32816ebc8c
Koh, E. H., Lee, W. J., Lee, S. A., Kim, E. H., Cho, E. H., Jeong, E., . . L Lee, K. U. (2011). Effects of alpha-lipoic Acid on body weight in obese subjects. Am J Med, 124(1), 85.e8188.

Kolotkin, R. L., Corey-Lisle, P. K., Crosby, R. D., Swanson, J. M., Tuomari, A. V., L'Italien G, J., \& Mitchell, J. E. (2008). Impact of obesity on health-related quality of life in schizophrenia and bipolar disorder. Obesity (Silver Spring), 16(4), 749754. doi: 10.1038/oby.2007.133

Kucukgoncu, S., \& Bestepe, E. (2014). Night Eating Syndrome in Major Depression and Anxiety Disorders. Noro Psikiyatr Ars, 51(4), 368-375. doi: 10.5152/npa.2014.7204

Kucukgoncu, S., Midura, M., \& Tek, C. (2015). Optimal management of night eating syndrome: challenges and solutions. Neuropsychiatr Dis Treat, 11, 751-760. doi: 10.2147/NDT.S70312

Kulkarni, J., Storch, A., Baraniuk, A., Gilbert, H., Gavrilidis, E., \& Worsley, R. (2015). Antipsychotic use in pregnancy. Expert Opin Pharmacother, 16(9), 1335-1345. doi: 10.1517/14656566.2015.1041501

Lawrentschuk, N., McCall, J., \& Güller, U. (2009). Critical appraisal of meta-analyses: an introductory guide for the practicing surgeon. Patient safety in surgery, 3(1), 16-16. doi: 10.1186/1754-9493-3-16

Lee, W. H., Loo, C. Y., Bebawy, M., Luk, F., Mason, R. S., \& Rohanizadeh, R. (2013). Curcumin and its Derivatives: Their Application in Neuropharmacology and Neuroscience in the 21st Century. 
Current Neuropharmacology, 11(4), 338-378. doi:

10.2174/1570159x11311040002

Levkovitz, Y., Mendlovich, S., Riwkes, S., Braw, Y., Levkovitch-Verbin, H., Gal, G., . . . Kron, S. (2010). A doubleblind, randomized study of minocycline for the treatment of negative and cognitive symptoms in early-phase schizophrenia. J Clin Psychiatry, 71(2), 138-149. doi: 10.4088/JCP.08m04666yel

Lieberman, J. A., Stroup, T. S., McEvoy, J. P., Swartz, M. S., Rosenheck, R. A., Perkins, D. O., . . . Hsiao, J. K. (2005). Effectiveness of antipsychotic drugs in patients with chronic schizophrenia. N Engl J Med, 353(12), 1209-1223. doi: 10.1056/NEJMoa051688

Liu, F., Guo, X., Wu, R., Ou, J., Zheng, Y., Zhang, B., . . Z Zhao, J. (2014). Minocycline supplementation for treatment of negative symptoms in early-phase schizophrenia: a double blind, randomized, controlled trial. Schizophr Res, 153(1-3), 169-176. doi: 10.1016/j.schres.2014.01.011

Lundgren, J. D., Allison, K. C., Crow, S., O'Reardon, J. P., Berg, K. C., Galbraith, J., . . . Stunkard, A. J. (2006). Prevalence of the night eating syndrome in a psychiatric population. Am.J.Psychiatry, 163(1), 156-158. doi: $\quad 163 / 1 / 156$ [pii]; 10.1176/appi.ajp.163.1.156 [doi]

Lundgren, J. D., Allison, K. C., O'Reardon, J. P., \& Stunkard, A. J. (2008). A descriptive study of nonobese persons with night eating syndrome and a weight-matched comparison group. Eat.Behav., 9(3), 343-351.
Lundgren, J. D., Newberg, A. B., Allison, K. C., Wintering, N. A., Ploessl, K., \& Stunkard, A. J. (2008). 123I-ADAM SPECT imaging of serotonin transporter binding in patients with night eating syndrome: a preliminary report. Psychiatry Res., 162(3), 214-220. doi: S09254927(07)00147-3

[pii];10.1016/j.pscychresns.2007.07.0 06 [doi]

Mangurian, C., Newcomer, J. W., Modlin, C., \& Schillinger, D. (2016). Diabetes and Cardiovascular Care Among People with Severe Mental Illness: A Literature Review. J Gen Intern Med, 31(9), 1083-1091. doi: 10.1007/s11606-016-3712-4

McAfoose, J., \& Baune, B. T. (2009). Evidence for a cytokine model of cognitive function. Neurosci Biobehav Rev, 33(3), 355-366. doi: 10.1016/j.neubiorev.2008.10.005

McCauley-Elsom, K., Gurvich, C., Elsom, S. J., \& Kulkarni, J. (2010). Antipsychotics in pregnancy. $J$ Psychiatr Ment Health Nurs, 17(2), 97-104. doi: 10.1111/j.13652850.2009.01481.x

McGinty, E. E., Baller, J., Azrin, S. T., Juliano-Bult, D., \& Daumit, G. L. (2015). Quality of medical care for persons with serious mental illness: A comprehensive review. Schizophr Res, 165(2-3), 227-235. doi: 10.1016/j.schres.2015.04.010

McKenna, K., Koren, G., Tetelbaum, M., Wilton, L., Shakir, S., Diav-Citrin, O., . . . Einarson, A. (2005). Pregnancy outcome of women using atypical antipsychotic drugs: a prospective comparative study. $J$ Clin Psychiatry, 66(4), 444-449; quiz 546. 
McNeilly, A. M., Davison, G. W., Murphy, M. H., Nadeem, N., Trinick, T., Duly, E., . . . McEneny, J. (2011). Effect of alpha-lipoic acid and exercise training on cardiovascular disease risk in obesity with impaired glucose tolerance. Lipids Health Dis, 10, 217. doi: 10.1186/1476-511x-10217

Mefferd, R. B., Jr., Labrosse, E. H., Gawienowski, A. M., \& Williams, R. J. (1958). Influence of chlorpromazine on certain biochemical variables of chronic male schizophrenics. J Nerv Ment Dis, 127(2), 167-179.

Miller, B. J., Buckley, P., Seabolt, W., Mellor, A., \& Kirkpatrick, B. (2011). Meta-analysis of cytokine alterations in schizophrenia: clinical status and antipsychotic effects. Biol Psychiatry, 70(7), 663-671. doi: 10.1016/j.biopsych.2011.04.013

Muller, N., Riedel, M., Schwarz, M. J., \& Engel, R. R. (2005). Clinical effects of COX-2 inhibitors on cognition in schizophrenia. Eur Arch Psychiatry Clin Neurosci, 255(2), 149-151. doi: 10.1007/s00406-004-0548-4

Naksuriya, O., Okonogi, S., Schiffelers, R. M., \& Hennink, W. E. (2014). Curcumin nanoformulations: a review of pharmaceutical properties and preclinical studies and clinical data related to cancer treatment. Biomaterials, 35(10), 3365-3383. doi: 10.1016/j.biomaterials.2013.12.090

Nasrallah, H. A., Meyer, J. M., Goff, D. C., McEvoy, J. P., Davis, S. M., Stroup, T. S., \& Lieberman, J. A. (2006). Low rates of treatment for hypertension, dyslipidemia and diabetes in schizophrenia: data from the CATIE schizophrenia trial sample at baseline. Schizophr Res, 86(1-3),
$15-22$.

doi:

10.1016/j.schres.2006.06.026

Newcomer, J. W., \& Hennekens, C. H. (2007). Severe mental illness and risk of cardiovascular disease. JAMA, 298(15), 1794-1796. doi: 10.1001/jama.298.15.1794

Newcomer, J. W., \& S., C. N. (2005). Second-generation

(atypical) antipsychotics and metabolic effects: a comprehensive I iterature review. 19 Suppl, 1 SRC - BaiduScholar, 1-93.

Nguyen, T. N., Faulkner, D., Frayne, J. S., Allen, S., Hauck, Y. L., Rock, D., \& Rampono, J. (2013). Obstetric and neonatal outcomes of pregnant women with severe mental illness at a specialist antenatal clinic. Medical Journal of Australia, 199(3), 26-29. doi: 10.5694/mjao11.11152

Nitta, M., Kishimoto, T., Muller, N., Weiser, M., Davidson, M., Kane, J. M., \& Correll, C. U. (2013). Adjunctive Use of Nonsteroidal Anti-inflammatory Drugs for Schizophrenia: A Metaanalytic Investigation of Randomized Controlled Trials. Schizophr Bull, 39(6), 1230-1241. doi: 10.1093/schbul/sbt070

O'Reardon, J. P., Ringel, B. L., Dinges, D. F., Allison, K. C., Rogers, N. L., Martino, N. S., \& Stunkard, A. J. (2004). Circadian eating and sleeping patterns in the night eating syndrome. Obes.Res., 12(11), 1789-1796. doi: 12/11/1789

[pii];10.1038/oby.2004.222 [doi]

Orhan, F. O., Ozer, U. G., Ozer, A., Altunoren, O., Celik, M., \& Karaaslan, M. F. (2011). Night eating syndrome among patients with depression. Isr.J.Psychiatry Relat Sci., 48(3), 212217. 
Osborn, D. P., Wright, C. A., Levy, G., King, M. B., Deo, R., \& Nazareth, I. (2008). Relative risk of diabetes, dyslipidaemia, hypertension and the metabolic syndrome in people with severe mental illnesses: systematic review and metaanalysis. $B M C$ Psychiatry, 8, 84. doi: 10.1186/1471244X-8-84

Palmese, L. B., Ratliff, J. C., Reutenauer, E. L., Tonizzo, K. M., Grilo, C. M., \& Tek, C. (2012). Prevalence of night eating in obese individuals with schizophrenia and schizoaffective disorder. Compr.Psychiatry. doi: S0010440X(12)00143-5

[pii];10.1016/j.comppsych.2012.07.01 4 [doi]

Park, Y., Hernandez-Diaz, S., Bateman, B. T., Cohen, J. M., Desai, R. J., Patorno, E., . . Huybrechts, K. F. (2018). Continuation of Atypical Antipsychotic Medication During Early Pregnancy and the Risk of Gestational Diabetes. $A m$ J Psychiatry, 175(6), 564-574. doi: 10.1176/appi.ajp.2018.17040393

Parsons, B., Allison, D. B., Loebel, A., Williams, K., Giller, E., Romano, S., \& Siu, C. (2009). Weight effects associated with antipsychotics: a comprehensive database analysis. Schizophr Res, 110(1-3), 103-110. doi: 10.1016/j.schres.2008.09.025

Perry, B. I., McIntosh, G., Weich, S., Singh, S., \& Rees, K. (2016). The association between first-episode psychosis and abnormal glycaemic control: systematic review and metaanalysis. Lancet Psychiatry, 3(11), 1049-1058. doi: 10.1016/S22150366(16)30262-0
Pillinger, T., Beck, K., Gobjila, C., Donocik, J. G., Jauhar, S., \& Howes, O. D. (2017). Impaired glucose homeostasis in first-episode schizophrenia: A systematic review and meta-analysis. JAMA Psychiatry. doi:

10.1001/jamapsychiatry.2016.3803

Plows, J. F., Stanley, J. L., Baker, P. N., Reynolds, C. M., \& Vickers, M. H. (2018). The Pathophysiology of Gestational Diabetes Mellitus. International journal of molecular sciences, 19(11), 3342. doi: 10.3390/ijms 19113342

Prieto-Hontoria, P. L., Perez-Matute, P., Fernandez-Galilea, M., Alfredo Martinez, J., \& Moreno-Aliaga, M. J. (2013). Effects of lipoic acid on AMPK and adiponectin in adipose tissue of low- and high-fat-fed rats. Eur J Nutr, 52(2), 779-787. doi: 10.1007/s00394012-0384-7

Prieto-Hontoria, P. L., Perez-Matute, P., Fernandez-Galilea, M., Barber, A., Martinez, J. A., \& Moreno-Aliaga, M. J. (2009). Lipoic acid prevents body weight gain induced by a high fat diet in rats: effects on intestinal sugar transport. J Physiol Biochem, 65(1), 43-50.

Ramaswamy, K., Masand, P. S., \& Nasrallah, H. A. (2006). Do certain atypical antipsychotics increase the risk of diabetes? A critical review of 17 pharmacoepidemiologic studies. Ann Clin Psychiatry, 18(3), 183-194. doi: 10.1080/10401230600801234

Rand, C. S., Macgregor, A. M., \& Stunkard, A. J. (1997). The night eating syndrome in the general population and among postoperative obesity surgery patients. Int.J.Eat.Disord., 22(1), 65-69. doi: 
$10.1002 /(\mathrm{SICl}) 1098-$

$108 X(199707) 22: 1<65:: A I D-$

EAT8>3.0.CO;2-0 [pii]

Ratliff, J. C., Palmese, L. B., Reutenauer, E. L., Liskov, E., Grilo, C. M., \& Tek, C. (2012). The effect of dietary and physical activity pattern on metabolic profile in individuals with schizophrenia: a cross-sectional study. Compr Psychiatry, 53(7), 10281033. doi: 10.1016/j.comppsych.2012.02.003

Regenold, W. T., Thapar, R. K., Marano, C., Gavirneni, S., \& Kondapavuluru, P. V. (2002). Increased prevalence of type 2 diabetes mellitus among psychiatric inpatients with bipolar I affective and schizoaffective disorders independent of psychotropic drug use. J Affect Disord, 70(1), 19-26.

Reis, M., \& Kallen, B. (2008). Maternal use of antipsychotics in early pregnancy and delivery outcome. $J$ Clin Psychopharmacol, 28(3), 279288.

\subsection{7/JCP.0b013e318172b8d5}

Rockwell, W. J., Ellinwood, E. H., Jr., \& Trader, D. W. (1983). Psychotropic drugs promoting weight gain: health risks and treatment implications. South Med J, 76(11), 1407-1412.

Rummel-Kluge, C., Komossa, K., Schwarz, S., Hunger, H., Schmid, F., Lobos, C. A., . . . Leucht, S. (2010). Head-to-head comparisons of metabolic side effects of second generation antipsychotics in the treatment of schizophrenia: a systematic review and meta-analysis. Schizophr Res, 123(2-3), 225-233. doi: 10.1016/j.schres.2010.07.012
Saari, K. M., Lindeman, S. M., Viilo, K. M., Isohanni, M. K., Jarvelin, M. R., Lauren, L. H., . . . Koponen, H. J. (2005). A 4-fold risk of metabolic syndrome in patients with schizophrenia: the Northern Finland 1966 Birth Cohort study. J Clin Psychiatry, 66(5), 559-563.

Schulz, S. C., \& Murray, A. (2016). Assessing cognitive impairment in patients with schizophrenia. J Clin Psychiatry, 77 Suppl 2, 3-7. doi: 10.4088/JCP.14074su1c.01

Stunkard, A. J., Allison, K. C., Lundgren, J. D., Martino, N. S., Heo, M., Etemad, B., \& O'Reardon, J. P. (2006). A paradigm for facilitating pharmacotherapy at a distance: sertraline treatment of the night eating syndrome. J.Clin.Psychiatry, 67(10), 1568-1572.

Stunkard, A. J., GRACE, W. J., \& WOLFF, H. G. (1955). The nighteating syndrome; a pattern of food intake among certain obese patients. Am.J.Med., 19(1), 78-86. doi: 00029343(55)90276-X [pii]

Toh, S., Li, Q., Cheetham, T. C., Cooper, W. O., Davis, R. L., Dublin, S., . . . Andrade, S. E. (2013). Prevalence and trends in the use of antipsychotic medications during pregnancy in the U.S., 2001-2007: a population-based study of 585,615 deliveries. Arch Womens Ment Health, 16(2), 149-157. doi: $10.1007 / \mathrm{s} 00737-013-0330-6$

Van Lieshout, R. J., \& Voruganti, L. P. (2008). Diabetes mellitus during pregnancy and increased risk of schizophrenia in offspring: a review of the evidence and putative mechanisms. J Psychiatry Neurosci, 33(5), 395-404. 
van Winkel, R., De Hert, M., Van Eyck, D., Hanssens, L., Wampers, M., Scheen, A., \& Peuskens, J. (2008). Prevalence of diabetes and the metabolic syndrome in a sample of patients with bipolar disorder. Bipolar Disord, 10(2), 342-348. doi: 10.1111/j.1399-5618.2007.00520.x

Vancampfort, D., Correll, C. U., Galling, B., Probst, M., De Hert, M., Ward, P. B., . . . Stubbs, B. (2016). Diabetes mellitus in people with schizophrenia, bipolar disorder and major depressive disorder: a systematic review and large scale meta-analysis. World Psychiatry, 15(2), 166-174. doi: 10.1002/wps.20309

Vigod, S. N., Gomes, T., Wilton, A. S., Taylor, V. H., \& Ray, J. G. (2015). Antipsychotic drug use in pregnancy: high dimensional, propensity matched, population based cohort study. Bmj-British Medical Journal, 350. doi: $10.1136 / \mathrm{bmj} . \mathrm{h} 2298$

Vreeker, A., van Bergen, A. H., \& Kahn, R. S. (2015). Cognitive enhancing agents in schizophrenia and bipolar disorder. Eur Neuropsychopharmacol, 25(7), 9691002. doi:

10.1016/j.euroneuro.2015.04.014

Walker, E., Hernandez, A. V., \& Kattan, M. W. (2008). Meta-analysis: Its strengths and limitations. Cleveland Clinic journal of medicine, 75(6), 431-439. doi: 10.3949/ccjm.75.6.431

Walker, E. R., McGee, R. E., \& Druss, B. G. (2015). Mortality in mental disorders and global disease burden implications: a systematic review and meta-analysis. JAMA Psychiatry,
$72(4)$,

334-341.

doi:

10.1001/jamapsychiatry.2014.2502

Whitworth, A. B. (2017). Psychopharmacological treatment of schizophrenia during pregnancy and lactation. Current Opinion in Psychiatry, 30(3), 184-190. doi: 10.1097/yco.0000000000000329

Woodbury-Farina, M., Cernovsky, Z., Chiu, S., Bureau, Y., Campbell, R., Houicin, J., Terpstra, K., Rehab, H., Husni, M., Badmeav, V. (2012). Proof of concept of randomized controlled study of Curcumin C-3 Complex as adjunct treatment in schizophrenia: effects on negative and depressive symptoms. . Paper presented at the Natural Bioactives Conference, Ontario, Canada.

Wynn, J. K., Green, M. F., Hellemann, G., Karunaratne, K., Davis, M. C., \& Marder, S. R. (2017). The effects of curcumin on brain-derived neurotrophic factor and cognition in schizophrenia: A randomized controlled study. Schizophr Res. doi: 10.1016/j.schres.2017.09.046 


\section{Chapter 2}




\begin{abstract}
Glucose Metabolism Dysregulation at The Onset of Mental Illness Is Not Limited to First Episode Psychosis: A Systematic Review and MetaAnalysis
\end{abstract}

Suat Kucukgoncu, Urska Kosir, Elton Zhou, Erin Sullivan, Vinod H. Srihari, Cenk Tek

Early Intervention in Psychiatry 2018; 13;1021-1031. doi : 10.1111/eip.12749 


\section{Chapter 2. Glucose Metabolism Disorders in Mental Illness}

\section{Backgrounds}

Research in treatment-naïve, first episode patients with severe mental illnesses (SMIs) suggest a pre-diabetic condition at the onset of illness. However, we have limited knowledge on glucose metabolism differences across diagnostic categories of SMIs.

\section{Aims}

To compare the differences of glucose metabolism outcomes between treatment-naïve, patients with first episode psychosis (FEP) and mood disorders.

Method

We conducted a systematic review and meta-analysis of glucose intolerance in treatment-naïve, first episode patients with SMIs.

Results

We identified 31 eligible studies. Compared to healthy controls, FEP group have higher insulin and insulin resistance levels, and both groups have higher glucose tolerance test results. No significant differences were found in glucose metabolism outcomes between FEP and mood disorder groups.

\section{Conclusions}

Our results highlight impaired glucose metabolism at the onset of SMIs, suggesting both patients with psychosis and mood disorders are high-risk groups for diabetes development.

Key-words: First episode, psychosis, insulin, diabetes, mood disorders

Funding Source:

The study was funded by a grant to me from the U.S. National Institutes of Health (DK093924). 


\section{Chapter 2. Glucose Metabolism Disorders in Mental IIIness}

\section{Introduction}

It is widely acknowledged that type 2 diabetes mellitus (DM2) incidence is significantly higher in patients with schizophrenia compared to the general population.(Mclntyre et al., 2005; Mitchell, Vancampfort, De Herdt, Yu, \& De Hert, 2013; Vancampfort et al., 2016) Several factors, including adverse effects of antipsychotic medications, altered inflammatory processes and possibly shared genetic links between schizophrenia and DM2 likely contribute to comorbidity between these two disorders.(Calkin, Gardner, Ransom, \& Alda, 2013; Ferentinos \& Dikeos, 2012; Garcia-Rizo, Kirkpatrick, Fernandez-Egea, Oliveira, \& Bernardo, 2016; Perry, McIntosh, Weich, Singh, \& Rees, 2016; Yamagata et al., 2016) Research dating back to the pre-antipsychotic era (Henneman, Altschule, \& Goncz, 1954) as well as findings from treatment-naïve, first episode psychosis (FEP) patients suggest a prediabetic condition with impaired glucose metabolism at the onset of the psychotic illness.(Arranz et al., 2004; Greenhalgh et al., 2016; Misiak et al., 2016; Perry et al., 2016; Ryan, Collins, \& Thakore, 2003; Spelman, Walsh, Sharifi, Collins, \& Thakore, 2007) A recent Danish register study published in by Rajkumar et al. reported 3.07 adjusted hazard ratio of diabetes diagnosis in treatment-naïve FEP patients compared to population sample, suggesting an increased endogenic risk for DM2 in FEP patients.(Cohen \& De Hert, 2011; Rajkumar et al., 2017) Three recent meta-analyses have shown significantly higher insulin resistance (IR), HbA1c, fasting insulin and glucose levels after oral glucose tolerance test (OGTT) in treatment-naïve, FEP compared to healthy controls. (Greenhalgh et al., 2016; Perry et al., 2016; Pillinger et al., 2017) One of these meta-analyses (Greenhalgh et al., 2016) also showed higher fasting glucose levels in patients with FEP compared to healthy controls, whereas others reported no difference on fasting glucose levels between these two groups.

If the association between schizophrenia and DM2 reflected shared biological vulnerability, this might suggest new avenues to explore the 


\section{Chapter 2. Glucose Metabolism Disorders in Mental Illness}

pathophysiology of both disorders. Increased DM2 prevalence, however, is an emerging medical problem not only in patients with schizophrenia, but also in patients with other severe mental illnesses (SMI), such as bipolar disorder and depression. (Mclntyre et al., 2005; Vancampfort et al., 2016) Epidemiological studies have indicated higher DM2 incidence, as well as increased insulin resistance in patients with bipolar disorder and depression.(Calkin et al., 2013; Charles, Lambert, \& Kerner, 2016; Fagiolini, Frank, Scott, Turkin, \& Kupfer, 2005; McIntyre et al., 2005; Roy \& Lloyd, 2012) Furthermore, findings in treatment-naïve first episode patients with bipolar disorder (Garcia-Rizo et al., 2016; Guha et al., 2014) and depression (Chang et al., 2013; Garcia-Rizo et al., 2013) indicated impaired glucose tolerance, insulin resistance and increased rates of DM2, similar as FEP patients. Impaired glucose metabolism may thus be a non-specific finding common to SMIs near illness onset.

One way to test this hypothesis is to compare the differences of glucose metabolism between different diagnostic groups of treatment-naïve, first episode patients with SMIs. However, only one study has tested this hypothesis and only did so in a relatively small sample. The sample consisted of treatment-naïve patients with FEP $(n=84)$, first episode patients with bipolar I disorder $(n=6)$, first episode patients with depression $(n=12)$, patients with adjustment disorder $(n=17)$ and healthy controls $(n=98)$. (Garcia-Rizo et al., 2016) Findings from this study showed an increased 2-hour glucose load value in patients with FEP, bipolar I disorder, and depression, compared to both adjustment disorder and healthy controls. No significant differences were found in fasting blood glucose and insulin levels between patients with FEP, bipolar I disorder and depression in this study.

While research regarding glucose metabolism in treatment-naïve, first episode patients with individual SMI suggest a pre-diabetic condition, we have limited knowledge on the differences of glucose metabolism across different diagnostic categories of SMls. Therefore, the first aim of this study 


\section{Chapter 2. Glucose Metabolism Disorders in Mental Illness}

is to extend previous findings in patients with FEP (Greenhalgh et al., 2016; Perry et al., 2016; Pillinger et al., 2017) by conducting a systematic review and a meta-analysis of glucose intolerance in first episode, treatment-naïve patients with FEP, as well as first episode, treatment-naïve patients with depression and bipolar disorder. The second aim of this study is to compare the differences of pooled results from glucose metabolism outcomes between these diagnostic categories.

\section{Methods}

Studies were identified using PubMed, Psych INFO, Science Direct, and Web of Science (1950 to June 2017). Additionally, a manual search was used to find relevant references from retrieved articles, related review articles and meta-analyses. Two reviewers (SK and UK) independently conducted the literature search using the following $\mathrm{MESH}$ and free-text search terms: first-episode, antipsychotic-naïve, treatment-naïve, unmedicated, bipolar, mania, manic episode, bipolar depression, euthymic, depression, dysthymia, mood, psychosis, schizophrenia, insulin, insulin resistance, glucose, HbA1c, metabolic disturbances and diabetes.

\section{Selection Criteria}

The following inclusion criteria was used: (i) studies that were conducted with first episode patients who were either treatment-naïve or with life-time prior treatment for less than two weeks and diagnosed with schizophrenia spectrum disorders, bipolar disorders or depressive disorders according to DSM or ICD criteria, (ii) studies that included healthy control subjects, (iii) subjects were with a mean age of $\geq 15$ years of age, (iv) studies that reported fasting blood glucose, insulin, HbA1c, OGTT or IR levels in both first episode patients and healthy controls. The present meta-analysis was conducted and reported according to the PRISMA (Preferred Reporting Items of Systematic Reviews and Meta-analysis) guidelines (Supplementary Table 1).(Moher, Liberati, Tetzlaff, Altman, \& Group, 2009) 


\section{Data Extraction}

Two reviewers (UK and EZ) independently reviewed each article and extracted all data. A third reviewer (SK) checked all extracted data to clarify missing data. Any conflicts were discussed with the third reviewer (SK). The following data were extracted: study design, sample size characteristics of participants (age, gender), body mass index (BMI), fasting blood glucose, insulin, IR, HbA1c levels and OGTT results. To obtain the missing information, we contacted the authors to request relevant data. Outcomes of overlapping samples from the same investigators were extracted from the more detailed report.

The quality of the cohort and case-control studies was peer-reviewed using the Newcastle-Ottawa Scale (NOS) for observational studies.(Wells, 2009) A modified version for NOS was used to asses cross-sectional studies (Supplementary Table 2).

Statistical Analyses

To avoid publication bias, we conducted a comprehensive search among published studies. We examined the differences on metabolic outcomes between healthy controls and first episode patients by calculating effect size (ES) estimates (Hedges' g) using the software Comprehensive Meta-Analysis Version 2 (Biostat, Englewood, NJ, USA). Statistical heterogeneity was assessed using $Q$ and $I 2$ test, in which $12 \geq 50 \%$ was considered to indicate heterogeneity. Publication bias was assessed visually with funnel plots and statistically with Egger's regression test.(Egger, Davey Smith, Schneider, \& Minder, 1997)

We performed subgroup and meta-regression analysis to examine the relationship between glucose metabolism outcomes and BMI, age and gender. There are differences on weight outcomes and weight gain liabilities on FEP patients from Western countries as opposed to patients from Asian countries.(Tek et al., 2016) Previous studies has also shown differences in 
prevalence of type II diabetes and in glucose metabolism outcomes between different ethnicities.(Li, Dong, Wu, \& Tong, 2016; Whiting, Guariguata, Weil, \& Shaw, 2011) Therefore, we also performed a sub-group analysis to compare glucose metabolism outcomes between different regions (Asian vs Non-Asian). The random-effects model was used to compare ES estimate differences. The results for a fixed-effects model were presented as a sensitivity analysis.

\section{Results}

Our research strategy resulted in a total of 1616 articles, excluding duplicates. After screening the title and abstract, 152 articles were selected for further evaluation. After full-text review, 121 articles that were not fulfilling the selection criteria were excluded. Of the excluded studies, 47 did not report relevant metabolic outcomes, 23 did not have a healthy control group, and 29 were not conducted with treatment-naïve first episode patients. Our study selection process is presented in Figure 1. 
Records identified through database searching (252 PubMed, 738 Web of Science, 760 Psychinfo, 767 Science Direct)
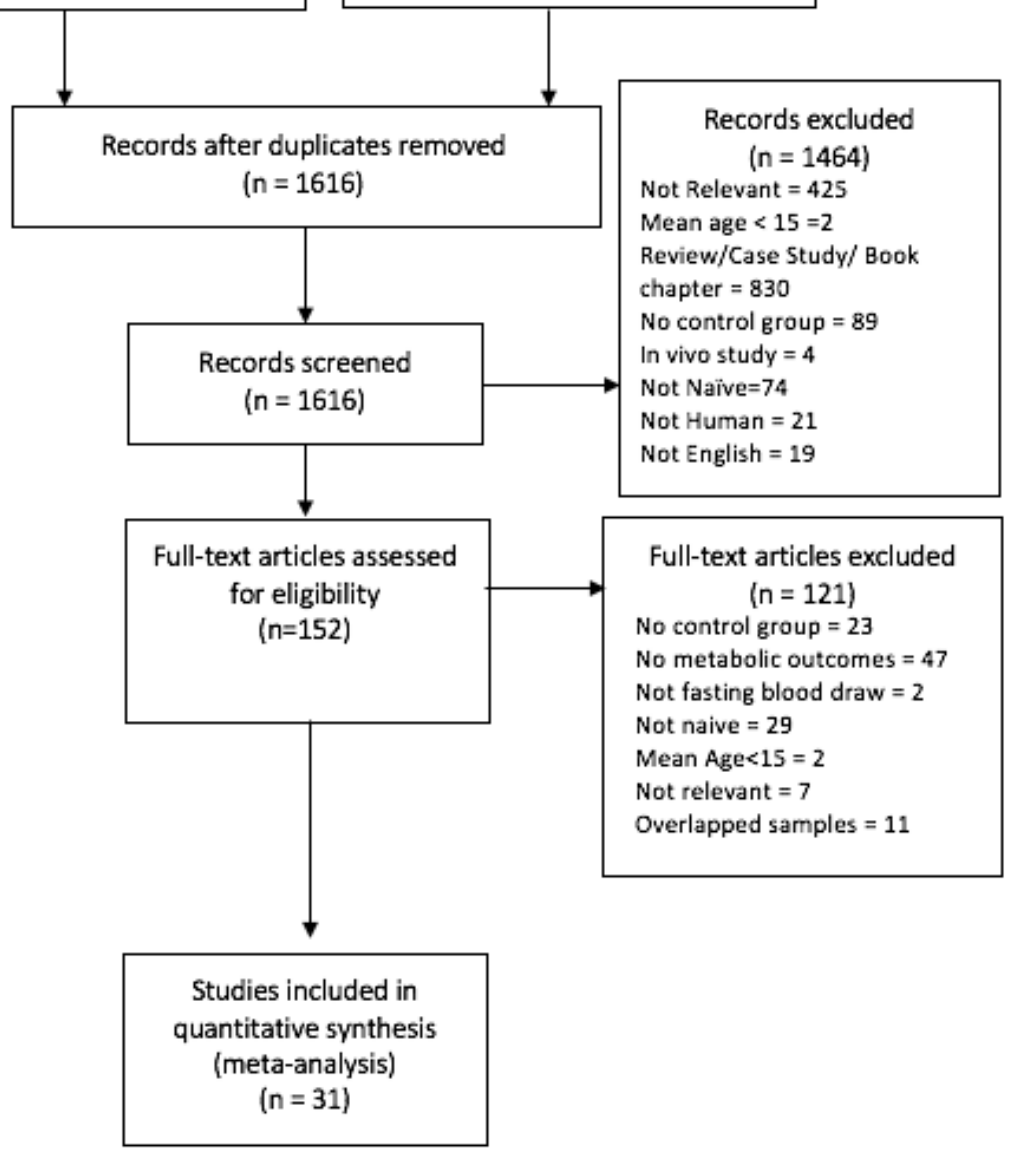

Figure 1. PRISMA Flow Diagram

Overall, we identified 31 eligible studies for inclusion in this metaanalysis (Supplementary Table 3-4).(Arranz et al., 2004; Basoglu et al., 2010; Cai et al., 2012; Canan et al., 2014; Chang et al., 2013; D. C. Chen et al., 2016; S. Chen et al., 2016; Dasgupta, Singh, Rout, Saha, \& Mandal, 2010; Enez Darcin, Yalcin Cavus, Dilbaz, Kaya, \& Dogan, 2015; E. Fernandez-Egea 
et al., 2009; Clemente Garcia-Rizo et al., 2013; C. Garcia-Rizo et al., 2016; Grover, Nebhinani, Chakrabarti, Avasthi, \& Kulhara, 2013; Kavzoglu \& Hariri, 2013; Keinanen et al., 2015; Leo et al., 2006; Misiak et al., 2016; Nyboe, Vestergaard, Moeller, Lund, \& Videbech, 2015; Petrikis et al., 2015; Ryan et al., 2003; Saddichha, Manjunatha, Ameen, \& Akhtar, 2008; Saloojee, Burns, \& Motala, 2017; Sengupta et al., 2008; Spelman et al., 2007; Turan, Kesebir, \& Suner, 2014; van Nimwegen et al., 2008; Venkatasubramanian et al., 2007; Wani et al., 2015; Wu et al., 2013; Yildirim et al., 2014; Zhang et al., 2015) Of these studies, one was conducted with patients who had a first episode mania, (Turan et al., 2014) five were conducted with patients who had first episode depression, (Canan et al., 2014; Chang et al., 2013; Garcia-Rizo et al., 2013; Grover et al., 2013; Leo et al., 2006) and one was conducted with patients who had first episode mania or depression. (Garcia-Rizo et al., 2016) Twenty-four were conducted in patients with FEP. (Arranz et al., 2004; Basoglu et al., 2010; Cai et al., 2012; D. C. Chen et al., 2016; S. Chen et al., 2016; Dasgupta et al., 2010; Enez Darcin et al., 2015; E. Fernandez-Egea et al., 2009; Kavzoglu \& Hariri, 2013; Keinanen et al., 2015; Misiak et al., 2016; Nyboe et al., 2015; Petrikis et al., 2015; Ryan et al., 2003; Saddichha et al., 2008; Saloojee et al., 2017; Sengupta et al., 2008; Spelman et al., 2007; van Nimwegen et al., 2008; Venkatasubramanian et al., 2007; Wani et al., 2015; Wu et al., 2013; Yildirim et al., 2014; Zhang et al., 2015) Among FEP studies, one study included patients with schizoaffective disorders $(n=4)$ in their patient group ( $n=38$ ). (Sengupta et al., 2008) The total number of subjects in these studies was 1242 for FEP group, 214 for mood disorder group and 1361 for healthy control group.

\section{Meta-analyses}

In order to evaluate the differences of glucose metabolism outcomes, we first compared the pooled effect size estimates between patient and control samples. We then combined the outcomes from bipolar and depression groups as mood disorder group to compare estimated effect sizes 


\section{Chapter 2. Glucose Metabolism Disorders in Mental Illness}

with first episode psychosis group. Finally, we compared the pooled effect size estimates of glucose metabolism outcomes between three diagnostic categories when there is enough outcome from each group.

\section{Fasting Glucose}

For the fasting blood glucose analysis, 32 outcomes were extracted from 30 studies. (Arranz et al., 2004; Basoglu et al., 2010; Cai et al., 2012; Canan et al., 2014; Chang et al., 2013; D. C. Chen et al., 2016; S. Chen et al., 2016; Dasgupta et al., 2010; Enez Darcin et al., 2015; E. Fernandez-Egea et al., 2009; Clemente Garcia-Rizo et al., 2013; C. Garcia-Rizo et al., 2016; Grover et al., 2013; Kavzoglu \& Hariri, 2013; Keinanen et al., 2015; Leo et al., 2006; Misiak et al., 2016; Nyboe et al., 2015; Petrikis et al., 2015; Ryan et al., 2003; Saddichha et al., 2008; Saloojee et al., 2017; Sengupta et al., 2008; Spelman et al., 2007; Turan et al., 2014; van Nimwegen et al., 2008; Venkatasubramanian et al., 2007; Wani et al., 2015; Wu et al., 2013; Yildirim et al., 2014; Zhang et al., 2015) In our overall analysis, there was no significant difference on fasting glucose levels between patient and control groups ( $E S=0.10, \mathrm{Cl}=-0.03$ to 0.23 ). Fasting glucose levels were similar in FEP patients ( $E S=0.12, \mathrm{Cl}=-0.02$ to 0.27 ) and mood disorders patients ( $E S=0.02, C l=-0.25$ to 0.29 ) compared to control subjects (Figure 2). 


\section{Chapter 2. Glucose Metabolism Disorders in Mental Illness}

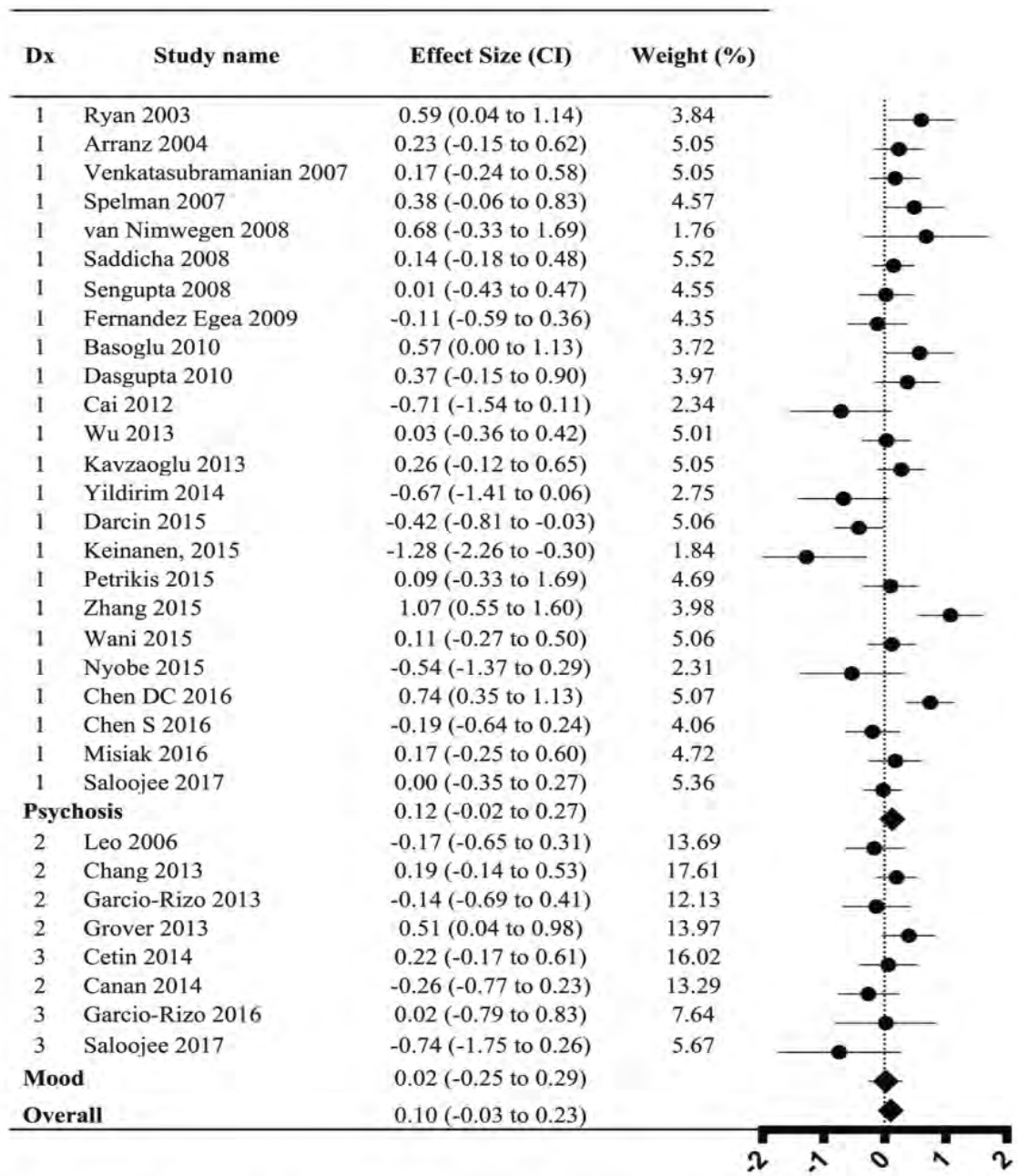

Figure 2. Meta-analysis of fasting blood glucose levels in first episode patients

Heterogeneity: Tau $^{2}=0.07 ; I^{2}=57.35 \% ; Q=72.69$, d.f $=31, p<0.001$

Overall effect (Fixed): $\mathrm{Z}=2.977, \mathrm{p}=0.003$

Overall effect (Random): $Z=1.474, p=0.14$

Dx. Diagnoses. 1=First episode psychosis, 2=First episode depression, 3=First episode bipolar disorder

In subgroup analysis, there was no significant difference on ES estimates of fasting glucose levels between psychotic patients and mood disorders patients $(\mathrm{Q}=0.30, \mathrm{df}=1, \mathrm{p}=0.58)$. ES estimates of fasting glucose levels between first episode psychosis and mania groups $(n=3, E S=-0.01$, $\mathrm{Cl}=-0.50$ to 0.48$)($ psychosis vs. mania: $\mathrm{Q}=0.25$, $\mathrm{df}=1, \mathrm{p}=0.61$ ), and first 
episode psychosis and depression groups ( $\mathrm{n}=5, \mathrm{ES}=0.05, \mathrm{Cl}=-0.22$ to 0.32 ) were similar ( $p$ sychosis vs. depression: $Q=0.20, d f=1, p=0.65$ ). ES estimates of fasting glucose levels were also similar between the depression and bipolar subgroups $(Q=0.04, d f=1, p=0.83)$.

No evidence of publication bias was found in fasting glucose analysis (Egger's intercept=-1.64, $\mathrm{Cl}=-3.63$ to 0.34 ). There was a significant heterogeneity on fasting glucose outcomes across all studies included in the meta-analysis $\left(I^{2}=57.35, \mathrm{df}=31, \mathrm{p}<0.001\right)$. Heterogeneity was also significant in subgroup analysis that was carried out in studies with psychotic patients $\left(l^{2}=62.89, d f=22, p<0.001\right)$. Studies in mood disorders revealed no significant heterogeneity $\left(I^{2}=31.67 .78, d f=7, p=0.17\right)$.

\section{Insulin Levels}

We extracted 15 outcomes from FEP samples (Arranz et al., 2004; Cai et al., 2012; D. C. Chen et al., 2016; S. Chen et al., 2016; Enez Darcin et al., 2015; E. Fernandez-Egea et al., 2009; Keinanen et al., 2015; Petrikis et al., 2015; Ryan et al., 2003; Sengupta et al., 2008; Spelman et al., 2007; van Nimwegen et al., 2008; Venkatasubramanian et al., 2007; Wu et al., 2013; Zhang et al., 2015) and 4 outcomes from mood disorder samples (Chang et al., 2013; C. Garcia-Rizo et al., 2016; Leo et al., 2006) for the meta-analysis of fasting insulin levels. In our overall analysis, first episode patients have similar insulin levels compared to the control group ( $E S=0.21, C l=-0.24$ to $0.67)$. The difference in insulin levels was significant between FEP patients and control groups ( $E S=0.40, \mathrm{Cl}=0.16$ to 0.64 ). There was no significant difference in insulin levels between first episode mood disorder and control groups (ES=-0.06, $\mathrm{Cl}=-0.54-0.40)$. (Figure 3 ). 


\section{Chapter 2. Glucose Metabolism Disorders in Mental Illness}

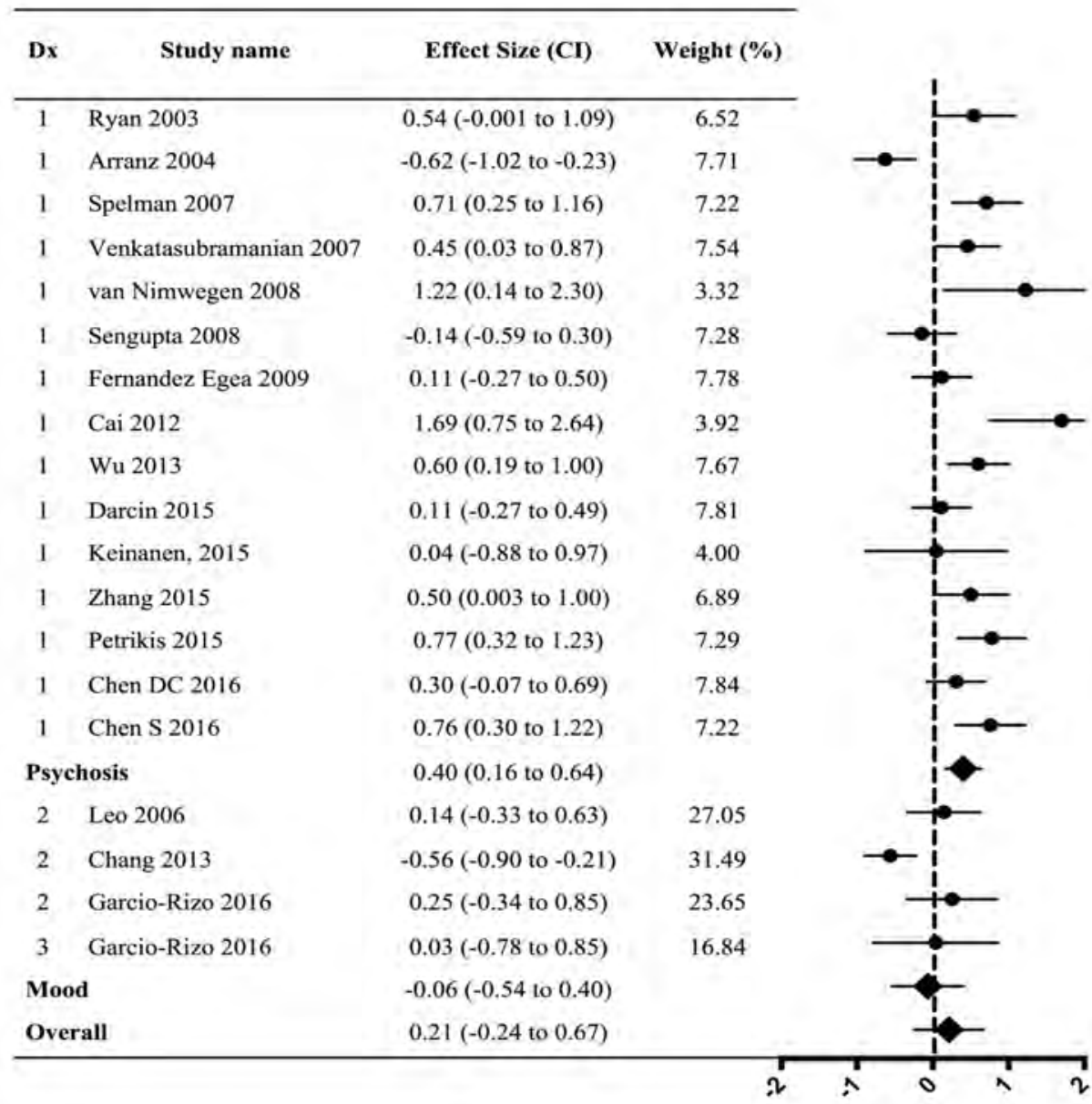

Figure 3. Meta-analysis of insulin levels in first episode patients Heterogeneity: Tau $^{2}=0.19 ; \mathrm{I}^{2}=76.52 \% ; \mathrm{Q}=76.66$, d. $\mathrm{f}=18, \mathrm{p}<0.001$

Overall effect (Fixed): $Z=4.148, \mathrm{p}<0.001$

Overall effect: $Z=0.092, p=0.35$

Dx: Diagnoses. $1=$ First episode psychosis, $2=$ First episode depression, $3=$ =First episode bipolar disorder

In subgroup analysis, ES estimates of insulin levels were similar between first episode psychosis and mood disorder groups $(\mathrm{Q}=3.35, \mathrm{df}=1$, $p=0.06)$. There was no significant difference in insulin levels between first episode psychosis and depression groups $(n=3, E S=-0.08, C l=-0.64$ to 0.47 )(psychosis vs. depression group: $\mathrm{Q}=2.55, \mathrm{df}=1, \mathrm{p}=0.10$ ). 
No evidence of publication bias was found in insulin level analysis (Egger's intercept=3.14, $\mathrm{Cl}=-0.26$ to 6.56 ). There was a significant heterogeneity across all studies included in the meta-analysis $\left(I^{2}=76.66\right.$, $d f=18, p<0.001)$. Heterogeneity was also significant in subgroup analyses that were carried out in studies with FEP patients $\left(\mathrm{I}^{2}=73.46, \mathrm{df}=14, \mathrm{p}<0.001\right)$ and mood disorders $\left(\mathrm{I}^{2}=66.06, \mathrm{df}=3, \mathrm{p}=0.03\right)$.

\section{Insulin Resistance}

For meta-analysis of IR levels, we extracted 14 outcomes from FEP groups (Arranz et al., 2004; D. C. Chen et al., 2016; S. Chen et al., 2016; Dasgupta et al., 2010; Enez Darcin et al., 2015; E. Fernandez-Egea et al., 2009; Keinanen et al., 2015; Petrikis et al., 2015; Ryan et al., 2003; Sengupta et al., 2008; Spelman et al., 2007; Venkatasubramanian et al., 2007; Wu et al., 2013; Zhang et al., 2015) and 2 outcomes from depressive disorder groups (Chang et al., 2013; Leo et al., 2006). In our overall analysis, no significant difference was found between first episode patients and the healthy controls on ES estimates of IR levels ( $E S=0.24, C I=-0.08$ to 0.56 ) (Figure 4). 


\section{Chapter 2. Glucose Metabolism Disorders in Mental Illness}

\begin{tabular}{|c|c|c|c|}
\hline Dx & Study name & Effect Size (CI) & Weight (\%) \\
\hline 1 & Ryw 2003 & $0.68(0.13$ to 1.23$)$ & 5.72 \\
\hline I & Arranz 2004 & $-0.14(-0.53$ to 0.24$)$ & 8.75 \\
\hline $\mathrm{t}$ & Venkatasubramanian 2007 & $0.47(0.05$ to 0.89$)$ & 8.06 \\
\hline $\mathrm{t}$ & Spelman 2007 & $0.68(0.22$ to 1.13$)$ & 7.28 \\
\hline 1 & Sengupta 2008 & $-0.04(-0.62$ to 0.53$)$ & 5,33 \\
\hline 1 & Fernandez Egea 2009 & $0.09(-0.29$ to 0.48$)$ & 8.76 \\
\hline 1 & Dasgupta 2010 & $0.55(0.02$ to 1.09$)$ & 5.99 \\
\hline 1 & Wu 2013 & $0.55(0.15$ to 0.95$)$ & 8.45 \\
\hline 1 & Keinanen 2015 & $0.25(-0.68$ to 1.18$)$ & 2.51 \\
\hline 1 & Petrikis 2015 & $0.65(0.20$ to 1.01$)$ & 7.52 \\
\hline 1 & Darcin 2015 & $0.06(-0.32$ to 0.44$)$ & 8.84 \\
\hline I & Zhang 2015 & $0.66(0.16$ to 1.17$)$ & 6.43 \\
\hline 1 & Chen DC 2016 & $0.60(0.22$ to 0.99$)$ & 8.84 \\
\hline$t$ & Chen S 2016 & $0,15(-0,29$ to 0.59$)$ & 7.53 \\
\hline \multicolumn{2}{|c|}{ Psychosis } & $0.36(0.21$ to 0.52$)$ & \\
\hline 2 & Leo 2006 & $0.15(-0.33$ to 0.63$)$ & 40.14 \\
\hline 2 & Chang 2013 & $-0.06(-0.40$ to 0.27$)$ & 59.86 \\
\hline \multicolumn{2}{|c|}{ Mood } & $0.02(-0.36$ to 0.40$)$ & \\
\hline \multicolumn{2}{|c|}{ Overall } & $0.24(-0.08$ to 0.56$)$ & \\
\hline
\end{tabular}

Figure 4. Meta-analysis of insulin resistance in first episode patients

Heterogeneity: $\mathrm{Tau}^{2}=0.047 ; \mathrm{I}^{2}=47.61 \% ; \mathrm{Q}=28.63, \mathrm{~d}, \mathrm{f}=15, \mathrm{p}=0.018$

Overall effect (Fixed) $: Z=5.34, p<0.001$

Overall effect (Random): $\mathrm{Z}=1.451, \mathrm{p}=0.14$

Dx: Diagnoses. 1=First episode psychosis, $2=$ First episode depression, $3=$ First episode bipolar disorder

In subgroup analyses, a significant difference in IR levels was found between FEP patients and control groups ( $E S=0.36, \mathrm{Cl}=0.21$ to 0.52 ). There was no significant difference on IR levels between first episode depression and control groups ( $E S=0.02, \mathrm{Cl}=-0.22$ to 0.40$)$. ES estimates of IR levels were similar between first episode psychosis and depression groups $(Q=2.64$, $d f=1, p=0.10)$.

We found no evidence of publication bias in IR analysis (Egger's intercept=1.94, $\mathrm{Cl}=-1.80$ to 5.69). IR levels across all studies included in the meta-analysis showed a significant heterogeneity $\left(l^{2}=47.61, d f=15, p=0.018\right)$. 


\section{Chapter 2. Glucose Metabolism Disorders in Mental Illness}

Heterogeneity was significant in subgroup analysis that was carried out in studies with psychotic patients $\left(I^{2}=43.01, d f=13, p=0.04\right)$. Heterogeneity was non-significant in subgroup analysis that was carried out in studies with mood disorders patients $\left(\mathrm{I}^{2}=0.01, \mathrm{df}=1, \mathrm{p}=0.47\right)$.

\section{HbA1c Levels}

For the meta-analysis of $\mathrm{HbA} 1 \mathrm{c}$ levels, we extracted 4 outcomes from the FEP group (Petrikis et al., 2015; Sengupta et al., 2008; Spelman et al., 2007; Yildirim et al., 2014) and two outcomes from the depressive disorders group. (Canan et al., 2014; Chang et al., 2013) In our overall analysis, no significant difference was found on ES estimate of $\mathrm{HbA} 1 \mathrm{c}$ levels between first episode patients and the healthy controls ( $E S=0.15, C l=-0.07$ to 0.37 ) (Supplementary Figure 1).

In subgroup analyses, compared to the healthy controls no significant difference was found on $\mathrm{HbA} 1 \mathrm{c}$ levels in first episode depression ( $E S=0.40$, $\mathrm{Cl}=-0.001$ to 0.80 ) and psychosis group ( $\mathrm{ES}=0.04, \mathrm{Cl}=-0.22$ to 0.30 ). ES estimates of $\mathrm{HbA} 1 \mathrm{c}$ levels were similar between first episode psychosis and depression groups $(\mathrm{Q}=2.12, \mathrm{df}=1, \mathrm{p}=0.14)$. 
Chapter 2. Glucose Metabolism Disorders in Mental IIIness

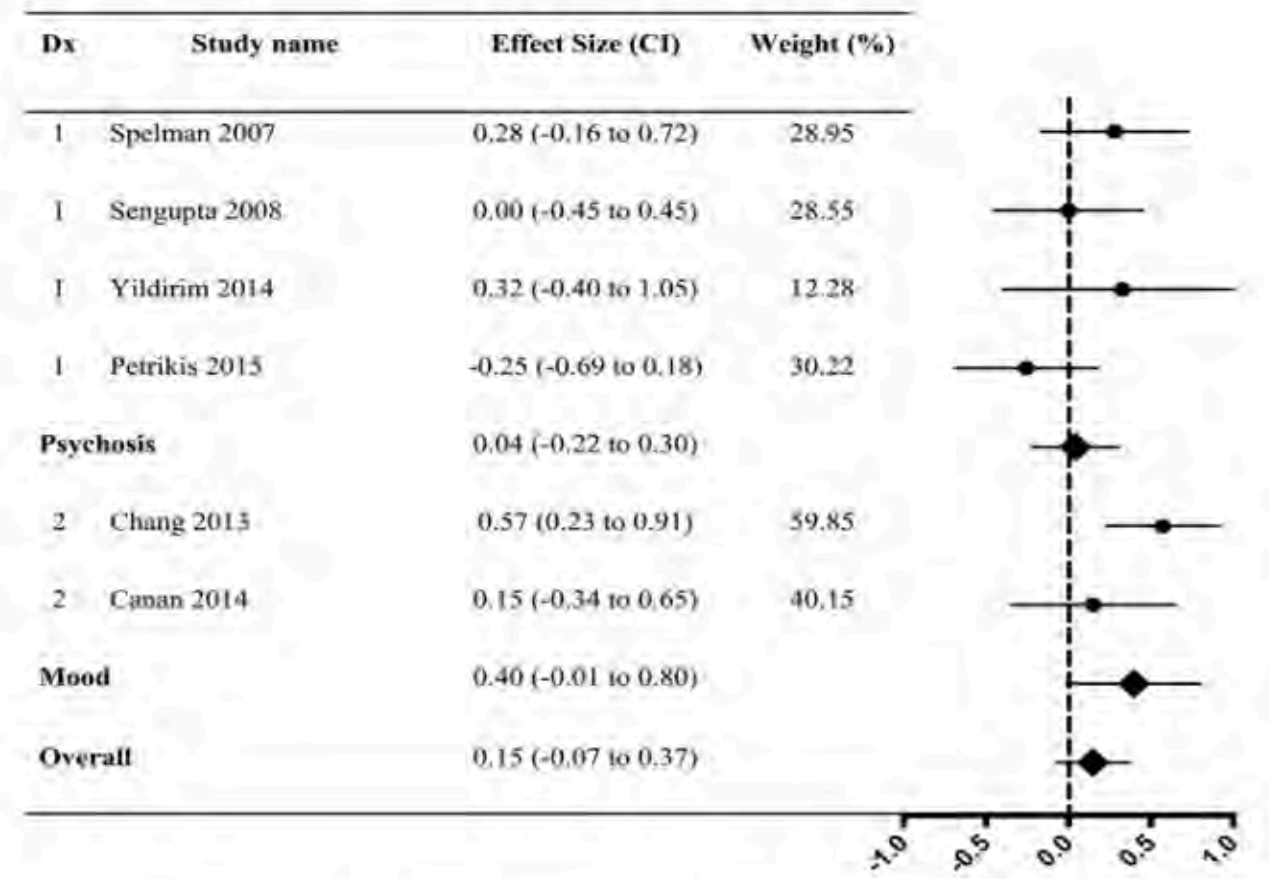

Supplementary Figure 1. Meta-analysis of $\mathrm{HbAlc}$ levels in first episode patients Heterogeneity: $\mathrm{Tau}^{2}=0.052 ; \mathrm{I}^{2}=48.83 \% ; \mathrm{Q}=9.77, \mathrm{~d} . \mathrm{f}=5, \mathrm{p}=0.08$

Overall effect (Fixed): $Z=2.22, p=0.02$ Overall effect (Random): $Z=1.34, p=0.145$

Dx: Diagnoses. 1=First episode psychosis, $2=$ First episode depression, $3=$ First episode bipolar disorder

No evidence of publication bias was found in HbA1c analysis (Egger's intercept=-1.96, $\mathrm{Cl}=-10.13$ to 6.21 ). There was no significant heterogeneity across all studies included in HbA1c level meta-analysis $\left(\mathrm{I}^{2}=48.83, \mathrm{df}=5\right.$, $p=0.08)$. Heterogeneity was non-significant in subgroup analysis that were carried out in studies with psychotic patients $\left(I^{2}=14.50, d f=3, p=0.32\right)$ and mood disorders patients $\left(\mathrm{I}^{2}=45.84, \mathrm{df}=1, \mathrm{p}=0.17\right)$.

\section{Two-hour oral glucose tolerance test}

We extracted 4 outcomes from first episode psychosis patients ( $E$. Fernandez-Egea et al., 2009; Saddichha et al., 2008; Spelman et al., 2007; Wani et al., 2015) and 2 outcomes from depression and bipolar patients (Clemente Garcia-Rizo et al., 2013; C. Garcia-Rizo et al., 2016) for the meta- 
analysis of fasting insulin levels. In our overall analysis, first episode patients have significantly higher ES estimates of OGTT compared to the control group ( $\mathrm{ES}=0.94, \mathrm{Cl}=0.59$ to 1.29$)$ (Supplementary Figure 2).

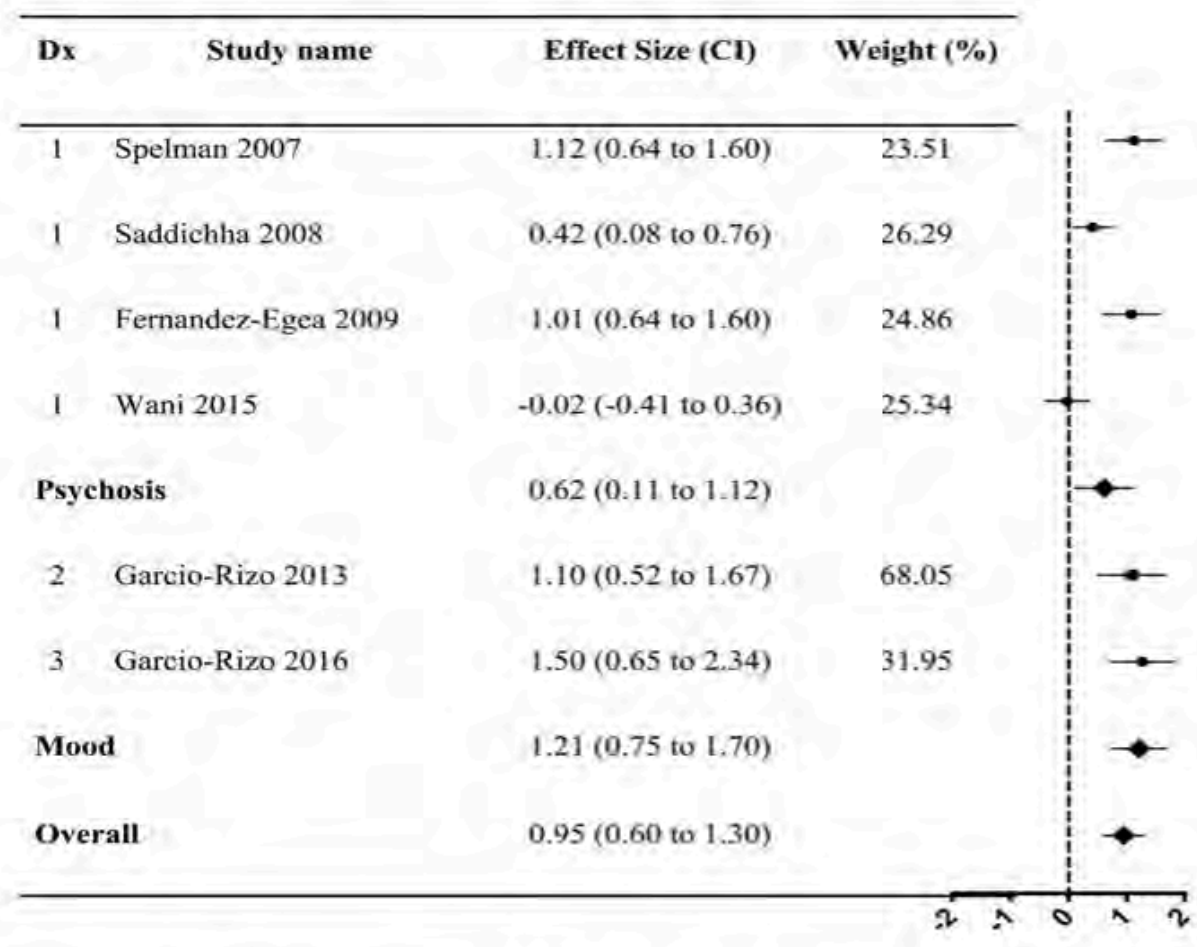

Supplementary Figure 2. Meta-analysis of OGTT levels in first episode patients Heterogeneity: $\mathrm{Tau}^{2}=0.223 ; \mathrm{I}^{2}=80.97 \% ; \mathrm{Q}=26.27, \mathrm{~d} . \mathrm{f}=5, \mathrm{p}<0.001$

Overall effect (Fixed): $Z=7.07, p<0.001$; Overall effect (Random): $Z=5.32, p<0.001$

Dx: Diagnoses. 1=First episode psychosis, $2=$ First episode depression, $3=$ First episode bipolar disorder

Patients with FEP ( $E S=0.62, \mathrm{Cl}=0.11$ to 1.12$)$ and patients with mood disorders ( $E S=1.22, C l=0.75$ to 1.70 ) both have higher OGTT levels compared to the healthy controls. ES estimates of OGTT levels were similar between FEP and mood disorder groups $(\mathrm{Q}=2.929, \mathrm{df}=1, \mathrm{p}=0.08)$.

No evidence of publication bias was found in OGTT analysis (Egger's intercept $=5.49, \mathrm{Cl}=-2.78$ to 13.78 ). There was a significant heterogeneity across all studies included in OGTT level meta-analysis 
$\left(I^{2}=80.9, d f=5, p<0.001\right)$. Heterogeneity was also significant in subgroup analyses that were carried out in studies with psychotic patients $\left(I^{2}=84.42\right.$, $d f=3, p<0.001)$. Studies in mood disorders revealed no significant heterogeneity $\left(\mathrm{I}^{2}<0.001, \mathrm{df}=1, \mathrm{p}=0.44\right)$.

\section{Meta-regression analysis}

We carried out meta-regression analyses in FEP and mood disorder groups to test the effects of sample age, BMl and gender distribution on glucose metabolism outcomes (Supplementary Table 5). In the FEP group, there was no significant interaction between age, gender, BMI and glucose metabolism outcomes. In the mood disorder group, only age was found to be significantly related with fasting blood glucose levels $(P E=0.03, \mathrm{Cl}=0.002$ to 0.05). In the mood disorder group, we were not able to carry out metaregression analysis on IR, OGGT and $\mathrm{HbA} 1 \mathrm{c}$ outcomes due to the limited data.

\begin{tabular}{|c|c|c|c|c|c|c|}
\hline \multicolumn{7}{|c|}{ Supplementary Table 5. Meta-regression analysis } \\
\hline & \multicolumn{3}{|c|}{ Schizophrenia } & \multicolumn{3}{|c|}{ Mood Disorders } \\
\hline & Age & BMI & Gender & Age & BMI & Gender \\
\hline & PE (CI) & PE (CI) & PE (CI) & PE (CI) & PE (CI) & PE (CI) \\
\hline \multirow{2}{*}{ Glucose } & -0.01 & -0.08 & -0.006 & 0.03 & -0.04 & 0.005 \\
\hline & $(-0.06$ to 0.02$)$ & $(-0.22$ to 0.06$)$ & $(-0.01$ to 0.01$)$ & $(0.002-0.05)$ & $(-0.13$ to 0.05$)$ & $(-0.0053$ to 0.01$)$ \\
\hline \multirow{2}{*}{ Insulin } & 0.01 & -0.07 & -0.007 & -0.06 & 0.05 & 0.01 \\
\hline & $(-0.06$ to 0.09$)$ & $(-0.29$ to 0.14$)$ & $(-0.02$ to 0.008$)$ & $(-0.12$ to 0.00$)$ & $(-0.15$ to 0.26$)$ & $(-0.001$ to 0.03$)$ \\
\hline \multirow{2}{*}{ HOMA-IR } & 0.01 & -0.05 & -0.006 & \multirow{2}{*}{ NA } & \multirow{2}{*}{ NA } & \multirow{2}{*}{ NA } \\
\hline & $(-0.03$ to 0.06$)$ & $(-0.18$ to 0.09$)$ & $(-0.01$ to 0.005$)$ & & & \\
\hline \multirow{2}{*}{$\mathrm{HbAlc}$} & -0.01 & 0.13 & -0.001 & \multirow{2}{*}{ NA } & \multirow{2}{*}{ NA } & \multirow{2}{*}{ NA } \\
\hline & $(-0.07$ to 0.06$)$ & $(-0.24$ to 0.51$)$ & $(-0.03$ to 0.03$)$ & & & \\
\hline \multirow{2}{*}{ OGTT } & 0.21 & \multirow{2}{*}{ NA } & 0.03 & \multirow{2}{*}{ NA } & \multirow{2}{*}{ NA } & \multirow{2}{*}{ NA } \\
\hline & $(-0.59$ to 1.01$)$ & & $(-0.02$ to 0.10$)$ & & & \\
\hline
\end{tabular}

There was no significant effect of study regions (Asian vs. Non-Asian) on fasting blood glucose, insulin and IR levels in the FEP group (Supplementary Table 6). Among the studies that included Asian patients with FEP, only one study reported OGTT levels, (Wani et al., 2015) and none of them reported $\mathrm{HbA} 1 \mathrm{c}$ levels. Therefore, we were not able to test the effect of 
study regions in OGTT and $\mathrm{HbA} 1 \mathrm{c}$ levels in patients with FEP. In the mood disorder group, only one study in Asian samples reported glucose metabolism outcomes. (Chang et al., 2013) Therefore we were not able to test the differences between Asian and Non-Asian samples in the mood disorder group.

\begin{tabular}{|c|c|c|c|}
\hline \multicolumn{4}{|c|}{$\frac{\text { Supplementary Table 6. Differences in Asian and Non-Asian Samples }}{\text { Schizophrenia }}$} \\
\hline & Asia & Non-Asia & \\
\hline & ES (CI) & ES (CI) & $Q(\mathbf{p})$ \\
\hline \multirow{2}{*}{ Glucose } & 0.23 & 0.08 & \multirow{2}{*}{$0.66(0.41)$} \\
\hline & $(-0.08$ to 0.55$)$ & $(-0.10$ to 0.27$)$ & \\
\hline \multirow{2}{*}{ Insulin } & 0.67 & 0.26 & \multirow{2}{*}{$2.50(0.11)$} \\
\hline & $(0.26$ to 1.07$)$ & $(-0.02$ to 0.55$)$ & \\
\hline \multirow{2}{*}{ HOMA-IR } & 0.49 & 0.31 & \multirow{2}{*}{$1.05(0.30)$} \\
\hline & $(0.20$ to 0.78$)$ & (0.11 to 0.50$)$ & \\
\hline HbAlc & NA & NA & NA \\
\hline OGTT & NA & NA & NA \\
\hline
\end{tabular}

\section{Discussion}

To our knowledge, this is the first meta-analysis that compares glucose metabolism outcomes of treatment-naïve patients with SMls. Cumulative results in this meta-analysis suggest a few differences between patients with SMIs and healthy controls. Compared to healthy controls, treatment-naïve patients with FEP have higher fasting insulin and IR levels. Two-hour OGTT results were also found to be higher in both SMI groups compared to the healthy controls. No significant differences were found in glucose metabolism outcomes between patients with FEP and mood disorders.

In patients with FEP, our cumulative analyses on glucose metabolism outcomes are in line with previous meta-analyses, which showed significant increases in fasting insulin levels and impaired oral glucose tolerance in this 


\section{Chapter 2. Glucose Metabolism Disorders in Mental Illness}

patient population. (Greenhalgh et al., 2016; Perry et al., 2016; Pillinger et al., 2017) Our meta-analysis also confirms previous reports of an impaired oral glucose tolerance in first episode, treatment-naïve patients with mood disorders. (Garcia-Rizo et al., 2016; Guha et al., 2014) Previous studies mostly focused on a specific diagnosis of SMIs, particularly FEP, while only one study compared the differences on glucose metabolism outcomes between various SMIs. (Garcia-Rizo et al., 2016) Our meta-analysis on insulin, IR and HbA1c levels showed some contrast between patients with FEP and first episode treatment-naïve patients with mood disorders. Compared to healthy controls, patients with FEP have higher insulin and IR levels whereas patients with mood disorders tend to have higher, but nonsignificant, HbA1c levels. These differences were not significant between SMI groups. Divergence between patient groups are most likely related with the limited number of studies in each arm. Future studies on glucose metabolism outcomes in drug-naïve first episode SMls are needed to explain the differences and similarities between diagnostic groups. Nevertheless, our results underline abnormalities in glucose metabolism at the beginning of the SMls, suggesting a pre-diabetic condition in early phases of both SMIs with high-risk of DM2 development and a subsequent increase in the risk of diabetes-related complications such as cardiovascular diseases and cognitive deterioration later in life.

Research suggests that altered systemic inflammation, shared genetic make-up between SMIs and DM2, and adverse gestational events may play a role in this pre-diabetic condition. There is some support for these arguments. (Amare, Schubert, Klingler-Hoffmann, Cohen-Woods, \& Baune, 2017; C. Garcia-Rizo, Fernandez-Egea, Bernardo, \& Kirkpatrick, 2015; Goldsmith, Rapaport, \& Miller, 2016; Greenhalgh et al., 2016; Thakore, 2004; van Nimwegen et al., 2008) Systemic inflammation is a feature of both disorders. SMls (Drexhage et al., 2010; Goldsmith et al., 2016; Modabbernia, Taslimi, Brietzke, \& Ashrafi, 2013; Monji et al., 2013) and DM2 (Calle \& Fernandez, 2012; Kubaszek et al., 2003) are associated with increased 


\section{Chapter 2. Glucose Metabolism Disorders in Mental Illness}

concentrations of inflammatory cytokines, such as interleukin 6, tumor necrosis factor-alpha, and acute phase reactants like C-reactive protein. Furthermore, mutations in genes encoding these inflammatory markers have been reported in both SMIs and DM2. (Amare et al., 2017; Lin \& Shuldiner, 2010) In addition to inflammation, findings from several studies suggest shared genetic liability between DM2 and schizophrenia. Family studies have shown that first-degree relatives of people with psychosis have an increased risk for DM and other abnormalities of glucose regulation. (Emilio FernandezEgea et al., 2008; van Welie et al., 2013) It has also been shown that genetic polymorphisms in several genes increase the risk of SMls and diabetes. (Amare et al., 2017; Chubb, Bradshaw, Soares, Porteous, \& Millar, 2008; Jurczyk et al., 2016; Scholz et al., 2010) Finally, early environmental factors can explain the part of the relationship between SMIs and DM2. Both SMIs and DM2 show an increased risk of prenatal and postnatal adverse events, as well as gestational complications. As suggested by the 'thrifty psychiatric phenotype' concept early environmental adverse events may interact with genetic programing and lead to SMls and DM2 in adulthood. (Garcia-Rizo et al., 2015)

In addition to these hypotheses, the hypothalamus-pituitary-adrenal (HPA) axis has been proposed as one locus of common pathophysiologic mechanisms underlying DM2 and SMIs. (Belvederi Murri et al., 2016; Calkin et al., 2013; Joseph \& Golden, 2016; Ryan et al., 2003) The HPA axis is a tightly regulated system that responds to acute and chronic stress by increasing cortisol levels through a cascade of physiological events. (Joseph \& Golden, 2016) Elevated cortisol levels can lead to glucose metabolism abnormalities, a decrease in insulin secretion and an increase in

gluconeogenesis, resulting in hyperglycemia with progression to DM2. (Fitzgerald, 2009; Joseph \& Golden, 2016) Increased cortisol response is common in both patients with mood disorders (Belvederi Murri et al., 2016; Watson, Gallagher, Ritchie, Ferrier, \& Young, 2004) and with schizophrenia. (Ryan et al., 2003; Spelman et al., 2007; Steen et al., 2014) As an acutely 


\section{Chapter 2. Glucose Metabolism Disorders in Mental Illness}

stressful state, onset of any SMI can increase cortisol levels, subsequently impair glycemic control, and lead to a pre-diabetic condition.

It is important to take note of the limitations of this meta-analysis. Our meta-analysis is based on cross-sectional studies, which cannot determine the causality of the relationship between SMls and glucose metabolism abnormalities. Despite the fact that our analysis revealed no evidence of publication bias in glucose metabolism outcomes, the possibility cannot be ruled out due to the small number of studies included in this meta-analysis, and the possibility of unreported negative findings. On several outcomes, our meta-analysis showed significant heterogeneity between study results in both FEP and mood disorder groups. Our meta-regression analyses on the interaction between BMI and gender distribution with glucose metabolism outcomes did not point to any significant determinants of the ES differences between studies in both samples. Only in the mood disorders group, age was significantly related with fasting glucose outcomes. Although, fasting glucose outcomes in mood disorders group did not show significant heterogeneity, this interaction may explain the heterogeneity in cumulative analysis. It is important to note that the number of studies we could consider for the metaregression analyses was limited as we had to exclude those that failed to report BMI and/or age outcomes between SMI and healthy control groups. (Chang et al., 2013; Nyboe et al., 2015; Saddichha et al., 2008; Spelman et al., 2007; Wani et al., 2015; Zhang et al., 2015) For future studies on glucose metabolism, it is crucial to match SMI and healthy control samples on BMI and age to report more reliable outcomes. Another possible explanation for not detecting any interaction between BMI levels and glucose metabolism outcomes on meta-regression analyses is that the first episode SMI samples in our analyses typically presented with normal to overweighed BMI levels, between 19.63 to 27.7 (Supplementary Table 3). However, compared to healthy controls BMI levels increases with antipsychotic treatments in patients with first episode SMIs. (Tek et al., 2016; Sengupta et al., 2008) Thus, we 


\section{Chapter 2. Glucose Metabolism Disorders in Mental IIIness}

posit that the relationship between BMI and glucose metabolism outcomes may emerge later in the course of disease.

We could test the effect of study regions only in FEP sub-group, which revealed no significant differences between Asian and European studies. Although we used the random-effects model to eliminate the heterogeneity between studies, our results should be interpreted with caution. Finally, our meta-analysis included a relatively small number of studies in mood disorder $(n=6)$ groups compared to FEP studies $(n=25)$. Therefore, our sub-group analysis on glucose metabolism outcomes between these two SMI groups should be evaluated cautiously. Small number of studies in mood disorders also limited our ability to compare most glucose metabolism outcomes between depression, bipolar disorder and FEP. It is clear that further studies are necessary to explore glucose metabolism in first episode, treatment-naïve patients with mood disorders.

Despite the limitations of our study, our results highlight impaired glucose metabolism at the onset of all SMIs, suggesting both patients with FEP and mood disorders are high-risk groups for DM2 development. It appears that less attention is paid to non-psychotic first episode illness and glucose metabolism dysregulation. Thus, it is hard to conclude if this phenomenon of glucose metabolism dysregulation is related to psychosis, schizophrenia or a stressful new onset of any serious psychiatric condition. Regardless, it is critically important to determine baseline DM2 risk at initial presentation of SMI. Detailed medical history and physical examination, family history of DM2, smoking status, dietary and physical activity habits, body mass index and fasting blood glucose and insulin, perhaps even oral glucose testing as a gold standard should be obtained before the initiation of psychotropic medications.(Vancampfort et al., 2016) After the initiation of psychotropic treatment, DM2 risk should be evaluated annually, with more frequent assessments in ultra-high-risk patients, such as those with multiple psychotic or mood episodes, significant weight gain, a family history of DM2 
and a need of polypharmacy treatments.(De Hert, Detraux, van Winkel, Yu, \& Correll, 2011; Gierisch et al., 2014; Vancampfort et al., 2016) Further research is needed to explore the mechanisms underlying early glucose metabolism abnormalities in SMls. 
References

Amare, A. T., Schubert, K. O., Klingler-Hoffmann, M., CohenWoods, S., \& Baune, B. T. (2017). The genetic overlap between mood disorders and cardiometabolic diseases: a systematic review of genome wide and candidate gene studies. Transl Psychiatry, 7(1), e1007. doi:10.1038/tp.2016.261

Arranz, B., Rosel, P., Ramirez, N., Duenas, R., Fernandez, P., Sanchez, J. M., . . San, L. (2004). Insulin resistance and increased leptin concentrations in noncompliant schizophrenia patients but not in antipsychotic-naive firstepisode schizophrenia patients. J Clin Psychiatry, 65(10), 1335-1342.

Basoglu, C., Oner, O., Gunes, C., Semiz, U. B., Ates, A. M., Algul, A., . .. Ipcioglu, O. (2010). Plasma orexin A, ghrelin, cholecystokinin, visfatin, leptin and agouti-related protein levels during 6-week olanzapine treatment in first-episode male patients with psychosis. Int Clin Psychopharmacol, 25(3), 165-171. doi:10.1097/YIC.0b013e328337785 0

Belvederi Murri, M., Prestia, D., Mondelli, V., Pariante, C., Patti, S., Olivieri, B., . . Amore, M. (2016). The HPA axis in bipolar disorder: Systematic review and metaanalysis.

Psychoneuroendocrinology, 63, 327342.

Cai, H.-L., Li, H.-D., Yan, X.-Z., Sun, B., Zhang, Q., Yan, M., . . Ye, H.-S. (2012). Metabolomic Analysis of Biochemical Changes in the Plasma and Urine of First-Episode Neuroleptic-Naive Schizophrenia
Patients after Treatment with Risperidone. J Proteome Res, 11(8), 4338-4350. doi:10.1021/pr300459d

Calkin, C. V., Gardner, D. M., Ransom, T., \& Alda, M. (2013). The relationship between bipolar disorder and type 2 diabetes: more than just co-morbid disorders. Ann Med, 45(2), 171-181. doi:10.3109/07853890.2012.687835

Calle, M. C., \& Fernandez, M. L. (2012). Inflammation and type 2 diabetes. Diabetes Metab, 38(3), 183-191.

doi:10.1016/j.diabet.2011.11.006

Canan, F., Yildirim, O., Tosun, M., Kayka, N., Tuman, T. C., \& Alcelik, A. (2014). Serum levels of omentin are not altered in drug-naive patients with major depression: a pilot study. Psychiatr Danub, 26(1), 34-38.

Chang, H. H., Chi, M. H., Lee, I. H., Tsai, H. C., Gean, P. W., Yang, Y. K., . . Chen, P. S. (2013). The change of insulin levels after six weeks antidepressant use in drug-naive major depressive patients. J Affect Disord, 150(2), 295-299. doi:10.1016/j.jad.2013.04.008

Charles, E. F., Lambert, C. G., \& Kerner, B. (2016). Bipolar disorder and diabetes mellitus: evidence for disease-modifying effects and treatment implications. Int $J$ Bipolar Disord, 4(1), doi:10.1186/s40345-016-0054-4

Chen, D. C., Du, X. D., Yin, G. Z., Yang, K. B., Nie, Y., Wang, N., . . . Zhang, X. Y. (2016). Impaired glucose tolerance in first-episode drug-naive patients with schizophrenia: relationships with 
clinical phenotypes and cognitive deficits. Psychol Med, 1-12. doi:10.1017/S0033291716001902

Chen, S., Broqueres-You, D., Yang, G., Wang, Z., Li, Y., Yang, F., \& Tan, Y. (2016). Male sex may be associated with higher metabolic risk in first-episode schizophrenia patients: A preliminary study. Asian $\mathrm{J}$ Psychiatr, 21, 25-30. doi:10.1016/j.ajp.2015.12.001

Chubb, J. E., Bradshaw, N. J., Soares, D. C., Porteous, D. J., \& Millar, J. K. (2008). The DISC locus in psychiatric illness. Mol Psychiatry, 13(1), 36-64. doi:10.1038/sj.mp.4002106

Cohen, D., \& De Hert, M. (2011). Endogenic and iatrogenic diabetes mellitus in drug-naive schizophrenia: the role of olanzapine and its place in the treatment psychopharmacological Neuropsychopharmacology, 36(11), 2368-2369.

Dasgupta, A., Singh, O. P., Rout, J. K., Saha, T., \& Mandal, S. (2010). Insulin resistance and metabolic profile in antipsychotic naive schizophrenia patients. Prog Neuropsychopharmacol Biol Psychiatry, 34(7), 1202-1207. doi:10.1016/j.pnpbp.2010.06.011

De Hert, M., Detraux, J., van Winkel, R., Yu, W., \& Correll, C. U. (2011). Metabolic and cardiovascular adverse effects associated with antipsychotic drugs. Nat Rev Endocrinol, 8(2), 114-126. doi:10.1038/nrendo.2011.156

Drexhage, R. C., Knijff, E. M., Padmos, R. C., HeulNieuwenhuijzen, L., Beumer, W.,
Versnel, M. A., \& Drexhage, H. A. (2010). The mononuclear phagocyte system and its cytokine inflammatory networks in schizophrenia and bipolar disorder. Expert Rev Neurother, 10(1), 59-76. doi:10.1586/ern.09.144

Egger, M., Davey Smith, G., Schneider, M., \& Minder, C. (1997). Bias in meta-analysis detected by a simple, graphical test. BMJ, 315(7109), 629-634.

Enez Darcin, A., Yalcin Cavus, S., Dilbaz, N., Kaya, H., \& Dogan, E. (2015). Metabolic syndrome in drugnaive and drug-free patients with schizophrenia and in their siblings. Schizophr Res, 166(1-3), 201-206. doi:10.1016/j.schres.2015.05.004

Fagiolini, A., Frank, E., Scott, J. A., Turkin, S., \& Kupfer, D. J. (2005). Metabolic syndrome in bipolar disorder: findings from the Bipolar Disorder Center for Pennsylvanians. Bipolar Disord, 7(5), 424-430.

Ferentinos, P., \& Dikeos, D. (2012). Genetic correlates of medical comorbidity associated with schizophrenia and treatment with antipsychotics. Curr Opin Psychiatry, 25(5), 381-390. doi:10.1097/YCO.0b013e32835685 37

Fernandez-Egea, E., Bernardo, M., Donner, T., Conget, I., Parellada, E., Justicia, A., . . Kirkpatrick, B. (2009). Metabolic profile of antipsychoticnaive individuals with non-affective psychosis. Br J Psychiatry, 194(5), 434-438.

doi:10.1192/bjp.bp.108.052605

Fernandez-Egea, E., Bernardo, M., Parellada, E., Justicia, A., Garcia- 
Rizo, C., Esmatjes, E., . . . Kirkpatrick, B. (2008). Glucose abnormalities in the siblings of people with schizophrenia. Schizophr Res, 103(1-3), 110-113. doi:10.1016/j.schres.2008.04.017

Fitzgerald, P. J. (2009). Is elevated noradrenaline an aetiological factor in a number of diseases? Auton Autacoid Pharmacol, 29(4), 143-156. doi:10.1111/j.1474-

8665.2009.00442.x

Garcia-Rizo, C., Fernandez-Egea, E., Bernardo, M., \& Kirkpatrick, B. (2015). The thrifty psychiatric phenotype. Acta Psychiatr Scand, 131(1),

18-20.

doi:10.1111/acps.12309

Garcia-Rizo, C., Fernandez-Egea, E., Miller, B. J., Oliveira, C., Justicia, A., Griffith, J. K., . . . Kirkpatrick, B. (2013). Abnormal glucose tolerance, white blood cell count, and telomere length in newly diagnosed, antidepressant-naïve patients with depression. Brain Behav Immun, 28, 49-53.

Garcia-Rizo, C., Kirkpatrick, B., Fernandez-Egea, E., Oliveira, C., \& Bernardo, M. (2016). Abnormal glycemic homeostasis at the onset of serious mental illnesses: A common pathway.

Psychoneuroendocrinology, 67, 7075.

doi:10.1016/j.psyneuen.2016.02.001

Gierisch, J. M., Nieuwsma, J. A., Bradford, D. W., Wilder, C. M., MannWrobel, M. C., McBroom, A. J., . . . Williams, J. W., Jr. (2014). Pharmacologic and behavioral interventions to improve cardiovascular risk factors in adults with serious mental illness: a systematic review and metaanalysis. J Clin Psychiatry, 75(5), e424-440.

doi:10.4088/JCP.13r08558

Goldsmith, D. R., Rapaport, M. H., \& Miller, B. J. (2016). A meta-analysis of blood cytokine network alterations in psychiatric patients: comparisons between schizophrenia, bipolar disorder and depression. $\mathrm{Mol}$ Psychiatry, 21(12), 1696-1709. doi:10.1038/mp.2016.3

Greenhalgh, A. M., GonzalezBlanco, L., Garcia-Rizo, C., Fernandez-Egea, E., Miller, B., Arroyo, M. B., \& Kirkpatrick, B. (2016). Meta-analysis of glucose tolerance, insulin, and insulin resistance in antipsychotic-naive patients with nonaffective psychosis. Schizophr doi:10.1016/j.schres.2016.09.026

Grover, S., Nebhinani, N., Chakrabarti, S., Avasthi, A., \& Kulhara, P. (2013). Metabolic Syndrome in Drug-naive Patients with Depressive Disorders. Indian $J$ Psychol Med, 35(2), 167-173. doi:10.4103/0253-7176.116247

Guha, P., Bhowmick, K., Mazumder, P., Ghosal, M., Chakraborty, I., \& Burman, P. (2014). Assessment of insulin resistance and metabolic syndrome in drug naive patients of bipolar disorder. Indian journal of clinical biochemistry : IJCB, 29(1), 51-56. doi:10.1007/s12291-0120292-x

Henneman, D. H., Altschule, M. D., \& Goncz, R. M. (1954). Carbohydrate metabolism in brain disease. II. Glucose metabolism in Schizophrenic, manic-depressive, 
and involutional psychoses. $A M A$ Arch Intern Med, 94(3), 402-416.

Joseph, J. J., \& Golden, S. H. (2016). Cortisol dysregulation: the bidirectional link between stress, depression, and type 2 diabetes mellitus. Ann $N$ Y Acad Sci. doi:10.1111/nyas. 13217

Jurczyk, A., Nowosielska, A., Przewozniak, N., Aryee, K. E., Dilorio, P., Blodgett, D., . . . Bortell, R. (2016). Beyond the brain: disrupted in schizophrenia 1 regulates pancreatic beta-cell function via glycogen synthase kinase-3beta. Faseb j, 30(2), 983993. doi:10.1096/fj.15-279810

Kavzoglu, S. O., \& Hariri, A. G. (2013). Intracellular Adhesion Molecule (ICAM-1), Vascular Cell Adhesion Molecule (VCAM-1) and ESelectin Levels in First Episode Schizophrenic Patients. Klinik Psikofarmakoloji Bulteni-Bulletin of Clinical Psychopharmacology, 23(3), 205-214.

Keinanen, J., Mantere, O., Kieseppa, T., Mantyla, T., Torniainen, M., Lindgren, M., . . Suvisaari, J. (2015). Early insulin resistance predicts weight gain and waist circumference increase in first-episode psychosis-A one year follow-up study. Schizophr Res, 169(1-3), 458-463.

Kubaszek, A., Pihlajamaki, J., Komarovski, V., Lindi, V., Lindstrom, J., Eriksson, J., . . . Finnish Diabetes Prevention, S. (2003). Promoter polymorphisms of the TNF-alpha (G308A) and IL-6 (C-174G) genes predict the conversion from impaired glucose tolerance to type 2 diabetes: the Finnish Diabetes Prevention Study. Diabetes, 52(7), 1872-1876.
Leo, R., Di Lorenzo, G., Tesauro, M., Cola, C., Fortuna, E., Zanasi, M., .. . Romeo, F. (2006). Decreased plasma adiponectin concentration in major depression. Neurosci Lett, 407(3),

211-213.

doi:10.1016/j.neulet.2006.08.043

Li, J., Dong, Y. J., Wu, T. X., \& Tong, N. W. (2016). Differences between Western and Asian type 2 diabetes patients in the incidence of vascular complications and mortality: A systematic review of randomized controlled trials on lowering blood glucose. Journal of Diabetes, 8(6), 824-833.

doi:10.1111/17530407.12361

Lin, P. I., \& Shuldiner, A. R. (2010). Rethinking the genetic basis for comorbidity of schizophrenia and type 2 diabetes. Schizophr Res, 123(2-3), 234-243. doi:10.1016/j.schres.2010.08.022

Mclntyre, R. S., Mancini, D. A., Pearce, M. M., Silverstone, P., Chue, P., Misener, V. L., \& Konarski, J. Z. (2005). Mood and Psychotic Disorders and Type 2 Diabetes: A Metabolic Triad. Canadian Journal of Diabetes, 29(2), 122-132.

Misiak, B., Laczmanski, L., Sloka, N. K., Szmida, E., Piotrowski, P., Loska, O., . . . Frydecka, D. (2016). Metabolic dysregulation in firstepisode schizophrenia patients with respect to genetic variation in onecarbon metabolism. Psychiatry Res, 238, 60-67. doi:10.1016/j.psychres.2016.01.077

Mitchell, A. J., Vancampfort, D., De Herdt, A., Yu, W., \& De Hert, M. (2013). Is the prevalence of metabolic syndrome and metabolic abnormalities increased in early 
schizophrenia? A comparative metaanalysis of first episode, untreated and treated patients. Schizophr Bull, 39(2), 295-305. doi:10.1093/schbul/sbs082

Modabbernia, A., Taslimi, S., Brietzke, E., \& Ashrafi, M. (2013). Cytokine alterations in bipolar disorder: a meta-analysis of 30 studies. Biol Psychiatry, 74(1), 1525.

doi:10.1016/j.biopsych.2013.01.007

Moher, D., Liberati, A., Tetzlaff, J., Altman, D. G., \& Group, P. (2009). Preferred reporting items for systematic reviews and metaanalyses: the PRISMA statement. $J$ Clin Epidemiol, 62(10), 1006-1012. doi:10.1016/j.jclinepi.2009.06.005

Monji, A., Kato, T. A., Mizoguchi, Y., Horikawa, H., Seki, Y., Kasai, M., ... Kanba,

$S$.

(2013).

Neuroinflammation in schizophrenia especially focused on the role of microglia.

Neuropsychopharmacol

Prog

Psychiatry, 42, 115-121. doi:10.1016/j.pnpbp.2011.12.002

Nyboe, L., Vestergaard, C. H., Moeller, M. K., Lund, H., \& Videbech, P. (2015). Metabolic syndrome and aerobic fitness in patients with firstepisode schizophrenia, including a 1year follow-up. Schizophr Res, 168(1-2), 381-387. doi:10.1016/j.schres.2015.07.053

Perry, B. I., Mclntosh, G., Weich, S., Singh, S., \& Rees, K. (2016). The association between first-episode psychosis and abnormal glycaemic control: systematic review and metaanalysis. Lancet Psychiatry, 3(11), 1049-1058. doi:10.1016/S22150366(16)30262-0
Petrikis, P., Tigas, S., Tzallas, A. T., Papadopoulos, I., Skapinakis, P., \& Mavreas, V. (2015). Parameters of glucose and lipid metabolism at the fasted state in drug-naive firstepisode patients with psychosis: Evidence for insulin resistance. Psychiatry Res, 229(3), 901-904. doi:10.1016/j.psychres.2015.07.041

Pillinger, T., Beck, K., Gobjila, C., Donocik, J. G., Jauhar, S., \& Howes, O. D. (2017). Impaired glucose homeostasis in first-episode schizophrenia: A systematic review and meta-analysis. JAMA Psychiatry.

doi:10.1001/jamapsychiatry.2016.38 03

Rajkumar, A. P., Horsdal, H. T., Wimberley, T., Cohen, D., Mors, O., Borglum, A. D., \& Gasse, C. (2017). Endogenous and AntipsychoticRelated Risks for Diabetes Mellitus in Young People With Schizophrenia: A Danish Population-Based Cohort Study. Am J Psychiatry, 174(7), 686694.

Roy, T., \& Lloyd, C. E. (2012). Epidemiology of depression and diabetes: a systematic review. J Affect Disord, 142 Suppl, S8-21.

Ryan, M. C., Collins, P., \& Thakore, J. H. (2003). Impaired fasting glucose tolerance in first-episode, drug-naive patients with schizophrenia. Am J Psychiatry, 160(2), 284-289. doi:10.1176/appi.ajp.160.2.284

Saddichha, S., Manjunatha, N., Ameen, S., \& Akhtar, S. (2008). Diabetes and schizophrenia - effect of disease or drug? Results from a randomized, double-blind, controlled prospective study in first-episode 
schizophrenia. Acta

Scand, 117(5),

doi:10.1111/j.1600-

0447.2008.01158.x

Saloojee, S., Burns, J. K., \& Motala, A. A. (2017). Metabolic syndrome in antipsychotic naive African patients with severe mental illness in usual care. Early Interv Psychiatry. doi:10.1111/eip.12428

Scholz, C. J., Jacob, C. P., Buttenschon, H. N., Kittel-Schneider, S., Boreatti-Hummer, A., Zimmer, M., . . Reif, A. (2010). Functional variants of TSPAN8 are associated with bipolar disorder and schizophrenia. Am J Med Genet B Neuropsychiatr Genet, 153b(4), 967972. doi:10.1002/ajmg.b.31057

Sengupta, S., Parrilla-Escobar, M. A., Klink, R., Fathalli, F., Ying Kin, N., Stip, E., . . J Joober, R. (2008). Are metabolic indices different between drug-naive first-episode psychosis patients and healthy controls? Schizophr Res, 102(1-3), 329-336. doi:10.1016/j.schres.2008.02.013

Spelman, L. M., Walsh, P. I., Sharifi, N., Collins, P., \& Thakore, J. H. (2007). Impaired glucose tolerance in first-episode drug-naive patients with schizophrenia. Diabet Med, 24(5), 481-485. doi:10.1111/j.14645491.2007.02092.x

Steen, N. E., Methlie, P., Lorentzen, S., Dieset, I., Aas, M., Nerhus, M., .. . Andreassen, O. A. (2014). Altered systemic cortisol metabolism in bipolar disorder and schizophrenia spectrum disorders. J Psychiatr Res, 52 , 57-62. doi:10.1016/j.jpsychires.2014.01.01 7
Tek, C., Kucukgoncu, S., Guloksuz, S., Woods, S. W., Srihari, V. H., \& Annamalai, A. (2016). Antipsychoticinduced weight gain in first-episode psychosis patients: a meta-analysis of differential effects of antipsychotic medications. Early Interv Psychiatry, 10(3), 193-202. doi:10.1111/eip.12251

Thakore, J. H. (2004). Metabolic disturbance in first-episode schizophrenia. $\mathrm{Br} J$ Psychiatry Suppl, 47, S76-79.

Turan, C., Kesebir, S., \& Suner, O. (2014). Are ICAM, VCAM and Eselectin levels different in first manic episode and subsequent remission? $J$ Affect Disord, 163, 76-80. doi:10.1016/j.jad.2014.03.052

van Nimwegen, L. J. M., Storosum, J. G., Blumer, R. M. E., Allick, G., Venema, H. W., de Haan, L., . . . Sauerwein, H. P. (2008). Hepatic insulin resistance in antipsychotic naive schizophrenic patients: Stable isotope studies of glucose metabolism. Journal of Clinical Endocrinology \& Metabolism, 93(2), 572-577. doi:10.1210/jc.2007-1167

van Welie, H., Derks, E. M., Verweij, K. H., de Valk, H. W., Kahn, R. S., \& Cahn, W. (2013). The prevalence of diabetes mellitus is increased in relatives of patients with a nonaffective psychotic disorder. Schizophr Res, 143(2-3), 354-357. doi:10.1016/j.schres.2012.11.011

Vancampfort, D., Correll, C. U., Galling, B., Probst, M., De Hert, M., Ward, P. B., . . Stubbs, B. (2016). Diabetes mellitus in people with schizophrenia, bipolar disorder and major depressive disorder: a systematic review and large scale 
meta-analysis. World Psychiatry, 15(2),

doi:10.1002/wps.20309

Venkatasubramanian, G., Chittiprol, S., Neelakantachar, N., Naveen, M. N., Thirthall, J., Gangadhar, B. N., \& Shetty, K. T. (2007). Insulin and insulin-like growth factor-1 abnormalities in antipsychotic-naive schizophrenia. Am J Psychiatry, 164(10), 1557-1560. doi:10.1176/appi.ajp.2007.0702023 3

Wani, R. A., Dar, M. A., Margoob, M. A., Rather, Y. H., Haq, I., \& Shah, M. S. (2015). Diabetes mellitus and impaired glucose tolerance in patients with schizophrenia, before and after antipsychotic treatment. $J$ Neurosci Rural Pract, 6(1), 17-22. doi:10.4103/0976-3147.143182

Watson, S., Gallagher, P., Ritchie, J. C., Ferrier, I. N., \& Young, A. H. (2004). Hypothalamic-pituitaryadrenal axis function in patients with bipolar disorder. $\mathrm{Br} J$ Psychiatry, 184, 496-502.

Wells, G. S., B; O'Connell, B; Peterson, J; Welch, V; Losos, M; Tugwell, P. (2009). The NewcastleOttawa scale (NOS) for assessing the quality of nonrandomized studies in meta-analyses.

Whiting, D. R., Guariguata, L., Weil, C., \& Shaw, J. (2011). IDF Diabetes Atlas: Global estimates of the prevalence of diabetes for 2011 and 2030. Diabetes Research and Clinical Practice, 94(3), 311-321. doi:10.1016/j.diabres.2011.10.029

Wu, X., Huang, Z., Wu, R., Zhong, Z., Wei, Q., Wang, H., ... Zhang, J. (2013). The comparison of glycometabolism parameters and lipid profiles between drug-naive, first-episode schizophrenia patients and healthy controls. Schizophr Res, 150(1), 157-162. doi:10.1016/j.schres.2013.07.051

Yamagata, A. S., Mansur, R. B., Rizzo, L. B., Rosenstock, T., McIntyre, R. S., \& Brietzke, E. (2016). Selfish brain and selfish immune system interplay: A theoretical framework for metabolic comorbidities of mood disorders. Neurosci Biobehav Rev, 72, 43-49. doi:10.1016/j.neubiorev.2016.11.01 0

Yildirim, O., Canan, F., Tosun, M., Kayka, N., Tuman, T. C., Alhan, C., \& Alcelik, A. (2014). Plasma Omentin Levels in Drug-Free Patients with Schizophrenia. Neuropsychobiology, 69(3), 159-164.

doi:10.1159/000360736

Zhang, X. Y., Chen, D. C., Tan, Y. L., An, H. M., Zunta-Soares, G. B., Huang, X. F., \& Soares, J. C. (2015). Glucose disturbances in first-episode drug-naive schizophrenia: Relationship to psychopathology. Psychoneuroendocrinology, 62, 376380. 
Supplementary Table I. PRISMA Checklist

\begin{tabular}{|c|c|c|c|}
\hline Section/topic & \# & Checklist item & $\begin{array}{l}\text { Reported } \\
\text { on page } \\
\text { \# }\end{array}$ \\
\hline Title & 1 & Identify the report as a systematic review, meta-analysis, or both. & \#1 \\
\hline \multicolumn{4}{|l|}{ ABSTRACT } \\
\hline $\begin{array}{l}\text { Structured } \\
\text { summary }\end{array}$ & 2 & $\begin{array}{l}\text { Provide a structured summary including, as applicable: background; objectives; data } \\
\text { sources; study eligibility criteria, participants, and interventions; study appraisal and } \\
\text { synthesis methods; results; limitations; conclusions and implications of key findings; } \\
\text { systematic review registration number. }\end{array}$ & \#1 \\
\hline \multicolumn{4}{|c|}{ INTRODUCTION } \\
\hline Rationale & 3 & Describe the rationale for the review in the context of what is already known. & \#2,3 \\
\hline Objectives & 4 & $\begin{array}{l}\text { Provide an explicit statement of questions being addressed with reference to } \\
\text { participants, interventions, comparisons, outcomes, and study design (PICOS). }\end{array}$ & \#2,3 \\
\hline \multicolumn{4}{|l|}{ METHODS } \\
\hline $\begin{array}{l}\text { Protocol and } \\
\text { registration }\end{array}$ & 5 & $\begin{array}{l}\text { Indicate if a review protocol exists, if and where it can be accessed (e.g., Web } \\
\text { address), and, if available, provide registration information including registration } \\
\text { number. }\end{array}$ & \#4 \\
\hline Eligibility criteria & 6 & $\begin{array}{l}\text { Specify study characteristics (e.g., PICOS, length of follow-up) and report } \\
\text { characteristics (e.g., years considered, language, publication status) used as criteria } \\
\text { for eligibility, giving rationale. }\end{array}$ & \#4 \\
\hline $\begin{array}{l}\text { Information } \\
\text { sources }\end{array}$ & 7 & $\begin{array}{l}\text { Describe all information sources (e.g., databases with dates of coverage, contact } \\
\text { with study authors to identify additional studies) in the search and date last } \\
\text { searched. }\end{array}$ & \#4 \\
\hline
\end{tabular}




\begin{tabular}{|c|c|c|c|}
\hline Search & 8 & $\begin{array}{l}\text { Present full electronic search strategy for at least one database, including any limits } \\
\text { used, such that it could be repeated. }\end{array}$ & \#4 \\
\hline Study selection & 9 & $\begin{array}{l}\text { State the process for selecting studies (i.e., screening, eligibility, included in } \\
\text { systematic review, and, if applicable, included in the meta-analysis). }\end{array}$ & \#4 \\
\hline $\begin{array}{l}\text { Data collection } \\
\text { process }\end{array}$ & 10 & $\begin{array}{l}\text { Describe method of data extraction from reports (e.g., piloted forms, independently, } \\
\text { in duplicate) and any processes for obtaining and confirming data from investigators. }\end{array}$ & \#4 \\
\hline Data items & 11 & $\begin{array}{l}\text { List and define all variables for which data were sought (e.g., PICOS, funding } \\
\text { sources) and any assumptions and simplifications made. }\end{array}$ & \#4 \\
\hline $\begin{array}{l}\text { Risk of bias in } \\
\text { individual studies }\end{array}$ & 12 & $\begin{array}{l}\text { Describe methods used for assessing risk of bias of individual studies (including } \\
\text { specification of whether this was done at the study or outcome level), and how this } \\
\text { information is to be used in any data synthesis. }\end{array}$ & \#5 \\
\hline $\begin{array}{l}\text { Summary } \\
\text { measures }\end{array}$ & 13 & State the principal summary measures (e.g., risk ratio, difference in means). & \#5 \\
\hline $\begin{array}{l}\text { Synthesis of } \\
\text { results }\end{array}$ & 14 & $\begin{array}{l}\text { Describe the methods of handling data and combining results of studies, if done, } \\
\text { including measures of consistency }\left(\text { e.g., } \mathrm{I}^{2}\right) \text { for each meta-analysis. }\end{array}$ & \#5 \\
\hline
\end{tabular}


Supplementary Table 1. PRISMA Checklist

\begin{tabular}{|c|c|c|c|}
\hline Section/topic & \# & Checklist item & $\begin{array}{l}\text { Reported } \\
\text { on page \# }\end{array}$ \\
\hline $\begin{array}{l}\text { Risk of bias across } \\
\text { studies }\end{array}$ & 15 & $\begin{array}{l}\text { Specify any assessment of risk of bias that may affect the cumulative evidence } \\
\text { (e.g., publication bias, selective reporting within studies). }\end{array}$ & \#5 \\
\hline $\begin{array}{l}\text { Additional } \\
\text { analyses }\end{array}$ & 16 & $\begin{array}{l}\text { Describe methods of additional analyses (e.g., sensitivity or subgroup analyses, } \\
\text { meta-regression), if done, indicating which were pre-specified. }\end{array}$ & \#5 \\
\hline \multicolumn{4}{|l|}{ RESULTS } \\
\hline Study selection & 17 & $\begin{array}{l}\text { Give numbers of studies screened, assessed for eligibility, and included in the } \\
\text { review, with reasons for exclusions at each stage, ideally with a flow diagram. }\end{array}$ & \#6 \\
\hline $\begin{array}{l}\text { Study } \\
\text { characteristics }\end{array}$ & 18 & $\begin{array}{l}\text { For each study, present characteristics for which data were extracted (e.g., study } \\
\text { size, PICOS, follow-up period) and provide the citations. }\end{array}$ & \#6 \\
\hline $\begin{array}{l}\text { Risk of bias within } \\
\text { studies }\end{array}$ & 19 & $\begin{array}{l}\text { Present data on risk of bias of each study and, if available, any outcome level } \\
\text { assessment (see item 12). }\end{array}$ & \#6-9 \\
\hline $\begin{array}{l}\text { Results of } \\
\text { individual studies }\end{array}$ & 20 & $\begin{array}{l}\text { For all outcomes considered (benefits or harms), present, for each study: (a) simple } \\
\text { summary data for each intervention group (b) effect estimates and confidence } \\
\text { intervals, ideally with a forest plot. }\end{array}$ & \#6-9 \\
\hline $\begin{array}{l}\text { Synthesis of } \\
\text { results }\end{array}$ & 21 & $\begin{array}{l}\text { Present results of each meta-analysis done, including confidence intervals and } \\
\text { measures of consistency. }\end{array}$ & \#6-9 \\
\hline $\begin{array}{l}\text { Risk of bias across } \\
\text { studies }\end{array}$ & 22 & Present results of any assessment of risk of bias across studies (see Item 15). & \#6-9 \\
\hline Additional analysis & 23 & $\begin{array}{l}\text { Give results of additional analyses, if done (e.g., sensitivity or subgroup analyses, } \\
\text { meta-regression [see Item 16]). }\end{array}$ & $\# 9,10$ \\
\hline \multicolumn{3}{|l|}{ DISCUSSION } & \\
\hline
\end{tabular}




\begin{tabular}{|l|c|l|l|}
\hline $\begin{array}{l}\text { Summary of } \\
\text { evidence }\end{array}$ & 24 & $\begin{array}{l}\text { Summarize the main findings including the strength of evidence for each main } \\
\text { outcome; consider their relevance to key groups (e.g., healthcare providers, users, } \\
\text { and policy makers). }\end{array}$ & $\# 11-13$ \\
\hline Limitations & 25 & $\begin{array}{l}\text { Discuss limitations at study and outcome level (e.g., risk of bias), and at review- } \\
\text { level (e.g., incomplete retrieval of identified research, reporting bias). }\end{array}$ & $\# 13-14$ \\
\hline Conclusions & 26 & $\begin{array}{l}\text { Provide a general interpretation of the results in the context of other evidence, and } \\
\text { implications for future research. }\end{array}$ & $\# 14,15$ \\
\hline \hline FUNDING & 27 & $\begin{array}{l}\text { Describe sources of funding for the systematic review and other support (e.g., } \\
\text { supply of data); role of funders for the systematic review. }\end{array}$ & $\# 16$ \\
\hline Funding
\end{tabular}

From: Moher D, Liberati A, Tetzlaff J, Altman DG, The PRISMA Group (2009). Preferred Reporting Items for Systematic Reviews and Meta-Analyses: The PRISMA Statement. PLoS Med 6(7): e1000097. doi:10.1371/journal.pmed1000097 
Supplementary Table 2. Quality of the published studies

\begin{tabular}{|c|c|c|c|}
\hline \multirow[b]{2}{*}{ Source/Diagnosis } & \multicolumn{3}{|c|}{ NOS } \\
\hline & Selection & Comparability & $\begin{array}{l}\text { Outcome } \\
\text { /Exposure }\end{array}$ \\
\hline Arranz B., 2004/ FEP & $* * * *$ & $* *$ & $* * *$ \\
\hline Basoglu C., 2010/FEP ${ }^{2}$ & **** & ** & *** \\
\hline Cai. HL, 20I2/FEP ${ }^{3}$ & ** & ** & **** \\
\hline Canan, 20I4/MDD ${ }^{4}$ & **** & ** & ** \\
\hline Cetin, 20I4/BBD ${ }^{5}$ & $* * * *$ & $* *$ & $*$ \\
\hline Chang, 2013/MDD 6 & $* * *$ & ** & $* * *$ \\
\hline Chen DC, $2016 /$ FEP $^{7}$ & **** & ** & **** \\
\hline Chen S., 2016/FEP 8 & ***** & ** & **** \\
\hline Darcin A. Enez, 2015/FEP9 & $* * * *$ & * & $*$ \\
\hline Dasgupta A., 2010/FEP 10 & ** & ** & $* * *$ \\
\hline Fernandez Egea, 2009/FEP ${ }^{\prime \prime}$ & $* * * *$ & ** & $* * *$ \\
\hline Garcia-Rizo, 2013/MDD ${ }^{12}$ & ***** & ** & **** \\
\hline $\begin{array}{l}\text { Garcia-Rizo, 2016/MDD- } \\
\text { repeated }^{13}\end{array}$ & **** & $* *$ & **** \\
\hline Grover, 20I3/MDD ${ }^{14}$ & **** & ** & $*$ \\
\hline Kavzoglu \& Hariri, 20 I3/FEP ${ }^{15}$ & **** & $*$ & ** \\
\hline Keinanen J., 20I5/FEP 16 & ** & $*$ & **** \\
\hline Leo, 2006/MDD ${ }^{17}$ & $* * * *$ & ** & $* * *$ \\
\hline Misiak B. 2016/FEP ${ }^{18}$ & $* * * *$ & $* *$ & $* * *$ \\
\hline Nyobe 2015/FEP* 19 & $* * *$ & $*$ & $*$ \\
\hline Petrikis P., 20I5/FEP 20 & $* * * *$ & ** & $* * *$ \\
\hline Ryan MC, 2003/FEP 21 & **** & ** & **** \\
\hline Saddichha S., 2008/FEP ${ }^{22}$ & ***** & $* *$ & $* *$ \\
\hline Saloojee, 20I7/FEP, BBD ${ }^{23}$ & $* * *$ & ** & $* *$ \\
\hline Sengupta S., 2008/FEP ${ }^{24}$ & $* * * *$ & $* *$ & $* * *$ \\
\hline Spelman, 2007/FEP 25 & $* * * *$ & $*$ & $* * *$ \\
\hline $\begin{array}{l}\text { van Nimwegen Lonneke JM, } \\
\text { 2008/FEP } 26\end{array}$ & $* * *$ & $* *$ & $* * *$ \\
\hline $\begin{array}{l}\text { Venkatasubramanian, } \\
\text { 2007/FEP } 27\end{array}$ & $* * * *$ & $* *$ & $* *$ \\
\hline Wani, 20I5/FEP 28 & $* * *$ & $*$ & $* *$ \\
\hline Wu., 2013/FEP ${ }^{29}$ & $* * * *$ & $* *$ & $* * *$ \\
\hline Yildirim, 20I4/FEP 30 & ** & ** & $* * *$ \\
\hline Zhang XY, 20I5/FEP 31 & ***** & ** & **** \\
\hline
\end{tabular}


Modified Newcastle-Ottawa Scale for cross-sectional studies

Selection-Maximum 4 stars:

I) Representativeness of the sample:

a. Representative of the average in the target population (all subjects or random sampling) *

b. Somewhat representative of the average in the target population (non-random sampling)*

c. Selected group or no description of the selection process

2) Sample size:

a. Justified and satisfactory*

b. Not Justified

3) Selection and definition of controls

a. Community controls *

b. Hospital control, within the same community

c. No description

4) Diagnosis and definition of patient population

a. Independent validation (e.g. patients were diagnosed by $>$ I professional) or use of reliable diagnostic tools (e.g. SCID, MINI) or adequate definition of the cases according to DSM or ICD criteria. *

b. No description

Comparability-Maximum 2 stars:

I) Comparability of cases and controls on the bases of the design or analysis

a. Study controls for BMI*

b. Study controls for additional factors (weight, age, ethnicity) * Outcomes/Exposure-Maximum 3 Stars:

I) Assessment of the outcome

a. Laboratory procedures defined clearly **

b. Clearly defined fasting period**

c. No description

2) Statistical comparison:

a. The statistical test used to analyze the data is clearly described and appropriate, and study presented critical information of the associations of outcomes, including confidence intervals, means and standard deviations and the probability levels.*

b. No adequate definition of statistical procedure 
Chapter 2. Glucose Metabolism Disorders in Mental Illness

Supplementary Table 3. Summary of the studies included in meta-analysis

\begin{tabular}{|c|c|c|c|c|c|c|c|c|c|}
\hline \multirow{2}{*}{$\begin{array}{c}\text { Source, } \\
\text { Year/Diagnosis }\end{array}$} & \multirow[t]{2}{*}{ Country } & \multicolumn{2}{|c|}{$\begin{array}{l}\text { Sample } \\
\text { Size }\end{array}$} & \multicolumn{2}{|c|}{ Mean age } & \multicolumn{2}{|c|}{$\begin{array}{l}\text { Gender } \\
\text { Male \% }\end{array}$} & \multicolumn{2}{|c|}{ BMI } \\
\hline & & $\mathbf{P t}$ & C & $\mathbf{P t}$ & C & $\mathbf{P t}$ & C & $\mathbf{P t}$ & C \\
\hline Arranz B., 2004/ FEP' & Spain & 50 & 50 & $25.2 \pm 0.6$ & $29.8 \pm 0.6$ & 66 & 62 & $24.5 \pm 09$ & $22.2 \pm 0.3$ \\
\hline Basoglu C., 20I0/FEP 2 & Turkey & 27 & 22 & $21.2 \pm 0.7$ & $21.7 \pm 1.1$ & 100 & 100 & $22.0 \pm 2.2$ & $22.4 \pm 2.0$ \\
\hline Cai. HL, 20I2/FEP 3 & China & 11 & $\mathrm{II}$ & $27.6 \pm 9.5$ & $27.6 \pm 9.5$ & 54.5 & 55 & $21 \pm 1.7$ & $21.1 \pm 0.7$ \\
\hline Canan, 20I4/MDD ${ }^{4}$ & Turkey & 30 & 30 & $34.9 \pm 10.9$ & $39.7 \pm 14.2$ & 33 & 33 & $25.2 \pm 2.9$ & $24.6 \pm 3.3$ \\
\hline Cetin, 20I4/BBD ${ }^{5}$ & Turkey & 48 & 50 & $30.46 \pm 9.9$ & $29.96 \pm 5.45$ & 44 & 42 & $25.8 \pm 2.4$ & $24.2 \pm 3.1$ \\
\hline Chang, 20I3/MDD ${ }^{6}$ & Taiwan & 50 & 104 & $38.6 \pm 11.2$ & $34.1 \pm I I .7$ & 28 & 41 & $22.5 \pm 4.5$ & $22.7 \pm 3.4$ \\
\hline Chen DC, 20I6/FEP ${ }^{7}$ & China & 172 & 31 & $28.7 \pm 9.9$ & $26.9 \pm 5.2$ & 48.2 & 45 & $21.8 \pm 3.8$ & $22.4 \pm 3.5$ \\
\hline Chen S., 2016/FEP 8 & China & 60 & 28 & $28.24 \pm 9.9$ & $26.9 \pm 3.9$ & 30 & 32 & $21.8 \pm 3.8$ & $21.4 \pm 2.4$ \\
\hline $\begin{array}{c}\text { Darcin A. Enez, } \\
\text { 2015/FEP }\end{array}$ & Turkey & 40 & 70 & $34.6 \pm 1.1$ & $34.6 \pm 8.9$ & 73.2 & 53 & $24.3 \pm 7.4$ & $24.9 \pm 7.04$ \\
\hline Dasgupta A., 2010/FEP 10 & India & 25 & 30 & $32.5 \pm 10.5$ & $35.6 \pm 9.5$ & 46.6 & 48 & $20.9 \pm 3.07$ & $21.01 \pm 2.7$ \\
\hline $\begin{array}{c}\text { Fernandez Egea, } \\
\text { 2009/FEP }\end{array}$ & Spain & 50 & 50 & $29.4 \pm 8.8$ & $28.8 \pm 7.7$ & 70 & 70 & $22.9 \pm 3.9$ & $23.9 \pm 3.1$ \\
\hline $\begin{array}{c}\text { Garcia-Rizo, } \\
2013 / M^{12}\end{array}$ & Spain & 15 & 70 & $27.8 \pm 6.8$ & $30.7 \pm 10$ & 60 & 62.2 & $23.4 \pm 4.1$ & $23.7 \pm 2.9$ \\
\hline $\begin{array}{c}\text { Garcia-Rizo, } \\
\text { 20।6/MDD-repeated }{ }^{13} \\
\end{array}$ & Spain & 12 & 98 & $26.5 \pm 5.6$ & $26.66 \pm 4.3$ & 58 & 62 & $22.6 \pm 3.4$ & $23.2 \pm 2.6$ \\
\hline $\begin{array}{c}\text { Garcia-Rizo, 2016/BB } \\
\text { Garcia-Rizo, 2016 \#939\} }\end{array}$ & Spain & 6 & 98 & $29.7 \pm 4.9$ & $26.66 \pm 4.3$ & 83 & 62 & $24.7 \pm 7.8$ & $23.2 \pm 2.6$ \\
\hline Grover, 2013/MDD ${ }^{14}$ & India & 29 & 22 & $47.6 \pm 16.7$ & $45.8 \pm I I .4$ & 51.2 & 51.2 & $23.2 \pm 5.1$ & $25.38 \pm 4.63$ \\
\hline
\end{tabular}




\begin{tabular}{|c|c|c|c|c|c|c|c|c|c|}
\hline $\begin{array}{c}\text { Kavzoglu \& Hariri, } \\
\text { 2013/FEP } 15\end{array}$ & Turkey & 50 & 50 & $30.1 \pm 7.5$ & $30.9 \pm 6.4$ & 42 & 50 & $\mathrm{~N} / \mathrm{A}$ & $\mathrm{N} / \mathrm{A}$ \\
\hline Keinanen J., 20I5/FEP ${ }^{16}$ & Finland & 5 & 27 & $\mathrm{~N} / \mathrm{A}$ & $\mathrm{N} / \mathrm{A}$ & 67.2 & 48 & N/A & N/A \\
\hline Leo, 2006/MDD ${ }^{17}$ & Italy & 32 & 32 & $34.85 \pm 5.88$ & $35.1 I \pm 5.22$ & 50 & 47 & $27.7 \pm 1.9$ & $28.2 \pm 2.06$ \\
\hline Misiak B. 20I6/FEP ${ }^{18}$ & Poland & 135 & 146 & $27.2 \pm 6.5$ & $27.6 \pm 5.5$ & 55.5 & 46 & $23.0 \pm 3.2$ & $22.6 \pm 3.6$ \\
\hline Nyobe $2015 / F E P * 19$ & Denmark & 17 & 50 & Outsource & Outsource & & & & \\
\hline Petrikis P., 20I5/FEP ${ }^{20}$ & Greece & 40 & 40 & $32.45 \pm 9.8$ & $31.9 \pm 8.2$ & 67.5 & 63 & $22.8 \pm 3.7$ & $22.7 \pm 1.6$ \\
\hline Ryan MC, 2003/FEP ${ }^{21}$ & Ireland & 26 & 26 & $33.6 \pm 13.5$ & $34.4 \pm 1.9$ & 57.6 & 58 & $24.5 \pm 3.6$ & $24.6 \pm 3.7$ \\
\hline Saddichha S., 2008/FEP ${ }^{22}$ & India & 99 & 51 & $26.0 \pm 5.5$ & $27.5 \pm 5.9$ & 52.5 & 59 & N/A & N/A \\
\hline Saloojee, $2017 /$ FEP $^{23}$ & South Africa & 55 & 67 & $22.9 \pm 3.8$ & $23.3 \pm 2.6$ & & 69.4 & 24.5 & $24.6 \pm 5.3$ \\
\hline Saloojee, 20I7/BBD ${ }^{23}$ & South Africa & 4 & 67 & $23.3 \pm 0.9$ & $23.3 \pm 2.6$ & & 69.4 & 23.1 & $24.6 \pm 5.3$ \\
\hline Sengupta S., 2008/FEP ${ }^{24}$ & Canada & 38 & 36 & $25.4 \pm 5.6$ & $25.1 \pm 5.3$ & 86.8 & 78 & $22.8 \pm 3.2$ & $23.9 \pm 3.5$ \\
\hline Spelman, 2007/FEP 25 & Ireland & 38 & 38 & $25.2 \pm 5.6$ & $25.2 \pm 5.6$ & 73.6 & 74 & $22.8 \pm 3.1$ & $24.2 \pm 2.9$ \\
\hline $\begin{array}{c}\text { van Nimwegen Lonneke } \\
\text { JM, 2008/FEP } 26\end{array}$ & $\begin{array}{c}\text { The } \\
\text { Netherlands }\end{array}$ & 7 & 7 & $25.4 \pm 4.8$ & $26.6 \pm 2.4$ & 100 & 100 & $\mathrm{~N} / \mathrm{A}$ & $\mathrm{N} / \mathrm{A}$ \\
\hline $\begin{array}{c}\text { Venkatasubramanian, } \\
2007 / F E P \\
27\end{array}$ & India & 44 & 44 & $33.0 \pm 7.7$ & $32.5 \pm 7.6$ & 52.2 & 52.2 & $19.9 \pm 3.3$ & $20.8 \pm 2.8$ \\
\hline Wani, 20I5/FEP ${ }^{28}$ & India & 50 & 50 & $33.0 \pm 7.7$ & $32.5 \pm 7.6$ & 64 & 70 & N/A & $\mathrm{N} / \mathrm{A}$ \\
\hline Wu., 2013/FEP 29 & China & 70 & 37 & $24.4 \pm 6.9$ & $26.2 \pm 4.2$ & 52.8 & 45 & $19.63 \pm 2.5$ & $20.3 \pm 2.7$ \\
\hline Yildirim, 20I4/FEP ${ }^{30}$ & Turkey & 9 & 33 & $\mathrm{~N} / \mathrm{A}$ & N/A & 62.5 & 52 & $\mathrm{~N} / \mathrm{A}$ & $\mathrm{N} / \mathrm{A}$ \\
\hline Zhang XY, 20I5/FEP ${ }^{31}$ & China & 120 & 31 & $26.5 \pm 6.3$ & $26.9 \pm 5.2$ & 50.8 & 45 & $22.0 \pm 3.9$ & $21.2 \pm 2.2$ \\
\hline
\end{tabular}

PT: Patient mean \pm standard deviation C: Control mean \pm standard deviation *Outcomes were derived from Greenhalgh et.al. 
Supplementary Table 4. Glucose metabolism outcomes

\begin{tabular}{|c|c|c|c|c|c|c|c|c|c|c|}
\hline \multirow{2}{*}{$\begin{array}{c}\text { Source, } \\
\text { Year/Diagnosis }\end{array}$} & \multicolumn{2}{|c|}{ Fasting Glucose } & \multicolumn{2}{|c|}{ Insulin } & \multicolumn{2}{|c|}{ Insulin resistance } & \multicolumn{2}{|c|}{ HBAIC } & \multicolumn{2}{|c|}{ OGTT } \\
\hline & Pt & C & $\mathbf{P t}$ & C & $\mathbf{P t}$ & C & $\mathbf{P t}$ & C & $\mathbf{P t}$ & C \\
\hline $\begin{array}{c}\text { Arranz B., 2004/ } \\
\text { FEP' }\end{array}$ & $78.02 \pm 6.3$ & $76.4 \pm 10.1$ & $9.3 \pm 2.3$ & $10.7 \pm 2.1$ & $\begin{array}{c}1.82 \pm 0.0 \\
7\end{array}$ & $2.01 \pm 1.8$ & $\mathrm{~N} / \mathrm{A}$ & N/A & $\mathrm{N} / \mathrm{A}$ & $\mathrm{N} / \mathrm{A}$ \\
\hline $\begin{array}{l}\text { Basoglu C., } \\
\text { 2010/FEP }\end{array}$ & $79.9 \pm 6.3$ & $76.2 \pm 6.5$ & $N / A$ & $N / A$ & $\mathrm{~N} / \mathrm{A}$ & N/A & $\mathrm{N} / \mathrm{A}$ & $\mathrm{N} / \mathrm{A}$ & $N / A$ & N/A \\
\hline $\begin{array}{c}\text { Cai. HL, } \\
2012 / \text { FEP }^{3}\end{array}$ & $82.8 \pm 16.2$ & $91.8 \pm 5.4$ & $10.9 \pm 1.4$ & $9.0 \pm 0.6$ & $\mathrm{~N} / \mathrm{A}$ & N/A & $N / A$ & N/A & $\mathrm{N} / \mathrm{A}$ & $\mathrm{N} / \mathrm{A}$ \\
\hline $\begin{array}{c}\text { Canan, } \\
2014 / \mathrm{MDD}^{4}\end{array}$ & $90.6 \pm 12.50$ & $93.8 \pm 11$ & $\mathrm{~N} / \mathrm{A}$ & $N / A$ & $\mathrm{~N} / \mathrm{A}$ & N/A & $5.4 \pm 0.7$ & $5.3 \pm 0.6$ & $\mathrm{~N} / \mathrm{A}$ & $\mathrm{N} / \mathrm{A}$ \\
\hline Cetin, ${ }_{5}^{20 \text { I4/BBD }}$ & $\begin{array}{c}97.83 \pm 22.4 \\
6\end{array}$ & $\begin{array}{c}93.72 \pm 13 . \\
57\end{array}$ & N/A & $\mathrm{N} / \mathrm{A}$ & $\mathrm{N} / \mathrm{A}$ & $\mathrm{N} / \mathrm{A}$ & $\mathrm{N} / \mathrm{A}$ & N/A & $N / A$ & N/A \\
\hline $\begin{array}{c}\text { Chang, } \\
\text { 2013/MDD }\end{array}$ & $89.8 \pm 9.1$ & $88.2 \pm 7.8$ & $5.1 \pm 4.2$ & $7.7 \pm 4.8$ & $1.5 \pm 2.2$ & $1.6 \pm 1.1$ & $\begin{array}{c}0.06 \pm 0 . \\
2\end{array}$ & $\begin{array}{c}0.05 \pm 0 . \\
4\end{array}$ & $\mathrm{~N} / \mathrm{A}$ & N/A \\
\hline $\begin{array}{l}\text { Chen DC, } \\
2016 / \text { FEP }^{7}\end{array}$ & $90.0 \pm 18.0$ & $77.4 \pm 7.2$ & $5.1 \pm 2.4$ & $4.4 \pm 1.2$ & $1.2 \pm 0.7$ & $0.8 \pm 0.3$ & N/A & $\mathrm{N} / \mathrm{A}$ & $\mathrm{N} / \mathrm{A}$ & N/A \\
\hline $\begin{array}{l}\text { Chen S., } \\
2016 / \text { FEP }^{8}\end{array}$ & $89.9 \pm 10.6$ & $91.8 \pm 7.9$ & $6.7 \pm 4.1$ & $4.03 \pm 1.8$ & $0.26 \pm 0.5$ & $0.18 \pm 0.4$ & N/A & N/A & $\mathrm{N} / \mathrm{A}$ & $\mathrm{N} / \mathrm{A}$ \\
\hline $\begin{array}{c}\text { Darcin A. Enez, } \\
2015 / \text { FEP }^{9}\end{array}$ & $81.0 \pm 18.5$ & $86.2 \pm 6.2$ & $7.3 \pm 10.3$ & $6.45 \pm 5.3$ & $1.37 \pm 2.3$ & $\begin{array}{c}1.27 \pm 1.0 \\
5\end{array}$ & $\mathrm{~N} / \mathrm{A}$ & N/A & $N / A$ & N/A \\
\hline $\begin{array}{c}\text { Dasgupta A., } \\
2010 / \mathrm{FEP}^{10}\end{array}$ & $96.0 \pm 14.0$ & $91.3 \pm 9.9$ & N/A & N/A & I. $34 \pm 0.5$ & $1.12 \pm 0.1$ & $\mathrm{~N} / \mathrm{A}$ & $\mathrm{N} / \mathrm{A}$ & $\mathrm{N} / \mathrm{A}$ & $\mathrm{N} / \mathrm{A}$ \\
\hline $\begin{array}{c}\text { Fernandez Egea, } \\
\text { 2009/FEP }\end{array}$ & $85.4 \pm 7.1$ & $86.2 \pm 6.2$ & $10.3 \pm 7.3$ & $9.6 \pm 3.8$ & $\begin{array}{c}.48 \pm \mathrm{I} .0 \\
8\end{array}$ & $1.4 \pm 0.5$ & N/A & $\mathrm{N} / \mathrm{A}$ & $\begin{array}{c}111.0 \pm 35 \\
.2 \\
\end{array}$ & $\begin{array}{c}82.0 \pm 19 . \\
3\end{array}$ \\
\hline $\begin{array}{l}\text { Garcia-Rizo, } \\
\text { 2013/MDD }\end{array}$ & $83.4 \pm 6.8$ & $84.9 \pm 11.2$ & N/A & N/A & $\mathrm{N} / \mathrm{A}$ & $\mathrm{N} / \mathrm{A}$ & $\mathrm{N} / \mathrm{A}$ & $\mathrm{N} / \mathrm{A}$ & $\begin{array}{c}125.0 \pm 67 \\
.9\end{array}$ & $\begin{array}{c}84.6 \pm 25 \\
6\end{array}$ \\
\hline
\end{tabular}


Chapter 2. Glucose Metabolism Disorders in Mental Illness

\begin{tabular}{|c|c|c|c|c|c|c|c|c|c|c|}
\hline $\begin{array}{l}\text { Garcia-Rizo, } \\
\text { 2016/MDD- } \\
\text { repeated }^{13}\end{array}$ & $82.6 \pm 83.8$ & $83.8 \pm 6.8$ & $9.6 I \pm 3.8$ & $8.75 \pm 3.3$ & N/A & N/A & $\mathrm{N} / \mathrm{A}$ & N/A & $\begin{array}{c}106.5 \pm 32 \\
.0\end{array}$ & $\begin{array}{c}82.1 \pm 23 . \\
3\end{array}$ \\
\hline $\begin{array}{c}\text { Garcia-Rizo, } \\
\text { 20I6/BB Garcia- } \\
\text { Rizo, 2016 \#939\} }\end{array}$ & $84 \pm 10.6$ & $83.8 \pm 6.8$ & $8.8 \pm 4.6$ & $8.75 \pm 3.3$ & $\mathrm{~N} / \mathrm{A}$ & $N / A$ & $\mathrm{~N} / \mathrm{A}$ & N/A & $\begin{array}{c}118.3 \pm 34 \\
.3\end{array}$ & $\begin{array}{c}\text { 82. } 1 \pm 23 \text {. } \\
3\end{array}$ \\
\hline $\begin{array}{c}\text { Grover, } \\
\text { 2013/MDD }\end{array}$ & $\begin{array}{c}\text { I I } 0.97 \pm 68 . \\
33\end{array}$ & $88.3 \pm 6.7$ & N/A & N/A & $\mathrm{N} / \mathrm{A}$ & $\mathrm{N} / \mathrm{A}$ & $\mathrm{N} / \mathrm{A}$ & N/A & $N / A$ & $\mathrm{~N} / \mathrm{A}$ \\
\hline $\begin{array}{c}\text { Kavzoglu \& Hariri, } \\
2013 / \text { FEP } 15\end{array}$ & $93.3 \pm \mid 4.1$ & $89.9 \pm 11.2$ & N/A & N/A & $\mathrm{N} / \mathrm{A}$ & N/A & N/A & N/A & N/A & N/A \\
\hline $\begin{array}{l}\text { Keinanen J., } \\
\text { 2015/FEP } 16\end{array}$ & $68.6 \pm 7.9$ & $78.8 \pm 7.7$ & $8.42 \pm 6.3$ & $8.21 \pm 4.2$ & $1.48 \pm 1.5$ & I. $24 \pm 0.8$ & $\mathrm{~N} / \mathrm{A}$ & N/A & $\mathrm{N} / \mathrm{A}$ & $\mathrm{N} / \mathrm{A}$ \\
\hline Leo, $\underset{17}{2006 / M D D}$ & $93.0 \pm 8.3$ & $92.4 \pm 7.3$ & $\begin{array}{c}6.21 \pm 1.4 \\
6\end{array}$ & $\begin{array}{c}5.99 \pm 1.4 \\
5\end{array}$ & I. $35 \pm 0.4$ & I. $29 \pm 0.3$ & N/A & N/A & N/A & N/A \\
\hline $\begin{array}{c}\text { Misiak B. } \\
\text { 2016/FEP }{ }^{18} \\
\end{array}$ & $85.6 \pm 8.3$ & $83.9 \pm 10.0$ & $N / A$ & N/A & N/A & $\mathrm{N} / \mathrm{A}$ & $N / A$ & $\mathrm{~N} / \mathrm{A}$ & $\mathrm{N} / \mathrm{A}$ & $N / A$ \\
\hline Nyobe ${ }_{19}^{2015 / F E P *}$ & Outsource & $\begin{array}{c}\text { Outsourc } \\
\text { e }\end{array}$ & $N / A$ & N/A & N/A & $\mathrm{N} / \mathrm{A}$ & N/A & N/A & N/A & N/A \\
\hline $\begin{array}{l}\text { Petrikis P., } \\
\text { 20I5/FEP } 20\end{array}$ & $87.5 \pm 11.2$ & $86.6 \pm 6.3$ & $\begin{array}{c}14.8 \pm 16 \\
8\end{array}$ & $\begin{array}{c}5.28 \pm 2.7 \\
3 \\
\end{array}$ & $1.84 \pm 0.9$ & $0.92 \pm 1.7$ & $\begin{array}{c}5.14 \pm 0 . \\
4 \\
\end{array}$ & $\begin{array}{c}5.25 \pm 0 \\
4 \\
\end{array}$ & N/A & $\mathrm{N} / \mathrm{A}$ \\
\hline $\begin{array}{c}\text { Ryan MC, } \\
\text { 2003/FEP } 21\end{array}$ & $95.8 \pm 16.9$ & $88.2 \pm 5.4$ & $9.8 \pm 3.9$ & $7.7 \pm 3.7$ & $2.3 \pm 1.0$ & $1.7 \pm 0.7$ & $\mathrm{~N} / \mathrm{A}$ & N/A & N/A & N/A \\
\hline $\begin{array}{l}\text { Saddichha S., } \\
\text { 2008/FEP } 22\end{array}$ & $82.2 \pm 10.7$ & $80.8 \pm 6.3$ & $N / A$ & $\mathrm{~N} / \mathrm{A}$ & N/A & N/A & $\mathrm{N} / \mathrm{A}$ & N/A & $\begin{array}{c}95.6 \pm 12 \\
3\end{array}$ & $90.9 \pm 7.9$ \\
\hline $\begin{array}{c}\text { Saloojee, } \\
\text { 2017/FEP }{ }^{23} \\
\end{array}$ & $86.48 \pm 12.6$ & $86.48 \pm 7.0$ & N/A & N/A & $\mathrm{N} / \mathrm{A}$ & $\mathrm{N} / \mathrm{A}$ & N/A & $\mathrm{N} / \mathrm{A}$ & $\mathrm{N} / \mathrm{A}$ & $N / A$ \\
\hline $\begin{array}{c}\text { Saloojee, } \\
2017 / \text { BBD }^{23}\end{array}$ & $80.72 \pm 16.2$ & $86.48 \pm 7.0$ & N/A & $\mathrm{N} / \mathrm{A}$ & $\mathrm{N} / \mathrm{A}$ & $N / A$ & N/A & N/A & $\mathrm{N} / \mathrm{A}$ & N/A \\
\hline
\end{tabular}


Chapter 2. Glucose Metabolism Disorders in Mental Illness

\begin{tabular}{|c|c|c|c|c|c|c|c|c|c|c|}
\hline $\begin{array}{l}\text { Sengupta S., } \\
\text { 2008/FEP } 24\end{array}$ & $84.5 \pm 9.5$ & $84.3 \pm 9.0$ & $16.7 \pm 6.5$ & $\begin{array}{c}18.2 \pm 10 \\
9\end{array}$ & $3.90 \pm 1.3$ & $4.0 \pm 2.6$ & $5.0 \pm 0.5$ & $5.0 \pm 0.4$ & $N / A$ & N/A \\
\hline $\begin{array}{c}\text { Spelman, } \\
\text { 2007/FEP }{ }^{25}\end{array}$ & $84.6 \pm 9.7$ & $81.0 \pm 8.6$ & $6.5 \pm 3.4$ & $4.5 \pm 2.0$ & $1.15 \pm 0.7$ & $0.78 \pm 0.3$ & $5.3 \pm 0.4$ & $5.2 \pm 0.3$ & $\begin{array}{c}108.1 \pm 30 \\
.4\end{array}$ & $\begin{array}{c}81.0 \pm 14 . \\
6\end{array}$ \\
\hline $\begin{array}{c}\text { van Nimwegen } \\
\text { Lonneke JM, } \\
\text { 2008/FEP } 26\end{array}$ & $91.8 \pm 9.0$ & $86.4 \pm 5.4$ & $7.06 \pm 2.5$ & $4.18 \pm 1.7$ & $\mathrm{~N} / \mathrm{A}$ & $\mathrm{N} / \mathrm{A}$ & $\mathrm{N} / \mathrm{A}$ & $\mathrm{N} / \mathrm{A}$ & N/A & $\mathrm{N} / \mathrm{A}$ \\
\hline $\begin{array}{l}\text { Venkatasubramani } \\
\text { an, 2007/FEP } 27\end{array}$ & $94.8 \pm 19$ & $92.2 \pm 9.4$ & $9.5 \pm 6.4$ & $7.1 \pm 3.6$ & $1.21 \pm 0.8$ & $0.85 \pm 0.2$ & $\mathrm{~N} / \mathrm{A}$ & N/A & $N / A$ & $\mathrm{~N} / \mathrm{A}$ \\
\hline Wani, $2015 /$ FEP 28 & $88.3 \pm 9.3$ & $87.4 \pm 6.5$ & $\mathrm{~N} / \mathrm{A}$ & $N / A$ & $\mathrm{~N} / \mathrm{A}$ & $\mathrm{N} / \mathrm{A}$ & $N / A$ & $\mathrm{~N} / \mathrm{A}$ & $\begin{array}{l}129.9 \pm 6 . \\
5\end{array}$ & $\begin{array}{l}130.2 \pm 12 \\
.5\end{array}$ \\
\hline Wu., 20I3/FEP ${ }^{29}$ & $86.3 \pm 12.7$ & $85.9 \pm 8.2$ & $8.49 \pm 4.9$ & $5.96 \pm 2.1$ & $1.83 \pm 1.1$ & $1.28 \pm 0.5$ & $\mathrm{~N} / \mathrm{A}$ & $\mathrm{N} / \mathrm{A}$ & N/A & N/A \\
\hline Yildirim, & $87.5 \pm 11.0$ & $94.2 \pm 9.3$ & N/A & N/A & $\mathrm{N} / \mathrm{A}$ & $\mathrm{N} / \mathrm{A}$ & $5.5 \pm 0.4$ & $\begin{array}{c}5.38 \pm 0 . \\
3\end{array}$ & N/A & $\mathrm{N} / \mathrm{A}$ \\
\hline $\begin{array}{l}\text { Zhang } X Y, \\
\text { 20I5/FEP 31 }\end{array}$ & $88.6 \pm 12.0$ & $78.0 \pm 6.6$ & $5.6 \pm 3.1$ & $4.4 \pm 1.2$ & $\mathrm{I} .2 \mathrm{I} \pm 0.7$ & $0.85 \pm 0.2$ & $\mathrm{~N} / \mathrm{A}$ & $\mathrm{N} / \mathrm{A}$ & $N / A$ & $\mathrm{~N} / \mathrm{A}$ \\
\hline
\end{tabular}

PT: Patient mean \pm standard deviation C: Control mean \pm standard deviation *Outcomes were derived from Greenhalgh et.al. 


\section{Chapter 2. Glucose Metabolism Disorders in Mental Illness}

References

I. Arranz B, Rosel P, Ramirez N, Drug-Naive Patients With Major Duenas R, Fernandez P, Sanchez JM, et Depression: A Pilot Study. Psychiatr al. Insulin resistance and increased Danub 20I4; 26: 34-8. leptin concentrations in noncompliant schizophrenia patients but not in antipsychotic-naive first-episode schizophrenia patients. J Clinical Psychiatry 2004; 65: 1335-42.

2. Basoglu C, Oner O, Gunes C, Semiz UB, Ates AM, Algul A, et al. Plasma orexin $A$, ghrelin, cholecystokinin, visfatin, leptin and agouti-related protein levels during 6week olanzapine treatment in firstepisode male patients with psychosis. Int Clin P:sychopharmacol 2010; 25: 1657II.

3. Cai H-L, Li H-D, Yan X-Z, Sun B, Zhang Q, Yan M, et al. Metabolomic Analysis of Biochemical Changes in the Plasma and Urine of First-Episode Neuroleptic-Naive Schizophrenia Patients after Treatment with Risperidone. J Proteome Res 2012; I I: 4338-50.

4. Canan F, Yildirim O, Tosun M, Kayka N, Tuman TC, Alcelik A. Serum Levels Of Omentin Are Not Altered In

5. Turan C, Kesebir S, Suner $O$. Are ICAM, VCAM and E-selectin levels different in first manic episode and subsequent remission? J Affect Disord 20।4; 163: 76-80.

6. Chang $\mathrm{HH}$, Chi MH, Lee IH, Tsai HC, Gean PW, Yang YK, et al. The change of insulin levels after six weeks antidepressant use in drug-naive major depressive patients. J Affect Disord 2013; I 50: 295-9.

7. Chen DC, Du XD, Yin GZ, Yang KB, Nie $Y$, Wang $N$, et al. Impaired glucose tolerance in first-episode drugnaive patients with schizophrenia: relationships with clinical phenotypes and cognitive deficits. Psychol Med 2016: I-I 12 .

8. Chen S, Broqueres-You D, Yang G, Wang Z, Li Y, Yang F, et al. Male sex may be associated with higher metabolic risk in first-episode schizophrenia patients: A preliminary study. AsianJ Psychiatry 2016; 2 I: 25-30. 


\section{Chapter 2. Glucose Metabolism Disorders in Mental Illness}

9. Enez Darcin A, Yalcin Cavus S, the onset of serious mental illnesses: A

Dilbaz N, Kaya H, Dogan E. Metabolic syndrome in drug-naive and drug-free patients with schizophrenia and in their siblings. Schizophrenia Res 2015; 166: $201-6$

10. Dasgupta A, Singh OP, Rout JK, Saha T, Mandal S. Insulin resistance and metabolic profile in antipsychotic naive schizophrenia patients. Progress Neuropsychopharmacol Biol Psychiatry 2010; 34: 1202-7.

II. Fernandez-Egea E, Bernardo M, Donner T, Conget I, Parellada E, Justicia $A$, et al. Metabolic profile of antipsychotic-naive individuals with non-affective psychosis. $\mathrm{Br} J$ Psychiatry 2009; 194: 434-8.

12. Garcia-Rizo C, Fernandez-Egea E, Miller BJ, Oliveira C, Justicia A, Griffith JK, et al. Abnormal glucose tolerance, white blood cell count, and telomere length in newly diagnosed, antidepressant-naïve patients with depression. Brain Behavior Immun 2013; 28: 49-53.

13. Garcia-Rizo C, Kirkpatrick B, Fernandez-Egea E, Oliveira C, Bernardo M. Abnormal glycemic homeostasis at common pathway. Psychoneuroendocrinology 2016; 67: 70-5.

14. Grover S, Nebhinani N, Chakrabarti S, Avasthi A, Kulhara P. Metabolic Syndrome in Drug-naive Patients with Depressive Disorders. Indian J Psychol Med 20I3; 35: 167-73.

15. Kavzoglu SO, Hariri AG. Intracellular Adhesion Molecule (ICAMI), Vascular Cell Adhesion Molecule (VCAM-I) and E-Selectin Levels in First Episode Schizophrenic Patients. Klinik Psikofarmakol Bulteni 20I3; 23: 205-I4.

16. Keinanen J, Mantere $\mathrm{O}$, Kieseppa T, Mantyla T, Torniainen M, Lindgren $M$, et al. Early insulin resistance predicts weight gain and waist circumference increase in firstepisode psychosis--A one year followup study. Schizophrenia Res 2015; 169: 458-63.

17. Leo R, Di Lorenzo G, Tesauro M, Cola C, Fortuna E, Zanasi M, et al. Decreased plasma adiponectin concentration in major depression. Neurosci Lett 2006; 407: 211 -3.

18. Misiak B, Laczmanski L, Sloka NK, Szmida E, Piotrowski P, Loska O, 


\section{Chapter 2. Glucose Metabolism Disorders in Mental Illness}

et al. Metabolic dysregulation in firstepisode schizophrenia patients with respect to genetic variation in onecarbon metabolism. Psychiatry Res 2016;

238: 60-7.

19. Nyboe L, Vestergaard $\mathrm{CH}$, Moeller MK, Lund $H$, Videbech P. Metabolic syndrome and aerobic fitness in patients with first-episode schizophrenia, including a I-year followup. Schizophrenia Res 2015; I68: 38I-7.

20. Petrikis P, Tigas S, Tzallas AT, Papadopoulos I, Skapinakis P, Mavreas V. Parameters of glucose and lipid metabolism at the fasted state in drugnaive first-episode patients with psychosis: Evidence for insulin resistance. Psychiatry Res 2015; 229: $901-4$.

21. Ryan MC, Collins P, Thakore JH. Impaired fasting glucose tolerance in first-episode, drug-naive patients with schizophrenia. Am J Psychiatry 2003; 160: 284-9.

22. Saddichha $S$, Manjunatha $N$, Ameen S, Akhtar S. Diabetes and schizophrenia - effect of disease or drug? Results from a randomized, double-blind, controlled prospective study in first-episode schizophrenia. Acta Psychiatr Scand 2008; I I 7: 342-7.

23. Saloojee S, Burns JK, Motala AA. Metabolic syndrome in antipsychotic naive African patients with severe mental illness in usual care. Early Interv Psychiatry 2017. doi: 10.1 I I I/eip.12428. [Epub ahead of print]

24. Sengupta S, Parrilla-Escobar MA, Klink R, Fathalli F, Ying Kin N, Stip E, et al. Are metabolic indices different between drug-naive first-episode psychosis patients and healthy controls? Schizophrenia Res 2008; 102: 329-36.

25. Spelman LM, Walsh PI, Sharifi N, Collins P, Thakore JH. Impaired glucose tolerance in first-episode drug-naive patients with schizophrenia. Diabetic Med 2007; 24: 48I-5.

26. van Nimwegen LJM, Storosum JG, Blumer RME, Allick G, Venema HW, de Haan L, et al. Hepatic insulin resistance in antipsychotic naive schizophrenic patients: Stable isotope studies of glucose metabolism. J Clin Endocrinol Metab 2008; 93: 572-7.

27. Venkatasubramanian G, Chittiprol S, Neelakantachar N, Naveen $\mathrm{MN}$, Thirthall J, Gangadhar BN, et al. 


\section{Chapter 2. Glucose Metabolism Disorders in Mental Illness}

Insulin and insulin-like growth factor-I abnormalities in antipsychotic-naive schizophrenia. Am J Psychiatry 2007; 164: $1557-60$.

28. Wani RA, Dar MA, Margoob MA, Rather YH, Haq I, Shah MS. Diabetes mellitus and impaired glucose tolerance in patients with schizophrenia, before and after antipsychotic treatment. J Neurosciences Rural Pract 2015; 6: 17-22.

29. Wu X, Huang Z, Wu R, Zhong Z, Wei $Q$, Wang $H$, et al. The comparison of glycometabolism parameters and lipid profiles between drug-naive, first-episode schizophrenia patients and healthy controls. Schizophrenia Res 2013; 150: 157-62.
30. Yildirim O, Canan F, Tosun M, Kayka N, Tuman TC, Alhan C, et al. Plasma Omentin Levels in Drug-Free Patients with Schizophrenia. Neuropsychobiology 2014; 69: 159-64.

3I. Zhang XY, Chen DC, Tan YL, An HM, Zunta-Soares GB, Huang XF, et al. Glucose disturbances in first-episode drug-naive schizophrenia: Relationship to psychopathology. Psychoneuroendocrinology 2015; 62: 37680.

32. Greenhalgh AM, GonzalezBlanco L, Garcia-Rizo C, FernandezEgea E, Miller B, Arroyo MB, et al. Metaanalysis of glucose tolerance, insulin, and insulin resistance in antipsychoticnaive patients with nonaffective psychosis. Schizophr Res 2016. 


\section{Chapter 2. Glucose Metabolism Disorders in Mental Illness}

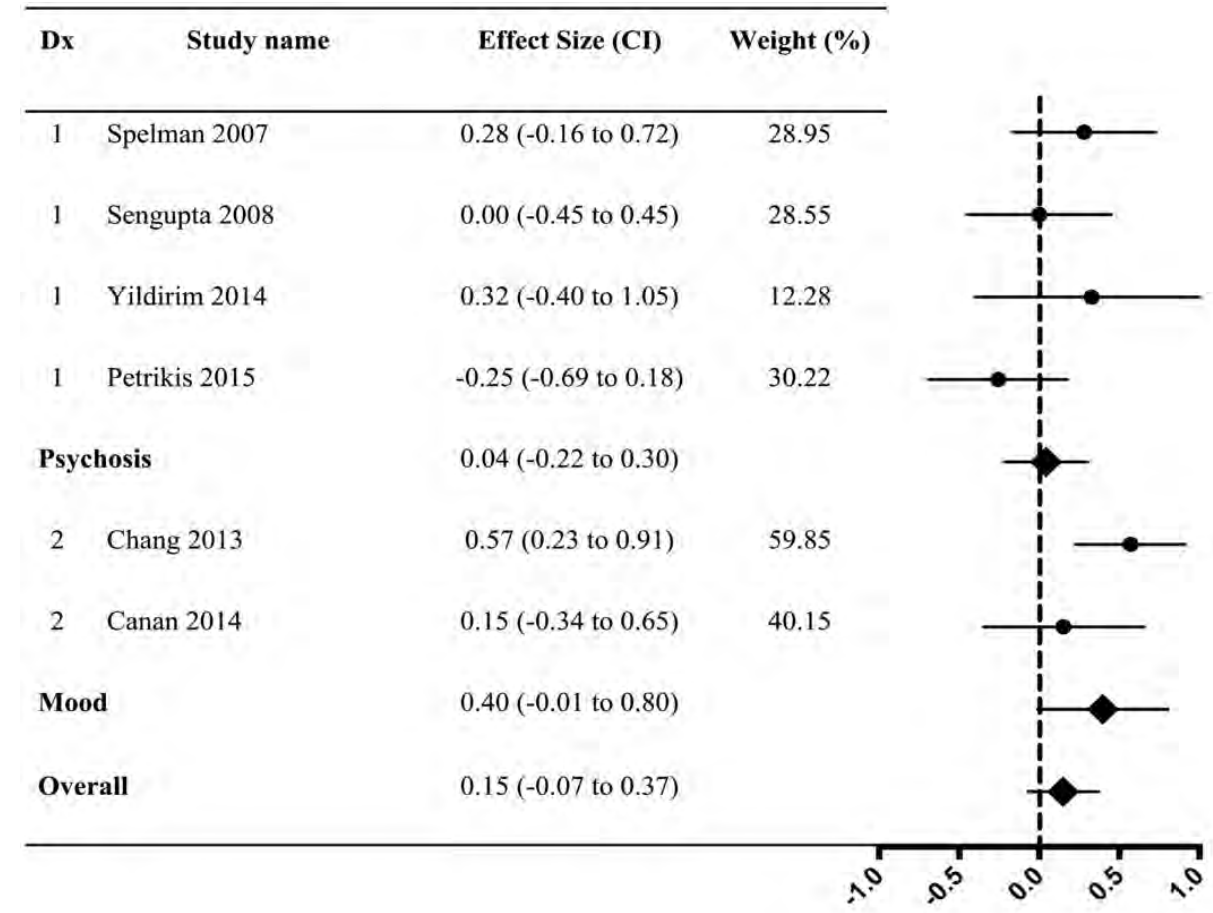

Supplementary Figure I. Meta-analysis of $\mathrm{HbAlc}$ levels in first episode patients

Heterogeneity: $\operatorname{Tau}^{2}=0.052 ; I^{2}=48.83 \% ; Q=9.77, d . f=5, P=0.08$

Overall effect (Fixed): $Z=2.22, p=0.02$

Overall effect (Random): Z=I.34, p=0.145

Dx: Diagnoses. I=First episode psychosis, 2=First episode depression, 3=First episode bipolar disorder 


\section{Chapter 2. Glucose Metabolism Disorders in Mental Illness}

\begin{tabular}{|c|c|c|c|c|}
\hline Dx & Study name & Effect Size (CI) & Weight (\%) & \\
\hline 1 & Spelman 2007 & $1.12(0.64$ to 1.60$)$ & 23.51 & \\
\hline 1 & Saddichha 2008 & $0.42(0.08$ to 0.76$)$ & 26.29 & \\
\hline 1 & Fernandez-Egea 2009 & $1.01(0.64$ to 1.60$)$ & 24.86 & \\
\hline 1 & Wani 2015 & $-0.02(-0.41$ to 0.36$)$ & 25.34 & \\
\hline \multicolumn{2}{|c|}{ Psychosis } & $0.62(0.11$ to 1.12$)$ & & \\
\hline 2 & Garcio-Rizo 2013 & $1.10(0.52$ to 1.67$)$ & 68.05 & \\
\hline 3 & Garcio-Rizo 2016 & $1.50(0.65$ to 2.34$)$ & 31.95 & $\longrightarrow$ \\
\hline \multicolumn{2}{|c|}{ Mood } & $1.21(0.75$ to 1.70$)$ & & $\multimap$ \\
\hline \multicolumn{2}{|c|}{ Overall } & $0.95(0.60$ to 1.30$)$ & & - \\
\hline
\end{tabular}

Supplementary Figure 2. Meta-analysis of OGTT levels in first episode patients

Heterogeneity: $\operatorname{Tau}^{2}=0.223 ; I^{2}=80.97 \% ; Q=26.27, d . f=5, p<0.00$ I

Overall effect (Fixed): Z=7.07, $p<0.001$

Overall effect (Random): $Z=5.32, p<0.001$

Dx: Diagnoses. I=First episode psychosis, 2=First episode depression, 3=First episode bipolar disorder 
Supplementary Table 5. Meta-regression analysis

\begin{tabular}{|c|c|c|c|c|c|c|}
\hline & \multicolumn{3}{|c|}{ Schizophrenia } & \multicolumn{3}{|c|}{ Mood Disorders } \\
\hline & Age & BMI & Gender & Age & BMI & Gender \\
\hline & PE (CI) & PE (CI) & PE (CI) & PE (CI) & PE (CI) & PE (CI) \\
\hline & -0.01 & -0.08 & -0.006 & 0.03 & -0.04 & 0.005 \\
\hline Glucose & $\begin{array}{c}(-0.06 \text { to } \\
0.02)\end{array}$ & $\begin{array}{c}(-0.22 \text { to } \\
0.06)\end{array}$ & $\begin{array}{c}(-0.01 \text { to } \\
0.01)\end{array}$ & $\begin{array}{c}(0.002- \\
0.05)\end{array}$ & $\begin{array}{c}(-0.13 \text { to } \\
0.05)\end{array}$ & $\begin{array}{l}(-0.0053 \\
\text { to } 0.01)\end{array}$ \\
\hline & 0.01 & -0.07 & -0.007 & -0.06 & 0.05 & 0.01 \\
\hline Insulin & $\begin{array}{c}(-0.06 \text { to } \\
0.09)\end{array}$ & $\begin{array}{c}(-0.29 \text { to } \\
0.14)\end{array}$ & $\begin{array}{c}(-0.02 \text { to } \\
0.008)\end{array}$ & $\begin{array}{c}(-0.12 \text { to } \\
0.00)\end{array}$ & $\begin{array}{c}(-0.15 \text { to } \\
0.26)\end{array}$ & $\begin{array}{c}(-0.001 \text { to } \\
0.03)\end{array}$ \\
\hline & 0.01 & -0.05 & -0.006 & & & \\
\hline IR & $\begin{array}{c}(-0.03 \text { to } \\
0.06)\end{array}$ & $\begin{array}{c}(-0.18 \text { to } \\
0.09)\end{array}$ & $\begin{array}{c}(-0.01 \text { to } \\
0.005)\end{array}$ & NA & NA & NA \\
\hline & -0.01 & 0.13 & -0.001 & & & \\
\hline $\mathrm{HbAlc}$ & $\begin{array}{c}(-0.07 \text { to } \\
0.06)\end{array}$ & $\begin{array}{c}(-0.24 \text { to } \\
0.51)\end{array}$ & $\begin{array}{c}(-0.03 \text { to } \\
0.03)\end{array}$ & NA & NA & NA \\
\hline & 0.21 & & 0.03 & & & \\
\hline OGTT & $\begin{array}{c}(-0.59 \text { to } \\
\text { I.0I })\end{array}$ & NA & $\begin{array}{c}(-0.02 \text { to } \\
0.10)\end{array}$ & NA & NA & NA \\
\hline
\end{tabular}

PE: Point estimates, $\mathrm{Cl}$ : Confidence intervals 


\section{Chapter 2. Glucose Metabolism Disorders in Mental Illness}

Supplementary Table 6. Differences in Asian and Non-Asian Samples

\section{Schizophrenia}

\begin{tabular}{ccc}
\hline Asia & Non-Asia & \\
ES (Cl) & ES (Cl) & $\mathbf{Q ~ ( p ) ~}$ \\
\hline 0.23 & 0.08
\end{tabular}

Glucose

$$
(-0.08 \text { to } 0.55) \quad(-0.10 \text { to } 0.27)
$$

$0.66(0.4 I)$
0.67
0.26

Insulin

$$
\text { (0.26 to } 1.07)
$$

$(-0.02$ to 0.55$)$
0.49
0.31

HOMA-IR

$(0.1$ I to 0.50$)$

$1.05(0.30)$

$$
(0.20 \text { to } 0.78)
$$

NA

NA

$\mathrm{HbAlc}$

NA

NA

NA

NA

ES: Effect size estimates, $\mathrm{Cl}$ : Confidence intervals 


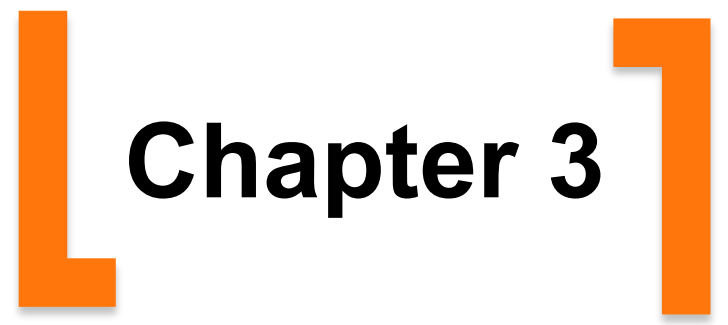


Antipsychotic Induced Weight Gain in First Episode Psychosis Patients: A Meta-Analysis of Differential Effects of Antipsychotic Medications

Cenk Tek, Suat Kucukgoncu, Sinan Guloksuz, Scott W. Woods, Vinod H. Srihari, Aniyizhai Annamalai Early Intervention in Psychiatry 2016;10:193-202. 


\section{ABSTRACT}

Aim: The first episode of psychosis (FEP) represents a critical period to prevent cardiovascular and metabolic morbidity decades later. Antipsychotic (AP) induced weight gain is one modifiable factor in this period. The purpose of this study is to conduct a meta-analysis of antipsychotic induced weight and body mass index (BMI) change in FEP.

Methods: A comprehensive literature search identified 28 articles that reported data on AP specific weight or BMI change in FEP. We conducted a meta-analysis of short- and long-term mean weight and BMI differences between placebo and AP medications. We also performed sub-group and meta-regression analysis to examine weight, BMI outcomes and their relationship with location (Asian vs. Western), sponsorship and baseline weight and BMls.

Results: Compared to placebo, AP-caused mean weight gain was $3.22 \mathrm{~kg}$ and 1.4 points $\mathrm{BMI}$ in the short-term, $5.30 \mathrm{~kg}$ and 1.86-point $\mathrm{BMI}$ in the longterm. Clinically significant weight gain risk was increased about two-fold with AP use. Weight gain was associated with duration of AP use. AP medications were associated with more weight gain in Western samples as opposed to Asian samples. Most AP medications were associated with significant body weight gain and BMI increase in FEP patients, except for ziprasidone. Olanzapine and clozapine caused the highest weight gain compared to placebo.

Conclusion: Except for ziprasidone, most AP medications were associated with body weight gain and BMI increase in FEP patients. Early and continuing effects of various AP medications on weight gain and BMI increase should be taken into consideration by clinicians.

Key-words: Obesity, side-effect, schizophrenia, haloperidol, ethnicity

Funding Source: U.S. National Institutes of Health (DK093924) 


\section{Introduction}

People with schizophrenia and related disorders die earlier than the general population (Chwastiak \& Tek, 2009; Tiihonen et al., 2009). Although suicide is an important factor, the majority of early mortality can be explained by cardiovascular disorders that are unrelated to the primary mental illness (Lahti et al., 2012). Main risk factors that increase the incidence of cardiovascular disorders in this population are excess rates of smoking and of obesity and its consequences, especially diabetes. Taken together, it is safe to assume that besides early mortality, these somatic problems also decrease health related quality of life significantly after the third decade of life. We have previously shown that cardiovascular risk doubles in the first year of psychotic illness (Srihari et al., 2013). This presents a rare opportunity for a "critical period" of intervention to prevent morbidity and mortality and improve quality of life for psychosis early intervention programs several decades later.

Our previous research has revealed that the impact of obesity on cardiovascular health of people with schizophrenia is about double as compared to general population (Ratliff, Palmese, Reutenauer, Srihari, \& Tek, 2013). Prevention of rapid weight gain should be a sine qua non piece of early intervention in psychosis. In patients with chronic schizophrenia lifestyle factors such as diet and exercise do contribute to obesity however most weight gain is mediated by antipsychotic medications as shown by studies of schizophrenia patients before antipsychotic medications were developed and of never medicated middle age patients (Baganz, 1943; Padmavati, McCreadie, \& Tirupati, 2010). Still, it is possible to provide some improvement in weight and metabolic status with structured lifestyle interventions (Daumit et al., 2013; Jean-Baptiste et al., 2007; Knowler et al., 2002; Ratliff, Palmese, Tonizzo, Chwastiak, \& Tek, 2012). In first episode and psychosis prodrome patients the lifestyle factors are more similar to their peers in the general population, which may explain contrary findings with life style interventions to 


\section{Chapter 3. Antipsychotic Induced Weight Gain}

improve weight and metabolic diseases this population (Alvarez-Jimenez et al., 2006; Lovell et al., 2014). Although first episode psychosis patients may benefit from the lifestyle interventions, a recent negative study in a first episode program to improve weight and metabolic status (Lovell et al., 2014) underlines the importance of antipsychotic medication use and choice gain for prevention of weight gain.

A seminal paper by Allison et al. (Allison et al., 1999) on antipsychotic induced weight gain has provided a framework on antipsychotic induced weight gain, whereby antipsychotic medications have differing effects, with second-generation drugs having a heavier impact than most first generation antipsychotics. Based on animal and human studies it was no surprise that most antihistaminic ( $\mathrm{H} 1)$ medications (clozapine, olanzapine, quetiapine, chlorpromazine, etc.) was associated with most weight gain, closely followed by medications that block serotonin $2 \mathrm{C}(5 \mathrm{HT} 2 \mathrm{C})$ receptors (risperidone, paliperidone etc.). Blockade of both of these receptors increases appetite (Deng, Weston-Green, \& Huang, 2010; He, Deng, \& Huang, 2013; Ratliff, Barber, Palmese, Reutenauer, \& Tek, 2010; Reynolds \& Kirk, 2010). What was surprising was the relatively low-risk weight profile of the pure dopamine 2 receptor blocker haloperidol that increases eating behavior and weight in rodents. This is possibly due to the design of the research synthesis by Allison et al., which focused on studies of chronic schizophrenia patients who likely had been on dopamine blocking agents previously. Thus, if dopamine induced weight gain is time limited to the first few years of use, and if the contribution of dopamine blockade to weight is relatively limited compared to blockade of histamine $\mathrm{H} 1$ and $5 \mathrm{HT} 2 \mathrm{c}$ receptors, weight gain by haloperidol and like agents would be statistically masked. Randomized clinical trials (Lieberman et al., 2005)'(Perez-Iglesias et al., 2008) provided some support for this line of thinking as well as a recent meta-analysis which showed that medication naïve patients, including first episode but mostly other diagnoses such as PTSD, depression, dementia etc. gain weight on first generation 


\section{Chapter 3. Antipsychotic Induced Weight Gain}

antipsychotic agents as well (Bak, Fransen, Janssen, van Os, \& Drukker, 2014; Lieberman et al., 2005).

Meta-analysis is a powerful technique for research synthesis to answer clinical questions such as AP-caused weight gain and to guide further leads research. On the other hand, mostly young prodrome and first episode psychosis patients present a special challenge when studying weight gain since a significant portion of them are still growing, thus some natural increase in weight is to be expected. Another challenge for a meta-analysis in this population is the dearth of studies that have utilized placebo control since it might be unethical for acutely psychotic patients. The only meta-analysis addressing AP-caused weight gain in FEP reported a $4.85 \mathrm{~kg}$ mean weight gain and $1.97 \mathrm{~kg} / \mathrm{m}^{2}$ BMI increase (Tarricone, Ferrari Gozzi, Serretti, Grieco, \& Berardi, 2010). However, this study reported only overall weight and BMI changes, but not AP specific outcomes. They also assumed that no weight change would occur without the antipsychotic medication use. Our group has previously conducted the only placebo controlled randomized study in the psychosis prodrome reporting weight data, which gives us the opportunity to examine antipsychotic medications' weight gain liability in this age group with psychotic symptoms (Woods et al., 2003).

Identification of specific weight gain liabilities of various antipsychotic agents utilized in early intervention of psychotic disorders is the first step in developing strategies to take advantage of the critical period to decrease overall cardiovascular risk down the road. Therefore, the aim of this report is to conduct a meta-analysis of all antipsychotic studies in first episode patients in terms of short-term ( $\leq 12$ weeks) and long-term (>12 weeks) weight gain and BMI change.

\section{Methods}

Studies were identified searching the following databases: PubMed, PsycINFO and Web of Science (1950 to August 2014). Additionally, 


\section{Chapter 3. Antipsychotic Induced Weight Gain}

references of retrieved articles, related review articles and meta-analyses were manually searched to include relevant articles. Two reviewers (SG and SK) independently conducted literature search using search terms: antipsychotics, medication-naïve, first episode schizophrenia, and weight (details were provided in the supplemental material). All articles were independently reviewed; and data were extracted by two reviewers (SG and SK). Any conflicts were discussed with the third reviewer (CT).

\section{Selection Criteria}

Inclusion criteria for this meta-analysis were as follows: (1) studies in FEP patients, who were either antipsychotic-naïve or with prior AP treatment for less than 16 weeks during their lifetime; (2) studies that were conducted with minimum age of 15 years-old patients to reduce confounding effect of continuing growth on weight and BMI (Strassnig, Miewald, Keshavan, \& Ganguli, 2007); (3) studies that were conducted in outpatient settings to limit restricted diet effects in inpatient settings, and (4) studies that reported available weight and/or BMI data during the intervention phase.

The present meta-analysis was conducted and reported according to the PRISMA guidelines (Preferred Reporting Items for Systematic Reviews and Meta-analyses) (Moher, Liberati, Tetzlaff, Altman, \& Group, 2009).

\section{Meta-Analysis Procedure}

Study design, medication dose, funding source, study region, weight and BMI outcomes were extracted. To analyze short- and long-term effects of AP medications on weight gain independently, short-term and long-term weight, BMI change and clinically significant weight gain (> $7 \%$ weight gain from baseline) outcomes were additionally retrieved when data were available. In this meta-analysis, the period for the short-term AP treatment was defined up to 12 weeks in accordance with the previous research (Leucht et al., 2013); the period for the long-term AP treatment was defined from 13 to 52 weeks. Studies with a study period of more than 1 year were only 
included if weight or BMI data were provided for the follow-up period between 4 weeks to 1 year. Outcomes of overlapping samples from the same investigators were extracted from the more detailed report. To obtain missing information, we contacted the authors to request relevant data. Correlation coefficients were used to calculate and impute the missing standard deviation of change from baseline applying methods described in Cochrane Handbook for Systematic Reviews of Interventions Version 5.1.0. (Abrams, Gillies, \& Lambert, 2005; Cochrane Handbook for Systematic Reviews of Interventions Version 5.1.0 [updated March 2011], 2011).

To the best of our knowledge, there is no placebo-controlled study of AP treatment in FEP patients, thereby the study sample consisting patients with of prodromal patients (McGlashan et al., 2006; Woods et al., 2003) was used to generate estimates of placebo control group outcomes. This study sample was consisted of 12-45 years old treatment-seeking outpatients with prodromal psychotic symptoms, who were randomized to placebo or olanzapine. In accordance with our age criterion, we analyzed the short-term and the long-term weight, BMI changes and clinically significant weight gain incidences for placebo in the subgroup of patients over 15-years old. In this subgroup short-term mean weight change was $0.31 \pm 1.99 \mathrm{~kg}$, BMl change was $-0.1 \pm 0.72 \mathrm{~kg} / \mathrm{m}^{2}$ and clinically significant weight gain estimate was $3.4 \%$. Long-term mean weight change was $1.95 \pm 7.03 \mathrm{~kg}$, BMI change was $0.5 \pm 2.34$ $\mathrm{kg} / \mathrm{m}^{2}$ and clinically significant weight gain estimate was $26.3 \%$. For each AP medication, a placebo control group with equal number of subjects was generated using these derived estimations.

We examined the difference between AP medications and placebo by calculating the mean difference (MD) using the software Comprehensive Meta-Analysis Version 2 (Biostat, Englewood, NJ). A random-effects model was used in all analyses with the results for a fixed-effects model presented as a sensitivity analysis.

To avoid publication bias we conducted a comprehensive search 
among published and unpublished studies. Publication bias also was assessed visually with funnel plots and statistically with Egger's regression test (Egger, Davey Smith, Schneider, \& Minder, 1997). Heterogeneity was assessed using $Q$ and $I^{2}$ statistics.

As a secondary analysis, we performed sub-group and metaregression analysis to examine weight, $\mathrm{BMI}$ outcomes and their relationship with study locations (Asian vs. Western), sponsorship bias (pharmaceutical companies vs. government/independent) and baseline weight and BMIs. For study location sub-group analysis, AP intervention studies from Japan $(n=3)$, China $(n=4)$, Korea $(n=2)$ and Singapore $(n=1)$ were considered as Asian studies, whereas interventions from other countries such as USA, UK, Spain were considered as Western studies. For all statistical analyses significant statistical threshold was $p<0.05$.

\section{Results}

Our search strategy initially yielded 3059 articles excluding the duplicates. After screening the abstract and the title, 760 articles were selected for full-text screening (Figure 1). After full-text review, 732 articles not fulfilling the selection criteria were excluded. Of the excluded studies, 451 were not conducted in a sample with only FEP patients, 220 provided no weight data, 9 did not specify prior AP use, 30 were conducted in inpatient settings, and 22 reported data from the samples that were already included in the analysis. 
Records identified through database searching (1598 PubMed; 2010 Web of Science; 604 PsycINFO)

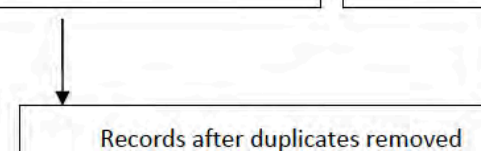
( $n=3059$ )
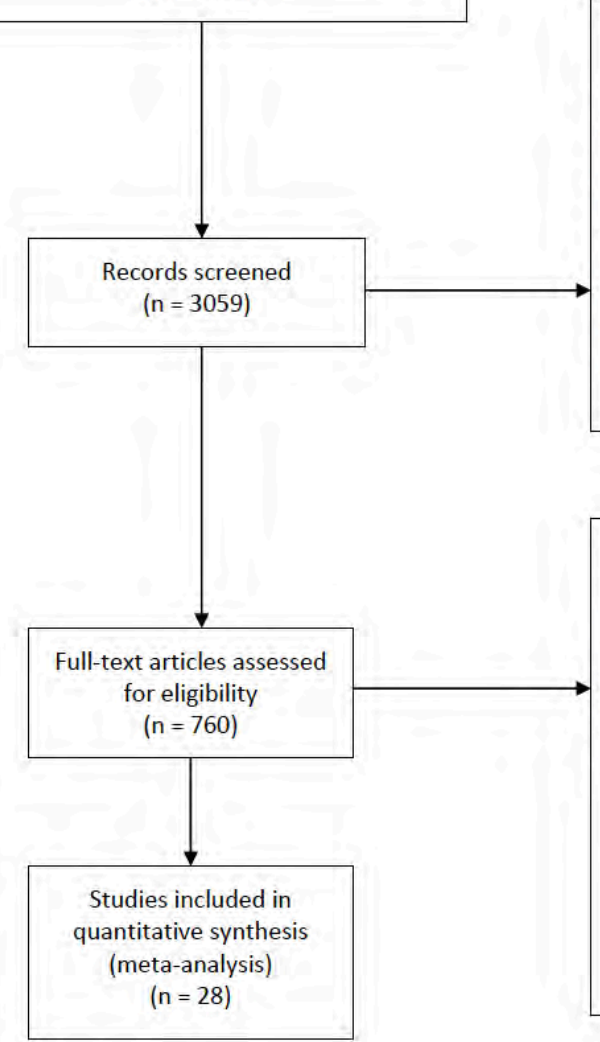

Figure 1. Prisma Checklist flow diagram
Additional records identified through other sources

$(n=4)$

\section{Records excluded}

( $\mathrm{n}=\mathbf{2 2 9 9}$ )

Case reports $(n=216)$

Comments/Reviews ( $\mathrm{n}=1051$ )

Not English ( $\mathrm{n}=208$ )

Not human studies ( $\mathrm{n}=108$ )

Sample age $<16(n=77)$

Other disorders $(\mathrm{n}=151)$

Cross-sectional studies ( $n=375$ ) Intervention studies (weight loss etc.) $(n=113)$

Full-text articles excluded ( $n=732$ )

Not First Episode Study $(n=451)$ Inpatient/diet $(\mathrm{n}=30)$ Weight data not given ( $n=187$ ) Not clear weight data $(n=33)$ Not clear pre-treatment $(n=9)$ Same sample $(n=22)$

Overall, we identified 28 eligible studies with 52 appropriate treatment arms for inclusion in this review (Fleischhacker et al., 2013; Gasquet et al., 2005; Grootens et al., 2011; Hori et al., 2009; Huq, 2004; Ingole, Belorkar, Waradkar, \& Shrivastava, 2009; Josiassen et al., 2010; Lee et al., 2010; Lieberman et al., 2003; Liu et al., 2014; McGorry et al., 2011; Ninomiya et al., 
2014; Ou et al., 2013; Patel et al., 2009; Perez-Iglesias et al., 2008; PerezIglesias et al., 2014; Rasmussen et al., 2014; Sanz-Fuentenebro et al., 2013; Schooler et al., 2005; Sengupta et al., 2005; Takahashi, Oshimo, \& Ishigooka, 2009; Tauscher-Wisniewski et al., 2002; Vinay et al., 2011; Yap et al., 2001; Zalsman et al., 2003; Zhao et al., 2012; Zipursky et al., 2005) (Table S1). The total number of patients in these studies was 4139 (2594 males, 1545 females). Five studies were double-blinded (Grootens et al., 2011; Lieberman et al., 2003; Patel et al., 2009; Schooler et al., 2005; Zipursky et al., 2005), one was single-blinded (Josiassen et al., 2010), and 22 were open-label (Fleischhacker et al., 2013; Gasquet et al., 2005; Hori et al., 2009; Huq, 2004; Ingole et al., 2009; Lee et al., 2010; McGorry et al., 2011; Ou et al., 2013; Perez-Iglesias et al., 2008; Sanz-Fuentenebro et al., 2013; Sengupta et al., 2005; Strassnig et al., 2007; Takahashi et al., 2009; Tauscher-Wisniewski et al., 2002; Vinay et al., 2011; Yap et al., 2001; Zalsman et al., 2003; Zhao et al., 2012). Of these 28 studies 12 (42.8\%) were funded by pharmaceutical companies, $6(21.4 \%)$ were funded by institutional or government agencies, and $3(10.7 \%)$ were funded by pharmaceutical companies and institutional agencies. Six studies were carried out independently.

\section{Short-term results $(\leq 12$ weeks)}

For the short-term meta-analysis 39 weight change outcomes were extracted from 21 unique intervention studies (Fleischhacker et al., 2013; Grootens et al., 2011; Hori et al., 2009; Huq, 2004; Ingole et al., 2009; Josiassen et al., 2010; Lee et al., 2010; McGorry et al., 2011; Ninomiya et al., 2014; Ou et al., 2013; Patel et al., 2009; Perez-Iglesias et al., 2008; PerezIglesias et al., 2014; Schooler et al., 2005; Sengupta et al., 2005; Takahashi et al., 2009; Tauscher-Wisniewski et al., 2002; Yap et al., 2001; Zalsman et al., 2003; Zhao et al., 2012; Zipursky et al., 2005), 23 BMl change outcomes from 11 unique samples (Hori et al., 2009; Ingole et al., 2009; Josiassen et al., 2010; Liu et al., 2014; Ninomiya et al., 2014; Ou et al., 2013; Patel et al., 2009; Perez-Iglesias et al., 2008; Perez-Iglesias et al., 2014; Sengupta et al., 
2005; Tauscher-Wisniewski et al., 2002). Nine of these studies lasted less than 12 weeks (Grootens et al., 2011; Hori et al., 2009; Josiassen et al., 2010; Lee et al., 2010; McGorry et al., 2011; Ou et al., 2013; Yap et al., 2001; Zalsman et al., 2003; Zhao et al., 2012).

\section{Weight change}

From analysis of the selected studies, the overall mean weight gain difference between antipsychotic medications and placebo was $3.22 \mathrm{~kg}$ $(\mathrm{Cl}=1.65-4.80, \mathrm{p}<0.001)$. Compared to the placebo, only ziprasidone did not cause significant weight gain in the short-term (Figure 2).

We found no evidence of publication bias in the short-term weight change analysis (Egger's Test intercept $=0.53, \mathrm{Cl}=-2.57$ to 3.64 ). The shortterm analysis showed considerable heterogeneity $(Q=50.57, d f=7, p<0.001)$.

Sub-group analysis showed no significant weight difference between pharmaceutical industry funding and other funding sources (e.g. governmental funding agencies) $(\mathrm{Q}=0.06, \mathrm{df}=1, \mathrm{p}=0.79)$. The mean weight difference was significantly higher in Western countries $(4.17 \mathrm{~kg}, \mathrm{Cl}=3.38$ 4.96) than in Asian countries ( $1.36 \mathrm{~kg}, \mathrm{Cl}=-0.25$ to 2.99$)(\mathrm{Q}=9.26, \mathrm{df}=1$, $p=0.002$ )(Figure $S 1$ ). Meta-regression analysis revealed that interventions with longer durations have a significant effect on weight change (P.E. $=1.23$, $\mathrm{Cl}=0.09-2.37, \mathrm{p}=0.033)$. Baseline weight has a significant effect on weight gain in the short-term (P.E. $=0.12, C . I .=0.000-0.24, p=0.048$ ). 
Chapter 3. Antipsychotic Induced Weight Gain

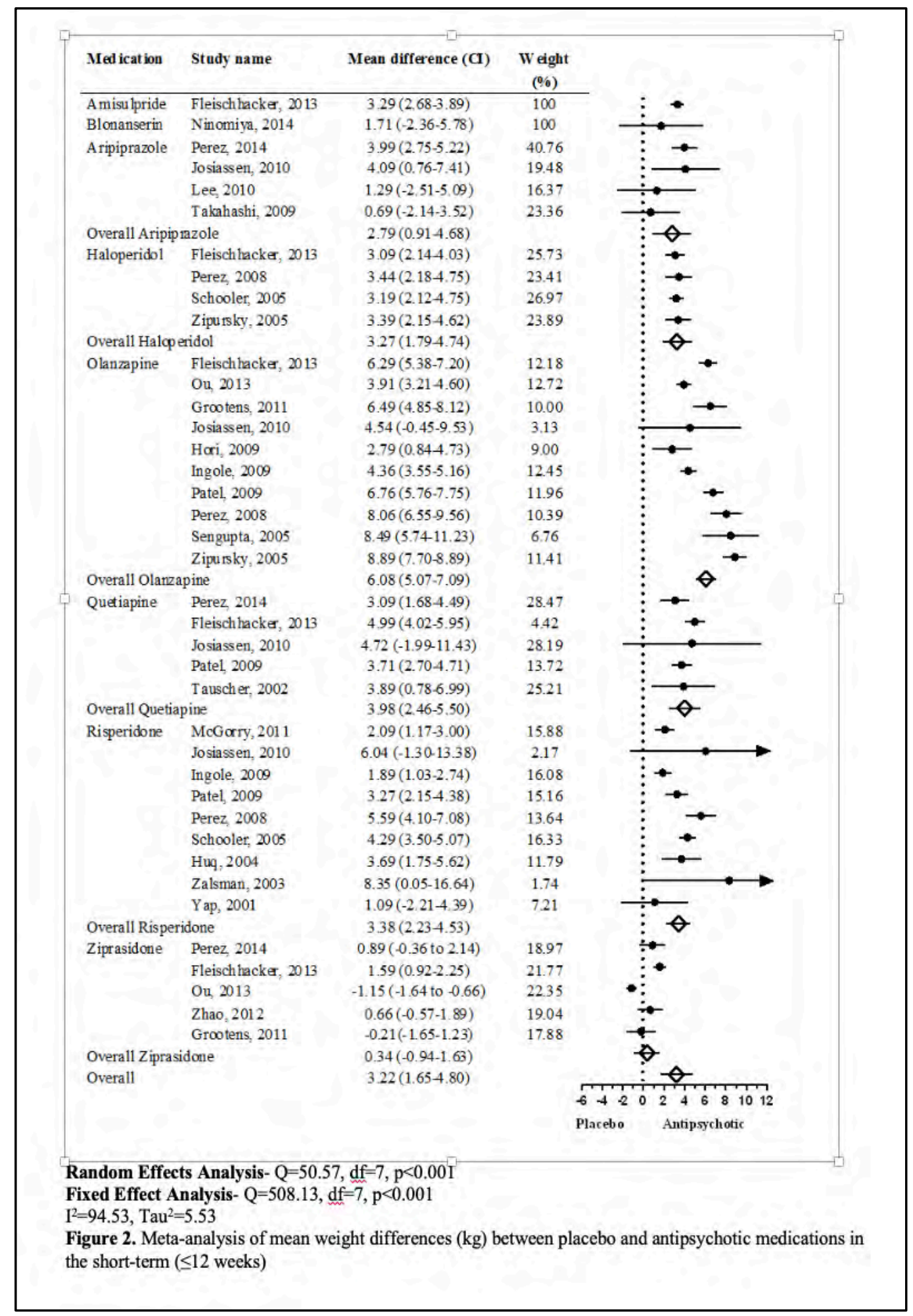




\section{BMI change}

Overall BMI change was $1.46 \mathrm{~kg} / \mathrm{m}^{2}(\mathrm{Cl}=0.90-2.03, \mathrm{p}<0.001)$ in $\mathrm{AP}$ treatment compared to that in placebo in the short-term (Figure S2). We found evidence of publication bias in the short-term BMI change analysis (Egger's Test intercept=4.20, $\mathrm{Cl}=0.11-8.29, \mathrm{p}=0.044)$. There was significant heterogeneity across interventions $(Q=18.09$, $d f=6, p=0.006)$.

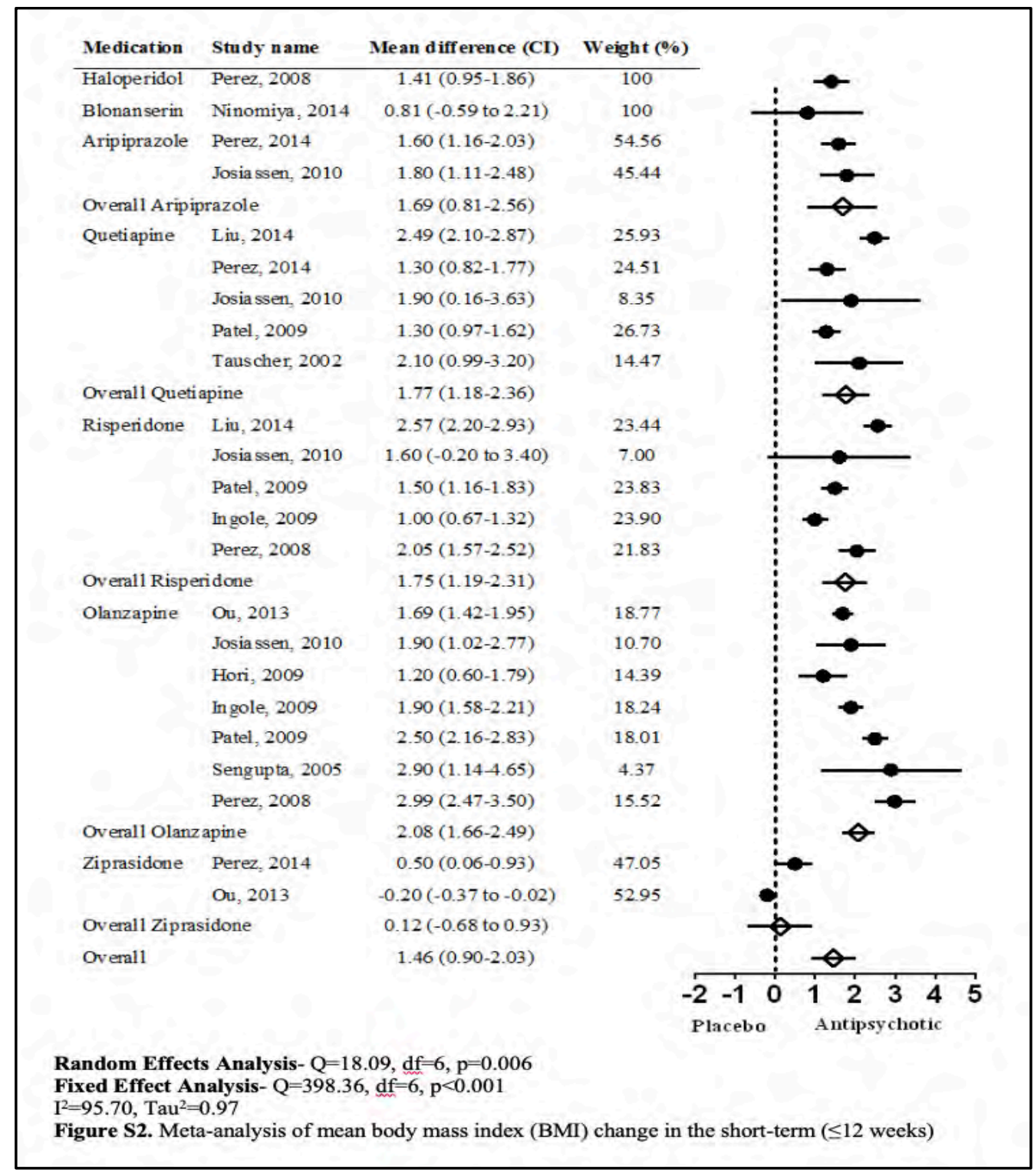


Compared to placebo, interventions in Western $(1.74 \mathrm{~kg}, \mathrm{Cl}=1.24-$ 2.24, $\mathrm{p}<0.001$ ) and Asian countries (1.45 kg, $\mathrm{Cl}=0.64-2.27, \mathrm{p}<0.001)$ showed significant BMI change in the short-term. (Figure S1). Subgroup analysis demonstrated no significant effect of study regions $(Q=0.34, d f=1, p=0.55)$ and funding source $(\mathrm{Q}=0.14, \mathrm{df}=1, \mathrm{p}=0.70)$ on $\mathrm{BMI}$. No significant relationships were found between $\mathrm{BMI}$ differences with baseline BMI (P.E. $=0.02, \mathrm{Cl}=-0.23$ to $0.27, p=0.87)$ and intervention durations $(P . E .=0.04$, $\mathrm{Cl}=-0.06$ to $0.15, \mathrm{p}=0.39)$.

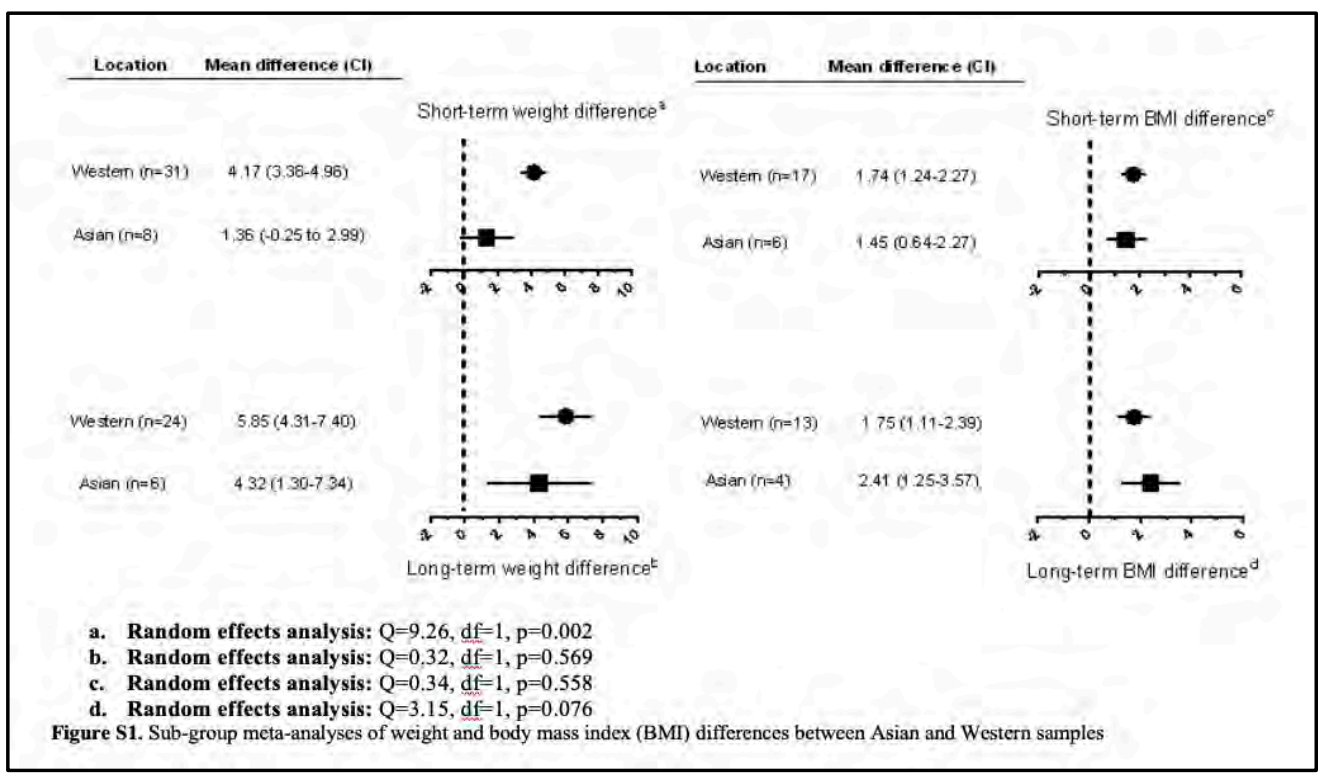

\section{Long-term results (>12 weeks)}

For the long-term meta-analysis we extracted 30 weight change outcomes from 13 unique samples (Fleischhacker et al., 2013; Gasquet et al., 2005; Lieberman et al., 2003; Liu et al., 2014; Ninomiya et al., 2014; Patel et al., 2009; Perez-Iglesias et al., 2008; Rasmussen et al., 2014; SanzFuentenebro et al., 2013; Schooler et al., 2005; Strassnig et al., 2007; Vinay et al., 2011; Zipursky et al., 2005), and 17 BMI change outcomes from 8 unique samples (Gasquet et al., 2005; Liu et al., 2014; Ninomiya et al., 2014; Patel et al., 2009; Perez-Iglesias et al., 2008; Rasmussen et al., 2014; 
Strassnig et al., 2007; Vinay et al., 2011). Of these studies, 3 of them lasted shorter than 52 weeks (Gasquet et al., 2005; Rasmussen et al., 2014; Schooler et al., 2005).

\section{Weight change}

Meta-analysis of the long-term mean weight differences is shown in Figure 3. A significant overall mean weight difference was found: $5.30 \mathrm{~kg}$ $(\mathrm{Cl}=2.87-7.74, \mathrm{p}<0.001)$ between antipsychotic medications and placebo. Olanzapine $(n=6,9.34 \mathrm{~kg}[\mathrm{C} . \mathrm{I} .=5.55-13.12], p<0.001)$ and clozapine $(n=2$, $7.19 \mathrm{~kg}$ [C.I. $=0.28-14.09], p=0.041)$ were the interventions associated with the highest weight gain compared to placebo. The only one intervention with perphenazine reported weight loss $(-0.41 \mathrm{~kg})$.

We found significant evidence of publication bias in the long-term analysis (Egger's Test intercept=2.96, $\mathrm{Cl}=1.48-4.45, \mathrm{p}=0.003$ ). Long-term weight analysis revealed no significant heterogeneity across interventions $(Q=8.73, d f=9, p=0.46)$. 


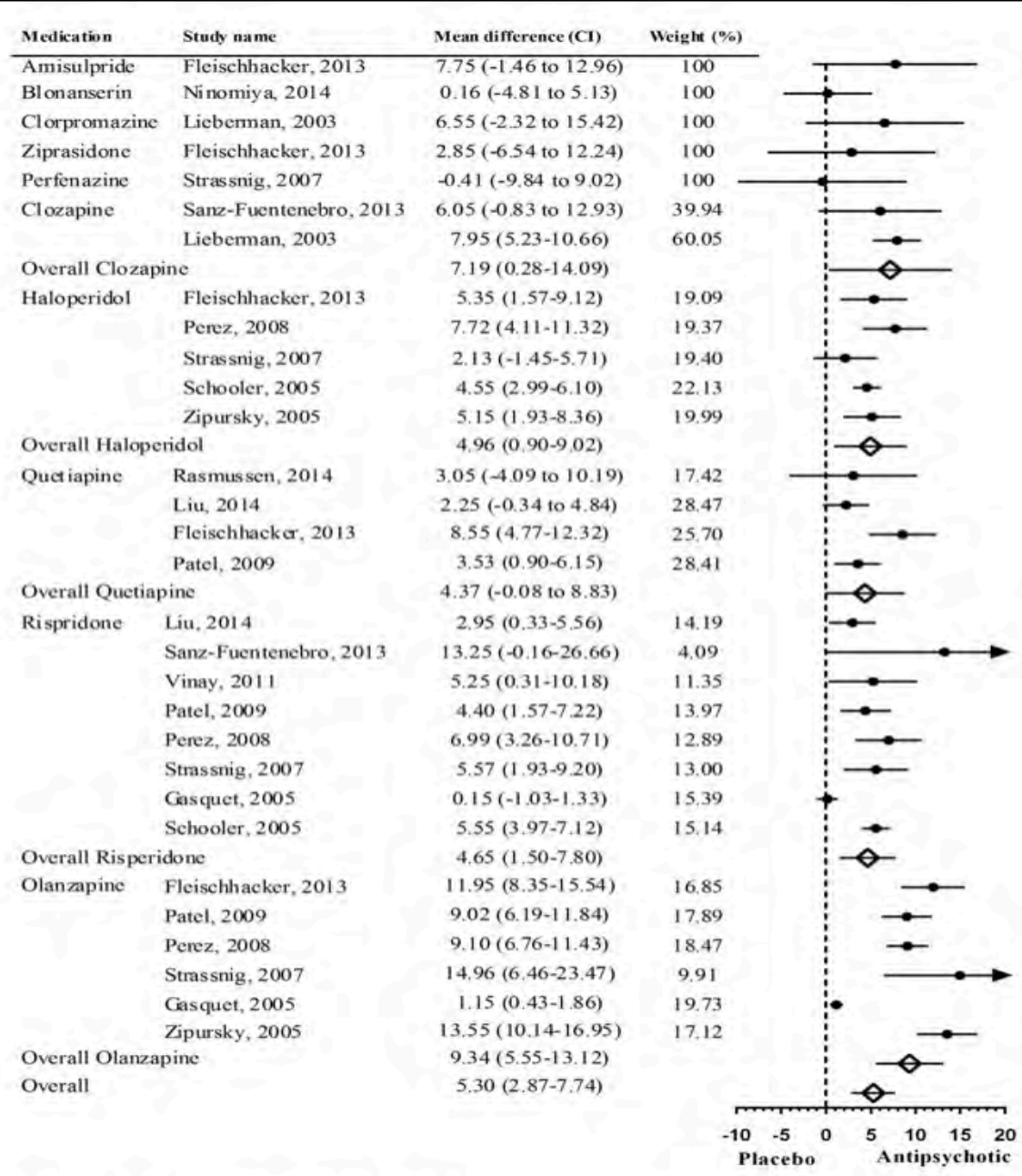

Random Effects Analysis- $\mathrm{Q}=8.73, \mathrm{df}=9, \mathrm{p}=0.463$

Fixed Effect Analysis- $\mathrm{Q}=35.98, \mathrm{df}=9, \mathrm{p}<0.001$

$I^{2}=87.31, \mathrm{Tau}^{2}=10.79$

Figure 3. Meta-analysis of mean weight differences $(\mathrm{kg})$ between placebo and antipsychotic medications in the long-term ( $>12$ weeks)

When the analysis was repeated after excluding 3 studies that lasted shorter than 52 weeks (Gasquet et al., 2005; Rasmussen et al., 2014; Schooler et al., 2005), order of weight gain liability across AP medications did not change. Weight gain with most AP medications remains similar to initial analysis with the exception of olanzapine, which was slightly higher $(n=5$, $10.83 \mathrm{~kg}[\mathrm{C} . \mathrm{I} .=8.83-12.83], \mathrm{p}<0.001)$. This analysis revealed significantly 
more long-term weight gain with olanzapine compared to other antipsychotic medications $(Q=39.542, d f=9, p<0.001)$ (Figure $S 3)$.

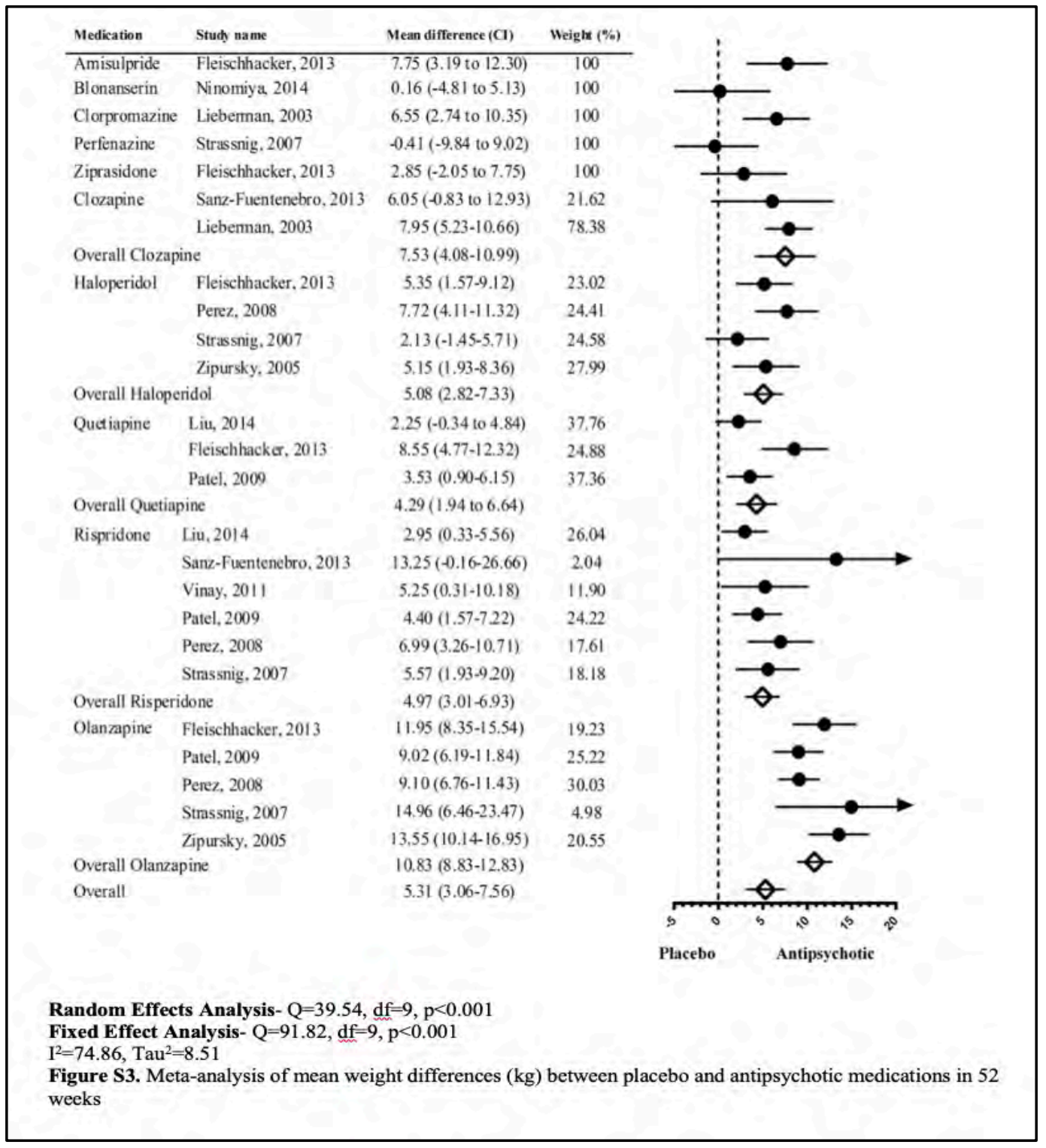

Subgroup analysis showed that interventions lasting longer caused greater weight gain than those the studies lasted shorter (P.E. $=0.55, \mathrm{Cl}=0.08$ 1.02, $\mathrm{p}=0.02)$. Funding source $(\mathrm{Q}=0.32, \mathrm{df}=1, \mathrm{p}=0.569)$, Asian vs. Western source $(Q=0.788, d f=1, \quad p=0.37)$ (Figure $S 1)$, and baseline weights 
(P.E. $=0.03, \mathrm{Cl}=-0.20$ to $0.28, \mathrm{p}=0.75)$ did have no significant effect on weight change.

\section{BMI change}

Overall BMI change was $1.86 \mathrm{~kg} / \mathrm{m}^{2}(\mathrm{Cl}=0.89-2.83, \mathrm{p}<0.001)$ in $\mathrm{AP}$ treatment compared to that in placebo in the long-term (Figure S4). Compared to placebo, pooled BMI differences were significant with olanzapine $\left(2.71 \mathrm{~kg} / \mathrm{m}^{2}[\mathrm{Cl}=1.12-4.29], \mathrm{p}<0.001\right)$, quetiapine $\left(2.20 \mathrm{~kg} / \mathrm{m}^{2}\right.$ $[\mathrm{Cl}=0.37-4.02], \quad \mathrm{p}<0.001)$ and risperidone $\left(1.85 \mathrm{~kg} / \mathrm{m}^{2} \quad[\mathrm{Cl}=0.88-2.83]\right.$, $p=0.004)$. There was a trend toward increased BMI with haloperidol use (1.90 $\mathrm{kg} / \mathrm{m}^{2}[\mathrm{Cl}=-0.31$ to 4.08$\left.], \mathrm{p}=0.09\right)$. 
Chapter 3. Antipsychotic Induced Weight Gain

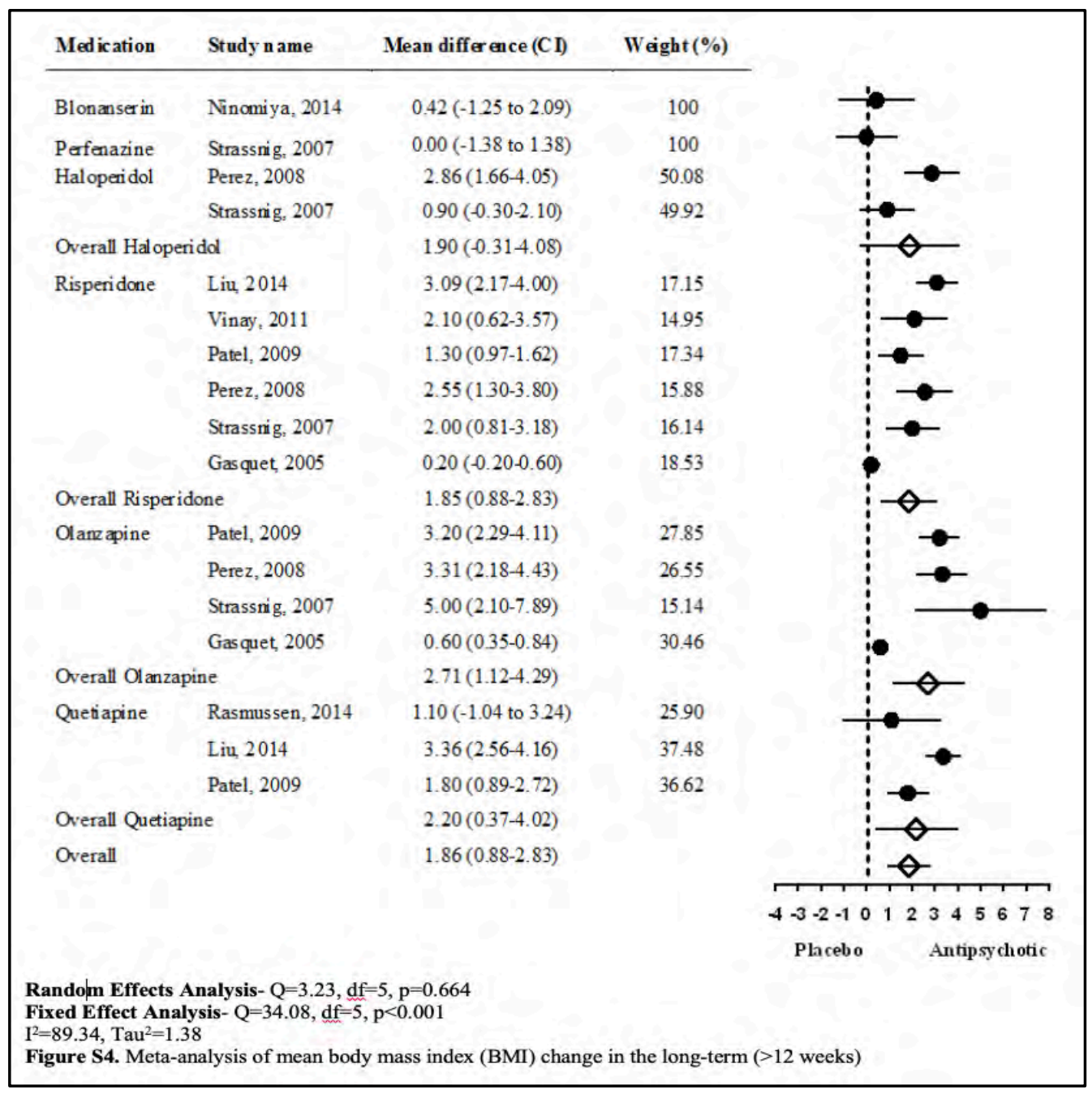

For the long-term BMI analysis, we found significant publication bias (Egger's Test intercept=3.12, $\mathrm{Cl}=1.06-5.18, \mathrm{p}=0.005)$. Heterogeneity between the studies was not significant $(Q=3.23, d f=5, p=0.66)$.

After excluding 2 studies that lasted shorter than 52 weeks (Gasquet et al., 2005; Rasmussen et al., 2014), pooled BMI differences were similar with the initial analysis (olanzapine [3.46 kg/m² [Cl=2.34-4.59], $\mathrm{p}<0.001]$, risperidone [2.22 kg/m² [Cl=1.43-3.01], $p<0.001]$, and quetiapine [2.61 kg/m² $[\mathrm{Cl}=1.47-3.75], \mathrm{p}<0.001])$. Heterogeneity between the studies was significant $(Q=13.08, d f=5, p=0.023)$. 
Subgroup analysis demonstrated no significant effect of study regions $(\mathrm{Q}=0.96, \mathrm{df}=1, \mathrm{p}=0.32)$, funding source $(\mathrm{Q}=3.15, \mathrm{df}=1, \mathrm{p}=0.07)$ or baseline BMls (P.E. $=-0.11,[\mathrm{Cl}=-0.47$ to 0.23$], p=0.51$ ) on $\mathrm{BMI}$ change in the long-term. Intervention duration significantly affect $\mathrm{BMI}$ change in the short-term (P.E. $=0.06,[\mathrm{Cl}=0.02-0.09], \mathrm{p}<0.001)$.

\section{Meta-analysis of percent weight change}

For percent weight change analysis, we analyzed the studies that reported the percentages of patients that gained of more than $7 \%$ of their baseline weight. Our search revealed a limited number of studies that reported on such clinically significant weight gain estimates. More than $7 \%$ weight gain estimates of interventions were reported in three studies at the short-term (Grootens et al., 2011; Zalsman et al., 2003; Zhao et al., 2012) and in four studies at the long-term (Fleischhacker et al., 2013; Patel et al., 2009; Perez-Iglesias et al., 2008; Vinay et al., 2011).

Meta-analysis results showed a significant effect of APs on percent weight change compared to placebo (R.R. $=2.14[\mathrm{Cl}=1.58-2.91], p<0.001$; risk difference $=0.30[\mathrm{Cl}=0.11-0.49], p=0.002)$. Of all the medications that were included in the analysis, the percent weight change was similar to placebo only with ziprasidone (R.R. $=1.05[\mathrm{Cl}=0.65-1.72], p=0.82$; R.D. $=0.30[\mathrm{Cl}=0.11-$ 0.49], $p=0.52$ ) (Figure S5). 
Chapter 3. Antipsychotic Induced Weight Gain

\begin{tabular}{|c|c|c|c|c|}
\hline Medication & Study name & Risk Ratio (CI) & Weight $(\%)$ & \\
\hline Amisul pride & Fleischhacker, 2013 & $2.39(1.47-3.90)$ & 100 & \\
\hline \multirow[t]{2}{*}{ Haloperidol } & Fleischhacker, 2013 & $2.01(1.39-2.92)$ & 70.01 & \\
\hline & Perez, 2008 & $3.32(1.67-6.61)$ & 29.98 & \\
\hline \multicolumn{2}{|c|}{ Overall Haloperidol } & $2.34(1.54-3.55)$ & & \\
\hline \multirow[t]{2}{*}{ Quetiapine } & Fleischhacker, 2013 & $2.47(1.73-3.51)$ & 6532 & \\
\hline & Patel, 2009 & $1.90(1.06-3.38)$ & 34.67 & \\
\hline \multicolumn{2}{|c|}{ Overall Quetiapine } & $2.25(1.52-3.34)$ & & \\
\hline \multirow[t]{3}{*}{ Ziprasidone } & Fleischhacker, 2013 & $1.40(0.88-2.22)$ & 7334 & \\
\hline & Zhao, 2012 & $0.70(0.25-1.93)$ & 20.85 & \\
\hline & Grootens, 2011 & $0.12(0.01-0.92)$ & 5.80 & \\
\hline \multicolumn{2}{|c|}{ Overall Ziprasidone } & $1.05(0.65-1.72)$ & & \\
\hline \multirow[t]{4}{*}{ Risperidone } & Vinay, 2011 & $0.70(0.19-2.52)$ & 10.19 & \\
\hline & Patel, 2009 & $2.19(1.19-4.01)$ & 37.00 & \\
\hline & Perez-Iglesias, 2008 & $2.71(1.50-4.91)$ & 3826 & \\
\hline & Zalsman, 2003 & $2.76(0.96-7.92)$ & 1453 & \\
\hline \multicolumn{2}{|c|}{ Overall Risperidone } & $2.19(1.43-3.33)$ & & \\
\hline \multirow[t]{4}{*}{ Olanzapine } & Fleischhacker, 2013 & $3.26(2.35-4.54)$ & 4137 & \\
\hline & Grootens, 2011 & $2.45(127-4.72)$ & 16.87 & \\
\hline & Perez, 2008 & $2.85(1.59-5.08)$ & 20.45 & \\
\hline & Patel, 2009 & $3.04(1.73-5.34)$ & 21.29 & \\
\hline \multicolumn{2}{|c|}{ Overall Olanzapine } & $2.98(2.20-4.03)$ & & $\epsilon$ \\
\hline \multirow[t]{3}{*}{ Overall } & & $2.14(1.58-2.91)$ & & $\theta$ \\
\hline & & & $\begin{array}{ll}-2 & 0\end{array}$ & 6 \\
\hline & & & Placebo & Antipsychotic \\
\hline \multicolumn{5}{|c|}{$\begin{array}{l}\text { Random Effects Analysis- } Q=12.65, \mathrm{df}=5, \mathrm{p}=0.027 \\
\text { Fixed Effect Analysis- } \mathrm{Q}=16.76, \mathrm{df}=5, \mathrm{p}=0.005 \mathrm{I}^{2}=19.46, \mathrm{Tau}^{2}=0.07 \\
\text { Figure S5. Meta-analysis of clinically significant weight change ( }>7 \% \text { weight gain) estimates between placebo and } \\
\text { antipsychotic medications }\end{array}$} \\
\hline
\end{tabular}

Regarding the percent weight change data, studies showed significant heterogeneity $(Q=12.65, d f=5, p=0.027)$. We also found evidence of publication bias (Egger's Test intercept $=-1.90, \mathrm{Cl}=-3.59$ to $-0.22, \mathrm{p}=0.029$ ).

Subgroup analysis showed no significant effect of funding source $(\mathrm{Q}=0.96, \mathrm{df}=1, \mathrm{p}=0.96)$, intervention duration (P.E. $=0.01, \mathrm{Cl}=-0.002$ to 0.02 , $p=0.12$ ) or baseline weights (P.E. $=0.02, \mathrm{Cl}=-0.008$ to $0.06, p=0.13$ ) on estimates of $>7 \%$ weight gain. 


\section{Chapter 3. Antipsychotic Induced Weight Gain}

\section{Discussion}

Most antipsychotic medications were associated with significant weight gain both in the short and long term in early psychosis patients. Weight gain was associated with duration of AP use. In the short-term weight gain with ziprasidone was similar to placebo, however it was not clear if this advantage carried over to the long term due to lack of studies. Haloperidol, unlike in studies of chronic schizophrenia patients, was associated with both short- and long-term weight gain. Similarly, aripiprazole, which appeared weight neutral in previous studies, was associated with short-term weight gain. Finally, AP medications were associated with higher weight gain in Western samples as opposed to Asian samples.

This meta-analytic study takes account of probable body growth in FEP population. The results are in line with and expand findings of a previous smaller meta-analysis of overall weight effects of antipsychotics in this population (Tarricone et al., 2010). The distribution of weight gain liabilities across antipsychotics appears to be similar to that in medication naïve older adult patients of all diagnoses (Bak et al., 2014), but not to that in chronic schizophrenia samples (Allison et al., 1999; Leucht et al., 2013). Notably the selectively and potent D2 blocker haloperidol was shown to be associated with very significant weight gain in FEP but not in chronic schizophrenia patients, which may point to a weight increasing effect that plateaus later. On the other hand, consistent results of weight gain with the worst offending agents olanzapine and clozapine, and to some extent quetiapine and risperidone, may suggest that weight gain with these agents remains highrisk over time. The short-term advantage of ziprasidone may translate well to long term since this agent maintains its weight gain advantage in chronic schizophrenia populations.

The initial selection of medication in FEP may present an opportunity for preventing morbidity decades later. Ziprasidone appear to confer advantages of not causing as much weight gain as the other antipsychotics. 


\section{Chapter 3. Antipsychotic Induced Weight Gain}

Possible pharmacological explanations for this may be noradrenaline reuptake blocking activity of ziprasidone, which differentiate this medication from others (Daniel et al., 1999). It is important to note that individual responses to medications may differ since 7 to 16 percent of the patients on ziprasidone gained clinically significant weight gain in the registration studies (Pfizer, 2014). The weight gain advantage of aripiprazole in previous studies, an agonist/antagonist of both D2 and 5-HT2c receptors (Zhang, Kowal, Nawoschik, Lou, \& Dunlop, 2006), did not emerge in the short term in this study. Long-term studies investigating the weight effect of aripiprazole are lacking. It may still be advantageous to consider aripiprazole when switched from higher weight gain liability medications (Stroup et al., 2011). Some previous studies (Álvarez-Jiménez et al., 2008; Perez-Iglesias et al., 2008; Schooler et al., 2005) reported the similar weight gain effects of haloperidol and second generation AP medications including olanzapine and risperidone over the longer-time in FEP. Our results revealed a significant weight gain with olanzapine compared to haloperidol and other second-generation AP medications in the short-term and long-term. (Perez-Iglesias et al., 2008; Schooler et al., 2005) There does not seem to be a good reason to choose olanzapine as a first or second choice of antipsychotic from a prevention of future cardiovascular morbidity and mortality point of view. Clozapine, of course, represents a separate case with its unique action for treatment refractory schizophrenia. Regardless, it does not seem to confer any special advantage as a first trial AP in FEP (Lieberman et al., 2003).

Our study underscores deficiencies in the literature, some of which represent limitations of this study. First, we have shown that studies from Asian countries report lower weight gain with AP as opposed to Western studies. Given the prevalence of Asian studies in the literature, this potential confound should be routinely addressed in future meta-analyses. Second, weight change is reported in a non-uniform manner across the studies, which create a difficulty for analyses such as ours. BMI takes height increase into account and BMI change should always be reported in FEP studies. We also 
advocate for baseline weights, weight change, clinically significant weight gain ( $>7 \%$ of total body weight) percentage being reported in every medication study. Third, studies do not consistently report on association between dose and weight change, which makes dose-weight gain analyses impossible without direct access to data. Relationship between weight gain and AP dose is not trivial from both clinical and research perspective. Fourth, long term studies with ziprasidone and aripiprazole in FEP are lacking, and thus some caution is required when interpreting our results. We also noted a dearth of studies with mid potency first generation AP such as perphenazine, which carried a weight advantage in the CATIE study and represented favorably with one small study in our meta-analysis. A limitation of the current study is the fact that the placebo control group was consisted of prodrome patients (McGlashan et al., 2006; Woods et al., 2003) since we could not find any placebo-controlled studies in FEP. Generating outcomes from a small sample size can reduce the precision of outcome estimations. Compared to prodromal psychotic patients, growth/placebo effects could also differ in FEP. We also found evidence of publication bias in long term weight and BMI change, which again calls for caution in interpretation of findings for the longer-term weight gain.

FEP represents a critical period both for psychiatric but also for preventive medicine care (Birchwood, Todd, \& Jackson, 1998; Srihari et al., 2013). Lifestyle change incorporated in phase specific FEP care could reap significant health and quality of life benefits several decades later for the FEP population. However, first and foremost, care in initial medication choice represents a relatively easy and inexpensive preventive health intervention for FEP. This meta-analysis sheds light on specific weight gain liabilities of various AP medications in early stages of psychosis. Except for ziprasidone, almost all AP medications were associated with body weight gain and BMI increase in FEP patients. Haloperidol and possibly other strong D2 receptor blockers are not weight neutral in FEP, as previously had been thought from chronic schizophrenia studies. Early and continuing effects of various AP 
medications on weight gain and BMl increase should be taken into consideration by clinicians. Initial AP medication selection of a lower weight gain liability AP or switching to one later in the treatment are important in preventing future weight gain and cardiovascular risk several decades later. 
References

Abrams, K. R., Gillies, C. L., \& Lambert, P. C. (2005). Meta-analysis of heterogeneously reported trials assessing change from baseline. Statistics in Medicine, 24(24), 38233844.

Allison, D. B., Mentore, J. L., Heo, M., Chandler, L. P., Cappelleri, J. C., Infante, M. C., \& Weiden, P. J. (1999). Antipsychotic-induced weight gain: a comprehensive research synthesis. Am J Psychiatry, 156(11), 1686-1696.

Álvarez-Jiménez, M., GonzálezBlanch, C., Crespo-Facorro, B., Hetrick, S., Rodríguez-Sánchez, J. M., Pérez-Iglesias, R., \& VázquezBarquero, Jose L. (2008). Antipsychotic-Induced Weight Gain in Chronic and First-Episode Psychotic Disorders: A Systematic Critical Reappraisal. CNS Drugs, 22(7), 547-563.

Alvarez-Jimenez, M., GonzalezBlanch, C., Vazquez-Barquero, J. L., Perez-Iglesias, R., Martinez-Garcia, O., Perez-Pardal, T., . . . CrespoFacorro, B. (2006). Attenuation of antipsychotic-induced weight gain with early behavioral intervention in drug-naive first-episode psychosis patients: A randomized controlled trial. J Clin Psychiatry, 67(8), 12531260.

Baganz, C. N., Norris, J.M. (1943). A study of malnutrition in chronic schizophrenia. American Journal of Psychiatry, 99, 534-541.
Bak, M., Fransen, A., Janssen, J., van Os, J., \& Drukker, M. (2014). Almost All Antipsychotics Result in Weight Gain: A Meta-Analysis. Plos One, 9(4).

Birchwood, M., Todd, P., \& Jackson, C. (1998). Early intervention in psychosis. The critical period hypothesis. $\mathrm{Br} J$ Psychiatry Suppl, 172(33), 53-59.

Chwastiak, L. A., \& Tek, C. (2009). The unchanging mortality gap for people with schizophrenia. Lancet, 374(9690), 590-592.

Cochrane Handbook for Systematic Reviews of Interventions Version 5.1.0 [updated March 2011]. (2011). The Cochrane Collaboration.

Daniel, D. G., Zimbroff, D. L., Potkin, S. G., Reeves, K. R., Harrigan, E. P., \& Lakshminarayanan, M. (1999). Ziprasidone $80 \mathrm{mg} /$ day and 160 $\mathrm{mg} /$ day in the acute exacerbation of schizophrenia and schizoaffective disorder: a 6-week placebocontrolled trial. Ziprasidone Study Group. Neuropsychopharmacology, 20(5), 491-505.

Daumit, G. L., Dickerson, F. B., Wang, N. Y., Dalcin, A., Jerome, G. J., Anderson, C. A., . . A Appel, L. J. (2013). A behavioral weight-loss intervention in persons with serious mental illness. $N$ Engl $J$ Med, 368(17), 1594-1602.

Deng, C., Weston-Green, K., \& Huang, X.-F. (2010). The role of 
histaminergic $\mathrm{H} 1$ and $\mathrm{H} 3$ receptors in food intake: A mechanism for atypical antipsychotic-induced weight gain? Progress in NeuroPsychopharmacology \& Biological Psychiatry, 34(1), 1-4.

Egger, M., Davey Smith, G., Schneider, M., \& Minder, C. (1997). Bias in meta-analysis detected by a simple, graphical test. BMJ, 315(7109), 629-634.

Fleischhacker, W. W., Siu, C. O., Boden, R., Pappadopulos, E., Karayal, O. N., \& Kahn, R. S. (2013). Metabolic risk factors in first-episode schizophrenia: baseline prevalence and course analysed from the European First-Episode Schizophrenia Trial. Int $J$ Neuropsychopharmacol, 16(5), 987995.

Gasquet, I., Haro, J. M., Novick, D., Edgell, E. T., Kennedy, L., \& Lepine, J. P. (2005). Pharmacological treatment and other predictors of treatment outcomes in previously untreated patients with schizophrenia: results from the European Schizophrenia Outpatient Health Outcomes (SOHO) study. Int Clin Psychopharmacol, 20(4), 199205.

Grootens, K. P., van Veelen, N. M., Peuskens, J., Sabbe, B. G., Thys, E., Buitelaar, J. K., . . . Kahn, R. S. (2011). Ziprasidone vs olanzapine in recent-onset schizophrenia and schizoaffective disorder: results of an 8-week double-blind randomized controlled trial. Schizophr Bull, 37(2), 352-361.
He, M., Deng, C., \& Huang, X. F. (2013). The role of hypothalamic $\mathrm{H} 1$ receptor antagonism in antipsychoticinduced weight gain. CNS Drugs, 27(6), 423-434.

Hori, H., Ueda, N., Yoshimura, R., Yamamoto, H., Wani, K., Etoh, Y., .. . Nakamura, J. (2009). Olanzapine orally disintegrating tablets (Zyprexa Zydis) rapidly improve excitement components in the acute phase of first-episode schizophrenic patients: an open-label prospective study. World J Biol Psychiatry, 10(4 Pt 3), 741-745.

Huq, Z. U. (2004). A trial of low doses of risperidone in the treatment of patients with first-episode schizophrenia, schizophreniform disorder, or schizoaffective disorder. J Clin Psychopharmacol, 24(2), 220224.

Ingole, S., Belorkar, N. R., Waradkar, P., \& Shrivastava, M. (2009). Comparison of effects of olanzapine and risperidone on body mass index and blood sugar level in schizophrenic patients. Indian J Physiol Pharmacol, 53(1), 47-54.

Jean-Baptiste, M., Tek, C., Liskov, E., Chakunta, U. R., Nicholls, S., Hassan, A. Q., . . . Wexler, B. E. (2007). A pilot study of a weight management program with food provision in schizophrenia. Schizophr Res, 96(1-3), 198-205.

Josiassen, R. C., Shaughnessy, R. A., Filymer, D. M., Donohue, A. M., Kacso, M., Finkel, N., . . Skuban, N. (2010). Early intervention with 
second-generation antipsychotics in first-episode psychosis: results of an 8-week naturalistic study. Early Interv Psychiatry, 4(1), 57-63.

Knowler, W. C., Barrett-Connor, E., Fowler, S. E., Hamman, R. F., Lachin, J. M., Walker, E. A., . . . Diabetes Prevention Program Research, G. (2002). Reduction in the incidence of type 2 diabetes with lifestyle intervention or metformin. $N$ Engl J Med, 346(6), 393-403.

Lahti, M., Tiihonen, J., Wildgust, H., Beary, M., Hodgson, R., Kajantie, E., Eriksson, J. (2012). Cardiovascular morbidity, mortality and pharmacotherapy in patients with schizophrenia. Psychol Med, 42(11), 2275-2285.

Lee, H. Y., Ham, B. J., Kang, R. H., Paik, J. W., Hahn, S. W., Lee, M. S., \& Lee, M. S. (2010). Trial of aripiprazole in the treatment of firstepisode schizophrenia. Psychiatry Clin Neurosci, 64(1), 38-43.

Leucht, S., Cipriani, A., Spineli, L., Mavridis, D., Orey, D., Richter, F., .. . Davis, J. M. (2013). Comparative efficacy and tolerability of 15 antipsychotic drugs in schizophrenia: a multiple-treatments meta-analysis. Lancet, 382(9896), 951-962.

Lieberman, J. A., Phillips, M., Gu, H., Stroup, S., Zhang, P., Kong, L., . . . Hamer, R. M. (2003). Atypical and conventional antipsychotic drugs in treatment-naive first-episode schizophrenia: a 52-week randomized trial of clozapine vs chlorpromazine.
Neuropsychopharmacology, 28(5), 995-1003.

Lieberman, J. A., Stroup, T. S., McEvoy, J. P., Swartz, M. S., Rosenheck, R. A., Perkins, D. O., . . Clinical Antipsychotic Trials of Intervention Effectiveness, I. (2005). Effectiveness of antipsychotic drugs in patients with chronic schizophrenia. $N$ Engl J Med, 353(12), 1209-1223.

Liu, J., Sun, J., Shen, X., Guo, W., Zhi, S., Song, G., . . Song, J. (2014). Randomized controlled trial comparing changes in serum prolactin and weight among female patients with first-episode schizophrenia over 12 months of treatment with risperidone or quetiapine. Shanghai Arch Psychiatry, 26(2), 88-94.

Lovell, K., Wearden, A., Bradshaw, T., Tomenson, B., Pedley, R., Davies, L. M., . . . Marshall, M. (2014). An exploratory randomized controlled study of a healthy living intervention in early intervention services for psychosis: the INTERvention to encourage ACTivity, improve diet, and reduce weight gain (INTERACT) study. J Clin Psychiatry, 75(5), 498505. doi:10.4088/JCP.13m08503

McGlashan, T. H., Zipursky, R. B., Perkins, D., Addington, J., Miller, T., Woods, S. W., . . Breier, A. (2006). Randomized, double-blind trial of olanzapine versus placebo in patients prodromally symptomatic for psychosis. Am J Psychiatry, 163(5), 790-799. 
McGorry, P. D., Cocks, J., Power, P., Burnett, P., Harrigan, S., \& Lambert, T. (2011). Very low-dose risperidone in first-episode psychosis: a safe and effective way to initiate treatment. Schizophr Res Treatment, 2011, 631690.

Moher, D., Liberati, A., Tetzlaff, J., Altman, D. G., \& Group, P. (2009). Preferred reporting items for systematic reviews and metaanalyses: the PRISMA statement. BMJ, 339, b2535.

Ninomiya, Y., Miyamoto, S., Tenjin, T., Ogino, S., Miyake, N., Kaneda, Y., ... Yamaguchi, N. (2014). Long-term efficacy and safety of blonanserin in patients with first-episode schizophrenia: A 1-year open-label trial. Psychiatry Clin Neurosci.

Ou, J. J., Xu, Y., Chen, H. H., Fan, X., Gao, K., Wang, J., . . . Zhao, J. P. (2013). Comparison of metabolic effects of ziprasidone versus olanzapine treatment in patients with first-episode schizophrenia. Psychopharmacology (Berl), 225(3), 627-635.

Padmavati, R., McCreadie, R. G., \& Tirupati, S. (2010). Low prevalence of obesity and metabolic syndrome in never-treated chronic schizophrenia. Schizophrenia Research, 121(1-3), 199-202.

Patel, J. K., Buckley, P. F., Woolson, S., Hamer, R. M., McEvoy, J. P., Perkins, D. O., \& Lieberman, J. A. (2009). Metabolic profiles of secondgeneration antipsychotics in early psychosis: findings from the CAFE study. Schizophr Res, 111(1-3), 9-16.

Perez-Iglesias, R., Crespo-Facorro, B., Martinez-Garcia, O., RamirezBonilla, M. L., Alvarez-Jimenez, M., Pelayo-Teran, J. M., . . . VazquezBarquero, J. L. (2008). Weight gain induced by haloperidol, risperidone and olanzapine after 1 year: findings of a randomized clinical trial in a drugnaive population. Schizophr Res, 99(1-3), 13-22.

Perez-Iglesias, R., Ortiz-Garcia de la Foz, V., Martinez Garcia, O., Amado, J. A., Garcia-Unzueta, M. T., AyesaArriola, R., . . . Crespo-Facorro, B. (2014). Comparison of metabolic effects of aripiprazole, quetiapine and ziprasidone after 12weeks of treatment in first treated episode of psychosis. Schizophr Res.

Pfizer, I. (2014, Januari1, 2014). Goedon Prescribing Information. Retrieved from http://labeling.pfizer.com/ShowLabeli ng.aspx?id=584

Rasmussen, H., Ebdrup, B. H., Oranje, B., Pinborg, L. H., Knudsen, G. M., \& Glenthoj, B. (2014). Neocortical serotonin2A receptor binding predicts quetiapine associated weight gain in antipsychotic-naive first-episode schizophrenia patients. Int $\mathrm{J}$ Neuropsychopharmacol, 1-8.

Ratliff, J. C., Barber, J. A., Palmese, L. B., Reutenauer, E. L., \& Tek, C. (2010). Association of prescription $\mathrm{H} 1$ antihistamine use with obesity: results from the National Health and 
Nutrition Examination Survey. Obesity (Silver Spring), 18(12), 23982400.

Ratliff, J. C., Palmese, L. B., Reutenauer, E. L., Srihari, V. H., \& Tek, C. (2013). Obese schizophrenia spectrum patients have significantly higher 10-year general cardiovascular risk and vascular ages than obese individuals without severe mental illness. Psychosomatics, 54(1), 67-73.

Ratliff, J. C., Palmese, L. B., Tonizzo, K. M., Chwastiak, L., \& Tek, C. (2012). Contingency management for the treatment of antipsychoticinduced weight gain: a randomized controlled pilot study. Obes Facts, 5(6), 919-927.

Reynolds, G. P., \& Kirk, S. L. (2010). Metabolic side effects of antipsychotic drug treatment-pharmacological mechanisms. Pharmacol Ther, 125(1), 169-179.

Sanz-Fuentenebro, J., Taboada, D., Palomo, T., Aragues, M., Ovejero, S., Del Alamo, C., \& Molina, V. (2013). Randomized trial of clozapine vs. risperidone in treatment-naive firstepisode schizophrenia: results after one year. Schizophr Res, 149(1-3), 156-161.

Schooler, N., Rabinowitz, J., Davidson, M., Emsley, R., Harvey, P. D., Kopala, L., ... De Smedt, G. (2005). Risperidone and haloperidol in first-episode psychosis: a longterm randomized trial. $A m \mathrm{~J}$ Psychiatry, 162(5), 947-953.
Sengupta, S. M., Klink, R., Stip, E., Baptista, T., Malla, A., \& Joober, R. (2005). Weight gain and lipid metabolic abnormalities induced by olanzapine in first-episode, drugnaive patients with psychotic disorders. Schizophr Res, 80(1), 131133.

Srihari, V. H., Phutane, V. H., Ozkan, B., Chwastiak, L., Ratliff, J. C., Woods, S. W., \& Tek, C. (2013). Cardiovascular mortality in schizophrenia: Defining a critical period for prevention. Schizophrenia Research, 146(1-3), 64-68.

Strassnig, M., Miewald, J., Keshavan, M., \& Ganguli, R. (2007). Weight gain in newly diagnosed first-episode psychosis patients and healthy comparisons: one-year analysis. Schizophr Res, 93(1-3), 90-98.

Stroup, T. S., McEvoy, J. P., Ring, K. D., Hamer, R. H., LaVange, L. M., Swartz, M. S., . . Lieberman, J. A. (2011). A randomized trial examining the effectiveness of switching from olanzapine, quetiapine, or risperidone to aripiprazole to reduce metabolic risk: comparison of antipsychotics for metabolic problems (CAMP). Am J Psychiatry, 168(9), 947-956. doi:10.1176/appi.ajp.2011.10111609

Takahashi, H., Oshimo, T., \& Ishigooka, J. (2009). Efficacy and tolerability of aripiprazole in firstepisode drug naive patients with schizophrenia: An open-label trial. Clinical Neuropharmacology, 32(3), 149-150. 
Tarricone, I., Ferrari Gozzi, B., Serretti, A., Grieco, D., \& Berardi, D. (2010). Weight gain in antipsychoticnaive patients: a review and metaanalysis. Psychol Med, 40(2), 187200.

Tauscher-Wisniewski, S., Kapur, S., Tauscher, J., Jones, C., Daskalakis, Z. J., Papatheodorou, G., . . . Zipursky, R. B. (2002). Quetiapine: an effective antipsychotic in firstepisode schizophrenia despite only transiently high dopamine-2 receptor blockade. J Clin Psychiatry, 63(11), 992-997.

Tiihonen, J., Lonnqvist, J., Wahlbeck, K., Klaukka, T., Niskanen, L., Tanskanen, A., \& Haukka, J. (2009). 11-year follow-up of mortality in patients with schizophrenia: a population-based cohort study (FIN11 study). Lancet, 374(9690), 620-627.

Vinay, H. R., Sundar, G. S. K., Behere, R. V., Arasappa, R., Rao, N. P., Venkatasubramanian, G., . . . Gangadhar, B. N. (2011). Effect of risperidone on metabolic parameters in antipsychotic-naïve schizophrenia: A prospective one year follow-up study. Asian Journal of Psychiatry, 4(1), 73-74.

Woods, S. W., Breier, A., Zipursky, R. B., Perkins, D. O., Addington, J., Miller, T. J., . . . McGlashan, T. H. (2003). Randomized trial of olanzapine versus placebo in the symptomatic acute treatment of the schizophrenic prodrome. Biol Psychiatry, 54(4), 453-464.
Yap, H. L., Mahendran, R., Lim, D., Liow, P. H., Lee, A., Phang, S., \& Tiong, A. (2001). Risperidone in the treatment of first episode psychosis. Singapore Med J, 42(4), 170-173.

Zalsman, G., Carmon, E., Martin, A., Bensason, D., Weizman, A., \& Tyano, S. (2003). Effectiveness, safety, and tolerability of risperidone in adolescents with schizophrenia: an open-label study. J Child Adolesc Psychopharmacol, 13(3), 319-327.

Zhang, J. Y., Kowal, D. M., Nawoschik, S. P., Lou, Z., \& Dunlop, J. (2006). Distinct functional profiles of aripiprazole and olanzapine at RNA edited human 5-HT2C receptor isoforms. Biochem Pharmacol, 71(4), 521-529.

Zhao, T., Park, T. W., Yang, J. C., Huang, G. B., Kim, M. G., Lee, K. H., \& Chung, Y. C. (2012). Efficacy and safety of ziprasidone in the treatment of first-episode psychosis: an 8-week, open-label, multicenter trial. Int Clin Psychopharmacol, 27(4), 184-190.

Zipursky, R. B., Gu, H., Green, A. I., Perkins, D. O., Tohen, M. F., McEvoy, J. P., . . Lieberman, J. A. (2005). Course and predictors of weight gain in people with firstepisode psychosis treated with olanzapine or haloperidol. $\mathrm{Br} J$ Psychiatry, 187, 537-543. 
Chapter 3. Antipsychotic Induced Weight Gain

II0 Metabolic Disturbances in Mental IIIness - S Kucukgoncu 
Chapter 3. Antipsychotic Induced Weight Gain

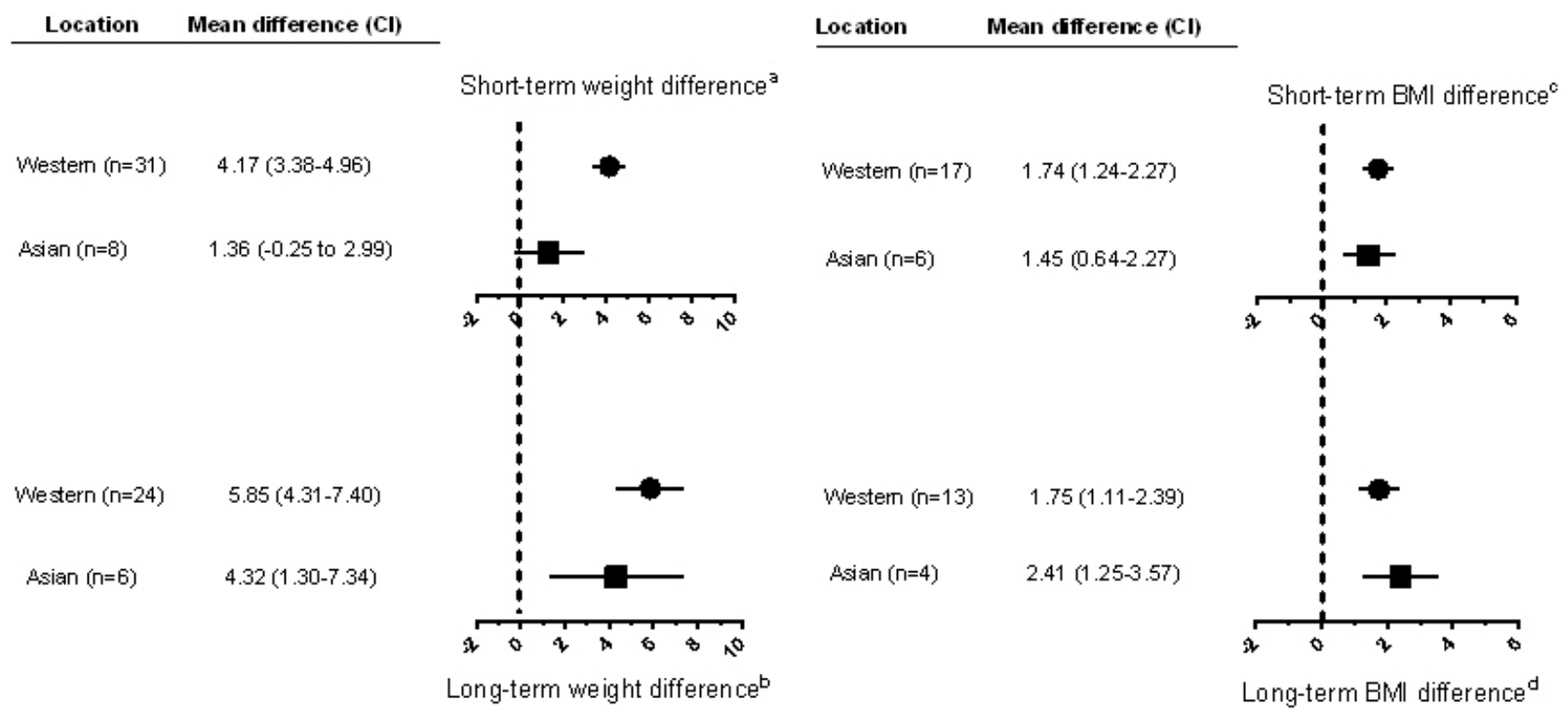

a. Random effects analysis: $Q=9.26, d f=I, P=0.002$

b. Random effects analysis: $Q=0.32, \mathrm{df}=\mathrm{I}, \mathrm{p}=0.569$

c. Random effects analysis: $Q=0.34, \mathrm{df}=\mathrm{I}, \mathrm{P}=0.558$

d. Random effects analysis: $Q=3.15, d f=I, p=0.076$

Figure SI. Sub-group meta-analyses of weight and body mass index (BMI) differences between Asian and Western samples 
Chapter 3. Antipsychotic Induced Weight Gain

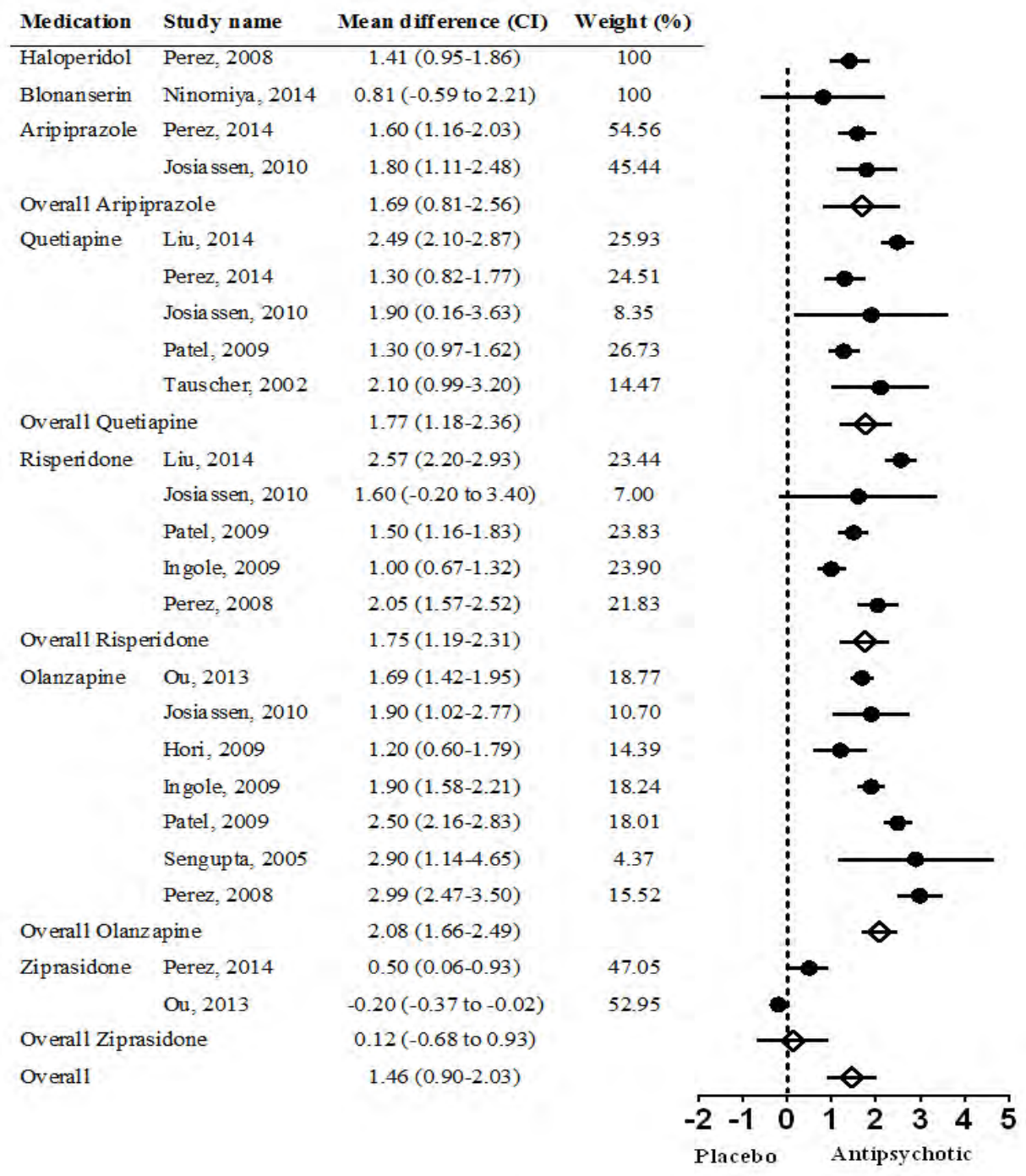

Random Effects Analysis- $Q=18.09, \mathrm{df}=6, \mathrm{p}=0.006$

Fixed Effect Analysis- $Q=398.36, \mathrm{df}=6, \mathrm{p}<0.00 \mathrm{I}$

$I^{2}=95.70, \mathrm{Tau}^{2}=0.97$

Figure S2. Meta-analysis of mean body mass index (BMI) change in the short-term ( $\leq 12$ weeks) 


\section{Chapter 3. Antipsychotic Induced Weight Gain}

\begin{tabular}{|c|c|c|c|}
\hline Medication & Study name & Mean difference $(\mathrm{CI})$ & Weight $(\%)$ \\
\hline Amisulpride & Fleischhacker, 2013 & $7.75(3.19$ to 12.30$)$ & 100 \\
\hline Blonanserin & Ninomiya, 2014 & $0.16(-4.81$ to 5.13$)$ & 100 \\
\hline Clorpromazine & Lieberman, 2003 & $6.55(2.74$ to 10.35$)$ & 100 \\
\hline Perfenazine & Strassnig, 2007 & $-0.41(-9.84$ to 9.02$)$ & 100 \\
\hline Ziprasidone & Fleischhacker, 2013 & $2.85(-2.05$ to 7.75$)$ & 100 \\
\hline \multirow[t]{2}{*}{ Clozapine } & Sanz-Fuentenebro, 2013 & $6.05(-0.83$ to 12.93$)$ & 21.62 \\
\hline & Lieberman, 2003 & $7.95(5.23-10.66)$ & 78.38 \\
\hline \multicolumn{2}{|c|}{ Overall Clozapine } & $7.53(4.08-10.99)$ & \\
\hline \multirow[t]{4}{*}{ Haloperidol } & Fleischhacker, 2013 & $5.35(1.57-9.12)$ & 23.02 \\
\hline & Perez, 2008 & $7.72(4.11-11.32)$ & 24.41 \\
\hline & Strassnig, 2007 & $2.13(-1.45-5.71)$ & 24.58 \\
\hline & Zipursky, 2005 & $5.15(1.93-8.36)$ & 27.99 \\
\hline \multicolumn{2}{|c|}{ Overall Haloperidol } & $5.08(2.82-7.33)$ & \\
\hline \multirow[t]{3}{*}{ Quetiapine } & Liu, 2014 & $2.25(-0.34$ to 4.84$)$ & 37.76 \\
\hline & Fleischhacker, 2013 & $8.55(4.77-12.32)$ & 24.88 \\
\hline & Patel, 2009 & $3.53(0.90-6.15)$ & 37.36 \\
\hline \multicolumn{2}{|c|}{ Overall Quetiapine } & 4.29 (1.94 to 6.64$)$ & \\
\hline \multirow[t]{6}{*}{ Rispridone } & Liu, 2014 & $2.95(0.33-5.56)$ & 26.04 \\
\hline & Sanz-Fuentenebro, 2013 & $13.25(-0.16-26.66)$ & 2.04 \\
\hline & Vinay, 2011 & $5.25(0.31-10.18)$ & 11.90 \\
\hline & Patel, 2009 & $4.40(1.57-7.22)$ & 24.22 \\
\hline & Perez, 2008 & $6.99(3.26-10.71)$ & 17.61 \\
\hline & Strassnig, 2007 & $5.57(1.93-9.20)$ & 18.18 \\
\hline \multicolumn{2}{|c|}{ Overall Risperidone } & $4.97(3.01-6.93)$ & \\
\hline \multirow[t]{5}{*}{ Olanzapine } & Fleischhacker, 2013 & $11.95(8.35-15.54)$ & 19.23 \\
\hline & Patel, 2009 & $9.02(6.19-11.84)$ & 25.22 \\
\hline & Perez, 2008 & $9.10(6.76-11.43)$ & 30.03 \\
\hline & Strassnig, 2007 & $14.96(6.46-23.47)$ & 4.98 \\
\hline & Zipursky, 2005 & $13.55(10.14-16.95)$ & 20.55 \\
\hline \multicolumn{2}{|c|}{ Overall Olanzapine } & $10.83(8.83-12.83)$ & \\
\hline \multicolumn{2}{|c|}{ Overall } & $5.31(3.06-7.56)$ & \\
\hline
\end{tabular}

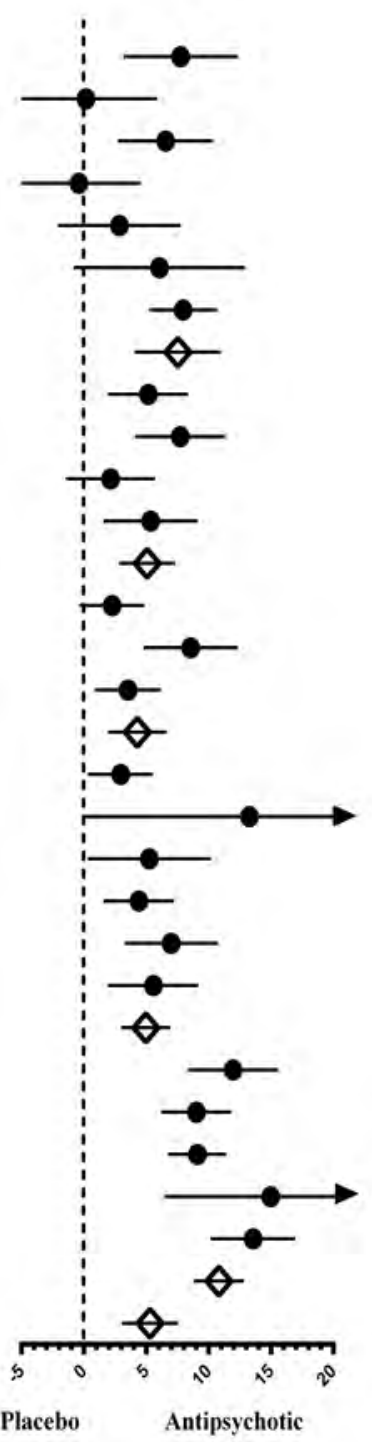

Random Effects Analysis- $Q=39.54, \mathrm{df}=9, \mathrm{p}<0.001$

Fixed Effect Analysis- $Q=91.82, \mathrm{df}=9, \mathrm{p}<0.001$

$I^{2}=74.86, \mathrm{Tau}^{2}=8.5 \mathrm{I}$

Figure S3. Meta-analysis of mean weight differences $(\mathrm{kg})$ between placebo and antipsychotic medications in 52 weeks 
Chapter 3. Antipsychotic Induced Weight Gain

\begin{tabular}{|c|c|c|c|c|}
\hline Medication & Study name & Mean differ ence (CI) & Weight (\%) & \\
\hline Blonanser in & Ninomiya, 2014 & $0.42(-1.25$ to 2.09$)$ & 100 & \\
\hline Perfenazine & Strassnig, 2007 & $0.00(-1.38$ to 1.38$)$ & 100 & \\
\hline \multirow[t]{2}{*}{ Haloperidol } & Perez, 2008 & $2.86(1.66-4.05)$ & 50.08 & \\
\hline & Strassnig, 2007 & $0.90(-0.30-2.10)$ & 49.92 & \\
\hline \multicolumn{2}{|c|}{ Overall Haloperidol } & $1.90(-0.314 .08)$ & & \\
\hline \multirow[t]{6}{*}{ Risperidone } & Liu, 2014 & $3.09(2.17-4.00)$ & 17.15 & 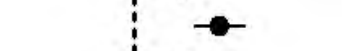 \\
\hline & Vinay, 2011 & $2.10(0.62-3.57)$ & 14.95 & \\
\hline & Patel, 2009 & $1.30(0.97-1.62)$ & 17.34 & \\
\hline & Perez, 2008 & $2.55(1.30-3.80)$ & 15.88 & \\
\hline & Strassnig, 2007 & $2.00(0.81-3.18)$ & 16.14 & \\
\hline & Gasquet, 2005 & $0.20(-0.20-0.60)$ & 18.53 & \\
\hline \multicolumn{2}{|c|}{ Overall Risperidone } & $1.85(0.88-2.83)$ & & \\
\hline \multirow[t]{4}{*}{ Olanz apine } & Patel, 2009 & $3.20(2.29-4.11)$ & 27.85 & ; \\
\hline & Perez, 2008 & $3.31(2.18-4.43)$ & 26.55 & - \\
\hline & Strassnig, 2007 & $5.00(2.10-7.89)$ & 15.14 & - \\
\hline & Gas quet, 2005 & $0.60(0.35-0.84)$ & 30.46 & \\
\hline \multicolumn{2}{|c|}{ Overall Olanzapine } & $2.71(1.12-4.29)$ & & 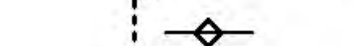 \\
\hline \multirow[t]{3}{*}{ Quetiapine } & Rasmussen, 2014 & $1.10(-1.04$ to 3.24$)$ & 25.90 & \\
\hline & Liu, 2014 & $3.36(2.56-4.16)$ & 37.48 & - \\
\hline & Patel, 2009 & $1.80(0.89-2.72)$ & 36.62 & \\
\hline \multicolumn{2}{|c|}{ Overall Quetiapine } & $2.20(0.37-4.02)$ & & - \\
\hline \multirow[t]{2}{*}{ Overall } & & $1.86(0.88-2.83)$ & & $i$ \\
\hline & & & & 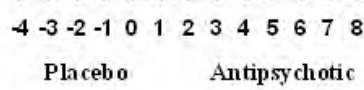 \\
\hline
\end{tabular}

Random Effects Analysis- $Q=3.23, \mathrm{df}=5, \mathrm{p}=0.664$

Fixed Effect Analysis- $Q=34.08, \mathrm{df}=5, \mathrm{p}<0.00 \mathrm{I}$

$1^{2}=89.34, \operatorname{Tau}^{2}=1.38$

Figure S4. Meta-analysis of mean body mass index (BMI) change in the long-term (>12 weeks) 


\section{Chapter 3. Antipsychotic Induced Weight Gain}

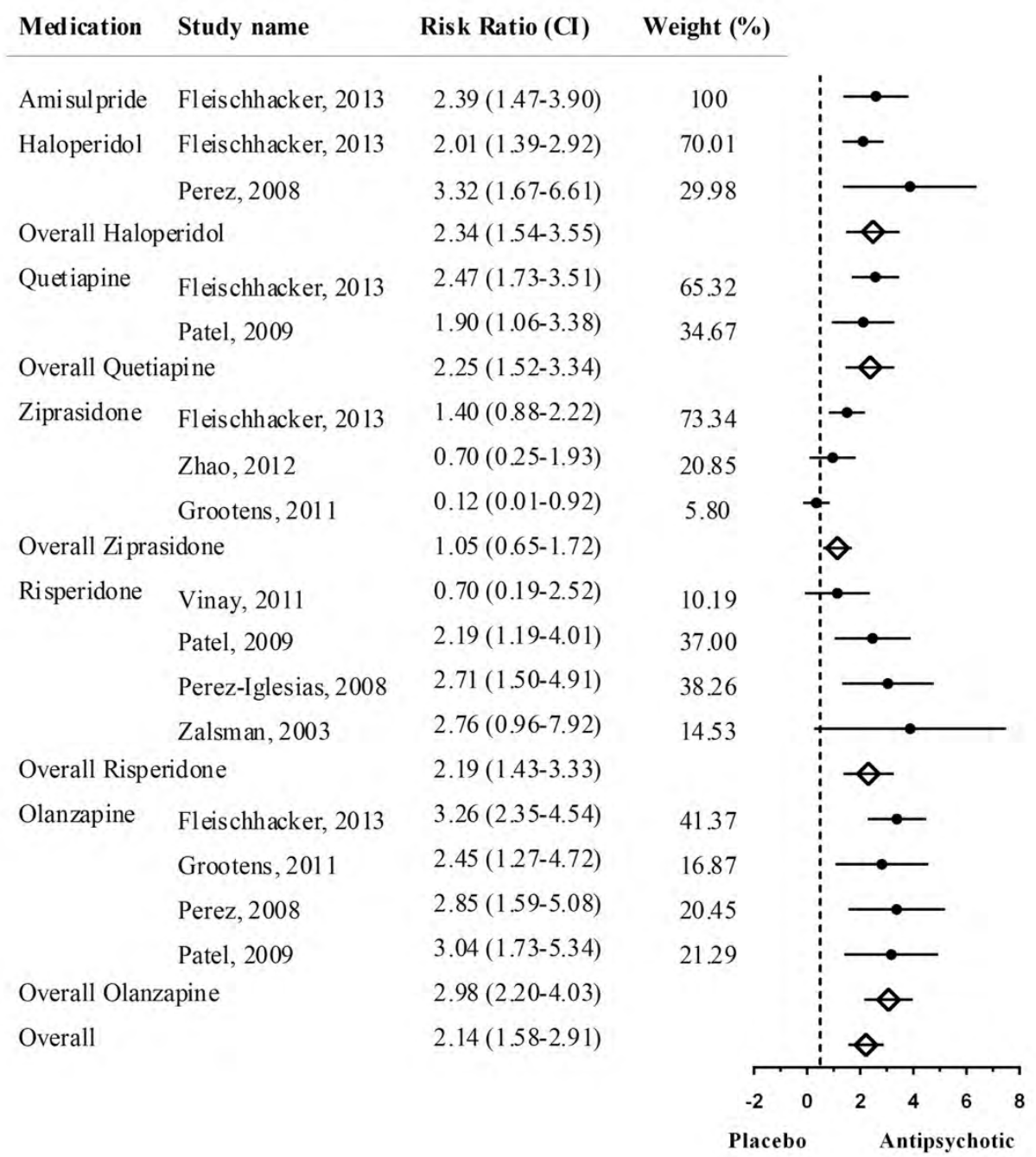

Random Effects Analysis- $Q=12.65, \mathrm{df}=5, \mathrm{p}=0.027$

Fixed Effect Analysis- $Q=16.76, d f=5, p=0.005$

$I^{2}=19.46, \mathrm{Tau}^{2}=0.07$

Figure S5. Meta-analysis of clinically significant weight change ( $>7 \%$ weight gain) estimates between placebo and antipsychotic medications 


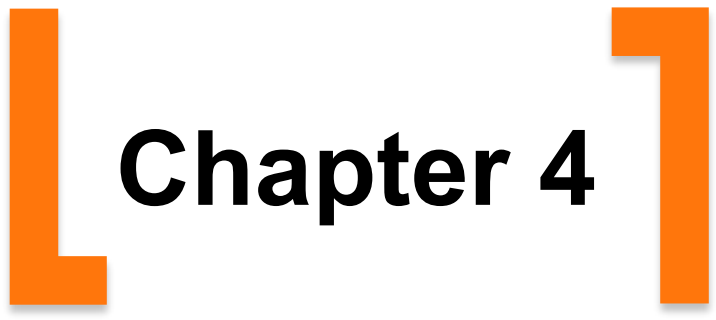

II6 Metabolic Disturbances in Mental IIIness - S Kucukgoncu 
Alpha-Lipoic Acid (ALA) as a supplementation for weight loss: Results from a Meta-Analysis of Randomized Controlled Trials

Suat Kucukgoncu, Elton Zhou, Katherine B Lucas, Cenk Tek

Obesity Reviews 2017;18:594-601. 


\section{Chapter 4. Alpha-Lipoic Acid for Weight Loss}

\section{Objectives}

Obesity is associated with significant morbidity and mortality rates. Even modest weight loss may be associated with health benefits. Alpha-lipoic acid (ALA) is a naturally occurring antioxidant. Studies have suggested antiobesity properties of ALA; however, results are inconsistent. The purpose of this study is to conduct a meta-analysis of the effect of ALA on weight and body mass index (BMI).

\section{Methods}

A comprehensive, systematic literature search identified 11 articles on randomized, double-blind, placebo-controlled studies involving ALA. We conducted a meta-analysis of mean weight and BMI change differences between ALA and placebo treatment groups.

\section{Results}

ALA treatment coincided with a statistically significant $1.27 \mathrm{~kg}$ $(\mathrm{Cl}=0.25$ to 2.29$)$ greater mean weight loss compared to the placebo group. A significant overall mean BMI difference of $-0.43 \mathrm{~kg} / \mathrm{m}^{2}$ ( $\mathrm{Cl}=-0.82$ to -0.03$)$ was found between the ALA and placebo groups. Meta-regression analysis showed no significance in ALA dose on BMI and weight changes. Study duration significantly affected BMI change, but not weight change.

\section{Conclusions}

ALA treatment showed small, yet significant short-term weight loss compared to placebo. Further research is needed to examine the effect of different doses and the long-term benefits of ALA on weight management.

Keywords: thioctic acid, weight, body mass, diabetes, alpha lipoic acid 


\section{Chapter 4. Alpha-Lipoic Acid for Weight Loss}

\section{INTRODUCTION}

Obesity is a growing worldwide epidemic with an estimated 1.9 billion overweight and 600 million obese adults ( $\mathrm{Ng}$ et al., 2014). Obesity is associated with significant morbidity and mortality through its close association with ailments such as cardiovascular disease and diabetes (Aronne, 2002). Even modest weight loss may be associated with prevention of diabetes, reduction in blood pressure, lower cholesterol and triglyceride levels, and other health benefits (Diabetes Prevention Program Research et al., 2009; Goldstein, 1992; Knowler et al., 2002).

Alpha lipoic acid (ALA), also known as thioctic acid, is a naturally occurring short chain fatty acid which contains a thiol bond (Evans \& Goldfine, 2000). It is an essential cofactor for energy production in the mitochondria (Packer, Kraemer, \& Rimbach, 2001). ALA is also a powerful antioxidant and a free radical scavenger (Bast \& Haenen, 2003; Deneke, 2000; Evans \& Goldfine, 2000). ALA is marketed in the US as an over-the-counter nutritional antioxidant supplement, alone or in combination with other antioxidants. In medicine, ALA has been shown to reduce symptoms of diabetic polyneuropathy, and several clinical trials established some efficacy and an excellent safety profile in this patient population (Ametov et al., 2003; Ziegler, 2004; Ziegler et al., 2006; Ziegler et al., 1999; Ziegler, Nowak, Kempler, Vargha, \& Low, 2004; Ziegler et al., 1997).

Previous studies have suggested anti-obesity properties of ALA (Carbonelli et al., 2010; Huerta, Navas-Carretero, Prieto-Hontoria, Martinez, \& Moreno-Aliaga, 2015; Koh et al., 2011). In animal studies, it has showed that ALA supplementation promotes the reduction of body weight and fat mass by decreasing food intake and enhancing energy expenditure, possibly by suppressing hypothalamic AMP-activated protein kinase (AMPK) activity (Prieto-Hontoria, Perez-Matute, Fernandez-Galilea, Alfredo Martinez, \& Moreno-Aliaga, 2013; Prieto-Hontoria et al., 2009; Prieto-Hontoria, PerezMatute, Fernandez-Galilea, Martinez, \& Moreno-Aliaga, 2011; Wang, Li, Guo, 


\section{Chapter 4. Alpha-Lipoic Acid for Weight Loss}

Chan, \& Guan, 2010). However, studies in humans with ALA supplementation are limited, and the results have been inconsistent. Some clinical trials have shown that ALA supplementation may help overweight or obese individuals lose weight (Carbonelli et al., 2010; Koh et al., 2011), while other studies have observed no effects of ALA on weight (Ansar, Mazloom, Kazemi, \& Hejazi, 2011; McNeilly et al., 2011). Nevertheless, ALA appears to have a wide range of beneficial effects on obesity related conditions such as insulin resistance, metabolic syndrome, and type II diabetes, including their complications such as vascular damage (Packer et al., 2001; Ziegler, 2004).

We performed a systematic review and comprehensive meta-analysis to assess the effects of ALA as a weight-loss supplement. On the basis of the results from single studies, we hypothesized that ALA is more effective than placebo for reducing body weight.

\section{METHODS}

Studies were identified using PubMed, PsychINFO, and Web of Science. Additionally, a manual search was used among references cited in retrieved articles, related review articles, and meta-analyses. Two reviewers ( $E Z$ and $\mathrm{KL}$ ) independently conducted the literature search using the following terms: ( $\alpha$-Lipoic OR alpha-lipoic OR “lipoic acid” OR thioctic OR “ $\alpha$-LA") AND (weight OR obesity OR overweight OR BMI OR "body mass" OR diabete* OR diabeti* OR diabeto* OR "diabetes mellitus" OR "body fat" OR "fat mass") AND ((clinical [Title/Abstract] AND trial [Title/Abstract]).

\section{Selection Criteria}

The following inclusion criteria were used: (i) studies were randomized and placebo-controlled, (ii) subjects were human with a mean age of $\geq 18$ years old (iii) studies were $\geq 3$ weeks in length, and (iv) studies reported weight and/or BMI before and after intervention regardless if the stated aim was weight reduction or else. The present meta-analysis was conducted and reported according to the PRISMA (Preferred Reporting Items 


\section{Chapter 4. Alpha-Lipoic Acid for Weight Loss}

of Systematic Reviews and Meta-Analysis) guidelines (Moher, Liberati, Tetzlaff, Altman, \& Group, 2009).

\section{Data Extraction}

Two reviewers ( $E Z$ and $K L$ ) independently reviewed each article and extracted all data. After study selection and data extraction, a third reviewer (SK) checked all extracted data to clarify any missing data. To obtain missing information, we contacted the authors to request relevant data. Correlation coefficients were used to calculate and impute the missing standard deviation of change from baseline applying the methods described in Cochrane Handbook for Systematic Reviews of Interventions Version 5.1.0. (Abrams, Gillies, \& Lambert, 2005; Collaboration, 2011). The following data were extracted: study design, sample size, medication dose, duration of follow-up, demographical variables (age, gender), body weight, and body mass index (BMI). Outcomes of overlapping samples from the same investigators were extracted from the more detailed report.

\section{Statistical Analyses}

To avoid publication bias, we conducted a comprehensive search among published studies. Publication bias was also assessed visually with funnel plots and statistically with Egger's regression test (Egger, Davey Smith, Schneider, \& Minder, 1997). Statistical heterogeneity was assessed using $Q$ and $\mathrm{I}^{2}$ test (in which $\mathrm{I}^{2} \geq 50 \%$ was considered to indicate heterogeneity). We examined the difference between ALA treatment and placebo by calculating the mean difference using the software Comprehensive Meta-Analysis Version 2 (Biostat, Englewood, NJ, USA). To combine studies, the random-effects model was used with the results for a fixed-effects model presented on figures. 


\section{Chapter 4. Alpha-Lipoic Acid for Weight Loss}

\section{RESULTS}

Our study selection process is presented in Figure 1. A total of 728 articles excluding duplicates were identified. After screening the title and abstract, 112 articles were selected for further evaluation. After full-text review, 101 articles not fulfilling the selection criteria were excluded. Of the excluded articles, 33 were not placebo controlled, 59 provided no weight data, 4 were not randomized, and 4 included patients under 18 years of age.

Overall, we identified 11 eligible studies with 12 appropriate treatment arms for inclusion in this review. Of these studies, eight of them reported weight outcomes and seven of them reported BMI outcomes. Studies in this meta-analysis were carried out in various populations, including patients with diabetes mellitus (Ansar et al., 2011; Udupa, Nahar, Shah, Kshirsagar, \& Ghongane, 2012; Ziegler et al., 1997), metabolic syndrome (Manning et al., 2013), rheumatoid arthritis (Gargari, Kolahi, Dehghan, Khabbazi, \& Mirtaheri, 2015), and non-alcoholic fatty liver disease (Gianturco et al., 2013). Three studies were designed as weight loss interventions, and conducted with overweight and obese individuals (Huerta, Prieto-Hontoria, et al., 2015; Kim et al., 2016; Koh et al., 2011). Three studies employed dietary interventions with ALA or placebo (Huerta, Navas-Carretero, et al., 2015; Koh et al., 2011, Gianturco et al., 2013). Details of the studies are summarized in Table 1. 


\section{Chapter 4. Alpha-Lipoic Acid for Weight Loss}

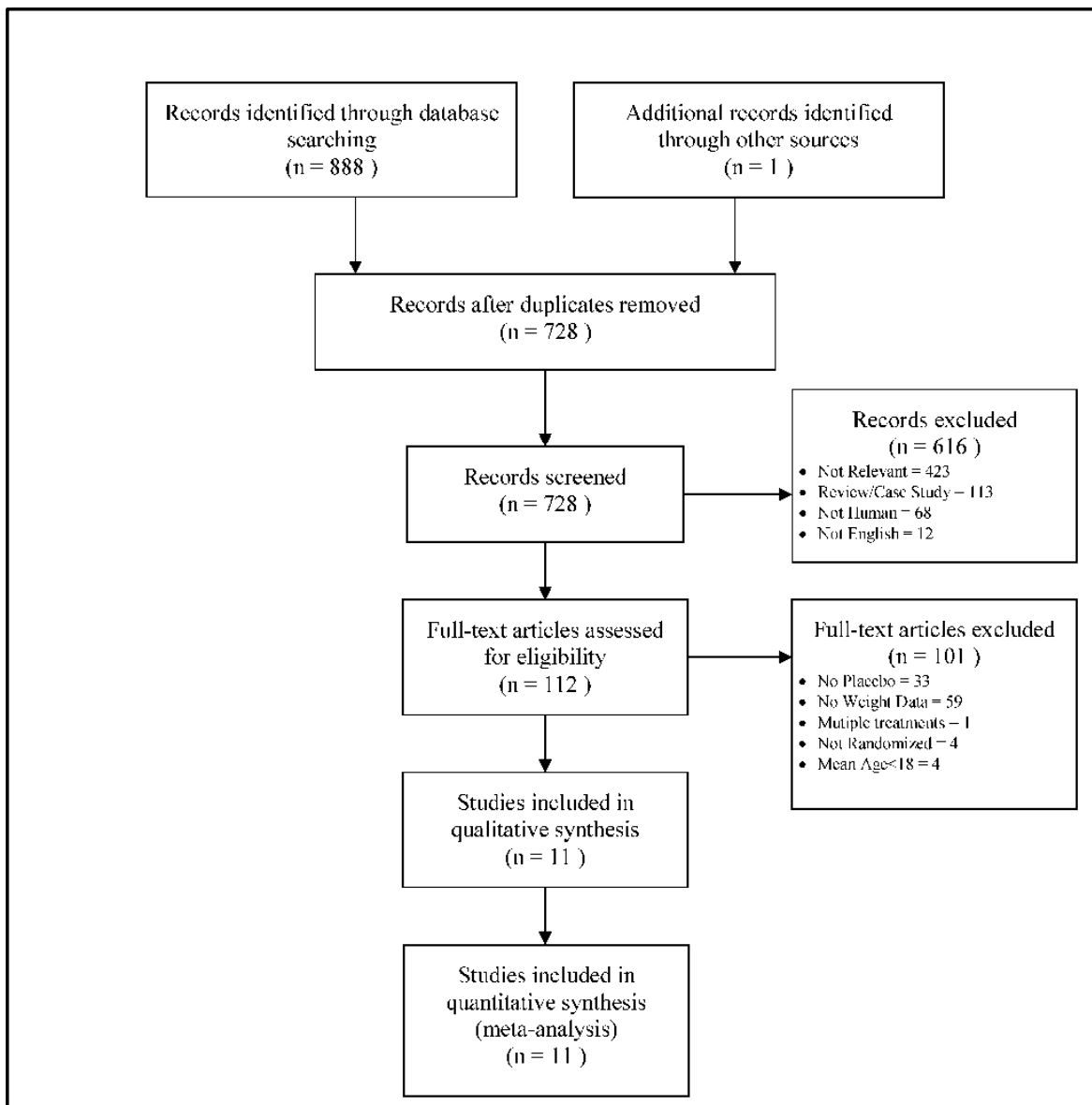

Figure 1. Flow Chart Depicting Selection of Studies

The total number of participants in these studies was 534 for the ALA group and 413 for the placebo group. The study durations were between 8 weeks to 52 weeks. ALA doses were between $300 \mathrm{mg} /$ day to $1800 \mathrm{mg} /$ day.

\section{Meta-analyses}

\section{Weight Change}

Overall weight loss was $1.27 \mathrm{~kg}(\mathrm{Cl}=-2.29$ to -0.25$)$ greater in ALA 
treatment compared to that in placebo group (Figure 2). We found no evidence of publication bias in the body weight change analysis (Egger's test intercept $=-1.659, \mathrm{Cl}=-5.10$ to 1.78 ). There was a significant heterogeneity across interventions $\left(\mathrm{I}^{2}=68.12\right.$, d.f. $\left.=8, \mathrm{p}<0.001\right)$.

Meta-regression analysis showed that neither intervention duration (P.E. $=-2.00, \mathrm{Cl}=-4.02$ to $0.01, \mathrm{p}=0.051$ ) nor ALA dose had a significant effect on weight change (P.E. $=-0.956, \mathrm{Cl}=-3.08$ to $1.16, \mathrm{p}=0.377$ ).

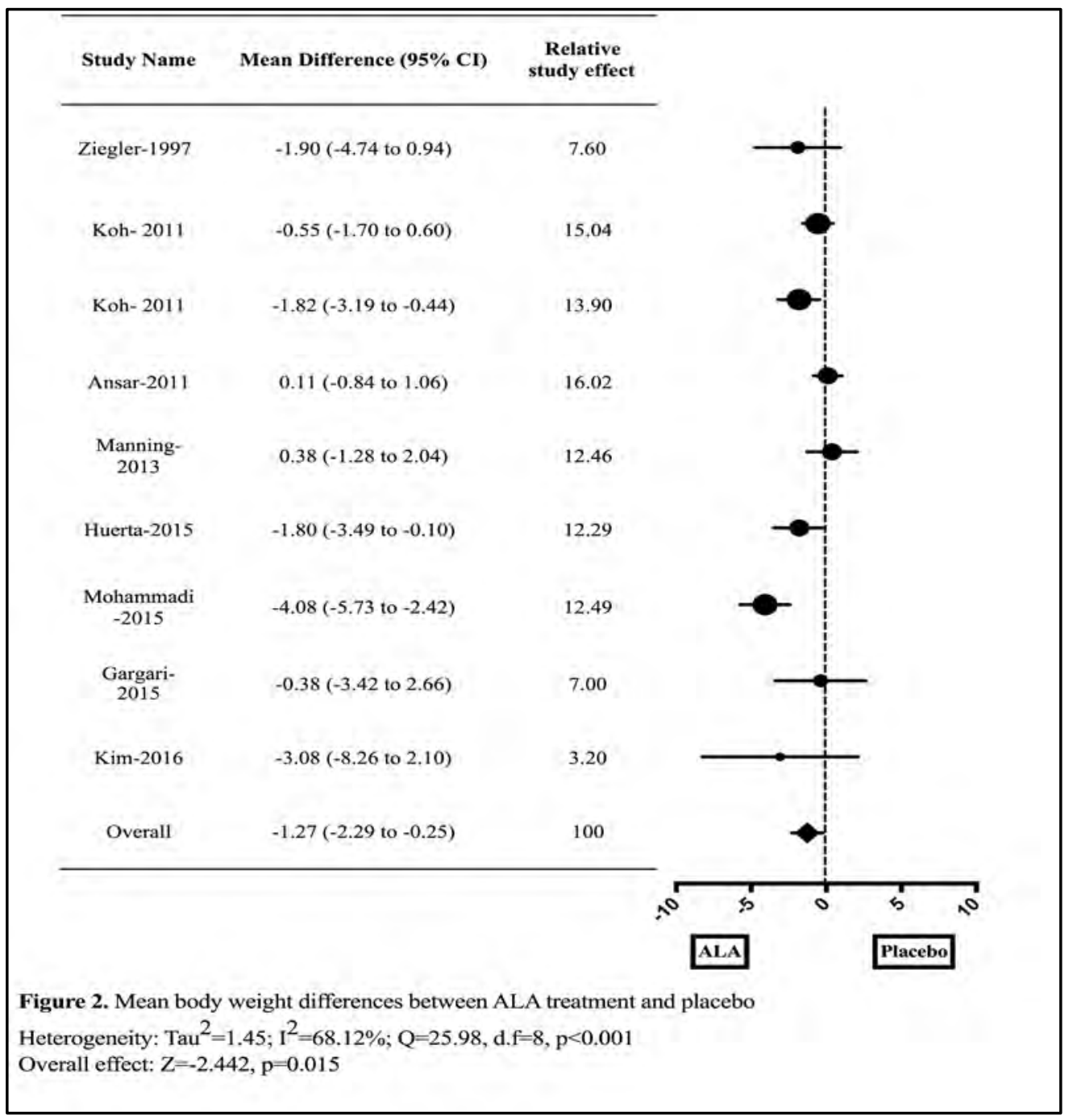




\section{Chapter 4. Alpha-Lipoic Acid for Weight Loss}

\section{BMI Change}

Meta-analysis of BMI changes between ALA and placebo groups is shown in Figure 3. A significant overall mean BMI difference was found -0.40 $\mathrm{kg} / \mathrm{m}^{2}(\mathrm{Cl}=-0.76$ to -0.03$)$ between the ALA and placebo groups. We found no evidence of publication bias in the body weight change analysis (Egger's test intercept $=-0.04, \mathrm{Cl}=-4.87$ to 4.77 ). There was a significant heterogeneity across interventions $\left(I^{2}=73.24\right.$, d.f. $\left.=8, p<0.001\right)$.

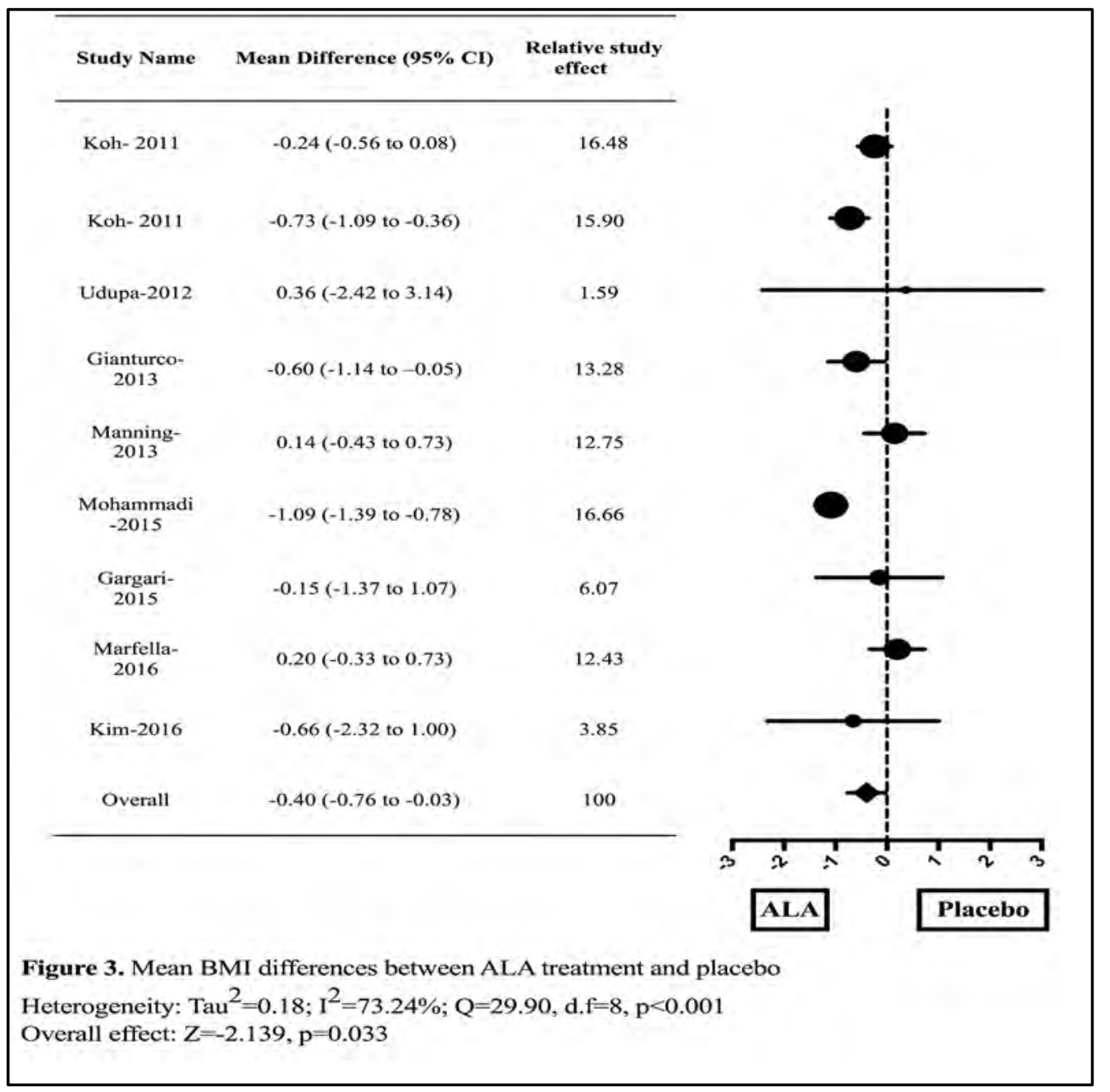




\section{Chapter 4. Alpha-Lipoic Acid for Weight Loss}

Meta-regression analysis showed no significant effect of ALA dose (P.E. $=-0.16, \mathrm{Cl}=-0.48$ to $0.14, \mathrm{p}=0.29$ ) on $\mathrm{BMl}$ change. Intervention duration significantly affects $\mathrm{BMI}$ change (P.E. $=-0.50, \mathrm{Cl}=-0.76$ to $-0.25, \mathrm{p}<0.001)$.

\section{Sub-group analyses}

We employed two separate sub-group analyses to test the effectiveness of ALA in weight loss interventions (Huerta, Navas-Carretero, et al., 2015; Kim et al., 2016; Koh et al., 2011) and in studies with diet intervention (Gianturco et al., 2013; Huerta, Navas-Carretero, et al., 2015; Koh et al., 2011). In the first analysis, we found no significant difference on effectiveness of ALA in weight loss interventions (-1.27, $\mathrm{Cl}=-2.04$ to -0.53$)$ compared to those non-weight loss interventions $(-1.14 \mathrm{Cl}=-2.99$ to 0.69$)$ $(Q=0.01$, d.f. $=1, p=0.90)$. Cumulative analysis of $B M I$ reduction in weight loss interventions $\left(-0.48 \mathrm{~kg} / \mathrm{m}^{2} \mathrm{Cl}=-0.88\right.$ to -0.08$)$ was similar to those non-weight loss interventions $\left(-0.30 \mathrm{~kg} / \mathrm{m}^{2} \mathrm{Cl}=-0.80\right.$ to 0.28$)(\mathrm{Q}=0.23$, d.f. $=1, \mathrm{p}=0.63)$. There was no significant heterogeneity in body weight $(Q=2.95$, d.f. $=3$, $p=0.399)$ and $B M I(Q=2.47$, d.f. $=2, p=0.291)$ analyses in weight loss interventions.

In the second sub-group analysis, we found no significant difference between body weight changes in ALA with diet intervention studies (-1.26 kg, $\mathrm{Cl}=-2.14$ to -0.37$)$ compared to those only ALA intervention studies $(-1.29 \mathrm{~kg}$, $\mathrm{Cl}=-3.03$ to 0.44$)(\mathrm{Q}=0.001$, d.f.=1, $\mathrm{p}=0.97)$. Cumulative analysis of $\mathrm{BMI}$ reduction in ALA with diet interventions $\left(-0.50 \mathrm{~kg} / \mathrm{m}^{2} \mathrm{Cl}=-0.83\right.$ to -0.17$)$ were similar to those ALA without diet interventions $\left(-0.26 \mathrm{~kg} / \mathrm{m}^{2} \mathrm{Cl}=-0.97\right.$ to $0.43)(Q=0.35$, d.f. $=1, p=0.55)$. There was no significant heterogeneity in body weight $(Q=2.47$, d.f. $=2, p=0.290)$ and $B M I(Q=4.09$, d.f. $=2, p=0.129)$ analyses in diet interventions.

\section{Safety}

Only three studies in this meta-analysis reported intervention related side effects and related withdrawal rates (Kim et al., 2016; Koh et al., 2011; 


\section{Chapter 4. Alpha-Lipoic Acid for Weight Loss}

Ziegler et al., 1997). Two of these studies specifically described the types of side effects (Kim et al., 2016; Koh et al., 2011). The most commonly reported side effects that were related with ALA in these two studies were gastrointestinal symptoms, such as abdominal pain and nausea, and dermatological symptoms, such as urticaria and itching sensation. No severe side effects were reported in any of the studies. Cumulative analysis of the percentage of subjects who experienced side effects (O.R. $=1.25, \mathrm{Cl}=0.84$ to $1.85)$ and withdrawal rates due to the side effects (O.R. $=0.43, \mathrm{Cl}=0.19$ to 0.98 ) did not differ among the ALA and placebo groups.

\section{DISCUSSION}

Cumulative results in this meta-analysis showed significant reduction of body weight and BMI with ALA treatment compared to placebo, regardless if it was used for weight loss or other purposes. Meta-regression analyses showed that shorter duration of ALA intervention achieved greater BMI reduction than longer interventions. Incidences of side effects and all-cause discontinuation was similar between ALA and placebo.

Small but significant reduction of body weight with ALA intervention is in line with previous open label (Carbonelli et al., 2010; Ratliff, Palmese, Reutenauer, \& Tek, 2013) and randomized studies (Huerta, Navas-Carretero, et al., 2015; Kim et al., 2016; Koh et al., 2011; Mohammadi et al., 2015). Although there was no indication of publication bias for all outcome measures in our analysis, significant heterogeneity across studies was detected. Possible explanations of this heterogeneity can be the diversity of study samples, as well as study aims. Of these 11 studies, only three were designed as a weight management intervention, which specifically recruited overweight and obese individuals (Huerta, Navas-Carretero, et al., 2015; Kim et al., 2016; Koh et al., 2011). Furthermore, most of the studies included in our analysis were conducted in various samples, including patients with diabetes mellitus, metabolic syndrome, and Takotsubo syndrome (Ansar et al., 2011; Marfella et al., 2016; Udupa et al., 2012; Ziegler et al., 1997). These studies focused 


\section{Chapter 4. Alpha-Lipoic Acid for Weight Loss}

on various effects of ALA intervention, such as anti-inflammatory or antidiabetic effects (Ansar et al., 2011; Marfella et al., 2016; Udupa et al., 2012; Ziegler et al., 1997). On the other hand, previous open label studies have well documented the effectiveness of ALA on weight loss in overweight and obese individuals (Carbonelli et al., 2010; Ratliff et al., 2013). Although, our subgroup analyses revealed no significant differences on body weight and BMI changes with ALA treatment in weight loss and non-weight loss interventions, as well as in diet and non-diet interventions, ALA yielded more robust effects when it is used in weight loss interventions or when it is used in addition to a diet intervention. These results conclude that ALA supplementation with diet intervention may provide more beneficial effects on body weight management in overweight and obese individuals.

Previous studies have suggested that weight reduction from ALA can be time and dose dependent (Kim et al., 2016; Koh et al., 2011). In our analyses, we found that intervention duration, but not ALA dose, significantly related with the reduction of BMI. Studies in our meta-analysis explored various doses of ALA intervention (300 mg/day to $1800 \mathrm{mg} /$ day) on different intervention durations ( 8 weeks to 52 weeks). Only one placebo-controlled study compared the effectiveness of different doses of ALA on body weight (Koh et al., 2011). Koh et al. (Koh et al., 2011) explored the effects of 1200 $\mathrm{mg} /$ day and $1800 \mathrm{mg} /$ day ALA intervention on body weight loss. They found that the higher dose of ALA resulted in significant weight loss and BMI reduction throughout the study compared to placebo. The lower dose of ALA led to significant weight loss in the first weeks of this study, however this effect was not sustainable through the entire duration of the study. From these findings, we can argue that the effect of ALA on body weight is limited to the short term, especially when it is used at lower doses with an adaptation mechanism taking over later. This may have implications for future study designs, for example phasic use of the medication may be tried. 


\section{Chapter 4. Alpha-Lipoic Acid for Weight Loss}

In our meta-analysis, the incidences of side effects were similar between the ALA and placebo treatment arms. Withdrawal rates due to side effects were lower in ALA treated patients than those in the placebo group. ALA has been reported as a well-tolerated supplementation with no serious side effects (Kim et al., 2016; Koh et al., 2011; Ziegler et al., 2006). Although the maximum dose of ALA has not been defined, previous studies have shown that ALA can be used safely up to as high as $1800 \mathrm{mg} /$ day (Koh et al., 2011). Only a small number of studies in our meta-analysis reported the side effect details. Therefore, we were not able to compare the incidences of specific side effects between the ALA and placebo groups.

Given our findings, it is important to note some limitations of this metaanalysis. The number of studies and included patients were small. Furthermore, studies, study populations, and main results in cumulative analyses were heterogeneous. Due to the relatively small number of studies, our meta-regression analyses had limited power. Although there was no evidence of publication bias for all outcome measures on funnel plots and Egger's Tests, the relatively small number of studies also limits the assessment of publication bias.

Finally, in our meta-analysis we were not able to evaluate the effects of ALA on specific compositions of body weight, such as lean mass, fat mass or body water composition. The reason of this limitation is that only one study (Koh et al., 2011) in our meta-analysis reported body fat mass changes measured by impedance meter. In this study treatment with $1800 \mathrm{mg} /$ day ALA resulted more body fat loss compared to the other arms; however, this difference was not significant. On the other hand, previous ALA studies in animals demonstrated significant reductions in body fat mass measured by weighing removed fat mass (Seo, Ha, \& Kim, 2012; Shen, Jones, Kalchayanand, Zhu, \& Du, 2005). Measurement methods of body compositions may explain this discrepancy between human and animal 
studies. Future studies are needed to evaluate the effects of ALA on specific body weight compositions.

In summary, findings from this meta-analysis suggest that ALA may be a useful supplementation for weight loss in overweight and obese individuals. The benefits of ALA compared to placebo appear smaller than that of available prescription weight loss medications (Keith, 2016; Khera et al., 2016; Krentz, Fujioka, \& Hompesch, 2016). However, ALA can be considered in clinical practice due to its benign side-effect profile, other beneficial effects such as in diabetic neuropathy, and low cost comparing to the available weight loss medications. Further research is needed to examine the effect of different doses and the long-term benefits of ALA on weight management.

Potential conflicts of interest: Authors report no competing interests

The study was funded by a grant to me from the U.S. National Institutes of Health (DK093924) 
Table. 1. Included ALA Studies

\begin{tabular}{|c|c|c|c|c|c|c|c|c|c|}
\hline & Study Sample & Diet & $\begin{array}{l}\text { Study } \\
\text { Duration }\end{array}$ & $\begin{array}{c}\text { Study Size } \\
\text { (ALA/ } \\
\text { Control) }\end{array}$ & $\begin{array}{c}\text { Dose (mg } \\
\text { PO QD) }\end{array}$ & $\begin{array}{c}\text { ALA } \\
\text { Weight } \\
\text { Change } \\
\text { (mean } \pm \\
\text { SD) }\end{array}$ & $\begin{array}{c}\text { Control } \\
\text { Weight } \\
\text { Change } \\
\text { (mean } \pm \\
\text { SD) }\end{array}$ & $\begin{array}{c}\text { ALA BMI } \\
\text { Change } \\
\text { (mean } \pm \\
\text { SD) }\end{array}$ & $\begin{array}{c}\text { Control } \\
\text { BMI } \\
\text { Change } \\
\text { (mean } \pm \\
\text { SD) }\end{array}$ \\
\hline $\begin{array}{l}\text { Ansar et al., } \\
2011 \text { (Ansar et } \\
\text { al., 2011) }\end{array}$ & $\begin{array}{c}\text { Patients with } \\
\text { Diabetes Mellitus }\end{array}$ & & 8 weeks & $29 / 28$ & 300 & $\begin{array}{c}-2.08 \pm \\
5.15\end{array}$ & $\begin{array}{c}-1.12 \pm \\
5.87\end{array}$ & & \\
\hline $\begin{array}{l}\text { Gargari et al., } \\
2015 \text { (Gargari et } \\
\text { al., 2015) }\end{array}$ & $\begin{array}{c}\text { Women with } \\
\text { Rheumatoid } \\
\text { Arthritis }\end{array}$ & & 8 weeks & $33 / 32$ & 1200 & $\begin{array}{c}-0.06 \pm \\
6.85\end{array}$ & $\begin{array}{c}0.32 \pm \\
5.59\end{array}$ & $\begin{array}{c}-0.01 \pm \\
2.89\end{array}$ & $\begin{array}{c}0.14 \pm \\
2.08\end{array}$ \\
\hline $\begin{array}{c}\text { Gianturco et al., } \\
2013 \text { (Gianturco } \\
\text { et al., 2013) }\end{array}$ & $\begin{array}{l}\text { Patients with } \\
\text { nonalcoholic fatty } \\
\text { liver disease }\end{array}$ & $\begin{array}{c}\text { Energy } \\
\text { restricted } \\
\text { diet }\end{array}$ & 52 weeks & $52 / 46$ & 400 & & & $-0.3 \pm 1.69$ & $0.3 \pm 0.92$ \\
\hline $\begin{array}{c}\text { Huerta et al., } \\
2015 \text { (Huerta, } \\
\text { Navas- } \\
\text { Carretero, et al., } \\
\text { 2015) }\end{array}$ & $\begin{array}{l}\text { BMI } 27.5 \text { to } 40 \\
\text { women } \\
\text { individuals }\end{array}$ & $\begin{array}{l}\text { Energy } \\
\text { restricted } \\
\text { diet }\end{array}$ & 10 weeks & $20 / 22$ & 300 & $-7 \pm 3.1$ & $-5.2 \pm 2.5$ & & \\
\hline $\begin{array}{c}\text { Kim et al., } 2016 \\
\text { (Kim et al., } \\
\text { 2016) }\end{array}$ & $\begin{array}{c}\text { Patients with } \\
\text { schizophrenia } \\
\text { who gained } \geq \\
10 \% \text { body weight } \\
\text { with antipsychotic } \\
\text { treatment }\end{array}$ & & 12 weeks & $10 / 12$ & $\begin{array}{c}600-1800 \\
\text { as tolerated; } \\
\text { mean } \\
1620.0\end{array}$ & $\begin{array}{c}-1.34 \pm \\
6.48\end{array}$ & $\begin{array}{l}1.74 \pm \\
5.93\end{array}$ & $\begin{array}{c}-0.52 \pm \\
1.99\end{array}$ & $\begin{array}{c}0.14 \pm \\
1.99\end{array}$ \\
\hline $\begin{array}{c}\text { Koh et al., } 2011 \\
\text { (Koh et al., } \\
\text { 2011) }\end{array}$ & $\mathrm{BMI} \geq 27$ & $\begin{array}{c}\text { Calorie- } \\
\text { restricted } \\
\text { diet }\end{array}$ & 20 weeks & $120 / 120$ & 1200 & $\begin{array}{c}-1.49 \pm \\
3.24\end{array}$ & $\begin{array}{c}-0.94 \pm \\
3.84\end{array}$ & $\begin{array}{c}-0.57 \pm \\
1.19\end{array}$ & $\begin{array}{c}-0.33 \pm \\
1.36\end{array}$ \\
\hline $\begin{array}{c}\text { Koh et al., } 2011 \\
\text { (Koh et al., } \\
\text { 2011) }\end{array}$ & $\mathrm{BMI} \geq 27$ & $\begin{array}{c}\text { Calorie- } \\
\text { restricted } \\
\text { diet }\end{array}$ & 20 weeks & $120 / 120$ & 1800 & $\begin{array}{c}-2.76 \pm \\
4.79\end{array}$ & $\begin{array}{c}-0.94 \pm \\
3.84\end{array}$ & $\begin{array}{c}-1.06 \pm \\
1.53\end{array}$ & $\begin{array}{c}-0.33 \pm \\
1.36\end{array}$ \\
\hline
\end{tabular}


Chapter 4. Alpha-Lipoic Acid for Weight Loss

\begin{tabular}{|c|c|c|c|c|c|c|c|c|}
\hline $\begin{array}{l}\text { Manning et al., } \\
2013 \text { (Manning } \\
\text { et al., 2013) }\end{array}$ & $\begin{array}{l}\text { Patients with } \\
\text { metabolic } \\
\text { syndrome }\end{array}$ & 12 months & $34 / 40$ & 600 & $\begin{array}{c}0.33 \pm \\
3.76\end{array}$ & $\begin{array}{c}-0.05 \pm \\
3.53\end{array}$ & $\begin{array}{c}0.15 \pm \\
1.27\end{array}$ & $\begin{array}{c}-0.01 \pm \\
1.29\end{array}$ \\
\hline $\begin{array}{l}\text { Marfella et al., } \\
2016 \text { (Marfella } \\
\text { et al., 2016) } \\
\end{array}$ & $\begin{array}{l}\text { Patients with } \\
\text { Takotsubo } \\
\text { syndrome } \\
\end{array}$ & 12 months & $24 / 24$ & 600 & & & $\begin{array}{c}-0.13 \pm \\
0.89\end{array}$ & $\begin{array}{c}-0.33 \pm \\
0.91\end{array}$ \\
\hline $\begin{array}{l}\text { Mohammadi et } \\
\text { al., 2015 } \\
\text { (Mohammadi et } \\
\text { al., 2015) }\end{array}$ & $\begin{array}{l}\text { Male patients } \\
\text { with chronic } \\
\text { spinal cord injury }\end{array}$ & 12 weeks & $28 / 30$ & 600 & $-3.7 \pm 4.4$ & $0.38 \pm 1.4$ & $-1 \pm 0.6$ & $0.09 \pm 0.6$ \\
\hline $\begin{array}{l}\text { Udupa et al., } \\
2012 \text { (Udupa et } \\
\text { al., 2012) } \\
\end{array}$ & $\begin{array}{c}\text { Patients with } \\
\text { Diabetes Mellitus }\end{array}$ & 90 days & $25 / 25$ & 300 & & & $-0.8 \pm 7.02$ & $\begin{array}{c}-1.16 \pm \\
1.12\end{array}$ \\
\hline $\begin{array}{l}\text { Ziegler et al., } \\
1997 \text { (Ziegler et } \\
\text { al., 1997) } \\
\end{array}$ & $\begin{array}{c}\text { Patients with } \\
\text { Diabetes Mellitus }\end{array}$ & 4 months & $39 / 34$ & 800 & $-1.2 \pm 5.28$ & $0.7 \pm 7.11$ & & \\
\hline
\end{tabular}


References

Abrams, K. R., Gillies, C. L., \& Lambert, P. C. (2005). Meta-analysis of heterogeneously reported trials assessing change from baseline. Stat Med, 24(24), 3823-3844.

Ametov, A. S., Barinov, A., Dyck, P. J., Hermann, R., Kozlova, N., Litchy, W. J., . . . Ziegler, D. (2003). The sensory symptoms of diabetic polyneuropathy are improved with alpha-lipoic acid: the SYDNEY trial. Diabetes Care, 26(3), 770-776.

Ansar, H., Mazloom, Z., Kazemi, F., \& Hejazi, N. (2011). Effect of alphalipoic acid on blood glucose, insulin resistance and glutathione peroxidase of type 2 diabetic patients. Saudi Med J, 32(6), 584588.

Aronne, L. J. (2002). Classification of obesity and assessment of obesityrelated health risks. Obes Res, 10 Suppl 2, 105S-115S.

Bast, A., \& Haenen, G. R. (2003). Lipoic acid: a multifunctional antioxidant. Biofactors, 17(1-4), 207213.

Carbonelli, M. G., Di Renzo, L., Bigioni, M., Di Daniele, N., De Lorenzo, A., \& Fusco, M. A. (2010). Alpha-lipoic acid supplementation: a tool for obesity therapy? Curr Pharm Des, 16(7), 840-846.

Collaboration, T. C. (2011). Handbook for Systematic Reviews of Interventions Version 5.1.0 [updated March 2011]. Available from http://handbook.cochrane.org.

Deneke, S. M. (2000). Thiol-based antioxidants. Curr Top Cell Regul, 36, 151-180.

Diabetes Prevention Program Research, G., Knowler, W. C., Fowler, S. E., Hamman, R. F., Christophi, C. A., Hoffman, H. J., . . . Nathan, D. M. (2009). 10-year followup of diabetes incidence and weight loss in the Diabetes Prevention Program Outcomes Study. Lancet, 374(9702), 1677-1686.

Egger, M., Davey Smith, G., Schneider, M., \& Minder, C. (1997). Bias in meta-analysis detected by a 
simple, graphical test. BMJ, Huerta, A. E., Navas-Carretero, S., 315(7109), 629-634.

Prieto-Hontoria, P. L., Martinez, J. A.,

Evans, J. L., \& Goldfine, I. D. (2000).

\& Moreno-Aliaga, M. J. (2015).

Alpha-lipoic acid: a multifunctional

Effects of alpha-lipoic acid and antioxidant that improves insulin sensitivity in patients with type 2 diabetes. Diabetes Technol Ther, 2(3), 401-413.

Gargari, B. P., Kolahi, S., Dehghan, P., Khabbazi, A., \& Mirtaheri, E. (2015). Effects of Alpha-Lipoic Acid Supplementation on Clinical Status and Anthropometric Indices in Women with Rheumatoid Arthritis. Current Topics in Nutraceutical Research, 13(1), 33-40.

Gianturco, V., Troisi, G., Bellomo, A., Bernardini, S., D'Ottavio, E., Formosa, V., . . . Marigliano, V. (2013). Impact of combined therapy with alpha-lipoic and ursodeoxycolic acid on nonalcoholic fatty liver disease: double-blind, randomized clinical trial of efficacy and safety. Hepatol Int, 7(2), 570-576.

Goldstein, D. J. (1992). Beneficial health effects of modest weight loss. Int J Obes Relat Metab Disord, 16(6), 397-415. eicosapentaenoic acid in overweight and obese women during weight loss. Obesity (Silver Spring), 23(2), 313321.

Huerta, A. E., Prieto-Hontoria, P. L., Fernandez-Galilea, M., Sainz, N., Cuervo, M., Martinez, J. A., \& Moreno-Aliaga, M. J. (2015). Circulating irisin and glucose metabolism in overweight/obese women: effects of alpha-lipoic acid and eicosapentaenoic acid. J Physiol Biochem, 71(3), 547-558.

Keith, J. N. (2016). Pharmacotherapy in Treatment of Obesity. Gastroenterol Clin North Am, 45(4), 663-672.

Khera, R., Murad, M. H., Chandar, A. K., Dulai, P. S., Wang, Z., Prokop, L. J., . . . Singh, S. (2016). Association of Pharmacological Treatments for Obesity With Weight Loss and Adverse Events: A Systematic Review and Meta-analysis. Jama, 315(22), 2424-2434. 
Kim, N. W., Song, Y. M., Kim, E., Manning, P. J., Sutherland, W. H. F., Cho, H. S., Cheon, K. A., Kim, S. J., Williams, S. M., Walker, R. J., Berry, \& Park, J. Y. (2016). Adjunctive E. A., De Jong, S. A., \& Ryalls, A. R. alpha-lipoic acid reduces weight gain (2013). The effect of lipoic acid and compared with placebo at 12 weeks vitamin $\mathrm{E}$ therapies in individuals with in schizophrenic patients treated with the metabolic syndrome. Nutrition atypical antipsychotics: a double- Metabolism and Cardiovascular blind randomized placebo-controlled Diseases, 23(6), 543-549. study. Int Clin Psychopharmacol, 31(5), 265-274.

Marfella, R., Barbieri, M., Sardu, C., Rizzo, M. R., Siniscalchi, M., Knowler, W. C., Barrett-Connor, E., Paolisso, P., . . Paolisso, G. (2016). Fowler, S. E., Hamman, R. F., Effects of alpha-lipoic acid therapy on Lachin, J. M., Walker, E. A., . . . sympathetic heart innervation in Diabetes Prevention Program patients with previous experience of Research, G. (2002). Reduction in transient takotsubo cardiomyopathy. the incidence of type 2 diabetes with J Cardiol, 67(2), 153-161.

lifestyle intervention or metformin. $N$ Engl J Med, 346(6), 393-403.

McNeilly, A. M., Davison, G. W., Murphy, M. H., Nadeem, N., Trinick, Koh, E. H., Lee, W. J., Lee, S. A., T., Duly, E., . . McEneny, J. (2011). Kim, E. H., Cho, E. H., Jeong, E., ... Effect of alpha-lipoic acid and Lee, K. U. (2011). Effects of alpha- exercise training on cardiovascular lipoic Acid on body weight in obese disease risk in obesity with impaired subjects. Am J Med, 124(1), 85.e81- glucose tolerance. Lipids Health Dis, 88. $10,217$.

Krentz, A. J., Fujioka, K., \& Mohammadi, V., Khalili, M., Hompesch, M. (2016). Evolution of Eghtesadi, S., Dehghani, S., pharmacological obesity treatments: Jazayeri, S., Aghababaee, S. K., . . . focus on adverse side-effect profiles. Gohari, M. R. (2015). The effect of Diabetes Obes Metab, 18(6), 558- alpha-lipoic acid (ALA) 570. supplementation on cardiovascular 
risk factors in men with chronic spinal cord injury: a clinical trial. Spinal Cord, 53(8), 646.

Moher, D., Liberati, A., Tetzlaff, J., Altman, D. G., \& Group, P. (2009). Preferred reporting items for systematic reviews and metaanalyses: the PRISMA statement. $J$ Clin Epidemiol, 62(10), 1006-1012.

$\mathrm{Ng}$, M., Fleming, T., Robinson, M., Thomson, B., Graetz, N., Margono, C., . . . Gakidou, E. (2014). Global, regional, and national prevalence of overweight and obesity in children and adults during 1980-2013: a systematic analysis for the Global Burden of Disease Study 2013. Lancet, 384(9945), 766-781.

Packer, L., Kraemer, K., \& Rimbach, G. (2001). Molecular aspects of lipoic acid in the prevention of diabetes complications. Nutrition, 17(10), 888895.

Prieto-Hontoria, P. L., Perez-Matute, P., Fernandez-Galilea, M., Alfredo Martinez, J., \& Moreno-Aliaga, M. J. (2013). Effects of lipoic acid on AMPK and adiponectin in adipose tissue of low- and high-fat-fed rats. Eur J Nutr, 52(2), 779-787.
Prieto-Hontoria, P. L., Perez-Matute, P., Fernandez-Galilea, M., Barber, A., Martinez, J. A., \& Moreno-Aliaga, M. J. (2009). Lipoic acid prevents body weight gain induced by a high fat diet in rats: effects on intestinal sugar transport. J Physiol Biochem, 65(1), 43-50.

Prieto-Hontoria, P. L., Perez-Matute, P., Fernandez-Galilea, M., Martinez, J. A., \& Moreno-Aliaga, M. J. (2011). Lipoic acid inhibits leptin secretion and Sp1 activity in adipocytes. Mol Nutr Food Res, 55(7), 1059-1069.

Ratliff, J. C., Palmese, L. B., Reutenauer, E. L., \& Tek, C. (2013). An open-label pilot trial of alpha-lipoic acid for weight loss in patients with schizophrenia without diabetes. Clin Schizophr Relat Psychoses, 1-13.

Seo, E. Y., Ha, A. W., \& Kim, W. K. (2012). alpha-Lipoic acid reduced weight gain and improved the lipid profile in rats fed with high fat diet. Nutr Res Pract, 6(3), 195-200.

Shen, Q. W., Jones, C. S., Kalchayanand, N., Zhu, M. J., \& Du, M. (2005). Effect of dietary alphalipoic acid on growth, body composition, muscle $\mathrm{pH}$, and AMP- 


\section{Chapter 4. Alpha-Lipoic Acid for Weight Loss}

activated protein kinase polyneuropathy: the SYDNEY 2 trial. phosphorylation in mice. J Anim Sci, Diabetes Care, 29(11), 2365-2370. 83(11), 2611-2617.

Ziegler, D., Hanefeld, M., Ruhnau, K. Udupa, A. S., Nahar, P. S., Shah, S. J., Hasche, H., Lobisch, M., Schutte, H., Kshirsagar, M. J., \& Ghongane, B. K., . . Malessa, R. (1999). Treatment B. (2012). Study of comparative of symptomatic diabetic effects of antioxidants on insulin polyneuropathy with the antioxidant sensitivity in type 2 diabetes mellitus. alpha-lipoic acid: a 7-month J Clin Diagn Res, 6(9), 1469-1473. multicenter randomized controlled Wang, Y., Li, X., Guo, Y., Chan, L., \& Guan, X. (2010). alpha-Lipoic acid increases energy expenditure by enhancing adenosine trial (ALADIN III Study). ALADIN III Study Group. Alpha-Lipoic Acid in Diabetic Neuropathy. Diabetes Care, 22(8), 1296-1301.

monophosphate-activated protein

Ziegler, D., Nowak, H., Kempler, P., kinase-peroxisome proliferator- Vargha, P., \& Low, P. A. (2004). activated receptor-gamma coactivator-1alpha signaling in the skeletal muscle of aged mice. Metabolism, 59(7), 967-976.

Treatment of symptomatic diabetic polyneuropathy with the antioxidant alpha-lipoic acid: a meta-analysis. Diabet Med, 21(2), 114-121.

Ziegler, D. (2004). Thioctic acid for patients with symptomatic diabetic polyneuropathy: a critical review. Treat Endocrinol, 3(3), 173-189.

Ziegler, D., Ametov, A., Barinov, A., Dyck, P. J., Gurieva, I., Low, P. A., . . - Samigullin, R. (2006). Oral treatment with alpha-lipoic acid improves symptomatic diabetic

Ziegler, D., Schatz, H., Conrad, F., Gries, F. A., Ulrich, H., \& Reichel, G. (1997). Effects of treatment with the antioxidant alpha-lipoic acid on cardiac autonomic neuropathy in NIDDM patients. A 4-month randomized controlled multicenter trial (DEKAN Study). Deutsche Kardiale Autonome Neuropathie. Diabetes Care, 20(3), 369-373. 
Chapter 4. Alpha-Lipoic Acid for Weight Loss 


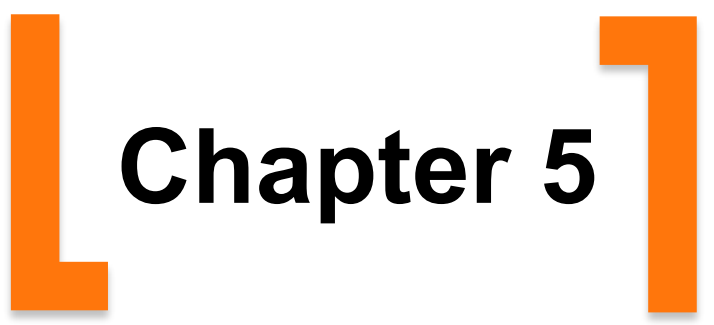


Antipsychotic-exposure in pregnancy and the risk of gestational diabetes: A Systematic Review and Meta-Analysis

Suat Kucukgoncu, Sinan Guloksuz, Kubra Celik, Mert Ozan Bahtiyar, Jurjen J. Luykx, Bart P. F. Rutten, Cenk Tek

Schizophr Bull. 2019; 46:311-318. pii: sbz058. doi: 10.1093/schbul/sbz058 


\section{Chapter 5. Antipsychotic Exposure and Gestational Diabetes}

Background: We have limited knowledge about the effects of antipsychotic exposure on the development of gestational diabetes (GDM). Aim of this study is to perform a systematic review and meta-analysis to assess GDM risk associated with antipsychotic-exposure in pregnancy.

Methods: Systematic literature search was performed using PubMed, Science Direct, Scopus and Web of Science databases up to August 22, 2018. No restrictions to language or date were applied. Randomized, controlled trials, case-control or cohort studies reporting GDM risk in antipsychotic-exposed, healthy controls or antipsychotic-ceased patients were included in the meta-analysis. The primary outcomes were study defined GDM, including number of events, odds ratios (OR) and/or risk ratios $(R R)$ with confidence intervals.

Results: Ten studies were included in the meta-analysis. The total number of subjects were 6,213 for the antipsychotic-exposed group, 6,836 for antipsychotic-ceased control group and 1,677,087 for the healthy control group. Compared to the healthy controls, the unadjusted cumulative RR for GDM associated with antipsychotic use was 1.63 (95\% $\mathrm{Cl}=1.20-2.22)$. Adjusted risk for GDM was significantly higher in antipsychotic exposure group than healthy controls ( $R R=1.30,95 \% \mathrm{Cl}=1.023-1.660)$. The adjusted $\mathrm{RR}$ for GDM was similar between the antipsychotic-exposed group and the antipsychotic-ceased group ( $\mathrm{RR}=0.78,95 \% \mathrm{Cl}=0.281-2.164)$. No significant association was found between study quality, smoking, alcohol use, gestational age and cumulative GDM risk.

Discussion: Our results indicate an increased risk of GDM with antipsychotic-exposure in pregnant women, who may benefit from close pregnancy monitoring, early testing for GDM, targeting modifiable risk factors and life-style modifications.

Key-words: Antipsychotic, gestational diabetes, pregnancy 


\section{Chapter 5. Antipsychotic Exposure and Gestational Diabetes}

\section{Introduction}

Gestational diabetes mellitus (GDM) is a common complication of pregnancy, defined as glucose intolerance with onset or first recognition during pregnancy.(Buchanan, Xiang, Kjos, \& Watanabe, 2007) The increasing prevalence of GDM is a growing public health concern.(DeSisto, Kim, \& Sharma, 2014) GDM is associated with several maternal and fetal adverse health consequences, including, macrosomia, gestational hypertension, preeclampsia, neonatal hypoglycemia, and development of diabetes mellitus and serious mental illnesses (SMI) later in life. (Bellamy, Casas, Hingorani, \& Williams, 2009; Buchanan et al., 2007; Shepherd et al., 2017; Van Lieshout \& Voruganti, 2008)

Some of the well-known risk factors for GDM are older maternal age, family history of diabetes mellitus, and obesity.(Buchanan et al., 2007; Ferrara, 2007) In addition to these risk factors, women with SMI, namely psychotic spectrum disorders, bipolar disorder and depression, form a unique and high-risk population for GDM development. First expression of SMI often occurs during young adulthood, i.e. at women's childbearing years (Kulkarni et al., 2014; Park et al., 2018), and over 50 percent of women with SMI become pregnant during their lives.(Coughlin et al., 2015; McCauley-Elsom, Gurvich, Elsom, \& Kulkarni, 2010)

Recent findings indicate that patients with SMI may have an innate vulnerability to insulin resistance and glucose imbalance.(Clemente GarciaRizo et al., 2013; C. Garcia-Rizo, Kirkpatrick, Fernandez-Egea, Oliveira, \& Bernardo, 2016; Greenhalgh et al., 2017; Guha et al., 2014; Perry, McIntosh, Weich, Singh, \& Rees, 2016; Pillinger et al., 2017) Research from treatmentnaïve first episode patients with SMI have shown higher insulin resistance, fasting insulin and glucose levels, and increased rates of diabetes mellitus compared to healthy controls.(Garcia-Rizo et al., 2013; Garcia-Rizo et al., 2016; Guha et al., 2014; Perry et al., 2016; Pillinger et al., 2017) Evidence has indicated that pregnancy itself reduces insulin sensitivity, most likely 


\section{Chapter 5. Antipsychotic Exposure and Gestational Diabetes}

related to placental hormones. This is overcome by increased insulin levels.(Buchanan et al., 2007) However, the combination of metabolic changes in pregnancy and risk factors, such as obesity before pregnancy, render women with SMI prone to develop GDM.(Buchanan et al., 2007; Ferrara, 2007)

The management of SMI during pregnancy and the postpartum period poses significant challenges to mothers, infants, and clinicians.(Kulkarni et al., 2014; Park et al., 2018) Key in the management in SMI is adequate dosing of antipsychotic medication during active and remission phases of the illness. Discontinuation of antipsychotic treatment leaves women with SMI at high risk of relapse during pregnancy and postpartum period.(Howard, Goss, Leese, Appleby, \& Thornicroft, 2004; Jones, Chandra, Dazzan, \& Howard, 2014; Kulkarni et al., 2008; Kulkarni et al., 2015) Anticipation to the risk of relapse and related dire outcomes have led to an increase in antipsychotic medication use in pregnancy.(Toh et al., 2013; Whitworth, 2017) However, antipsychotic medications can cause metabolic side effects including weight gain, insulin resistance, and diabetes mellitus. (Annamalai, Kosir, \& Tek, 2017; Tek et al., 2016)

A small number of studies and case reports evaluating the relationship between antipsychotic exposure during pregnancy and GDM have revealed inconsistent results.(Bellet et al., 2015; Boden, Lundgren, Brandt, Reutfors, \& Kieler, 2012; Galbally, Frayne, Watson, \& Snellen, 2018; McKenna et al., 2005; Panchaud et al., 2017; Park et al., 2018; Petersen et al., 2016; Reis \& Kallen, 2008; Sadowski, Todorow, Yazdani Brojeni, Koren, \& Nulman, 2013; Vigod, Gomes, Wilton, Taylor, \& Ray, 2015) Several studies have found that antipsychotic exposure during pregnancy is associated with development of GDM.(Boden et al., 2012; Park et al., 2018; Reis \& Kallen, 2008; Vigod et al., 2015) Antipsychotic exposure during pregnancy is reported to increase the risk of GDM development between 1.78 to 2.44 folds.(Boden et al., 2012; Reis \& Kallen, 2008) Conversely, some studies reported no 


\section{Chapter 5. Antipsychotic Exposure and Gestational Diabetes}

increase in risk of GDM development with antipsychotic exposure. (Bellet et al., 2015; McKenna et al., 2005; Panchaud et al., 2017; Sadowski et al., 2013)

In addition to SMI, antipsychotic medications are also being used in other psychiatric disorders for symptom management.(McKenna et al., 2005) Use of antipsychotic medications during pregnancy has increased from 3 per 1000 pregnancies in 2001 to 8 per 1000 pregnancies in 2007.(Toh et al., 2013; Vigod et al., 2015) Despite the increase in antipsychotic medication use in pregnancy, we still have limited information about the effects of antipsychotic exposure on the development of GDM.(Kulkarni et al., 2014) Previous research yielded inconsistent results and to date, no meta-analysis has been investigated the antipsychotic-exposure related risk of GDM development. Since antipsychotic treatment-related adverse effects may increase the risk of deleterious health outcomes for mother and infant, it is critical to understand the risk of developing GDM with these types of medications. The aim of this study is to conduct a systematic review and meta-analysis of existing literature to investigate the risk of developing GDM in pregnant patients treated with antipsychotic medication.

\section{Methods}

\section{Search strategy}

A systematic search was performed to find relevant articles through August 22, 2018. The following databases were searched for title, abstract and index terms of reference: PubMed, Science Direct, Scopus and Web of Science. Additionally, a manual search was carried out to identify relevant references by verifying references in retrieved articles, related review articles and meta-analyses. Two reviewers (SK and KC) independently conducted the literature search using the following MESH and free-text search terms: Antipsychotic, major tranquilizers, tranquilizing agents, neuroleptic medications, pregnancy, gestation, gestational diabetes, side-effects, insulin, insulin resistance, glucose, metabolic disturbances and diabetes. 


\section{Chapter 5. Antipsychotic Exposure and Gestational Diabetes}

\section{Selection criteria}

The following inclusion criteria were applied: (i) only randomized, controlled trials, case-control or cohort studies that included an antipsychoticexposed and non-exposed group during pregnancy were allowed; (ii) studies had to report antipsychotic-exposure during pregnancy and (iii) on gestational diabetes outcomes; (iv) and we limited findings to human research. This meta-analysis was conducted and reported according to the PRISMA (Preferred Reporting Items of Systematic Reviews and Meta-analysis) guidelines (Supplementary Table 1). (Moher, Liberati, Tetzlaff, Altman, \& Group, 2009) The quality of the cohort and case-control studies was peerreviewed using the Newcastle-Ottawa Scale (NOS). (Wells, 2009)

\section{Data Extraction}

Two reviewers (SK and $\mathrm{KC}$ ) independently extracted all data. After data extraction, a third reviewer (CT) checked all extracted data to clarify missing data. Any conflicts were discussed with the third reviewer (CT). The following data were extracted: study design, sample size, data source, gestational diabetes outcomes including number of events, odds ratios (OR) and/or risk ratios $(\mathrm{RR})$ with confidence intervals. To obtain any missing information, we contacted the authors to request relevant data. Outcomes of overlapping samples were extracted from the more detailed report.

\section{Statistical Analysis}

We examined the differences on GDM outcomes between antipsychotic-exposed and healthy controls; and antipsychotic-exposed and antipsychotic-ceased groups by calculating unadjusted and adjusted RR estimates using the software Comprehensive Meta-Analysis Version 2 (Biostat, Englewood, NJ, USA). Statistical heterogeneity was assessed using $Q$ and I-square test, in which I-square $\geq 50 \%$ was considered to indicate heterogeneity. When heterogeneity was present between studies, the antipsychotic-exposure period was examined. We examined the effects of 


\section{Chapter 5. Antipsychotic Exposure and Gestational Diabetes}

early antipsychotic-exposure (first and/or second-trimester exposure) and anytime antipsychotic-exposure on GDM outcomes by grouping the studies reporting outcomes during the relevant time of pregnancy. Publication bias was assessed with Egger's regression test.(Egger, Davey Smith, Schneider, \& Minder, 1997) A random-effects model was used due to the methodological and sampling differences between studies. The results for a fixed-effects model were also presented as a sensitivity analysis. We performed metaregression analyses to examine the relationship between study quality (NOS), smoking and alcohol use rates, gestational age and unadjusted GDM outcomes. Statistical significance was defined as $p<0.05$.

\section{Results}

Our search resulted in a total of 737 articles, and 651 studies were excluded based on the title and/or abstract as they did not deal with the topic under study here. Of the remaining 86 articles, 76 were excluded after fulltext review because they did not fulfill inclusion criteria, resulting in ten eligible studies for inclusion in this meta-analysis (Figure 1, eTable 2-3). (Bellet et al., 2015; Boden et al., 2012; Galbally et al., 2018; McKenna et al., 2005; Panchaud et al., 2017; Park et al., 2018; Petersen et al., 2016; Reis \& Kallen, 2008; Sadowski et al., 2013; Vigod et al., 2015) Of those, six studies (Boden et al., 2012; Galbally et al., 2018; Park et al., 2018; Petersen et al., 2016; Reis \& Kallen, 2008; Vigod et al., 2015) were retrospective database investigation and four studies were prospective cohort investigation.(Bellet et al., 2015; McKenna et al., 2005; Panchaud et al., 2017; Sadowski et al., 2013) Eight of them studies compared antipsychotic exposed group with healthy controls.(Bellet et al., 2015; Boden et al., 2012; McKenna et al., 2005; Panchaud et al., 2017; Petersen et al., 2016; Reis \& Kallen, 2008; Sadowski et al., 2013; Vigod et al., 2015) Three studies had an antipsychotic ceased group as a control group.(Galbally et al., 2018; Park et al., 2018; Petersen et al., 2016) The total number of subjects were 6,213 for the antipsychoticexposed group, 6,836 for antipsychotic-ceased control group and 1,677,087 
for the healthy control group. The study quality was high overall, with scores between 6 and 9 on the NOS (eTable 2). The mean (SD) NOS score was 8.3 (1.06), and the median NOS score was 9 .

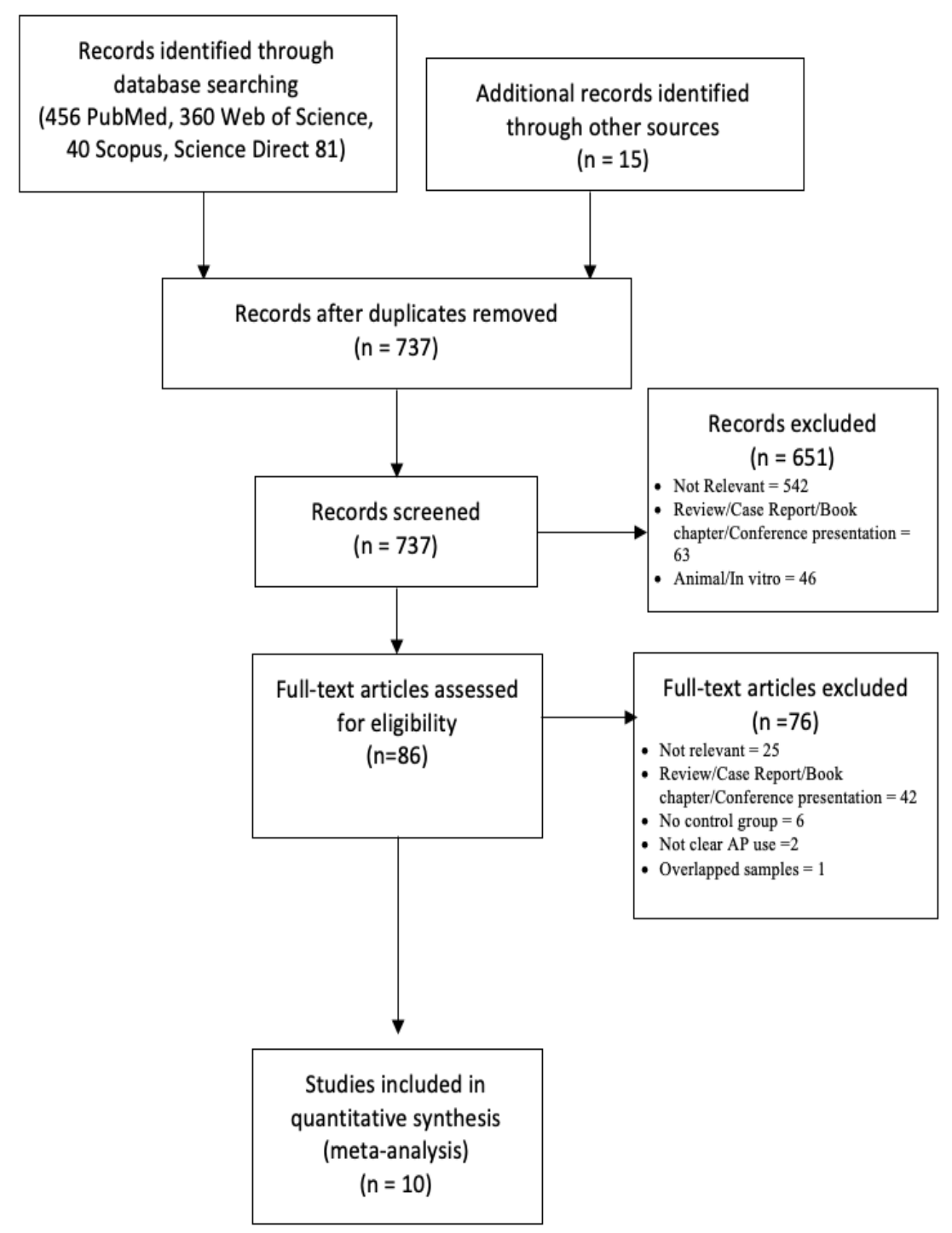

Figure 1. PRISMA Flow Diagram 


\section{Chapter 5. Antipsychotic Exposure and Gestational Diabetes}

\section{Outcome Definitions}

The time of antipsychotic exposure in the included studies was defined as: either at least one exposure during first trimester (Bellet et al., 2015; Galbally et al., 2018; McKenna et al., 2005; Panchaud et al., 2017; Reis \& Kallen, 2008); or as at least one exposure during first or second trimester (Park et al., 2018; Petersen et al., 2016; Vigod et al., 2015); or as exposure any time during pregnancy.(Boden et al., 2012; Sadowski et al., 2013)

All included studies provided general information about antipsychotic treatment class. Most studies investigated more than one antipsychotic classified as second-generation antipsychotic (SGAs), such as clozapine, olanzapine, risperidone.(McKenna et al., 2005; Panchaud et al., 2017; Park et al., 2018; Sadowski et al., 2013) Some studies investigated both SGAs and first-generation antipsychotics (FGAs) medication exposure.(Boden et al., 2012; Petersen et al., 2016; Reis \& Kallen, 2008; Vigod et al., 2015) A few studies investigated only one specific antipsychotic exposure during pregnancy.(Bellet et al., 2015; Galbally et al., 2018)

\section{GDM in antipsychotic-exposed group vs healthy controls}

In our overall meta-analysis, the crude risk for developing GDM in the antipsychotic exposure group was significantly higher than in healthy controls. Compared to the healthy controls, the unadjusted cumulative risk ratio for GDM associated with antipsychotic use was $1.63(95 \% \mathrm{Cl}=1.20-2.22, \mathrm{p}=0.02)$ (Figure 2). No evidence of publication bias was found for antipsychoticexposed and health control comparison (Egger's test $=0.805, \mathrm{Cl}=-1.75$ to 3.36). There was significant heterogeneity on the unadjusted risk for GDM outcomes across the studies included in this analysis $\left(I^{2}=59.64, d . f=7\right.$, $p=0.01)$. 


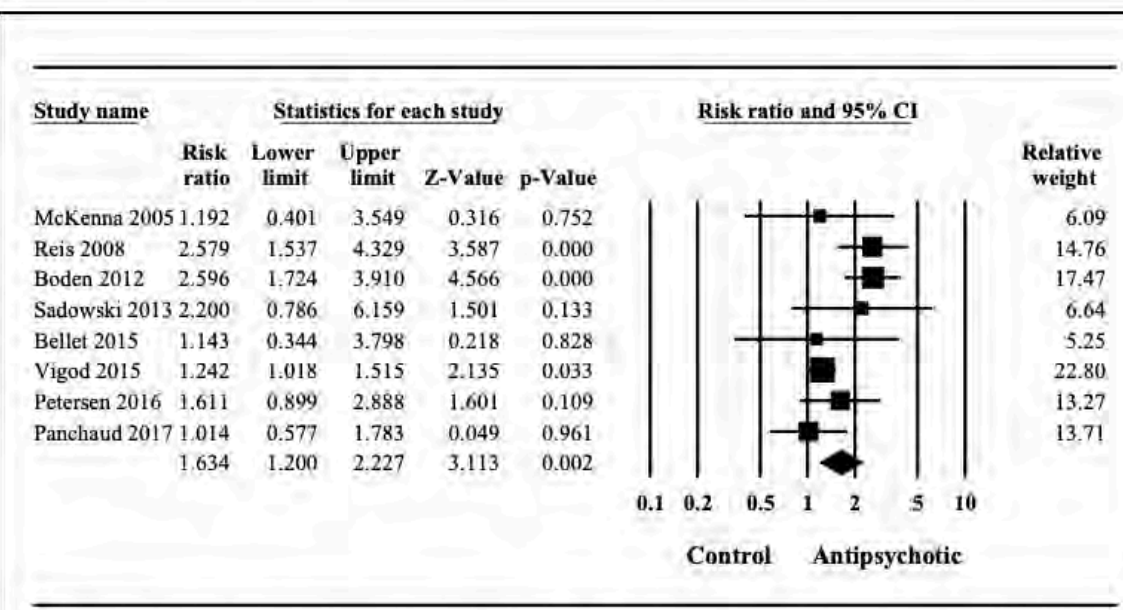

Figure 2. Meta-analysis of unadjusted GDM risk between antipsychotic users and healthy controls Heterogeneity: $\mathrm{Tau}^{2}=0.09 ; \mathrm{I}^{2}=59.64 \% ; \mathrm{Q}=17.34$, d. $\mathrm{f}=7, \mathrm{p}=0.015$

Overall effect (Fixed): $1.48(95 \% \mathrm{CI}=1.27$ to 1.72$), \mathrm{Z}=5.089, \mathrm{p}<0.001$

Four studies reported adjusted differences between antipsychotic exposure individuals and healthy controls.(Boden et al., 2012; Petersen et al., 2016; Reis \& Kallen, 2008; Vigod et al., 2015) The adjusted risk for GDM was significantly higher in antipsychotic exposure group than healthy controls (Estimated $\mathrm{RR}=1.30,95 \% \mathrm{Cl}=1.023$ to $1.660, \mathrm{p}=0.032$ ) (Figure 3 ). There was no significant heterogeneity in RRs across three studies $\left(I^{2}=14.37\right.$, d. $f=3$, $\mathrm{p}=0.32$ ). 


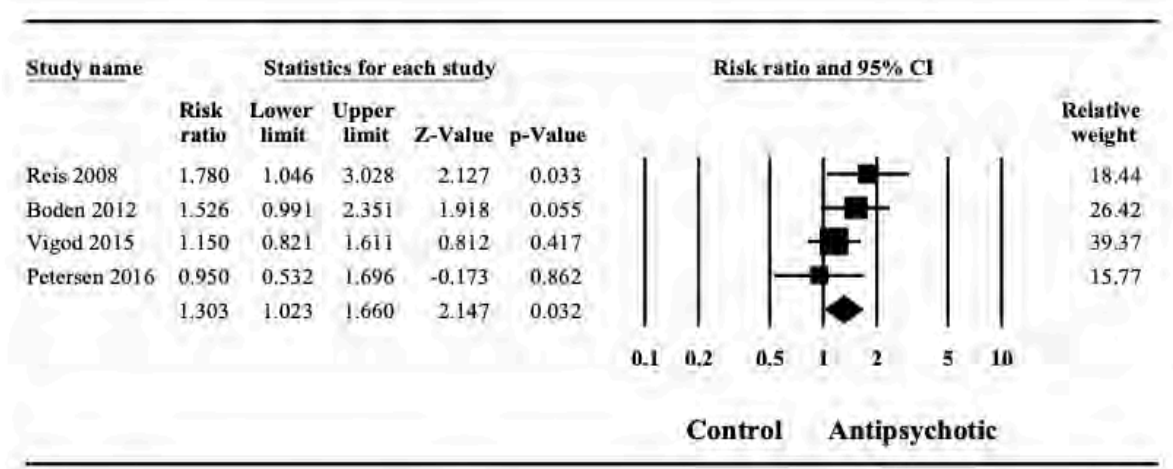

Figure 3. Meta-analysis of adjusted GDM risk between antipsychotic users and healthy controls Heterogeneity: Tau $^{2}=0.009 ; \mathrm{I}^{2}=14.37 \% ; \mathrm{Q}=3.504, \mathrm{~d} . \mathrm{f}=3, \mathrm{p}=0.32$

Overall effect-Fixed: $1.29(95 \% \mathrm{Cl}=1.04$ to 1.61$), \mathrm{Z}=2.321, \mathrm{p}=0.02$

We tested the effect of reported antipsychotic-exposure period (early exposure vs anytime exposure during pregnancy) across studies. Six studies reported outcomes from patients who had been exposed to antipsychotics during early pregnancy (at least once in the first and/or secondtrimester).(Bellet et al., 2015; McKenna et al., 2005; Panchaud et al., 2017; Petersen et al., 2016; Reis \& Kallen, 2008; Vigod et al., 2015) The antipsychotic-exposure period in the remaining two studies (Boden et al., 2012; Sadowski et al., 2013) was specified as anytime during pregnancy. Compared to the healthy controls, the unadjusted RR estimate for GDM in patients with early antipsychotic-exposure (Estimated $\mathrm{RR}=1.42,95 \% \mathrm{Cl}=$ 1.07 to $1.89, p=0.015$ ) and anytime antipsychotic-exposure (Estimated $R R=2.533,95 \% \mathrm{Cl}=1.73$ to $3.71, p<0.001$ ) was significantly higher. There was no significant heterogeneity in RR estimates of GDM risk in early antipsychotic-exposure and anytime antipsychotic-exposure groups (eFigure 1). 


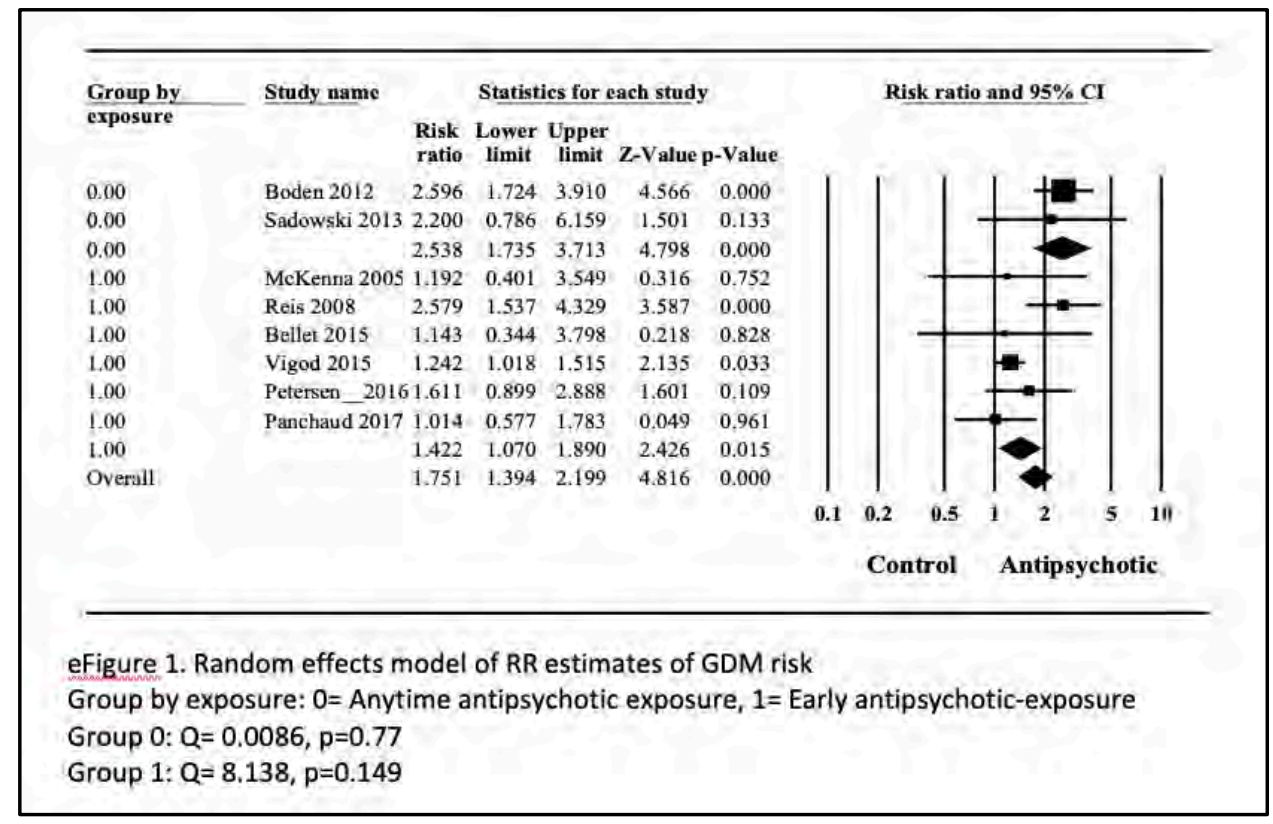

GDM in antipsychotic-exposed group vs antipsychotic-ceased group

We identified seven outcomes from three studies that examined the risk of GDM in the antipsychotic-exposed and the antipsychotic-ceased patients.(Galbally et al., 2018; Park et al., 2018; Petersen et al., 2016) The unadjusted RR estimate for GDM was significantly higher in the antipsychoticexposed group compared to the antipsychotic-ceased group (Estimated RR= $1.55,95 \% \mathrm{Cl}=1.187$ to $2.034, \mathrm{p}=0.001$ ) (eFigure 2). Only two studies (Park et al., 2018; Petersen et al., 2016) reported adjusted risk of GDM in the antipsychotic-exposed and the antipsychotic-ceased patients. The adjusted RR estimate for GDM was similar between the antipsychotic-exposed group and the antipsychotic-ceased group (Estimated $\mathrm{RR}=0.78,95 \% \mathrm{Cl}=0.28$ to 2.16, $p=0.633$ ) (Figure 4). Significant heterogeneity was detected on RRs across outcomes $\left(I^{2}=85.43\right.$, d. $\left.f=1, p=0.009\right)$. 


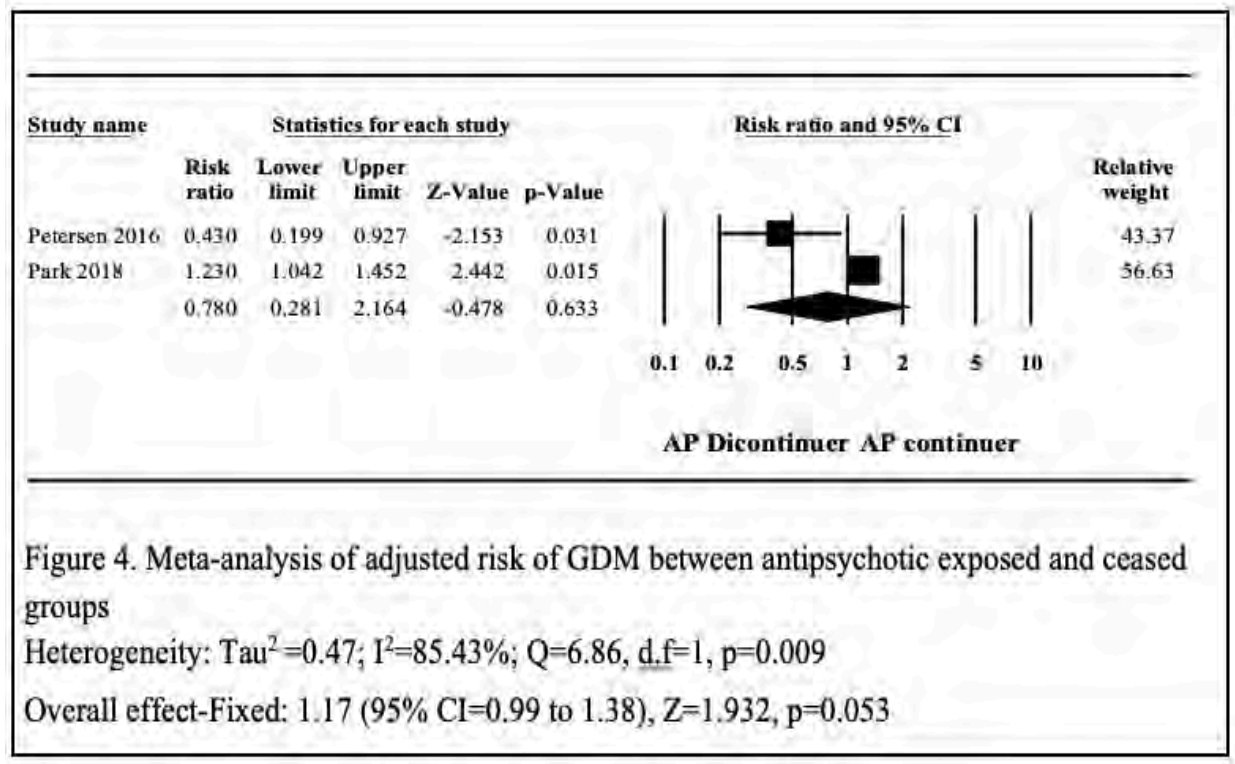

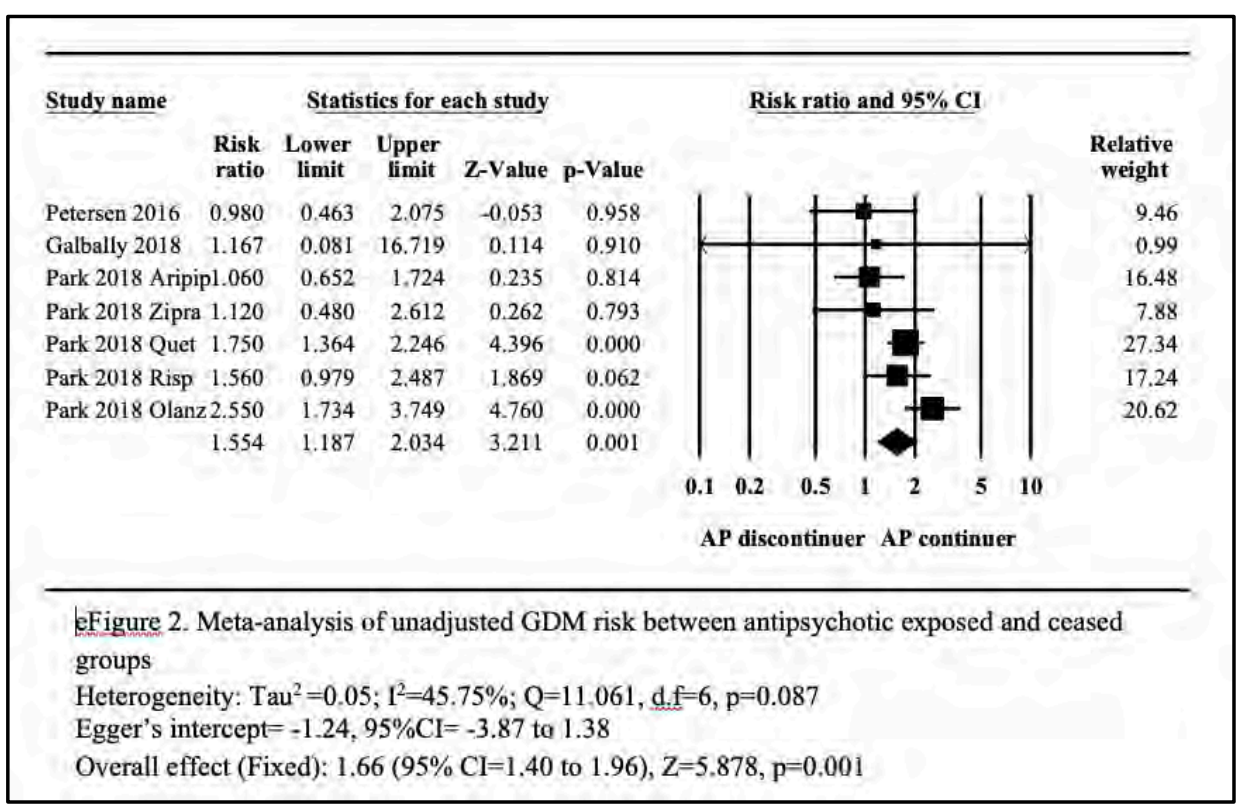




\section{Chapter 5. Antipsychotic Exposure and Gestational Diabetes}

Meta-regression

In meta-regression analyses no significant association was found between study quality (measured with NOS), smoking and alcohol use rates, gestational age and cumulative crude GDM risk (eTable 4).

eTable 4. Meta-regression results
\begin{tabular}{|l|c|c|c|c|}
\hline \hline Predictor & Point estimate & $95 \% \mathrm{CI}$ & $\mathrm{Z}$ & $\mathrm{p}$ \\
\hline NOS & -0.03 & -0.43 to 0.36 & -0.16 & 0.86 \\
\hline Smoking & 0.01 & -0.01 to 0.05 & 1.08 & 0.27 \\
\hline Alcohol & -0.02 & -0.07 to 0.01 & -1.27 & 0.20 \\
\hline Gestational age & 0.009 & -0.10 to 0.12 & 0.15 & 0.87 \\
\hline
\end{tabular}

NOS: Newcastle-Ottawa Scule score

\section{Discussion}

This meta-analysis of GDM risk in antipsychotic-exposed pregnant women indicates that the unadjusted, cumulative risk of GDM was 1.6-fold higher compared with healthy women. Compared to healthy controls, the adjusted risk of GDM was 1.3 in antipsychotic-exposed patients. The adjusted risk of GDM was similar between antipsychotic-exposed pregnant women and antipsychotic-ceased controls diagnosed with SMI.

Overall, unadjusted and adjusted results from our meta-analyses are in line with previous cohort studies and systematic reviews, which suggest an increase in risk of GDM with antipsychotic exposure during pregnancy. (Boden et al., 2012; Park et al., 2018; Reis \& Kallen, 2008; Vigod et al., 2015) Although alterations in glucose metabolism are a part of the natural course of pregnancy, increased risk of developing GDM with antipsychotic treatment can be explained by the nature of SMI and antipsychotic medication-related adverse effects. For example, recent meta-analyses have shown that having an SMI already increases risk for glucose metabolism impairments even before introducing antipsychotic medications. (Kucukgoncu et al., 2018; Perry et al., 2016; Pillinger et al., 2017) Although the exact mechanism has not been fully unraveled yet, research suggests that alterations in systemic inflammation and shared genetic liability may underlie associations between 


\section{Chapter 5. Antipsychotic Exposure and Gestational Diabetes}

SMI and glucose metabolism disturbances (Kucukgoncu et al., 2018), and may also contribute to the risk of developing GDM in pregnant patients with SMI. Additionally, early environmental factors can explain the part of the relationship between SMI and GDM. As suggested by the 'thrifty psychiatric phenotype' concept an epigenetic pathway initiated during gestation may interact with genetic programing and lead to SMIs and glucose metabolism disturbances in adulthood.

Our findings show significant heterogeneity across studies evaluating the unadjusted risk of GDM between antipsychotic-exposed and healthy pregnant women. A number of limitations pertinent to the studies and possible confounders can (at least in part) explain this heterogeneity. First, only a few studies reported adjusted of GDM between antipsychotic-exposed and healthy pregnant women. (Boden et al., 2012; Petersen et al., 2016; Reis \& Kallen, 2008) However, GDM development was associated with various risk factors, including maternal age, family history of diabetes mellitus, obesity, smoking and care during pregnancy term.(Buchanan et al., 2007; Ferrara, 2007) For instance, women treated with antipsychotic medications before pregnancy appear to be more overweight or obese when they became pregnant.(Kulkarni et al., 2015) Hence, advanced pre-pregnancy body weight is one of the well-known risk factors for GDM development. (Buchanan et al., 2007; Ferrara, 2007) However, our meta-regression results did not reveal any significant relationship between the risk of GDM and smoking, alcohol use rates and gestational age. Adjusted results from limited number of studies (Boden et al., 2012; Petersen et al., 2016; Reis \& Kallen, 2008; Vigod et al., 2015) indicate that pre-pregnancy confounding factors (e.g. BMI levels, smoking, additional medication use) may contribute to the risk of GDM development. Although the risk of GDM development was still significant in antipsychotic users after adjustments, considerable attenuation on the risk ratio suggests that controlling pre-pregnancy confounders in this patient population may help to prevent GDM development during pregnancy. 


\section{Chapter 5. Antipsychotic Exposure and Gestational Diabetes}

While the unadjusted outcomes show lower risk, cumulative results from adjusted outcomes suggest that cessation of antipsychotic medications during pregnancy may not affect the risk of GDM development in pregnant women with SMI. However, these findings are based on a very limited number of studies. From the outcomes provided by Park et al. (Park et al., 2018), it should be noted that continued use of particular antipsychotic medications (olanzapine $R R=1.61$; quetiapine $R R=1.28$ ) may increase the risk of GDM development. This relationship, as Park et al. noted, may be related with metabolic adverse-effect profiles of the specific antipsychotic medications. Antipsychotic medication-related adverse effects, particularly weight gain and alterations in glucose utilization, usually worsen glucose metabolism impairment and contribute to the development of diabetes in patients with SMI. (Kucukgoncu et al., 2018; Kulkarni et al., 2015; Zhang et al., 2017) Since different antipsychotic medications have varying metabolic profiles, it may be beneficial to switch to another antipsychotic medication with better metabolic adverse-effect profile.(Tek et al., 2016) This meta-analysis, however, does not answer this question. Excess body weight gain related to antipsychotic treatment in pregnancy most likely contributes to the development of GDM. (Kulkarni et al., 2015) While tapering antipsychotic treatment during pregnancy may decrease body weight gain, and decrease the risk of GDM development, it should be noted that this can also incur exacerbations in psychiatric symptoms, sometimes resulting in harm for the mother and even the baby. (Howard et al., 2004; Jones et al., 2014; Kulkarni et al., 2008; Kulkarni et al., 2015) Therefore, a careful review of individual patient related factors and shared clinical decision making on a case by case basis is crucial in managing GDM risk among antipsychotic users.

An important limitation of current literature is the lack of antipsychotic specific reports. While most studies included in this meta-analysis reported cumulative outcomes from SGAs and/or FGAs, (Boden et al., 2012; McKenna et al., 2005; Panchaud et al., 2017; Petersen et al., 2016; Reis \& Kallen, 2008; Sadowski et al., 2013) only a handful reported on antipsychotic-specific GDM 


\section{Chapter 5. Antipsychotic Exposure and Gestational Diabetes}

risks. (Bellet et al., 2015; Galbally et al., 2018; Park et al., 2018; Vigod et al., 2015) Furthermore, studies also reported that included patients were on more than one class of psychotropic medications, such as antidepressants or anxiolytics. Current literature on the risk of GDM development with antidepressants or anxiolytics is (thus far) limited but these medications may also contribute to body weight gain and development of diabetes. (Oyebode, Rastogi, Berrisford, \& Coccia, 2012; Salvi, Grua, Cerveri, Mencacci, \& Barone-Adesi, 2017)'(Lopez-Yarto, Ruiz-Mirazo, Holloway, Taylor, \& McDonald, 2012) Without antipsychotic medication-specific data, it is currently not possible to determine the true risk of GDM development for users of distinct antipsychotic medications, and this off course warrants further research.

We need to acknowledge the diversity of psychiatric diagnoses in the studies that included this meta-analysis. Despite most of these studies having been conducted in patients with SMI, some also included patients with various other psychiatric diagnoses, such as personality disorders, sleep disorders and alcohol/substance use disorders. (McKenna et al., 2005; Panchaud et al., 2017; Sadowski et al., 2013; Vigod et al., 2015) As mentioned earlier, patients with SMI may be more prone to develop glucose metabolism abnormalities related to nature of mental illness, as well as medication adverse-effects. While a number of studies have also suggested a relationship between diabetes and other mental illnesses and sleep disorders, (Bathla, Singh, Anjum, Kulhara, \& Jangli, 2017; Quirk et al., 2015; Ryan, 2018) the nature and extent of this relationship is not clear. Future studies with psychiatric diagnosis specified outcomes are necessary to evaluate the risk of antipsychotic treatment-related GDM.

In addition to the caveats of the current literature, it is important to note the limitations of this meta-analysis. The meta-analysis included only a limited number of studies. Therefore, we were not able to carry out analyses for publication bias on meta-analyses with fewer than 10 outcomes. 


\section{Chapter 5. Antipsychotic Exposure and Gestational Diabetes}

Furthermore, some of these studies were carried out with a small number of patients. Determining outcomes from small sample sizes can reduce the precision of outcome estimations. After adjustment for several confounding factors (i.e. lifestyle factors, maternal age, smoking), some studies included in this meta-analysis indicated no increased risk for GDM development with antipsychotic medication use. (Panchaud et al., 2017; Petersen et al., 2016; Vigod et al., 2015) It is possible that the unadjusted risk ratios reported in this metanalysis may also partially reflect the effects of other confounding variables on GDM. Finally, we carried out our literature search only on PubMed, Science Direct, Scopus and Web of Science. Although, these databases cover most scientific literature, not including other databases (i.e. Psych Info, Embase) in our search may limit our final article numbers.

Women receiving antipsychotic medications in pregnancy are of higher risk of developing GDM. Although terminating antipsychotic medication during pregnancy may reduce the risk of GDM somewhat, tapering may also lead to increased risk of exacerbations in psychiatric symptoms. Since GDM can lead to adverse consequences for both mother and offspring, antipsychotic medications should not be used without proper indication. Clinicians should carefully evaluate benefits and drawbacks of antipsychotic medication use during pregnancy and engage in shared decision-making on this topic. If antipsychotic medication is needed during pregnancy, using medications with lower weight gain liabilities, while considering patients' clinical stability, may decrease the risk of GDM development. This specific population may benefit from close pregnancy monitoring, targeting modifiable risk factors (i.e. smoking, weight reduction) and life-style modifications. (Coughlin et al., 2015; Kulkarni et al., 2015) Additionally, testing for GDM during first trimester rather than between 24 and 28 gestational weeks, as suggested by guidelines, can prevent the development of GDM in patients with SMI.

\section{Contributors}


SK, SG, JJL, BPFR and CT contributed to study conception, data interpretation, and writing of the manuscript. SK, KC, and CT contributed to data collection and analysis. SK, MOB, SG and CT contributed to study conception and data interpretation. All authors were involved in critically revising the article for important intellectual content and gave final approval of the version to be published. BPRF and CT were responsible for supervision of the meta-analysis.

\section{Declaration of interest}

All authors declare no competing interests.

\section{Funding}

This work was supported by National Institute of Diabetes and Digestive and Kidney Diseases of the National Institutes of Health under award number R01DK093924. 


\section{Chapter 5. Antipsychotic Exposure and Gestational Diabetes}

References

Annamalai, A., Kosir, U., \& Tek, C. (2017). Prevalence of obesity and diabetes in patients with schizophrenia. World J Diabetes, 8(8), 390-396.

Bathla, M., Singh, M., Anjum, S., Kulhara, P., \& Jangli, S. I. (2017). Metabolic syndrome in drug naive patients with substance use disorder. Diabetes Metab Syndr, 11(3), 167-171.

Bellamy, L., Casas, J. P., Hingorani, A. D., \& Williams, D. (2009). Type 2 diabetes mellitus after gestational diabetes: a systematic review and metaanalysis. Lancet, 373(9677), 1773-1779.

Bellet, F., Beyens, M.-N., Bernard, N., Beghin, D., Elefant, E., \& Vial, T. (2015). Exposure to aripiprazole during embryogenesis: a prospective multicenter cohort study. Pharmacoepidemiol Drug Saf, 24(4), 368-380.

Boden, R., Lundgren, M., Brandt, L., Reutfors, J., \& Kieler, H. (2012). Antipsychotics during pregnancy: relation to fetal and maternal metabolic effects. Arch Gen Psychiatry, 69(7), 715-721.

Buchanan, T. A., Xiang, A., Kjos, S. L., \& Watanabe, R. (2007). What is gestational diabetes? Diabetes Care, 30 Suppl 2, S105111.

Coughlin, C. G., Blackwell, K. A., Bartley, C., Hay, M., Yonkers, K. A., \& Bloch, M. H. (2015). Obstetric and neonatal outcomes after antipsychotic medication exposure in pregnancy. Obstet Gynecol, 125(5), 1224-1235.

DeSisto, C. L., Kim, S. Y., \& Sharma, A. J. (2014). Prevalence estimates of gestational diabetes mellitus in the United States, Pregnancy Risk Assessment Monitoring System (PRAMS), 2007-2010. Prev Chronic Dis, 11, E104.

Egger, M., Davey Smith, G., Schneider, M., \& Minder, C. (1997). Bias in meta-analysis detected by a simple, graphical test. BMJ, 315(7109), 629-634. 
Ferrara, A. (2007). Increasing prevalence of gestational diabetes mellitus: a public health perspective. Diabetes Care, 30 Suppl 2, S141-146.

Galbally, M., Frayne, J., Watson, S. J., \& Snellen, M. (2018). Aripiprazole and pregnancy: A retrospective, multicentre study. $J$ Affect Disord, 238, 593-596.

Garcia-Rizo, C., Fernandez-Egea, E., Miller, B. J., Oliveira, C., Justicia, A., Griffith, J. K., . . . Kirkpatrick, B. (2013). Abnormal glucose tolerance, white blood cell count, and telomere length in newly diagnosed, antidepressantnaïve patients with depression. Brain, Behavior, and Immunity, 28, 49-53.

Garcia-Rizo, C., Kirkpatrick, B., Fernandez-Egea, E., Oliveira, C., \& Bernardo, M. (2016). Abnormal glycemic homeostasis at the onset of serious mental illnesses: A common pathway. Psychoneuroendocrinology, 67, 70-75.
Greenhalgh, A. M., GonzalezBlanco, L., Garcia-Rizo, C., Fernandez-Egea, E., Miller, B., Arroyo, M. B., \& Kirkpatrick, B. (2017). Meta-analysis of glucose tolerance, insulin, and insulin resistance in antipsychotic-naïve patients with nonaffective psychosis. Schizophrenia Research, 179, 57-63.

Guha, P., Bhowmick, K., Mazumder, P., Ghosal, M., Chakraborty, I., \& Burman, P. (2014). Assessment of insulin resistance and metabolic syndrome in drug naive patients of bipolar disorder. Indian journal of clinical biochemistry : IJCB, 29(1), 51-56.

Howard, L. M., Goss, C., Leese, M., Appleby, L., \& Thornicroft, G. (2004). The psychosocial outcome of pregnancy in women with psychotic disorders. Schizophr Res, 71(1), 49-60.

Jones, I., Chandra, P. S., Dazzan, P., \& Howard, L. M. (2014). Bipolar disorder, affective psychosis, and schizophrenia in pregnancy and 


\section{Chapter 5. Antipsychotic Exposure and Gestational Diabetes}

the post-partum period. Lancet, 384(9956), 1789-1799.

Kucukgoncu, S., Kosir, U., Zhou, E., Sullivan, E., Srihari, V. H., \& Tek, C. (2018). Glucose metabolism dysregulation at the onset of mental illness is not limited to first episode psychosis: A systematic review and metaanalysis. Early Interv Psychiatry.

Kulkarni, J., McCauley-Elsom, K., Marston, N., Gilbert, H., Gurvich, C., de Castella, A., \& Fitzgerald, P. (2008). Preliminary findings from the National Register of Antipsychotic Medication in Pregnancy. Aust N Z J Psychiatry, 42(1), 38-44.

Kulkarni, J., Storch, A., Baraniuk, A., Gilbert, H., Gavrilidis, E., \& Worsley, R. (2015). Antipsychotic use in pregnancy. Expert Opin Pharmacother, 16(9), 1335-1345.

Kulkarni, J., Worsley, R., Gilbert, H., Gavrilidis, E., Van Rheenen, T. E., Wang, W., . . Fitzgerald, P. (2014). A prospective cohort study of antipsychotic medications in pregnancy: the first 147 pregnancies and 100 one year old babies. Plos One, 9(5), e94788.

Lopez-Yarto, M., Ruiz-Mirazo, E., Holloway, A. C., Taylor, V. H., \& McDonald, S. D. (2012). Do psychiatric medications, especially antidepressants, adversely impact maternal metabolic outcomes? J Affect Disord, 141(2-3), 120-129. McCauley-Elsom, K., Gurvich, C., Elsom, S. J., \& Kulkarni, J. (2010). Antipsychotics in pregnancy. $J$ Psychiatr Ment Health Nurs, 17(2), 97-104.

McKenna, K., Koren, G., Tetelbaum, M., Wilton, L., Shakir, S., Diav-Citrin, O., ... Einarson, A. (2005). Pregnancy outcome of women using atypical antipsychotic drugs: a prospective comparative study. $J$ Clin Psychiatry, 66(4), 444-449; quiz 546.

Moher, D., Liberati, A., Tetzlaff, J., Altman, D. G., \& Group, P. (2009). Preferred reporting items for systematic reviews and metaanalyses: the PRISMA statement. 
J Clin Epidemiol, 62(10), 10061012.

Oyebode, F., Rastogi, A., Berrisford, G., \& Coccia, F. (2012). Psychotropics in pregnancy: safety and other considerations. Pharmacol Ther, 135(1), 71-77.

Panchaud, A., Hernandez-Diaz, S., Freeman, M. P., Viguera, A. C., MacDonald, S. C., Sosinsky, A. Z., \& Cohen, L. S. (2017). Use of atypical antipsychotics in pregnancy and maternal gestational diabetes. Journal of Psychiatric Research, 95, 84-90.

Park, Y., Hernandez-Diaz, S., Bateman, B. T., Cohen, J. M., Desai, R. J., Patorno, E., . . . Huybrechts, K. F. (2018). Continuation of Atypical Antipsychotic Medication During Early Pregnancy and the Risk of Gestational Diabetes. Am J Psychiatry, 175(6), 564-574.

Perry, B. I., Mclntosh, G., Weich, S., Singh, S., \& Rees, K. (2016). The association between firstepisode psychosis and abnormal glycaemic control: systematic review and meta-analysis. Lancet Psychiatry, 3(11), 1049-1058.

Petersen, I., Sammon, C. J., McCrea, R. L., Osborn, D. P. J., Evans, S. J., Cowen, P. J., \& Nazareth, I. (2016). Risks associated with antipsychotic treatment in pregnancy: Comparative cohort studies based on electronic health records. Schizophrenia Research, 176(23), 349-356.

Pillinger, T., Beck, K., Gobjila, C., Donocik, J. G., Jauhar, S., \& Howes, O. D. (2017). Impaired glucose homeostasis in firstepisode schizophrenia: A systematic review and metaanalysis. JAMA Psychiatry.

Quirk, S. E., El-Gabalawy, R., Brennan, S. L., Bolton, J. M., Sareen, J., Berk, M., . . Williams, L. J. (2015). Personality disorders and physical comorbidities in adults from the United States: data from the National Epidemiologic Survey on Alcohol and Related Conditions. Soc Psychiatry Psychiatr Epidemiol, 50(5), 807820. 
Reis, M., \& Kallen, B. (2008). Maternal use of antipsychotics in early pregnancy and delivery outcome. $J \quad$ Clin Psychopharmacol, 28(3), 279288.

Ryan, S. (2018). Sleep and diabetes. Curr Opin Pulm Med, 24(6), 555-560.

Sadowski, A., Todorow, M., Yazdani Brojeni, P., Koren, G., \& Nulman, I. (2013). Pregnancy outcomes following maternal exposure to second-generation antipsychotics given with other psychotropic drugs: a cohort study. BMJ Open, 3(7).

Salvi, V., Grua, I., Cerveri, G., Mencacci, C., \& Barone-Adesi, F. (2017). The risk of new-onset diabetes in antidepressant users A systematic review and metaanalysis. Plos One, 12(7), e0182088.

Shepherd, E., Gomersall, J. C., Tieu, J., Han, S., Crowther, C. A., \& Middleton, P. (2017). Combined diet and exercise interventions for preventing gestational diabetes mellitus. Cochrane Database Syst Rev, 11, Cd010443.

Tek, C., Kucukgoncu, S., Guloksuz, S., Woods, S. W., Srihari, V. H., \& Annamalai, A. (2016). Antipsychotic-induced weight gain in first-episode psychosis patients: a metaanalysis of differential effects of antipsychotic medications. Early Interv Psychiatry, 10(3), 193-202.

Toh, S., Li, Q., Cheetham, T. C., Cooper, W. O., Davis, R. L., Dublin, S., . . . Andrade, S. E. (2013). Prevalence and trends in the use of antipsychotic medications during pregnancy in the U.S., 2001-2007: a populationbased study of 585,615 deliveries. Arch Womens Ment Health, 16(2), 149-157.

Van Lieshout, R. J., \& Voruganti, L. P. (2008). Diabetes mellitus during pregnancy and increased risk of schizophrenia in offspring: a review of the evidence and putative mechanisms. J Psychiatry Neurosci, 33(5), 395-404. 
Vigod, S. N., Gomes, T., Wilton, A. S., Taylor, V. H., \& Ray, J. G. (2015). Antipsychotic drug use in pregnancy: high dimensional, propensity matched, population based cohort study. Bmj-British Medical Journal, 350.

Wells, G. S., B; O'Connell, B; Peterson, J; Welch, V; Losos, M; Tugwell, P. (2009). The Newcastle-Ottawa scale (NOS) for assessing the quality of nonrandomized studies in metaanalyses. Retrieved from http://www.ohri.ca/programs/clinic al_epidemiology/oxford.asp

Whitworth, A. B. (2017). Psychopharmacological treatment of schizophrenia during pregnancy and lactation. Current Opinion in Psychiatry, 30(3), 184-190.

Zhang, Y., Liu, Y., Su, Y., You, Y., Ma, Y., Yang, G., . . Kou, C. (2017). The metabolic side effects of 12 antipsychotic drugs used for the treatment of schizophrenia on glucose: a network meta-analysis. BMC Psychiatry, 17(1), 373. 
Chapter 5. Antipsychotic Exposure and Gestational Diabetes 
eTable I. PRISMA Checklist

\begin{tabular}{|c|c|c|c|}
\hline & \# & Checklist item & Page \# \\
\hline \multicolumn{4}{|l|}{ TITLE } \\
\hline Title & 1 & Identify the report as a systematic review, meta-analysis, or both. & \#1 \\
\hline \multicolumn{4}{|l|}{ ABSTRACT } \\
\hline $\begin{array}{l}\text { Structured } \\
\text { summary }\end{array}$ & 2 & $\begin{array}{l}\text { Provide a structured summary including, as applicable: background; objectives; data } \\
\text { sources; study eligibility criteria, participants, and interventions; study appraisal and } \\
\text { synthesis methods; results; limitations; conclusions and implications of key findings; } \\
\text { systematic review registration number. }\end{array}$ & \#2-3 \\
\hline \multicolumn{4}{|c|}{ INTRODUCTION } \\
\hline Rationale & 3 & Describe the rationale for the review in the context of what is already known. & $\# 4-5$ \\
\hline Objectives & 4 & $\begin{array}{l}\text { Provide an explicit statement of questions being addressed with reference to } \\
\text { participants, interventions, comparisons, outcomes, and study design (PICOS). }\end{array}$ & \#4-5 \\
\hline \multicolumn{4}{|c|}{ ( } \\
\hline $\begin{array}{l}\text { Protocol and } \\
\text { registration }\end{array}$ & 5 & $\begin{array}{l}\text { Indicate if a review protocol exists, if and where it can be accessed (e.g., Web } \\
\text { address), and, if available, provide registration information including registration } \\
\text { number. }\end{array}$ & \#6 \\
\hline Eligibility criteria & 6 & $\begin{array}{l}\text { Specify study characteristics (e.g., PICOS, length of follow-up) and report } \\
\text { characteristics (e.g., years considered, language, publication status) used as criteria } \\
\text { for eligibility, giving rationale. }\end{array}$ & \#6 \\
\hline $\begin{array}{l}\text { Information } \\
\text { sources }\end{array}$ & 7 & $\begin{array}{l}\text { Describe all information sources (e.g., databases with dates of coverage, contact } \\
\text { with study authors to identify additional studies) in the search and date last } \\
\text { searched. }\end{array}$ & $\# 6$ \\
\hline Search & 8 & $\begin{array}{l}\text { Present full electronic search strategy for at least one database, including any limits } \\
\text { used, such that it could be repeated. }\end{array}$ & $\# 6$ \\
\hline
\end{tabular}




\begin{tabular}{|c|c|c|c|}
\hline Study selection & 9 & $\begin{array}{l}\text { State the process for selecting studies (i.e., screening, eligibility, included in } \\
\text { systematic review, and, if applicable, included in the meta-analysis). }\end{array}$ & $\# 6$ \\
\hline $\begin{array}{l}\text { Data collection } \\
\text { process }\end{array}$ & 10 & $\begin{array}{l}\text { Describe method of data extraction from reports (e.g., piloted forms, independently, } \\
\text { in duplicate) and any processes for obtaining and confirming data from } \\
\text { investigators. }\end{array}$ & \#6 \\
\hline Data items & 11 & $\begin{array}{l}\text { List and define all variables for which data were sought (e.g., PICOS, funding } \\
\text { sources) and any assumptions and simplifications made. }\end{array}$ & \#6 \\
\hline $\begin{array}{l}\text { Risk of bias in } \\
\text { individual studies }\end{array}$ & 12 & $\begin{array}{l}\text { Describe methods used for assessing risk of bias of individual studies (including } \\
\text { specification of whether this was done at the study or outcome level), and how this } \\
\text { information is to be used in any data synthesis. }\end{array}$ & \#6 \\
\hline $\begin{array}{l}\text { Summary } \\
\text { measures }\end{array}$ & 13 & State the principal summary measures (e.g., risk ratio, difference in means). & \#6 \\
\hline Synthesis of results & 14 & $\begin{array}{l}\text { Describe the methods of handling data and combining results of studies, if done, } \\
\text { including measures of consistency }\left(\text { e.g., }\left.\right|^{2}\right) \text { for each meta-analysis. }\end{array}$ & \#7 \\
\hline $\begin{array}{l}\text { Risk of bias across } \\
\text { studies }\end{array}$ & 15 & $\begin{array}{l}\text { Specify any assessment of risk of bias that may affect the cumulative evidence } \\
\text { (e.g., publication bias, selective reporting within studies). }\end{array}$ & \#6-7 \\
\hline Additional analyses & 16 & $\begin{array}{l}\text { Describe methods of additional analyses (e.g., sensitivity or subgroup analyses, } \\
\text { meta-regression), if done, indicating which were pre-specified. }\end{array}$ & \#7 \\
\hline
\end{tabular}




\begin{tabular}{|l|l|l|l|}
\hline \hline \multicolumn{2}{|l|}{ Section/topic } & $\#$ & Checklist item \\
\hline \hline RESULTS & 17 & $\begin{array}{l}\text { Give numbers of studies screened, assessed for eligibility, and included in the review, } \\
\text { with reasons for exclusions at each stage, ideally with a flow diagram. }\end{array}$ & \#8 \\
\hline Study selection & 18 & $\begin{array}{l}\text { For each study, present characteristics for which data were extracted (e.g., study size, } \\
\text { PICOS, follow-up period) and provide the citations. }\end{array}$ & \#8 \\
\hline $\begin{array}{l}\text { Study characteristics } \\
\text { studies }\end{array}$ & 19 & $\begin{array}{l}\text { Present data on risk of bias of each study and, if available, any outcome level } \\
\text { assessment (see item 12). }\end{array}$ & \#8-10 \\
\hline $\begin{array}{l}\text { Results of individual } \\
\text { studies }\end{array}$ & 20 & $\begin{array}{l}\text { For all outcomes considered (benefits or harms), present, for each study: (a) simple } \\
\text { summary data for each intervention group (b) effect estimates and confidence } \\
\text { intervals, ideally with a forest plot. }\end{array}$ & \#8-10 \\
\hline $\begin{array}{l}\text { Synthesis of results } \\
\text { studies }\end{array}$ & 21 & $\begin{array}{l}\text { Present results of each meta-analysis done, including confidence intervals and } \\
\text { measures of consistency. }\end{array}$ & \#8-10 \\
\hline
\end{tabular}




\begin{tabular}{|l|l|l|l|}
\hline Additional analysis & 23 & $\begin{array}{l}\text { Give results of additional analyses, if done (e.g., sensitivity or subgroup analyses, } \\
\text { meta-regression [see Item 16]). }\end{array}$ & \#8-10 \\
\hline \hline DISCUSSION & 24 & $\begin{array}{l}\text { Summarize the main findings including the strength of evidence for each main } \\
\text { outcome; consider their relevance to key groups (e.g., healthcare providers, users, } \\
\text { and policy makers). }\end{array}$ & \#11-14 \\
evidence & 25 & $\begin{array}{l}\text { Discuss limitations at study and outcome level (e.g., risk of bias), and at review-level } \\
\text { (e.g., incomplete retrieval of identified research, reporting bias). }\end{array}$ & \#12-14 \\
\hline Limitations & 26 & $\begin{array}{l}\text { Provide a general interpretation of the results in the context of other evidence, and } \\
\text { implications for future research. }\end{array}$ & \#14 \\
\hline Conclusions & 27 & $\begin{array}{l}\text { Describe sources of funding for the systematic review and other support (e.g., supply } \\
\text { of data); role of funders for the systematic review. }\end{array}$ & \#15 \\
\hline \hline FUNDING & &
\end{tabular}

From: Moher D, Liberati A, Tetzlaff J, Altman DG, The PRISMA Group (2009). Preferred Reporting Items for Systematic Reviews and Meta-Analyses: The PRISMA Statement. PLoS Med 6(7): e1000097. doi:10.1371/journal.pmed1000097

For more information, visit: www.prisma-statement.o 
eTable 2. Quality of the published studies

\begin{tabular}{|c|c|c|c|}
\hline \multirow[b]{2}{*}{ Source } & \multicolumn{3}{|c|}{ NOS } \\
\hline & Selection & Comparability & Outcome/Exposure \\
\hline McKenna et al., $2005^{\prime}$ & $* * * *$ & $*$ & $* * *$ \\
\hline Reis et al., $2008^{2}$ & $* * * *$ & $* *$ & $* * *$ \\
\hline Boden et al., $2012^{3}$ & $* * * *$ & *** & $* * *$ \\
\hline Sadowski et al. $2013^{4}$ & $* * * *$ & * & * \\
\hline Bellet et al., $2015^{5}$ & $* * * *$ & ** & ** \\
\hline Vigod et al., 20156 & $* * * *$ & ** & $* * *$ \\
\hline Petersen et al., $2016^{7}$ & $* * * *$ & ** & *** \\
\hline Panchaud et al., $2017^{8}$ & $* * * *$ & ** & $* * *$ \\
\hline Park et al., $2018^{9}$ & $* * * *$ & ** & **** \\
\hline Galbally et al., 201810 & $* * *$ & $*$ & $* * *$ \\
\hline
\end{tabular}

Newcastle-Ottawa Scale for cohort studies 
eTable 3. Summary of the studies included in meta-analysis

\begin{tabular}{|c|c|c|c|c|c|c|c|c|c|}
\hline \multirow{2}{*}{$\begin{array}{l}\text { Autho } \\
\text { r, } \\
\text { Year }\end{array}$} & \multirow{2}{*}{$\begin{array}{c}\text { Data } \\
\text { source/met } \\
\text { hodology }\end{array}$} & \multirow{2}{*}{$\begin{array}{l}\text { Antipsychotic } \\
\text { type }\end{array}$} & \multirow{2}{*}{$\begin{array}{l}\text { Other } \\
\text { medicati } \\
\text { ons }\end{array}$} & \multirow{2}{*}{ Clinical Dx } & GDM & \multicolumn{2}{|c|}{ Sample Size } & \multicolumn{2}{|c|}{ Gestational diabetes } \\
\hline & & & & & GDM based on & $\begin{array}{c}\text { Expose } \\
d\end{array}$ & $\begin{array}{c}\text { Contr } \\
\text { ol }\end{array}$ & $\mathrm{n}$ & $\begin{array}{l}\text { OR/RR* } \\
(95 \% \mathrm{Cl})\end{array}$ \\
\hline $\begin{array}{l}\text { McKe } \\
\text { nna et } \\
\text { al., } \\
2005 \text { । }\end{array}$ & $\begin{array}{c}\text { The } \\
\text { Motherisk } \\
\text { Program } \\
\text { (Canada), } \\
\text { The Israeli } \\
\text { Teratogen } \\
\text { Informatio } \\
\text { n Service } \\
\text { (Israel), } \\
\text { The Drug } \\
\text { Safety } \\
\text { Research } \\
\text { Unit } \\
\text { database } \\
\text { (England) } \\
\text { Prospectiv } \\
\text { e cohort }\end{array}$ & $\begin{array}{l}\text { Atypical } \\
\text { Antipsychotics } \\
\text { Olanzapine } \\
\text { Risperidone } \\
\text { Quetiapine } \\
\text { Clozapine }\end{array}$ & $\begin{array}{l}\text { Antidepr } \\
\text { essant } \\
57 \% \\
\text { Antiepile } \\
\text { ptic I7\% } \\
\text { Benzodia } \\
\text { zepines } \\
34 \% \\
\text { Typical } \\
\text { AP 16\% }\end{array}$ & $\begin{array}{l}\text { Schizophrenia } \\
24 \% \\
\text { Bipolar 18\% } \\
\text { Depression } \\
29 \% \\
\text { Schizoaffectiv } \\
\text { e } 2 \% \\
\text { Psychotic } \\
\text { episode } 7 \% \\
\text { OCD 2\% } \\
\text { PTSD 1\% }\end{array}$ & $\begin{array}{l}\text { Chart reviews, } \\
\text { delivery or } \\
\text { health records }\end{array}$ & 105 & 105 & $\begin{array}{c}\mathrm{AP}=6 \\
\text { Control }=6\end{array}$ & \\
\hline
\end{tabular}


Chapter 5. Antipsychotic Exposure and Gestational Diabetes

\begin{tabular}{|c|c|c|c|c|c|c|c|c|c|}
\hline $\begin{array}{l}\text { Reis } \\
\text { et al., } \\
2008^{2} \\
\text { Kallen } \\
\text { et al., } \\
2013 \\
11\end{array}$ & $\begin{array}{l}\text { Swedish } \\
\text { Medical } \\
\text { Birth } \\
\text { Register } \\
\text { I994-2005 } \\
\text { Swedish } \\
\text { Medical } \\
\text { Birth } \\
\text { Register } \\
\text { |996-20II } \\
\text { Retrospect } \\
\text { ive Cohort }\end{array}$ & $\begin{array}{c}\text { Typical and } \\
\text { atypical } \\
\text { antipsychotics }\end{array}$ & $\begin{array}{l}\text { Sedatives } \\
\text { Hypnotic } \\
\text { s } \\
\text { Antidepr } \\
\text { essants }\end{array}$ & & $\begin{array}{c}\text { Chart reviews, } \\
\text { delivery or } \\
\text { health records }\end{array}$ & 570 & $\begin{array}{c}958,72 \\
9\end{array}$ & $\begin{array}{c}\mathrm{AP}=14 \\
\text { Cont }=912 \\
9\end{array}$ & $\begin{array}{c}\text { Adjusted } \\
\text { I.78 (I.04- } \\
\quad 3.01) \\
\\
\text { Unadjusted } \\
2.61(1.38- \\
2.02)\end{array}$ \\
\hline $\begin{array}{l}\text { Bode } \\
\mathrm{n} \text { et } \\
\text { al., } \\
2012^{3}\end{array}$ & $\begin{array}{c}\text { The } \\
\text { Swedish } \\
\text { Prescribed } \\
\text { Drug } \\
\text { Register } \\
\text { 2005-2009 } \\
\text { The } \\
\text { Medical } \\
\text { Birth } \\
\text { Register } \\
\text { 2005-2009 } \\
\text { The } \\
\text { National } \\
\text { Patient } \\
\text { Register } \\
\text { 1997-2009 }\end{array}$ & $\begin{array}{l}\text { Typical and } \\
\text { Atypical } \\
\text { Antipsychotics } \\
\text { GI=Olanzapin } \\
\text { e/Clozapine } \\
\text { G2= Other } \\
\text { APs }\end{array}$ & & $\begin{array}{l}\text { Schizophrenia } \\
\text { Bipolar D } \\
\text { Other non- } \\
\text { affective } \\
\text { psychosis } \\
\text { Any } \\
\text { psychiatric } \\
\text { disorders }\end{array}$ & $\begin{array}{l}\text { Chart reviews, } \\
\text { delivery or } \\
\text { health records }\end{array}$ & $\begin{array}{c}\mathrm{GI}=\mathrm{I} 6 \\
9 \\
\mathrm{G} 2=33 \\
8\end{array}$ & $\begin{array}{c}357,69 \\
6\end{array}$ & $\begin{array}{c}\text { GI }=7 \\
G 2=15 \\
\text { Population } \\
=5979\end{array}$ & 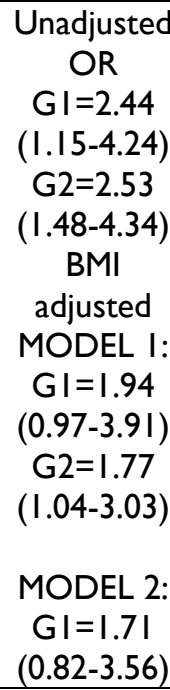 \\
\hline
\end{tabular}


Chapter 5. Antipsychotic Exposure and Gestational Diabetes

\begin{tabular}{|c|c|c|c|c|c|c|c|c|c|}
\hline & $\begin{array}{l}\text { Retrospect } \\
\text { ive cohort }\end{array}$ & & & & & & & & $\begin{array}{c}G 2=1.46 \\
(0.84-2.53\end{array}$ \\
\hline $\begin{array}{l}\text { Sado } \\
\text { wski } \\
\text { et al. } \\
2013^{4}\end{array}$ & $\begin{array}{c}\text { Motherisk } \\
\text { Program at } \\
\text { the } \\
\text { Hospital } \\
\text { for Sick } \\
\text { Children in } \\
\text { Toronto, } \\
\text { Canada, } \\
2005-2009 \\
\text { Prospectiv } \\
\text { e cohort }\end{array}$ & $\begin{array}{c}\text { Atypical } \\
\text { antipsychotics }\end{array}$ & $\begin{array}{c}\text { Antidepr } \\
\text { essants } \\
54 \% \\
\text { Typical } \\
\text { antipsych } \\
\text { otic } \\
\text { Anticonv } \\
\text { ulsant } \\
\text { use }\end{array}$ & $\begin{array}{c}\text { Schizophrenia } \\
3 \% \\
\text { Bipolar } 36.8 \% \\
\text { Depression } \\
27.1 \% \\
\text { Anxiety/depr } \\
\text { ession } 9.8 \% \\
\text { Sleep } 9.8 \% \\
\text { Schizoaffectiv } \\
\text { e I.5\% }\end{array}$ & $\begin{array}{l}\text { Patient reports } \\
\text { with clarification } \\
\text { from the general } \\
\text { practitioner or } \\
\text { study records }\end{array}$ & 133 & 133 & $\begin{array}{c}A P=11 \\
\text { Control }=5\end{array}$ & \\
\hline $\begin{array}{l}\text { Bellet } \\
\text { et al., } \\
2015^{5}\end{array}$ & $\begin{array}{l}\text { Terappel } \\
\text { database. } \\
\text { July } 2004 \\
\text { and } \\
\text { December } \\
2011 \\
\text { Prospectiv } \\
\text { e Cohort } \\
\text { study }\end{array}$ & Aripiprazole & $\begin{array}{l}\text { Other } \\
\text { antipsych } \\
\text { otics } \\
17.4 \% \\
\text { Antidepr } \\
\text { essants } \\
\text { Anticonv } \\
\text { ulsants } \\
\text { Benzodia } \\
\text { zepines }\end{array}$ & $\begin{array}{l}\text { Schizophrenia } \\
30.6 \% \\
\text { Psychosis } \\
19.4 \% \\
\text { Bipolar } 16.7 \% \\
\text { Depression } \\
\text { 15.3\% }\end{array}$ & $\begin{array}{l}\text { Patient reports } \\
\text { with clarification } \\
\text { from the general } \\
\text { practitioner or } \\
\text { study records }\end{array}$ & 86 & 172 & $\begin{array}{l}\mathrm{AP}=4 \\
\text { Control }=7\end{array}$ & $\begin{array}{l}\text { Unadjusted } \\
\text { I.I5 (0.33- } \\
4.04)\end{array}$ \\
\hline
\end{tabular}


Chapter 5. Antipsychotic Exposure and Gestational Diabetes

\begin{tabular}{|c|c|c|c|c|c|c|c|c|c|}
\hline $\begin{array}{l}\text { Vigod } \\
\text { et al., } \\
2015^{6}\end{array}$ & $\begin{array}{l}\text { Institute } \\
\text { for Clinical } \\
\text { Evaluative } \\
\text { Sciences } \\
\text { (ICES) } \\
2003-2012 \\
\text { Retrospect } \\
\text { ive Cohort } \\
\text { study }\end{array}$ & $\begin{array}{l}\text { Typical and } \\
\text { atypical } \\
\text { antipsychotics }\end{array}$ & $\begin{array}{l}\text { Antidepr } \\
\text { essants } \\
\text { Benzodia } \\
\text { zepines } \\
\text { Mood } \\
\text { stabilizer } \\
\text { s }\end{array}$ & $\begin{array}{l}\text { Schizophrenia } \\
\text { Bipolar } \\
\text { Depression } \\
\text { Alcohol/Subst } \\
\text { ance } \\
\text { Personality } \\
\text { Disorder }\end{array}$ & $\begin{array}{c}\text { Chart reviews, } \\
\text { delivery or } \\
\text { health records }\end{array}$ & 1209 & $40,3 \mid 4$ & $\begin{array}{l}\mathrm{AP}=93 \\
\text { Control=2 } \\
497\end{array}$ & $\begin{array}{l}\text { * } \\
\text { Unmatched } \\
\text { cohort } \\
\text { I.24 (I.0I- } \\
\text { I.53) } \\
\text { Matched } \\
\text { cohort } \\
\text { I.15 (0.82- } \\
1.61)\end{array}$ \\
\hline $\begin{array}{l}\text { Peter } \\
\text { sen et } \\
\text { al., } \\
2016^{7}\end{array}$ & $\begin{array}{l}\text { The } \\
\text { Health } \\
\text { Improveme } \\
\mathrm{nt} \\
\text { Network } \\
\text { (THIN) } \\
\text { and the } \\
\text { Clinical } \\
\text { Practice } \\
\text { Research } \\
\text { Datalink } \\
\text { (CPRD) } \\
\text { I995-20I2 } \\
\\
\text { Retrospect } \\
\text { ive Cohort } \\
\text { study }\end{array}$ & $\begin{array}{l}\text { Typical and } \\
\text { Atypical } \\
\text { Antipsychotics }\end{array}$ & $\begin{array}{l}\text { Anticonv } \\
\text { ulsants } \\
10.6 \% \\
\text { Lithium } \\
3.1 \% \\
\text { Antidepr } \\
\text { essants } \\
57.2 \\
\text { Anxiolyti } \\
\text { cs } 11.5 \% \\
\text { Hypnotic } \\
\text { s } 15.1 \%\end{array}$ & $\begin{array}{l}\text { Depression } \\
25.2 \% \\
\text { SMI } 60.1 \%\end{array}$ & $\begin{array}{c}\text { Chart reviews, } \\
\text { delivery or } \\
\text { health records }\end{array}$ & $\begin{array}{l}\text { All } \\
\text { AP=4I } \\
6 \\
\text { Typical } \\
\text { AP=15 } \\
7 \\
\text { Atypic } \\
\text { al } \\
\text { AP }=28 \\
0\end{array}$ & $\begin{array}{l}318,43 \\
4\end{array}$ & $\begin{array}{l}\mathrm{AP}=\mathrm{II} \\
\text { Control=5 } \\
227\end{array}$ & $\begin{array}{l}\text { Absolute } \\
\text { Risk } \\
\text { difference } \\
\text { I.0 (-0.5 to } \\
2.5)\end{array}$ \\
\hline $\begin{array}{l}\text { Panch } \\
\text { aud et }\end{array}$ & $\begin{array}{l}\text { The } \\
\text { Massachus } \\
\text { etts }\end{array}$ & $\begin{array}{l}\text { Atypical } \\
\text { Antipsychotics }\end{array}$ & $\begin{array}{l}\text { Antidepr } \\
\text { essants }\end{array}$ & $\begin{array}{l}\text { Psychosis 7\% } \\
\text { Bipolar D } \\
62 \%\end{array}$ & $\begin{array}{c}\text { Chart reviews, } \\
\text { delivery or } \\
\text { health records }\end{array}$ & 303 & 149 & $\begin{array}{l}\mathrm{AP}=33 \\
\text { Control=1 } \\
6\end{array}$ & $\begin{array}{l}\text { Unadjusted } \\
\mathrm{OR}=1.02 \\
(0.54-1.91) \\
\end{array}$ \\
\hline
\end{tabular}




\begin{tabular}{|c|c|c|c|c|c|c|c|c|c|}
\hline $\begin{array}{l}\text { al., } \\
2017^{8}\end{array}$ & $\begin{array}{l}\text { General } \\
\text { Hospital } \\
\text { (MGH) } \\
\text { National } \\
\text { Pregnancy } \\
\text { Registry } \\
\text { for } \\
\text { Atypical } \\
\text { Antipsycho } \\
\text { tics } \\
\text { (NPRAA) } \\
\text { Prospectiv } \\
\text { e Cohort } \\
\text { study }\end{array}$ & & $\begin{array}{l}\text { Anxiolyti } \\
\text { cs } \\
\text { Anticonv } \\
\text { ulsants }\end{array}$ & $\begin{array}{l}\text { Depression } \\
16 \% \\
\text { Anxiety } 5 \% \\
\text { Other } 10 \%\end{array}$ & No definition & & & & $\begin{array}{l}\text { Adjusted } \\
\text { OR=0.72 } \\
(0.34-1.54)\end{array}$ \\
\hline $\begin{array}{l}\text { Park } \\
\text { et al., } \\
2018^{9}\end{array}$ & $\begin{array}{l}\text { The } \\
\text { Medicaid } \\
\text { Analytic } \\
\text { eXtract } \\
2000-2010 \\
\text { Retrospect } \\
\text { ive Cohort } \\
\text { study }\end{array}$ & $\begin{array}{l}\text { Atypical } \\
\text { antipsychotics: } \\
\text { a) Aripiprazole } \\
\text { b) Ziprasidone } \\
\text { c) Quetiapine } \\
\text { d) Risperidone } \\
\text { e) Olanzapine }\end{array}$ & $\begin{array}{l}\text { Antidepr } \\
\text { essants } \\
\text { Benzodia } \\
\text { zepines } \\
\text { Mood } \\
\text { stabilizer } \\
\text { s }\end{array}$ & $\begin{array}{l}\text { Schizophrenia } \\
\text { /psychosis } \\
\text { Bipolar D } \\
\text { Depression } \\
\text { Anxiety D } \\
\text { ADHD }\end{array}$ & $\begin{array}{c}\text { Chart reviews, } \\
\text { delivery or } \\
\text { health records }\end{array}$ & $\begin{array}{l}\text { a) } 419 \\
\text { b) } 167 \\
\text { c) } \\
\text { I,543 } \\
\text { d) } 359 \\
\text { e) } 384\end{array}$ & $\begin{array}{l}\text { a) } \\
\text { I505 } \\
\text { b) } 506 \\
\text { c) } \\
2990 \\
\text { d) } \\
\text { I465 } \\
\text { e) } \\
\text { 104I }\end{array}$ & $\begin{array}{l}\text { a) } 20 / 419 \\
68 / 1505 \\
\text { b) }<11 / 167 \\
19 / 506 \\
\text { c) } 110 / 1543 \\
122 / 2990 \\
\text { d) } 23 / 359 \\
60 / 1465 \\
\text { e) } 46 / 384\end{array}$ & $\begin{array}{l}\text { Unadjusted } \\
\text { a) } 1.06 \\
(0.65-1.72) \\
\text { b) } 1.12 \\
(0.48-2.6 \mathrm{I}) \\
\text { c) } 1.75 \\
\text { (I.36-2.24) } \\
\text { d) } 1.56 \\
\text { (0.98-2.49) } \\
\text { e) } 2.55 \\
\text { (I.73-3.74) } \\
\text { Adjusted }\end{array}$ \\
\hline
\end{tabular}


Chapter 5. Antipsychotic Exposure and Gestational Diabetes

\begin{tabular}{|c|c|c|c|c|c|c|c|c|}
\hline & & & & & & & $49 / 1041$ & $\begin{array}{l}\text { a) } 0.82 \\
\text { (0.50-I.33) } \\
\text { b) } 0.76 \\
(0.29-2.00) \\
\text { c) } 1.28 \\
\text { (I.0I-I.62) } \\
\text { d) } 1.09 \\
\text { (0.70-I.70) } \\
\text { e) } 1.61(1.13- \\
2.29) ।\end{array}$ \\
\hline $\begin{array}{l}\text { Galbal } \\
\text { ly et. } \\
\text { al., } \\
2018 \\
10\end{array}$ & $\begin{array}{l}\text { Mercy } \\
\text { Hospital } \\
\text { for } \\
\text { Women } \\
\text { (Australia), } \\
\text { King } \\
\text { Edward } \\
\text { Memorial } \\
\text { Hospital } \\
\text { (Australia) } \\
\\
\text { Retrospect } \\
\text { ive Cohort }\end{array}$ & Aripiprazole & $\begin{array}{l}\text { Psychotic } \\
\text { Disorder 75\% } \\
\text { Bipolar D } \\
16.7 \% \\
\text { Non- } \\
\text { psychotic SMI } \\
8.3 \%\end{array}$ & $\begin{array}{c}\begin{array}{c}\text { Chart reviews, } \\
\text { delivery or } \\
\text { health records }\end{array} \\
\text { No definition }\end{array}$ & 12 & 14 & $\begin{array}{l}\mathrm{AP}=\mathrm{I} \\
\text { Control=I }\end{array}$ & \\
\hline
\end{tabular}

AP: Antipsychotic exposed group 
eTable 4. Meta-regression results

\begin{tabular}{|l|c|c|c|c|}
\hline Predictor & $\begin{array}{c}\text { Point } \\
\text { estimate }\end{array}$ & $95 \% \mathrm{Cl}$ & $\mathrm{Z}$ & $\mathrm{P}$ \\
\hline NOS & -0.03 & $\begin{array}{c}-0.43 \text { to } \\
0.36\end{array}$ & -0.16 & 0.86 \\
\hline Smoking & 0.01 & $\begin{array}{c}-0.01 \text { to } \\
0.05\end{array}$ & 1.08 & 0.27 \\
\hline Alcohol & -0.02 & $\begin{array}{c}-0.07 \text { to } \\
0.01\end{array}$ & -1.27 & 0.20 \\
\hline Gestational age & 0.009 & -0.10 to & 0.15 & 0.87 \\
& & 0.12 & & \\
\hline
\end{tabular}

NOS: Newcastle-Ottawa Scale score 


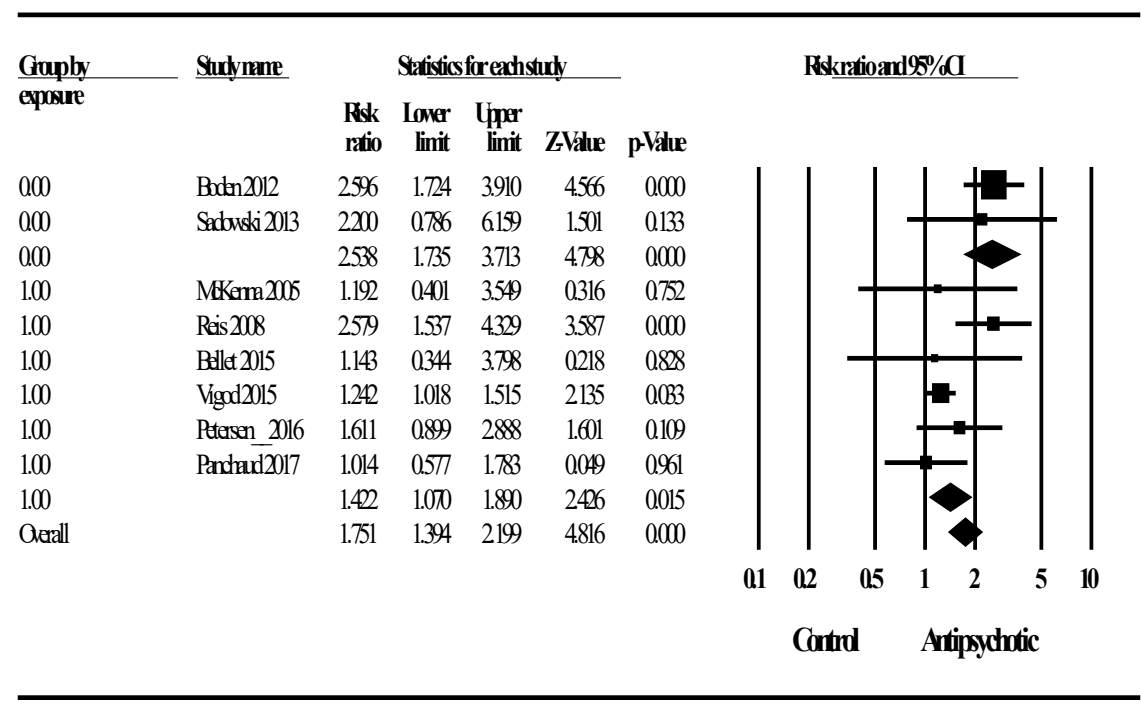

efigure I. Random effects model of RR estimates of GDM risk

Group by exposure: $0=$ Anytime antipsychotic exposure, $I=$ Early antipsychoticexposure

Group 0: $Q=0.0086, p=0.77$

Group I: $Q=8.138, p=0.149$ 


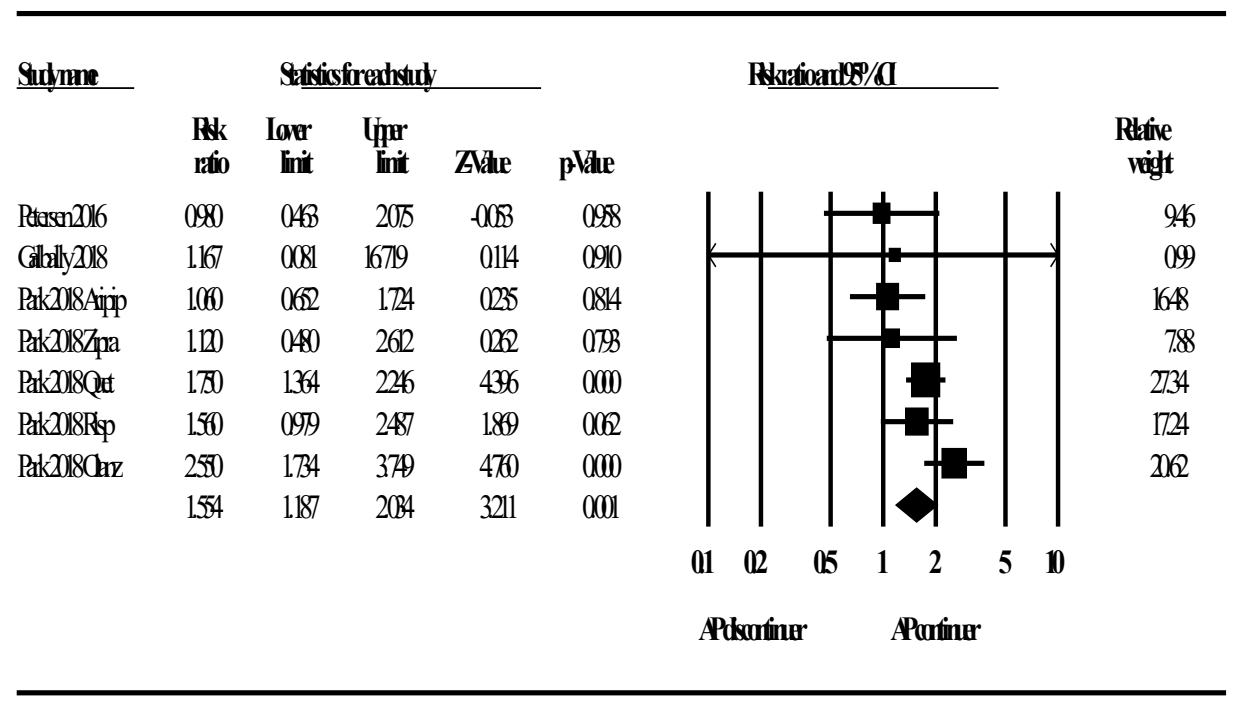

eFigure 2. Meta-analysis of unadjusted GDM risk between antipsychotic exposed and ceased groups

Heterogeneity: $\mathrm{Tau}^{2}=0.05 ; \mathrm{I}^{2}=45.75 \% ; \mathrm{Q}=\mid \mathrm{I} .06 \mathrm{I}$, d.f=6, $\mathrm{p}=0.087$

Egger's intercept $=-\mathrm{I} .24,95 \% \mathrm{Cl}=-3.87$ to $\mathrm{I} .38$

Overall effect (Fixed): I.66 (95\% Cl=I.40 to I.96), Z=5.878, $p=0.00 \mathrm{I}$ 
References

I. McKenna K, Koren G, Tetelbaum $M$, et al. Pregnancy outcome of women using atypical antipsychotic drugs: a prospective comparative study. J Clin Psychiatry. 2005;66(4):444449.

2. Reis M, Kallen B. Maternal use of antipsychotics in early pregnancy and delivery outcome. J Clin Psychopharmacol. 2008;28(3):279-288.

3. Boden R, Lundgren $M$, Brandt $L$, Reutfors J, Kieler H. Antipsychotics during pregnancy: relation to fetal and maternal metabolic effects. Arch Gen Psychiatry. 20I2;69(7):7I5-72I.

4. Sadowski A, Todorow M, Yazdani Brojeni P, Koren G, Nulman I. Pregnancy outcomes following maternal exposure to secondgeneration antipsychotics given with other psychotropic drugs: a cohort study. BMJ Open. 20I3;3(7).

5. Bellet F, Beyens M-N, Bernard N, Beghin D, Elefant E, Vial T. Exposure to aripiprazole during embryogenesis: a prospective multicenter cohort study. Pharmacoepidemiol Drug Saf. 20I 5;24(4):368-380.

6. Vigod SN, Gomes T, Wilton AS, Taylor VH, Ray JG. Antipsychotic drug use in pregnancy: high dimensional, propensity matched, population based cohort study. BMJ. $2015 ; 350$.

7. Petersen I, Sammon CJ, McCrea $\mathrm{RL}$, et al. Risks associated with antipsychotic treatment in pregnancy: Comparative cohort studies based on electronic health records. Schizophr Res. 2016;176(2-3):349-356.

8. Panchaud A, Hernandez-Diaz S, Freeman MP, et al. Use of atypical antipsychotics in pregnancy and maternal gestational diabetes. J Psychiatr Res. 2017;95:84-90.

9. Park $\mathrm{Y}$, Hernandez-Diaz $\mathrm{S}$, Bateman BT, et al. Continuation of Atypical Antipsychotic Medication During Early Pregnancy and the Risk of Gestational Diabetes. Am J Psychiatry. 20।8; I75(6):564-574.

10. Galbally M, Frayne J, Watson SJ, Snellen M. Aripiprazole and pregnancy: A retrospective, 
multicentre study. J Affect Disord. Pharmaceuticals

(Basel). 2018;238:593-596. 2013;6(I0):122I-1 286.

II. Kallen B, Borg N, Reis M. The use

of central nervous system active drugs during pregnancy. 


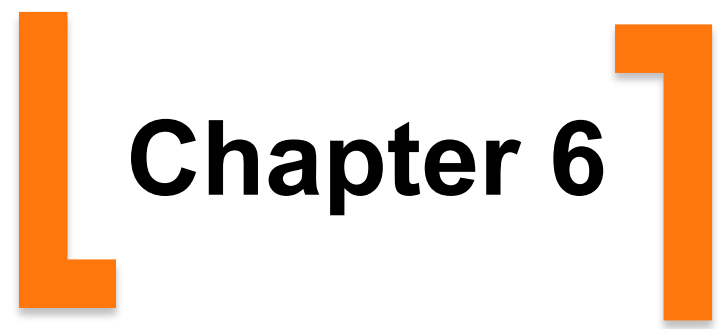


Clinical features of night eating syndrome among depressed patients

Suat Kucukgoncu, Cenk Tek, Emrem Bestepe, Christie Musket, Sinan Guloksuz

European Eating Disorders Review 2014;22:102-108. 


\section{Abstract \\ Objective}

The aim of this study was to investigate the frequency and clinical features of NES in a sample of patients with depression.

Methods

The study sample consisted of 155 depressed outpatients. Sociodemographic Form, Beck Depression Inventory (BDI), Beck Anxiety Inventory (BAI), Maudsley Obsessive-Compulsive Inventory (MOCI), Pittsburgh Sleep Quality Index (PSQI) and Night Eating Questionnaire (NEQ) were utilized for data collection.

Results

NES was identified in $21.3 \%$ of the patients. Comparisons between NES and non-NES patients revealed significant differences in BMI, smoking status, $\mathrm{BDI}, \mathrm{BAI}$, rumination, and PSQI sub-scores for sleep quality, latency, disturbances and daytime dysfunction. In our sample, the predictors of NES were BMI, smoking, and the subject's score on the PSQI sleep disturbances subscale.

Conclusions

NES is negatively associated with sleep, severity of anxiety, and depression. Our findings suggest that there is a complex relation between NES and depression, and it is recommended that depressed patients be evaluated for NES.

Key-words: Sleep, smoking, obesity, body mass index 


\section{Introduction}

Night Eating Syndrome (NES) is characterized by a delayed pattern of food intake in which the patients consume at least $25 \%$ of their total daily calories after dinner and/or during nocturnal awakenings (O'Reardon et al., 2004; Stunkard, Grace, \& Wolff, 1955). Over the years, NES has been studied in various populations under various definitions (Allison et al., 2006; Goel et al., 2009; Lundgren et al., 2006; Marshall, Allison, O'Reardon, Birketvedt, \& Stunkard, 2004; O'Reardon, Peshek, \& Allison, 2005; Striegel-Moore et al., 2004, 2005; Striegel-Moore, Franko, May, et al., 2006; Striegel-Moore, Franko, Thompson, Affenito, \& Kraemer, 2006). Lack of a standardized definition of NES impeded recognition of the syndrome, causing underestimation of its prevalence, and made it difficult to compare studies (Vander Wal, 2012). Recently, a new diagnostic criterion for NES was proposed to address this limitation (Allison et al., 2010)(Table 1).

\footnotetext{
Table 1. Proposed research diagnostic criteria for Night Eating Syndrome (Allison et al., 2010)

A. The daily pattern of eating demonstrates a significantly increased intake in the evening and/or nighttime, as manifested by one or both of the following:

1. At least $25 \%$ of food intake consumed after the evening meal

2. At least two episodes of nocturnal eating per week
}

B. Awareness and recall of evening and nocturnal eating episodes are present.

C. The clinical picture is characterized by at least three of the following features:

1. Lack of desire to eat in the morning and/or breakfast is omitted on four or more mornings per week

2. Presence of a strong urge to eat between dinner and sleep onset and/or during the night

3. Sleep onset and/or sleep maintenance insomnia are present four or more nights per week

4. Presence of a belief that one must eat in order to initiate or return to sleep

5. Mood is frequently depressed and/or mood worsens in the evening

D. The disorder is associated with significant distress or impairment in functioning.

E. The disordered pattern of eating has been maintained for at least 3 months.

F. The disorder is not secondary to substance abuse or dependence, medical disorder, medication, or another psychiatric disorder. 
NES was first described among obese patients, with an estimated prevalence of 6\%-16\% (Ceru-Bjork, Andersson, \& Rossner, 2001; Gluck, Geliebter, \& Satov, 2001; Stunkard et al., 1996). In the general population, the prevalence of NES was estimated to be 1.5\% (Rand, Macgregor, \& Stunkard, 1997; Striegel-Moore et al., 2005). Previous research with psychiatric patients found higher prevalence estimates than in the general population: $12.4 \%$ in psychiatric outpatients (Lundgren et al., 2006); $25 \%$ in overweight patients with serious mental illness (Lundgren, Rempfer, Brown, Goetz, \& Hamera, 2010); 12\% in obese patients with schizophrenia and schizoaffective disorders (Palmese et al., 2012); and $35.2 \%$ in patients with depression (Orhan et al., 2011).

Research with patients whose primary diagnosis is NES has revealed an association between the syndrome and depression (Allison, Grilo, Masheb, \& Stunkard, 2005; Birketvedt et al., 1999; Calugi, Dalle, \& Marchesini, 2009; Gluck et al., 2001; O'Reardon, Stunkard, \& Allison, 2004; Rand \& Kuldau, 1993; Stunkard et al., 1955). NES patients were reported to be more likely meet lifetime criteria for major depressive disorders (56\%) (de Zwaan, Roerig, Crosby, Karaz, \& Mitchell, 2006). Comparisons of patients with and without NES showed that NES patients scored significantly higher than controls in the Zung Depression Scale (Gluck et al., 2001) and Beck Depression Inventory (BDI) (Lundgren, Allison, O'Reardon, \& Stunkard, 2008). In a recent case control study, obese patients with NES had higher BDI scores than patients in a non-NES obese control group (Dalle, Calugi, Ruocco, \& Marchesini, 2011). There is, however, relatively less research investigating NES in depressed patients. Recently, the prevalence of NES was reported to be significantly higher in patients with depression (35.2\%) than in a healthy control group (19.2\%) (Orhan et al., 2011). The researchers also found that patients with depression were 2.64 times more likely to have NES than the healthy control group. 
At this point, it is not clear yet whether depression is a cause, an effect, or a feature of NES (Vander Wal, 2012). Studies have shown that the serotonin system, with its role on appetite, food intake, and circadian rhythms (Clifton \& Kennett, 2006; Frazer, 1997), may have an active role in the pathophysiology of NES (O'Reardon et al., 2004, 2006; Stunkard et al., 2006). Lundgren et al. (2008) reported higher levels of serotonin transporter (SERT) in the temporal lobe midbrain in night eaters. Elevations in SERT levels have been shown to lead to dysfunctions in post-synaptic serotonin transmission (Frazer, 1997), which may impair satiety, circadian rhythms, and thus lead to NES (Stunkard, Allison, Lundgren \& O'Reardon, 2009). Also, improvement in NES symptoms by selective serotonin reuptake inhibitor treatments support the role of the serotonin system in the pathopshysiology of NES (Allison et al., 2013; O'Reardon et al., 2004, 2006; Stunkard et al., 2006).

In the present study, we investigated the frequency and clinical features of NES in a sample of patients with depression, focusing on the differences in clinical features (i.e., levels of depression, anxiety, obsession and compulsion, and sleep parameters) of those with and without NES, and on the predictors of NES.

\section{Methods}

\section{Subject recruitment}

The study sample was depressed patients recruited from the outpatient clinic of the Bakırköy Neurological and Mental Health Training and Research Hospital in Istanbul, Turkey. The diagnosis of major depression was measured via the Turkish version of the Structured Clinical Interview for Diagnostic and Statistical Manual of Mental Disorders, fourth edition, Axis I Diagnosis Clinical Version. Patients were excluded if they had medical disorders, neurological disorders, eating disorders and alcohol or substance abuse. Patients who were on a diet or were fasting at the time of the study were also excluded from participation. The local ethics committee approved 
the study protocol, and all participants provided informed written consent before participation in the study.

A total of 190 individuals were consecutively recruited. Twelve patients who had neurological or medical disorders, 8 patients who met the diagnostic criteria of any eating disorders, 8 patients who did not complete the surveys, 4 patients who were on a diet, and 3 patients who were fasting were excluded from the study sample. The analyses were conducted with the scores from the remaining 155 patients (125 female $80.6 \%, 30$ male $19.4 \%$ ). The mean age of the study sample was $35.80 \pm 8.78$ years (minimum: 18 , max: 60 ), and the mean ages for men and women in the sample were similar $(t=0.388 ; p>0.05)$.

The NES symptoms were assessed via clinical interviews by the psychiatrist (SK, EB). The aforementioned diagnostic criteria for NES (Allison et al., 2010) were used for the diagnosis. To determine evening hyperphagia, Night Eating Questionnaire ("How much of your daily food intake o you consume after suppertime?") and open-ended questions to help to evaluate participants' food consumption for the last 24 hours were used. All patients' height and weight were measured after the clinical interview. Patients with a Body Mass Index (BMI) above $30 \mathrm{~kg} / \mathrm{m}^{2}$ were classified as obese between $25-29.9 \mathrm{~kg} / \mathrm{m}^{2}$ as overweight, and under $25 \mathrm{~kg} / \mathrm{m}^{2}$ as within the normal range.

\section{Measures}

Socio-demographic Evaluation Form: This form was utilized to obtain socio-demographic data such as age, gender, educational level, marital and professional status, lifestyle, and economic status of patients.

Structural Clinical Interview for DSM-IV Axis I Diagnosis (SCID-I): The SCID-I is a semi-structured clinical interview chart used by the interviewers in order to examine Axis I psychiatric disorders (First et al., 1997). 
Beck Depression Inventory (BDI): The Turkish version of the BDI (Beck, Ward, Mendekson, Mock, \& Erbaugh, 1961) was used to evaluate depressive symptoms. The BDI is a self-report questionnaire that includes 21 items. The total score is the sum of all items and the total score range is $0-63$.

Beck Anxiety Inventory (BAI): The BAI was originally developed by Beck et al. (Beck, Epstein, Brown, \& Steer, 1988). The BAl is a frequently used selfreport method for assessing the severity of anxiety. It has a 21-item form that requires subjects to indicate the presence and severity of symptoms.

Maudsley Obsessive-Compulsive Inventory ( $\mathrm{MOCl}$ ): The $\mathrm{MOCl}$ is a selfreport questionnaire used to evaluate obsessive-compulsive symptoms. The inventory, developed by Hodgson and Rachman (1977), consists of 30 true/false items. The $\mathrm{MOCl}$ contains five subscales that measure compulsive checking, cleaning, slowness, doubting, and rumination.

Pittsburgh Sleep Quality Index (PSQI): The PSQI is an instrument with previously established reliability and validity (Buysse, Reynolds, Monk, Berman, \& Kupfer, 1989), and was administered to assess sleep quality during the previous month. The PSQI is grouped into seven component scores: subjective sleep quality, sleep latency, sleep duration, habitual sleep efficiency, sleep disturbance, use of sleeping medications, and daytime dysfunction. The seven component scores are then summed to yield a global PSQI score, which has a range of $0-21$, with higher scores indicating worse sleep quality.

Night Eating Questionnaire (NEQ): The NEQ is a self-report measure for NES screening and was developed by Allison et al (2008). The NEQ consists of 14 questions concerning morning anorexia, nocturnal ingestions, evening hyperphagia and mood/sleep. Internal consistency reliability of NEQ was found to be 0.70 . The validity and reliability of the Turkish version of this scale have not yet been established. Authors of the present study made the 
translation of the NEQ. Cronbach's alpha was 0.69 for NEQ total score in this study.

\section{Statistical analysis}

The statistical package SPSS 19 for Mac was used for all analyses. The chi-square test and Fischer's exact test were utilized for parametric data. A student's t-test was used to compare continuous variables across the patients with NES and without NES. Forward Wald Multiple logistic regression analysis was performed to identify factors that were associated with NES. The statistically significant variables of the univariate analysis were chosen as the independent variables: smoking status, the average scores of the BDI, BAI, BMI, rumination subscale of $\mathrm{MOCl}$ and subscales of PSQI (subjective sleep quality, sleep latency, sleep disturbances and daytime dysfunction) scores. The dependent variable was NES status. For all statistical analyses, $p$ values were two-tailed, and differences were evaluated at $p<0.05$.

\section{Results}

Thirty-seven patients $(23.9 \%)$ reported consuming $25 \%$ or more of their daily food intake after their evening meal and experiencing two or more episodes of nocturnal eating per week. Four of these patients $(10.8 \%)$ (paroxetine $n=2$, sertraline hydrochloride $n=1$, venlafaxine hydrochloride $n=1$ ) did not meet the diagnostic criteria for NES because the onset of night eating behavior occurred after the beginning of psychopharmacological treatment. After excluding these patients, 33 patients $(21.3 \%)$ met criteria for a NES diagnosis. Among the patients with NES, 2 (6.1\%) consumed at least $25 \%$ of their total daily food intake after their evening meal, 14 (42.4\%) had at least two nocturnal eating episodes per week, and 17 (51.5\%) met both conditions. All of these patients reported awareness of the nocturnal eating episodes. The mean duration of NES symptoms was $31.51 \pm 59.21$ months. Four patients $(12.1 \%)$ reported that they were currently seeking treatment for their night eating behavior. 
NES and non-NES groups did not significantly differ from each other in age and had a similar gender distribution. The average BMI was significantly higher in NES group. The NES group also contained significantly more obese patients than the non-NES group (Table 2).

There was no significant difference between the groups in terms of alcohol use. Smoking was significantly more frequent in patients with NES. No significant differences were found between the groups in terms of antidepressant, antipsychotic, and mood stabilizer medications (Table 2).

Table 2. Comparisons of gender distribution, smoking, alcohol use, BMI and medications between NES and non-NES depressive patients

\begin{tabular}{|c|c|c|c|c|c|c|}
\hline & $\begin{array}{l}\text { Non } \\
n=\end{array}$ & $\begin{array}{l}\text { ES } \\
2\end{array}$ & & & & \\
\hline & $\mathbf{n}$ & $\%$ & $\mathbf{n}$ & $\%$ & $\mathbf{X}^{2}$ & $\mathbf{p}$ \\
\hline Gender & & & & & 2.830 & $>0.05$ \\
\hline Female & 95 & 77.9 & 30 & 90.9 & & \\
\hline Male & 27 & 22.1 & 3 & 9.1 & & \\
\hline Smoking & 50 & 41.0 & 23 & 69.7 & 8.595 & $<0.01$ \\
\hline Alcohol use & 19 & 15.6 & 8 & 24.2 & 1.357 & $>0.05$ \\
\hline BMI & & & & & 6.351 & $<0.05$ \\
\hline Normal & 54 & 44.3 & 9 & 27.3 & & \\
\hline Overweight & 47 & 38.5 & 12 & 36.4 & & \\
\hline Obese & 21 & 17.2 & 12 & 36.4 & & \\
\hline Medication & & & & & & \\
\hline Antidepressant & 96 & 78.7 & 25 & 75.8 & 0.130 & $>0.05$ \\
\hline Antipsychotic & 13 & 10.7 & 3 & 9.1 & 0.069 & $>0.05$ \\
\hline *Mood stabilizers & 7 & 5.7 & 0 & 0 & - & $>0.05$ \\
\hline & Mean & S.D. & Mean & S.D. & $\mathbf{t}$ & $\mathbf{p}$ \\
\hline Age & 35.93 & 8.72 & 35.33 & 9.18 & 0.348 & $>0.05$ \\
\hline BMI & 26.20 & 5.31 & 28.89 & 6.50 & 2.459 & $<0.05$ \\
\hline
\end{tabular}

$\mathrm{X}^{2}$. Chi Square test; * Fisher's exact test; t. Student $\mathrm{T}$ test; NES. Night Eating Syndrome; BMI. Body Mass Index 
Comparisons of the clinical measures across the NES and non-NES groups are summarized in Table 2. The average BDI $(t=3.023 ; p<0.01), B A I$ $(t=2.538 ; p<0.05)$, and Global PSQI scores $(t=3.342 ; p<0.001)$ were significantly higher in the NES group. The average scores of the rumination subscale of the $\mathrm{MOCl}(\mathrm{t}=2.423 ; p<0.05)$ were higher in the NES group. No significant difference was observed in the total $\mathrm{MOCl}$ scores between the groups $(t=1.549 ; p>0.05)$. The average NEQ scores, as expected, were significantly higher in the NES group $(t=12.466 ; p<0.001)$ (Table 3 ).

Table 3. Comparisons of the clinical scales between NES and non-NES depressive patients

\begin{tabular}{|c|c|c|c|c|c|c|}
\hline & \multicolumn{2}{|c|}{$\begin{array}{c}\text { Non-NES } \\
n=122\end{array}$} & \multicolumn{2}{|c|}{$\begin{array}{l}\text { NES } \\
n=33\end{array}$} & \multirow[b]{2}{*}{$\mathbf{t}$} & \multirow[b]{2}{*}{ p } \\
\hline & Mean & S.D. & Mean & S.D. & & \\
\hline BDI & 24.26 & 12.03 & 31.31 & 11.73 & -3.023 & $<0.01$ \\
\hline $\begin{array}{l}\text { BAI } \\
\text { MOCI }\end{array}$ & 17.24 & 13.97 & 24.54 & 16.98 & -2.538 & $<0.05$ \\
\hline $\begin{array}{l}\text { MOCl } \\
\text { Checking }\end{array}$ & 2.41 & 2.13 & 3.21 & \multicolumn{2}{|c|}{ MOCI } & $>0.05$ \\
\hline Cleaning & 3.15 & 2.48 & 3.24 & 2.20 & 0.182 & $>0.05$ \\
\hline Slowness & 1.91 & 1.62 & 2.51 & 1.93 & -1.796 & $>0.05$ \\
\hline Doubting & 2.81 & 1.58 & 3.27 & 1.87 & -1.424 & $>0.05$ \\
\hline Rumination & 3.81 & 2.52 & 5.06 & 2.97 & -2.423 & $<0.05$ \\
\hline Total & 10.11 & 6.85 & 12.24 & 7.53 & -1.549 & $>0.05$ \\
\hline \multicolumn{7}{|l|}{ PSQI } \\
\hline Subjective sleep quality & 1.44 & 0.91 & 1.84 & 0.75 & -2.332 & $<0.05$ \\
\hline Sleep latency & 1.57 & 0.98 & 2.09 & 0.87 & -2.730 & $<0.01$ \\
\hline Sleep duration & 0.81 & 0.83 & 0.81 & 0.76 & -0.042 & $>0.05$ \\
\hline Habitual sleep efficiency & 2.38 & 1.13 & 2.42 & 1.09 & -0.176 & $>0.05$ \\
\hline Sleep disturbance & 1.51 & 0.70 & 2.03 & 0.68 & -3.730 & $<0.001$ \\
\hline $\begin{array}{l}\text { Use of sleep } \\
\text { medications }\end{array}$ & 0.99 & 1.29 & 1.21 & 1.36 & -0.857 & $>0.05$ \\
\hline Daytime dysfunction & 1.17 & 0.95 & 1.66 & 1.08 & -2.574 & $<0.05$ \\
\hline Total & 9.15 & 3.57 & 11.45 & 3.22 & -3.342 & $<0.001$ \\
\hline NEQ & 18.62 & 4.61 & 30.15 & 5.07 & -12.466 & $<0.001$ \\
\hline
\end{tabular}

t: Student T test, S.D.: Standard deviation, NES: Night Eating Syndrome, PSQI: Pittsburg Sleep Quality Index, MOCl: Maudsley Obsessive Compulsive Inventory, BDI: Beck Depression Inventory, BAI: Beck Anxiety Inventory

To determine the predictors of NES in the study sample, multiple logistic regression analysis was used. Gender, smoking status, the average scores of $\mathrm{BDI}, \mathrm{BAI}, \mathrm{BMI}$, and the rumination subscale of $\mathrm{MOCl}$ and subscales of PSQI (subjective sleep quality, sleep latency, sleep disturbances and 
daytime dysfunction scores) were entered in the analysis as independent variables. Smoking status, the averages of PSQI sleep disturbances, and BMI were found as significant predictors of NES (Omnibus Chi Square $=23.791$; $\mathrm{df}=3 ; \mathrm{p}<0.01)($ Table 4$)$.

Table 4. Independent predictors of NES in Forward Ward Regression Models

\begin{tabular}{lccccccc}
\hline Variables & B & S.E. & Wald & df & P & Exp (B) & $\begin{array}{c}95.0 \% \\
\text { Cl }\end{array}$ \\
\hline BMI & 0.074 & 0.036 & 4.156 & 1 & 0.041 & 1.077 & $1.003-$ \\
PSQI-Sleep & 0.880 & 0.325 & 7.337 & 1 & 0.007 & 2.411 & $1.275-$ \\
Dist. & & & & & & & 4.559 \\
Smoking & 1.198 & 0.453 & 7.008 & 1 & 0.008 & 3.314 & $\begin{array}{c}1.365- \\
\text { Sm.045 }\end{array}$ \\
\hline
\end{tabular}

The average scores of $\mathrm{BDI}, \mathrm{BAI}, \mathrm{BMI}$, rumination subscale of $\mathrm{MOCl}$ and subscales of PSQI (Subjective sleep quality, sleep latency, sleep disturbances and daytime dysfunction scores) were independent variables.

PSQI: Pittsburg Sleep Quality Index, Sleep Disturbances Subscale

BMI: Body Mass Index

\section{Discussion}

In the present study, we investigated the prevalence of NES among patients with major depression and clinical differences between patients with and without NES. In our study sample, $21.3 \%$ of the patients met the proposed diagnostic criteria (Allison et al., 2010) for NES. Furthermore, the average BDI and BAI scores were found to be higher in the NES group than non-NES group, indicating a greater severity among people with a comorbid NES diagnosis.

In this study, we also aimed to determine predictors of NES among patients with depression. Multiple regression analysis showed that smoking status, PSQI sleep disturbance subscale scores, and BMI were significant predictors of NES in our sample. The relationship between NES and depression has been examined in previous studies (Allison et al., 2005; Birketvedt et al., 1999; Calugi et al., 2009; Gluck et al., 2001; O'Reardon et al., 2004; Rand \& Kuldau, 1993; Stunkard et al., 1955). However, it must be noted that comparing our findings with these previous studies demands great 
care, due to the lack of a unified set of criteria for NES diagnosis. Prior to publication of the proposed diagnostic criteria for NES (Allison et al., 2010), the syndrome was examined by using criteria that varied widely depending on the study, which greatly restricted our ability to compare our findings with these previous studies.

Although prevalence of depressive disorders and depressive symptoms in patients with NES has been examined by many studies, we have limited knowledge of the prevalence and specific clinical features of NES in patients with depression. Recently, Orhan et al. (2011) reported that $35.2 \%$ of patients with depression had NES, whereas the current study found $21.3 \%$. This discrepancy between the percentages reported in our and their study can likely be attributed differences in the study samples, resulting from differing exclusion and inclusion criteria. More specifically, in our study, we excluded patients with eating disorders such as binge eating disorder (BED), whereas such determining factors are not explicitly reported for the sample used in Orhan et al. (2011). Previous research has shown that BED might be a confounding factor on the relationship between NES and depression (Colles, Dixon, \& O'Brien, 2007). Nonetheless, the findings from both studies support the existence of a relationship between depression and NES, and suggest that NES is common and should be carefully evaluated among depressed patients by clinicians.

In our study, the NES group had a higher level of anxiety than the non-NES group. These parameters are important in understanding NES. In patients with NES, mood disturbances due to perceived stress or stressful life events might trigger overeating episodes as a coping response (Vander Wal, 2012). The changes in anxiety level during the day and night may better explain the relation between the two conditions. Furthermore, anxiety may cause additional effects on depressed mood and sleep distributions, and thus exacerbate night eating. A relaxation treatment study (Pawlow, O'Neil, \& Malcolm, 2003) was shown to be effective in reducing anxiety levels in 
patients with NES and to help manage night eating episodes. Further studies are needed to research daytime and nighttime anxiety changes and perceived stress level in NES patients.

In this study, rumination scores were found to be higher in the NES group. Some studies have shown a relationship between rumination and eating disorders (Fahy, Osacar, \& Marks, 1993; Nolen-Hoeksema, Stice, Wade, \& Bohon, 2007; Troop, Holbrey, \& Treasure, 1998), but to the best of our knowledge, there is no study examining rumination among patients with NES. Our result suggesting a relation between NES and rumination might also be explained by the relationship between rumination and depression (Lyubomirsky, Caldwell, \& Nolen-Hoeksema, 1998). In order to change their focus of thinking from negative thoughts, depressed ruminators tend to have incorrect cognitive thoughts or maladaptive behaviors such as overeating or drinking (Nolen-Hoeksema et al., 2007). This suggests that treatments focusing on negative thoughts and rumination may help eliminate NES.

Another important finding of this study is that smoking is a significant predictor of NES. Previous studies showed that smoking, like alcohol consumption and substance abuse, is common among eating disorders (Kendzor, Adams, Stewart, Baillie, \& Copeland, 2009; Pisetsky, Chao, Dierker, May, \& Striegel-Moore, 2008; Sandager et al., 2008; Saules et al., 2009). However, there is limited research examining the relationship between smoking and nocturnal eating. Provini et al. (2008) describe six patients who had nocturnal eating episodes and also nocturnal smoking. Lundgren et al. (2010) reported that smoking prevalence was significantly higher in persons with nocturnal eating $(51.4 \%)$ than those without nocturnal eating $(40.2 \%)$. While nicotine may reduce appetite and increase caloric consumption in the short-term, lack of physical activity, poor diet, and smoking itself can lead to weight gain in smokers (Chiolero, Faeh, Paccaud, \& Cornuz, 2008). In addition, nicotine has also been associated with increased caloric intake 
during meals (Perkins et al., 1991,1992). With our findings, we suggest that there is a strong relationship between smoking and night eating.

In our study, BMI was significantly higher in patients with NES and was a significant predictor of NES. Previous studies that have examined the relationship between BMI and NES have revealed different findings. Some studies showed that NES is more prevalent in obese people than in the general population (Adami, Campostano, Marinari, Ravera, \& Scopinaro, 2002; Aronoff, Geliebter, \& Zammit, 2001; Ceru-Bjork et al., 2001; Colles et al., 2007; de Zwaan, Burgard, Schenck, \& Mitchell, 2003; Gluck et al., 2001; Lundgren et al., 2006), whereas other studies did not find any association between BMI and NES (Lundgren, Williams \& Heitmann, 2010; StriegelMoore et al., 2005, 2006, 2008). Since most studies were conducted with obese or overweight populations, it is difficult to determine the specific association of BMI with NES and to make a direct comparison with our results. In the only other study conducted with depressed patients and healthy controls, Orhan et al. (Orhan et al., 2011) found BMI to be a risk factor for NES. However, unlike our results, in their study night eating was associated with BMI in the control group but not in the depressed group. Though the results remain ambiguous, NES was found to be associated with increased food intake which may cause unwanted weight gain and obesity (Gluck, Venti, Salbe, Votruba, \& Krakoff, 2011). Future studies are needed to explore weight changes and the relationship between NES and BMI as possible risk factors for each other, especially among depressed patients of all weight ranges.

Among the NES group in our study, PSQI sleep quality, sleep latency, sleep disturbances, daytime dysfunction subscales and PSQI total score were significantly higher than in the non-NES group. Furthermore, PSQI sleep disturbance scores were found to be significant predictors of NES. About twothirds of the people with NES experienced sleep difficulties and/or psychological problems, and inability to initiate and maintain sleep was often associated with NES (Allison et al., 2010; Ceru-Bjork et al., 2001; de Zwaan 
et al., 2006; Marshall et al., 2004; Rogers et al., 2006). In line with our findings, Rogers et al. (2006) reported that women with NES had greater sleep disturbances (measured by polysomnography and PSQI) than the healthy controls. The nocturnal eating episodes which define NES may be a result of a delayed circadian pattern of eating (Rogers et al., 2006), which could cause sleep disturbances in people with NES. Likewise, insomnia and sleep disturbances may precede NES. These findings suggest that NES may be prevented and managed by a detailed evaluation of sleep disturbances and by therapeutic interventions for sleep problems in depressed patients.

Finally, some limitations of our study should be pointed out. First, before the proposed diagnostic criteria for NES was published, it was defined in various ways. Therefore, the lack of a standardized definition of NES has restricted our ability to compare our results with earlier studies. Second, our study sample was small and consisted of only depressed patients. Consequently, it would be inappropriate to generalize our findings. Finally, this study was cross-sectional; therefore, the causality relationship cannot be tested and also the possibility that NES may be a part of depression cannot be excluded in this study design. Thus, longitudinal studies are necessary to better understand the relationship between depression and NES.

Despite its limitations, our study puts forward some important findings. We found that depressed patients frequently experience NES, and it is recommended that depressed patient be evaluated for NES. Furthermore, our results showed that NES may negatively affect clinical variables such as sleep, severity of anxiety, and depression. Finally, in our study BMI, smoking, and sleep disturbances were found to be significant risk factors for NES. Overall, we can suggest that there is a complex association between NES and depression in which sleep, smoking, and weight gain play important roles. Interventions for sleep disturbances, smoking and weight gain may prevent NES among depressed patients as well as help control depression. Further research is essential to augment our understanding of NES as it occurs in 
conjunction with depression in order to discover the effects and causes of NES among depression patients and how it might be better managed and/or prevented. 


\section{References}

Adami, G. F., Campostano, A., Marinari, G. M., Ravera, G., \& Scopinaro, N. (2002). Night eating in obesity: a descriptive study. Nutrition, 18(7-8), 587-589. doi: S089990070200761X [pii]

Allison, K. C., Grilo, C. M., Masheb, R. M., \& Stunkard, A. J. (2005). Binge eating disorder and night eating syndrome: a comparative study of disordered eating. Journal of Consulting And Clinical Psychology, 73(6), 1107-1115. doi: 2005-16405012 [pii];10.1037/0022006X.73.6.1107 [doi]

Allison, K. C., Lundgren, J. D., O'Reardon, J. P., Geliebter, A., Gluck, M. E., Vinai, P., Mitchell, J. E., Schenck, C. H., Howell, M. J., Crow, S. J., Engel, S., Latzer, Y., Tzischinsky, O., Mahowald, M. W., \& Stunkard, A. J. (2010). Proposed diagnostic criteria for night eating syndrome. The International Journal of Eating Disorders, 43(3), 241-247. doi: 10.1002/eat.20693 [doi]

Allison, K. C., Lundgren, J. D., O'Reardon, J. P., Martino, N. S., Sarwer, D. B., Wadden, T. A., Crosby, R. D., Engel, S. G., \& Stunkard, A. J. (2008). The Night Eating Questionnaire (NEQ): psychometric properties of a measure of severity of the Night Eating Syndrome. Eating Behaviors, $9(1)$, 62-72. doi: S14710153(07)00030-X

[pii];10.1016/j.eatbeh.2007.03.007 [doi]
Allison, K. C., Studt, S. K., Berkowitz, R. I., Hesson, L. A., Moore, R. H., Dubroff, J. G., Newberg, A., \& Stunkard, A. J. (2013). An open-label efficacy trial of escitalopram for night eating syndrome. Eating Behaviors, 14(2), 199-203.

Allison, K. C., Wadden, T. A., Sarwer, D. B., Fabricatore, A. N., Crerand, C. E., Gibbons, L. M., Stack, R. M., Stunkard, A. J., \& Williams, N. N. (2006). Night eating syndrome and binge eating disorder among persons seeking bariatric surgery: prevalence and related features. Surgery For Obesity And Related Diseases : Official Journal Of The American Society for Bariatric Surgery, 2(2), 153-158.

Aronoff, N. J., Geliebter, A., \& Zammit, G. (2001). Gender and body mass index as related to the nighteating syndrome in obese outpatients. Journal of the American Dietetic Association, 101(1), 102104. doi: S0002-8223(01)00022-0 [pii];10.1016/S0002-8223(01)000220 [doi]

Beck, A. T., Epstein, N., Brown, G., \& Steer, R. A. (1988). An inventory for measuring clinical anxiety: psychometric properties. Journal Of Consulting And Clinical Psychology, 56(6), 893-897.

Beck, A. T., Ward, C. H., Mendelson, M., Mock, J., \& Erbaugh, J. (1961). An inventory for measuring depression. Archives Of General Psychiatry, 4, 561-571. 
Birketvedt, G. S., Florholmen, J., Sundsfjord, J., Osterud, B., Dinges, D., Bilker, W., \& Stunkard, A. (1999). Behavioral and neuroendocrine characteristics of the night-eating syndrome. Journal of the American Medical Association, 282(7), 657663. doi: jpc90030 [pii]

Buysse, D. J., Reynolds, C. F., III, Monk, T. H., Berman, S. R., \& Kupfer, D. J. (1989). The Pittsburgh Sleep Quality Index: a new instrument for psychiatric practice and research. Psychiatry Research, 28(2), 193-213. doi: 01651781(89)90047-4 [pii]

Calugi, S., Dalle, G. R., \& Marchesini, G. (2009). Night eating syndrome in class II-III obesity: metabolic and psychopathological features. International Journal Of Obesity : Journal of the International Association for the Study of Obesity, 33(8), 899-904. doi: ijo2009105 [pii];10.1038/ijo.2009.105 [doi]

Ceru-Bjork, C., Andersson, I., \& Rossner, S. (2001). Night eating and nocturnal eating-two different or similar syndromes among obese patients? International Journal Of Obesity And Related Metabolic Disorders : Journal of the International Association for the Study of Obesity, 25(3), 365-372. doi: $10.1038 /$ sj.ijo.0801552 [doi]

Chiolero, A., Faeh, D., Paccaud, F., \& Cornuz, J. (2008). Consequences of smoking for body weight, body fat distribution, and insulin resistance. The American Journal Of Clinical
Nutrition, $87(4), \quad 801-809 . \quad$ doi: 87/4/801 [pii]

Clifton, P. G., \& Kennett, G. A. (2006). Monoamine receptors in the regulation of feeding behaviour and energy balance. CNS \& Neurological Disorders Drug Targets, 5(3), 293312.

Colles, S. L., Dixon, J. B., \& O'Brien, P. E. (2007). Night eating syndrome and nocturnal snacking: association with obesity, binge eating and psychological distress. International Journal of Obesity : Journal of the International Association for the Study of Obesity, 31(11), 1722-1730. doi:

0803664

[pii];10.1038/sj.ijo.0803664 [doi]

Dalle, G. R., Calugi, S., Ruocco, A., \& Marchesini, G. (2011). Night eating syndrome and weight loss outcome in obese patients. The International Journal of Eating Disorders, 44(2), 150-156. doi: 10.1002/eat.20786 [doi]

de Zwaan, M., Burgard, M. A., Schenck, C. H., \& Mitchell, J. E. (2003). Night time eating: A review of the literature. European Eating Disorders Review : The Journal of The Eating Disorders Association, 11, 7-24.

de Zwaan, M., Roerig, D. B., Crosby, R. D., Karaz, S., \& Mitchell, J. E. (2006). Night time eating: a descriptive study. The International Journal of Eating Disorders, 39(3), 224-232. doi: 10.1002/eat.20246 [doi] 
Fahy, T. A., Osacar, A., \& Marks, I. (1993). History of eating disorders in female patients with obsessivecompulsive disorder. The International Journal of Eating Disorders, 14(4), 439-443.

Frazer, A. (1997). Pharmacology of antidepressants. Journal of Clinical Psychopharmacology, 17 Suppl 1, 2S-18S.

Gluck, M. E., Geliebter, A., \& Satov, T. (2001). Night eating syndrome is associated with depression, low selfesteem, reduced daytime hunger, and less weight loss in obese outpatients. Obesity Research, 9(4), 264-267. doi: 10.1038/oby.2001.31 [doi]

Gluck, M. E., Venti, C. A., Salbe, A. D., Votruba, S. B., \& Krakoff, J. (2011). Higher 24-h respiratory quotient and higher spontaneous physical activity in nighttime eaters. Obesity (Silver Spring), 19(2), 319323. doi: oby2010206 [pii];10.1038/oby.2010.206 [doi]

Goel, N., Stunkard, A. J., Rogers, N. L., Van Dongen, H. P., Allison, K. C., O'Reardon, J. P., Ahima, R. S., Cummings, D. E., Heo, M., \& Dinges, D. F. (2009). Circadian rhythm profiles in women with night eating syndrome. Journal of Biological Rhythms, 24(1), 85-94. doi: 24/1/85 [pii];10.1177/0748730408328914 [doi]

Hodgson, R. J., \& Rachman, S. (1977). Obsessional-compulsive complaints. Behaviour Research
And Therapy, 15(5), 389-395. doi: 0005-7967(77)90042-0 [pii]

Kendzor, D. E., Adams, C. E., Stewart, D. W., Baillie, L. E., \& Copeland, A. L. (2009). Cigarette smoking is associated with body shape concerns and bulimia symptoms among young adult females. Eating Behaviors, 10(1), 56-58. doi: S1471-0153(08)00091-3 [pii];10.1016/j.eatbeh.2008.10.012 [doi]

Lundgren, J. D., Allison, K. C., Crow, S., O'Reardon, J. P., Berg, K. C., Galbraith, J., Martino, N. S., \& Stunkard, A. J. (2006). Prevalence of the night eating syndrome in a psychiatric population. American Journal of Psychiatry, 163(1), 156$158 . \quad$ doi: 163/1/156 [pii];10.1176/appi.ajp.163.1.156 [doi]

Lundgren, J. D., Allison, K. C., O'Reardon, J. P., \& Stunkard, A. J. (2008). A descriptive study of nonobese persons with night eating syndrome and a weight-matched comparison group. Eating Behaviors, 9(3), 343-351. doi: S14710153(08)00002-0

[pii];10.1016/j.eatbeh.2007.12.004 [doi]

Lundgren, J. D., Newberg, A. B., Allison, K. C., Wintering, N. A., Ploessl, K., \& Stunkard, A. J. (2008). 123I-ADAM SPECT imaging of serotonin transporter binding in patients with night eating syndrome:

a preliminary report. Psychiatry Research, 162(3), 214-220. doi: S0925-4927(07)00147-3 
[pii];10.1016/j.pscychresns.2007.07. 006 [doi]

Lundgren, J. D., Rempfer, M. V., Brown, C. E., Goetz, J., \& Hamera, E. (2010). The prevalence of night eating syndrome and binge eating disorder among overweight and obese individuals with serious mental illness. Psychiatry Research, 175(3), 233-236. doi: S01651781(08)00397-1

[pii]; 10.1016/j.psychres.2008.10.027 [doi]

Lundgren, J. D., Williams, K. B., \& Heitmann, B. L. (2010). Nocturnal eating predicts tooth loss among adults: results from the Danish MONICA study. Eating Behaviors, 11(3), 170-174. doi: S14710153(10)00024-3

[pii]; 10.1016/j.eatbeh.2010.02.003 [doi]

Lyubomirsky, S., Caldwell, N. D., \& Nolen-Hoeksema, S. (1998). Effects of ruminative and distracting responses to depressed mood on retrieval of autobiographical memories. Journal of Personality and Social Psychology, 75(1), 166177.

Marshall, H. M., Allison, K. C., O'Reardon, J. P., Birketvedt, G., \& Stunkard, A. J. (2004). Night eating syndrome among nonobese persons. The International Journal of Eating Disorders, 35(2), 217-222. doi: 10.1002/eat.10241 [doi]

Miyaoka, T., Yasukawa, R., Tsubouchi, K., Miura, S., Shimizu, Y., Sukegawa, T., Maeda, T., Mizuno,
S., Kameda, A., Uegaki, J., Inagaki, T., \& Horiguchi, J. (2003). Successful treatment of nocturnal eating/drinking syndrome with selective serotonin reuptake inhibitors. International Clinical Psychopharmacology, 18(3), 175177.

Nolen-Hoeksema, S., Stice, E., Wade, E., \& Bohon, C. (2007). Reciprocal relations between rumination and bulimic, substance abuse, and depressive symptoms in female adolescents. Journal of Abnormal Psychology, 116(1), 198207. doi: 2007-01891-019 [pii];10.1037/0021-843X.116.1.198 [doi]

O'Reardon, J. P., Allison, K. C., Martino, N. S., Lundgren, J. D., Heo, M., \& Stunkard, A. J. (2006). A randomized, placebo-controlled trial of sertraline in the treatment of night eating syndrome. American Journal of Psychiatry, 163(5), 893-898. doi: $163 / 5 / 893$

[pii];10.1176/appi.ajp.163.5.893 [doi]

O'Reardon, J. P., Peshek, A., \& Allison, K. C. (2005). Night eating syndrome : diagnosis, epidemiology and management. CNS Drugs, 19(12), 997-1008. doi: 19123 [pii]

O'Reardon, J. P., Ringel, B. L., Dinges, D. F., Allison, K. C., Rogers, N. L., Martino, N. S., \& Stunkard, A. J. (2004). Circadian eating and sleeping patterns in the night eating syndrome. Obesity Research, 12(11), 1789-1796. doi: 12/11/1789 [pii];10.1038/oby.2004.222 [doi] 
O'Reardon, J. P., Stunkard, A. J., \& Allison, K. C. (2004). Clinical trial of sertraline in the treatment of night eating syndrome. The International Journal of Eating Disorders, 35(1), 16-26. doi: 10.1002/eat.10224 [doi]

Orhan, F. O., Ozer, U. G., Ozer, A., Altunoren, O., Celik, M., \& Karaaslan, M. F. (2011). Night eating syndrome among patients with depression. The Israel Journal of Psychiatry and Related Sciences, 48(3), 212-217.

Palmese, L. B., Ratliff, J. C., Reutenauer, E. L., Tonizzo, K. M., Grilo, C. M., \& Tek, C. (2012). Prevalence of night eating in obese individuals with schizophrenia and schizoaffective disorder. Comprehensive Psychiatry, 54(3), 276-281.

Pawlow, L. A., O'Neil, P. M., \& Malcolm, R. J. (2003). Night eating syndrome: effects of brief relaxation training on stress, mood, hunger, and eating patterns International Journal of Obesity and Related Metabolic Disorders : Journal of the International Association for the Study of Obesity, 27(8), 970-978. doi: $\quad 10.1038 /$ sj.ijo.0802320 [doi];0802320 [pii]

Perkins, K. A., Epstein, L. H., Sexton, J. E., Solberg-Kassel, R., Stiller, R. L., \& Jacob, R. G. (1992). Effects of nicotine on hunger and eating in male and female smokers. Psychopharmacology, 106(1), 5359.
Perkins, K. A., Epstein, L. H., Stiller, R. L., Fernstrom, M. H., Sexton, J. E., Jacob, R. G., \& Solberg, R. (1991). Acute effects of nicotine on hunger and caloric intake in smokers and nonsmokers. Psychopharmacology, 103(1), 103-109.

Pisetsky, E. M., Chao, Y. M., Dierker, L. C., May, A. M., \& Striegel-Moore, R. H. (2008). Disordered eating and substance use in high-school students: results from the Youth Risk Behavior Surveillance System. The International Journal of Eating Disorders, 41(5), 464-470.

Provini, F., Vetrugno, R., \& Montagna, P. (2008). Sleep-related smoking syndrome. Sleep Med., 9(8), 903-905. doi: S13899457(07)00441-8

[pii];10.1016/j.sleep.2007.10.021 [doi]

Rand, C. S., \& Kuldau, J. M. (1993). Morbid obesity: a compraison between a general population and obesity surgery patients. International Journal of Obesity, 17, 657-661.

Rand, C. S., Macgregor, A. M., \& Stunkard, A. J. (1997). The night eating syndrome in the general population and among postoperative obesity surgery patients. The International Journal of Eating Disorders, 22(1), 65-69.

Rogers, N. L., Dinges, D. F., Allison, K. C., Maislin, G., Martino, N., O'Reardon, J. P., \& Stunkard, A. J. (2006). Assessment of sleep in 
women with night eating syndrome. Sleep, 29(6), 814-819.

Sandager, N., Peterson, C. B., Allen, S., Henderson, K. E., Crow, S., \& Thuras, P. (2008). Tobacco use and comorbidity in bulimia nervosa. The International Journal of Eating Disorders, 41(8), 734-738. doi: 10.1002/eat.20572 [doi]

Saules, K. K., Collings, A. S., Hoodin, F., Angelella, N. E., Alschuler, K., Ivezaj, V., Saunders-Scott, D., \& Wiedemann, A. A. (2009). The contributions of weight problem perception, BMI, gender, mood, and smoking status to binge eating among college students. Eating Behaviors, 10(1), 1-9.

Striegel-Moore, R. H., Dohm, F. A., Hook, J. M., Schreiber, G. B., Crawford, P. B., \& Daniels, S. R. (2005). Night eating syndrome in young adult women: prevalence and correlates. The International Journal of Eating Disorders, 37(3), 200-206. doi: 10.1002/eat.20128 [doi]

Striegel-Moore, R. H., Franko, D. L., May, A., Ach, E., Thompson, D., \& Hook, J. M. (2006). Should night eating syndrome be included in the DSM? The International Journal of Eating Disorders, 39(7), 544-549.

Striegel-Moore, R. H., Franko, D. L., Thompson, D., Affenito, S., \& Kraemer, H. C. (2006). Night eating: prevalence and demographic correlates. Obesity (Silver Spring), 14(1), 139-147.
Striegel-Moore, R. H., Franko, D. L., Thompson, D., Affenito, S., May, A., \& Kraemer, H. C. (2008). Exploring the typology of night eating syndrome. The International Journal of Eating Disorders, 41(5), 411-418.

Striegel-Moore, R. H., Thompson, D., Franko, D. L., Barton, B., Affenito, S., Schreiber, G. B., \& Daniels, S. R. (2004). Definitions of night eating in adolescent girls. Obes.Res., 12(8), 1311-1321.

Stunkard, A., Berkowitz, R., Wadden, T., Tanrikut, C., Reiss, E., \& Young, L. (1996). Binge eating disorder and the night-eating syndrome. International Journal of Obesity and Related Metabolic Disorders : Journal of the International Association for the Study of Obesity, 20(1), 1-6.

Stunkard, A. J., Allison, K. C., Lundgren, J. D., Martino, N. S., Heo, M., Etemad, B., \& O'Reardon, J. P. (2006). A paradigm for facilitating pharmacotherapy at a distance: sertraline treatment of the night eating syndrome. Journal of Clinical Psychiatry, 67(10), 1568-1572.

Stunkard, A. J., Allison, K. C., Lundgren, J. D., \& O'Reardon, J. P. (2009). A biobehavioural model of the night eating syndrome. Obesity Reviews : An Official Journal of The International Association for The Study of Obesity, 10 Suppl 2, 69-77.

Stunkard, A. J., Grace, W. J., \& Wolff, H. G. (1955). The night-eating syndrome; a pattern of food intake among certain obese patients. The 
American Journal of Medicine, 19(1), disorders. The International Journal 78-86. doi: 0002-9343(55)90276-X of Eating Disorders, 24(2), 157-166. [pii]

Vander Wal, J. S. (2012). Night Troop, N. A., Holbrey, A., \& eating syndrome: a critical review of Treasure, J. L. (1998). Stress, the literature. Clinical Psychology coping, and crisis support in eating Review, 32(1), 49-59. 
Chapter 6. Night Eating Syndrome in Depression 


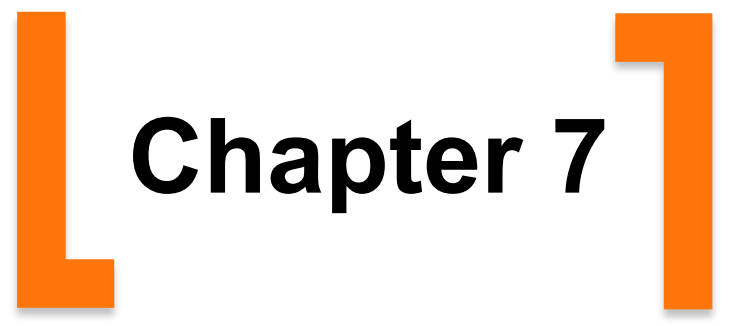


Effects of Curcumin on cognitive functioning and inflammatory state in schizophrenia: A double-blind placebo-controlled pilot trial

Suat Kucukgoncu, Sinan Guloksuz, Cenk Tek Journal of Clinical Psychopharmacology 2019;39:182184. 


\section{Effects of Curcumin on cognitive functioning and inflammatory state in schizophrenia: A double-blind placebo-controlled pilot trial}

Curcumin, derived from turmeric root, is a polyphenol with antioxidant and anti-inflammatory properties.(Naksuriya, Okonogi, Schiffelers, \& Hennink, 2014; Wynn et al., 2017) To our knowledge, only two studies have tested the effectiveness of add-on curcumin in patients with schizophrenia. (WoodburyFarina, 2012; Wynn et al., 2017) In an open-label study, curcumin 1g/day $(n=7)$ and curcumin $4 \mathrm{~g} /$ day $(n=8)$ improved overall neurocognitive index over 12 weeks. More recently, a randomized, double blind, placebo-controlled study showed that curcumin $360 \mathrm{mg} /$ day $(\mathrm{n}=17)$ increased brain-derived neurotrophic factor (BDNF) levels compared to placebo $(n=19)$ after an 8week trial. While this study did not show any significant changes in clinical symptoms and cognitive functioning, improvement on BDNF levels suggested possible long-term benefits of curcumin in cognition and clinical symptoms. (Wynn et al., 2017)

We tested the effects of add-on curcumin for the treatment of cognitive impairment in schizophrenia in an 8-week randomized, double-blind, placebocontrolled, parallel, fixed-dose pilot clinical trial. A total of 12 outpatients with schizophrenia were randomized to curcumin $(180 \mathrm{mg} /$ day $)$ or placebo in a 1:1 ratio. Written informed consent was obtained from all participants. A commercially available surface-controlled water-soluble form of $300 \mathrm{mg}$ curcumin (30\% formulation: $90 \mathrm{mg}$ pure curcumin) or matching placebo capsules were provided by Theravalues Corporation (Tokyo, Japan). Study protocol was approved by IRB (Yale HIC\#1412015121) and registered on ClinicalTrials.gov (NCT02476708). We monitored medication adherence by means of pill count method and patient reports.

The primary outcome measure was between-group changes in MCCB MATRICS Consensus Cognitive Battery (Kern et al., 2008). Secondary outcomes included changes in inflammatory markers (IL-6, TNF- $\alpha$, and High sensitive C-reactive protein), and clinical outcomes (Positive and Negative 
Symptom Scale (PANSS), Calgary Depression Scale for Schizophrenia (CDSS) and UKU Side Effect Checklist).

All statistical analyses were performed in SPSS Statistics Version 24.0 (IBM, NY, USA). Baseline differences and treatment effect in clinical symptoms, cognitive functioning and inflammatory markers were assessed with nonparametric tests. Pearson chi-square analysis and Fisher's exact tests were used for all categorical variables.

The study sample (9 male, 3 female) mostly consisted of chronic schizophrenia patients with mean duration of illness $21.66 \pm 14.84$ years (range 5-51). Mean age of the total sample was $41.33 \pm 12.73$ years and education level were $12.33 \pm 2.42$ years. At baseline, no significant difference was found in sample characteristics, inflammatory markers and clinical outcomes between treatment arms. Table 1 summarizes changes in inflammatory markers, clinical outcomes and cognitive functioning. Compared to placebo, add-on curcumin treatment significantly improved working memory $(Z=2.200, p=0.028)$, and reduced IL-6 levels $(Z=2.402$, $p=0.016)$. No significant effect of curcumin on PANSS and Calgary Depression scores was found. No significant adverse events were reported during the study. The majority of the patients reported that they took the medications as prescribed. Only two patients returned ten capsules in total during the whole study period (4 curcumin and 6 placebo capsules).

In this pilot study, we found that add-on curcumin improved working memory in patients with schizophrenia. Add-on curcumin also reduced IL-6 levels after 8-weeks of treatment. Although improvements in other cognitive domains, negative symptoms and total PANSS score were observed with add-on curcumin, these changes did not reach statistical significance.

To a degree, our findings are in line with previous studies. In an open-label study, Woodbury-Farina et. al. reported improvement in cognitive functioning and negative symptoms with curcumin treatment in patients with 
schizophrenia. (Woodbury-Farina, 2012) Several studies reported beneficial effects of curcumin in working memory, attention and overall cognitive functioning in age-associated cognitive decline. (Cox, Pipingas, \& Scholey, 2015; Rainey-Smith et al., 2016) In contrast, negative results have been reported in other clinical trials. (Sarker \& Franks, 2018) Including ours, most clinical trials on add-on curcumin treatment were conducted with modest to small sample sizes. Moreover, most of these clinical trials tested short-term effects of curcumin. Poor absorption due to low-solubility in water and rapid metabolism remarkably reduces the bioavailability of curcumin, often generating undetectable to low plasma curcumin levels. Recent evidence suggests the nanoparticle-based drug delivery system developed to improve water solubility of curcumin is more than 30 -fold more bioavailable and increases plasma curcumin levels in a dose-dependent manner.(Naksuriya et al., 2014; Sasaki et al., 2011) The conflicting findings on cognitive functioning between studies may be explained by curcumin dosing and bioavailability.(Volak et al., 2013) In our study we used a highly bioavailable and well-tolerated curcumin formulation (Theracurmin ${ }^{\circledR}$ ) at lower dose (180mg total per day) compared to a similar study by Wynn et al. (Wynn et al., 2017)Animal studies has shown that curcumin may act differently at lower and higher doses. At lower doses curcumin reduces cell migration and cell-cell adhesion, while higher doses of curcumin promote cell death in normal cells. (de Campos et al., 2017) Future studies are needed to evaluate different curcumin doses on cognitive functioning.

Our findings also indicated that add-on curcumin treatment decreases IL-6, and to a degree, hs-CRP level. Increased inflammatory response, oxidative stress, and abnormal neuronal pruning has been implicated in schizophrenia. (Barron, Hafizi, Andreazza, \& Mizrahi, 2017) Small sample size in our study limited our efforts to evaluate the relationship between IL-6 level changes and 
cognitive functioning. Nevertheless, our findings suggest that anti-oxidant and anti-inflammatory properties of curcumin may have beneficial effects in cognitive functioning.

This study has some important limitations. We tested short-term effects of curcumin in a small sample that may have resulted in insufficient power to detect small changes in other cognitive domains and clinical symptoms. Although, between group differences on working memory and IL-6 levels indicated improvements with curcumin, small sample size in each group have prevented us from drawing a conclusion regarding to clinical importance. The differences in cognitive functioning between curcumin and placebo groups suggest that the observed effect cannot be entirely explained by practice/learning effects. However, given the short follow-up period, the results should be cautiously interpreted. Finally, our sample mostly represented chronic patients. Therefore, it is also important to test effectiveness of curcumin in cognitive functioning in first episode psychosis patients who may be more amenable to the effects.

In summary, findings from this study suggest that add-on curcumin treatment may improve cognitive functioning in patients with schizophrenia. The underlying mechanism of this promising effect may be related to antiinflammatory effects of curcumin. Overall, a larger confirmatory trial is warranted. 
Table 1. Before and after treatment effects in inflammatory markers, MATRICS scores and clinical outcomes

\begin{tabular}{|c|c|c|c|c|}
\hline & Placebo $n=5$ & Curcumin $n=5$ & \multicolumn{2}{|c|}{$\begin{array}{c}\text { Mann-Whitney } \\
\text { U test }\end{array}$} \\
\hline & $\begin{array}{l}\text { Mean change } \\
\text { from baseline }\end{array}$ & $\begin{array}{l}\text { Mean change } \\
\text { from baseline }\end{array}$ & $Z$ & $\mathrm{p}$ \\
\hline \multicolumn{5}{|l|}{$\begin{array}{l}\text { Inflammatory } \\
\text { markers }\end{array}$} \\
\hline hs-CRP mg/L & $3.64 \pm 8.85$ & $-5.25 \pm 7.73$ & 1.776 & 0.076 \\
\hline IL-6 pg/ml & $0.63 \pm 0.91$ & $-1.15 \pm 0.86$ & 2.402 & 0.016 \\
\hline $\begin{array}{l}\text { TNF alpha } p g / m l \\
\text { MATRICS }\end{array}$ & $-0.01 \pm 0.19$ & $-0.13 \pm 0.17$ & 1.358 & 0.175 \\
\hline $\begin{array}{l}\text { Working } \\
\text { memory }\end{array}$ & $-4.00 \pm 5.52$ & $10.60 \pm 15.17$ & 2.200 & 0.028 \\
\hline $\begin{array}{l}\text { Attention- } \\
\text { Vigilance }\end{array}$ & $-6.80 \pm 12.79$ & $9.20 \pm 18.18$ & 1.257 & 0.209 \\
\hline Problem solving & $0.40 \pm 4.09$ & $2.00 \pm 2.91$ & 0.849 & 0.396 \\
\hline Verbal learning & $-2.00 \pm 8.21$ & $-4.60 \pm 6.34$ & 0.525 & 0.599 \\
\hline Visual learning & $2.60 \pm 9.20$ & $6.40 \pm 8.17$ & 0.524 & 0.600 \\
\hline $\begin{array}{l}\text { Speed } \\
\text { processing }\end{array}$ & $-3.00 \pm 13.20$ & $5.00 \pm 2.91$ & 1.571 & 0.116 \\
\hline Social cognition & $-4.80 \pm 16.85$ & $4.44 \pm 27.02$ & 0.522 & 0.602 \\
\hline $\begin{array}{l}\text { Composite } \\
\text { score } \\
\text { PANSS }\end{array}$ & $-3.80 \pm 8.84$ & $6.00 \pm 6.28$ & 1.485 & 0.138 \\
\hline Positive & $-0.60 \pm 3.04$ & $-0.40 \pm 3.13$ & 0.210 & 0.834 \\
\hline Negative & $-1.40 \pm 3.50$ & $-1.80 \pm 6.14$ & 0.318 & 0.750 \\
\hline General & $2.40 \pm 6.94$ & $0.20 \pm 4.20$ & 0.525 & 0.599 \\
\hline Total & $0.60 \pm 12.30$ & $-2.00 \pm 9.16$ & 0.211 & 0.833 \\
\hline $\begin{array}{l}\text { Calgary } \\
\text { Depression }\end{array}$ & $-0.50 \pm 0.57$ & $0.00 \pm 2.22$ & 1.028 & 0.304 \\
\hline
\end{tabular}


References

Barron, H., Hafizi, S., Andreazza, A. Psychiatry, 165(2), 214-220. doi: C., \& Mizrahi, R. (2017). 10.1176/appi.ajp.2007.07010043 Neuroinflammation and Oxidative

Stress in Psychosis and Psychosis

Risk. International Journal of Molecular Sciences, 18(3), 651. doi: 10.3390/ijms18030651

Cox, K. H., Pipingas, A., \& Scholey, A. B. (2015). Investigation of the effects of solid lipid curcumin on cognition and mood in a healthy older population. J Psychopharmacol, 29(5), 642-651. doi: $10.1177 / 0269881114552744$

de Campos, P. S., Matte, B. F., Diel, L. F., Jesus, L. H., Bernardi, L., Alves, A. M., . . . Lamers, M. L. (2017). Low Doses of Curcuma longa Modulates Cell Migration and CellCell Adhesion. Phytother Res, 31(9), 1433-1440. doi: 10.1002/ptr.5872

Kern, R. S., Nuechterlein, K. H., Green, M. F., Baade, L. E., Fenton, W. S., Gold, J. M., . . Marder, S. R. (2008). The MATRICS Consensus Cognitive Battery, part 2: co-norming and standardization. $A m \quad J$
Naksuriya, O., Okonogi, S., Schiffelers, R. M., \& Hennink, W. E. (2014). Curcumin nanoformulations: a review of pharmaceutical properties and preclinical studies and clinical data related to cancer treatment. Biomaterials, 35(10), 3365-3383. doi: 10.1016/j.biomaterials.2013.12.090 Rainey-Smith, S. R., Brown, B. M., Sohrabi, H. R., Shah, T., Goozee, K. G., Gupta, V. B., \& Martins, R. N. (2016). Curcumin and cognition: a randomised, placebo-controlled, double-blind study of communitydwelling older adults. $\mathrm{Br} J$ Nutr, 115(12), 2106-2113. doi: 10.1017/S0007114516001203

Sarker, M. R., \& Franks, S. F. (2018). Efficacy of curcumin for ageassociated cognitive decline: a narrative review of preclinical and clinical studies. Geroscience. doi: $10.1007 / s 11357-018-0017-z$ 
Sasaki, H., Sunagawa, Y., Woodbury-Farina, M., Cernovsky, Z., Takahashi, K., Imaizumi, A., Fukuda, Chiu, S., Bureau, Y., Campbell, R., H., Hashimoto, T., . . Morimoto, T. Houicin, J., Terpstra, K., Rehab, H., (2011). Innovative preparation of Husni, M., Badmeav, V. (2012). curcumin for improved oral Proof of concept of randomized bioavailability. Biol Pharm Bull, controlled study of Curcumin C-3 34(5), 660-665.

Complex as adjunct treatment in schizophrenia: effects on negative Volak, L. P., Hanley, M. J., Masse, and depressive symptoms. . Paper G., Hazarika, S., Harmatz, J. S., presented at the Natural Bioactives Badmaev, V., ... Court, M. H. (2013). Conference, Ontario, Canada.

Effect of a herbal extract containing curcumin and piperine on Wynn, J. K., Green, M. F., midazolam, flurbiprofen and Hellemann, G., Karunaratne, K., paracetamol (acetaminophen) Davis, M. C., \& Marder, S. R. (2017). pharmacokinetics in healthy The effects of curcumin on brainvolunteers. $\mathrm{Br} J$ Clin Pharmacol, derived neurotrophic factor and 75(2), 450-462. doi: 10.1111/j.1365- cognition in schizophrenia: A 2125.2012.04364.x randomized controlled study. Schizophr Res. doi: 10.1016/j.schres.2017.09.046 
Chapter 7. Curcumin on Cognitive Functioning and Inflammation

$216 \quad$ Metabolic Disturbances in Mental Illness - S Kucukgoncu 


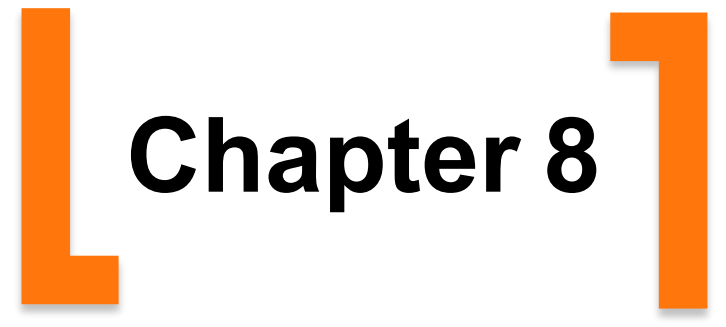

\section{Discussion}


The main aim of this thesis was to evaluate the factors that lead to the increased obesity rates and diabetes incidence in people with serious mental illness (SMI). For this purpose, I have explored various risk factors (e.g. antipsychotic medication adverse-effects, biological vulnerability, eating patterns) in SMI populations. Chapter 2 discussed the biological vulnerability for glucose metabolism disturbances in first episode, treatment-naïve patients with SMI. Individual effects of antipsychotic medications on body weight gain in patients with first episode psychosis (FEP) was discussed in Chapter 3. Chapter 4 provided the effects of alpha-lipoic acid as an alternative weight management supplementation in various diagnostic categories, including schizophrenia, diabetes and metabolic syndrome. In Chapter 5, the association between pregnancy term antipsychotic exposure and gestational diabetes was discussed. Chapter 6 discussed an altered eating pattern, Night Eating Syndrome (NES), in patients with major depression. Finally, Chapter 7 presented the results of add-on curcumin treatment on inflammatory markers and cognitive functioning in patients with schizophrenia.

\section{Shared Biological Vulnerability Between Serious Mental} IIInesses and Glucose Metabolism Disturbances

People with SMI have higher than expected rates of diabetes (Correll et al., 2017; Vancampfort et al., 2016; Walker, McGee, \& Druss, 2015). In order to explain the relationship between diabetes and SMI, following explanations have been provided: antipsychotic medication related adverseeffects, inflammation and innate vulnerability (D. B. Allison et al., 1999; Calkin, Gardner, Ransom, \& Alda, 2013; C. Garcia-Rizo, Kirkpatrick, Fernandez-Egea, Oliveira, \& Bernardo, 2016; Greenhalgh et al., 2016; Guha et al., 2014). It is no surprise that antipsychotic treatment related adverse effects, particularly body weight gain, has a considerable impact on the development of glucose metabolism abnormalities in SMI population. Similarly, the role of inflammatory mediators on both diabetes and SMIs partly explain the comorbidity (Calkin et al., 2013; Perry, Mclntosh, Weich, Singh, \& Rees, 2016; Vancampfort et al., 2016). In addition to these factors, research 


\section{Chapter 8. Discussion}

also suggests an inherent susceptibility to diabetes in patients with schizophrenia. Family studies have revealed that family members of patients with schizophrenia have an increased risk of diabetes (Miller et al., 2016; Mukherjee, Schnur, \& Reddy, 1989). Also, parental diabetes was reported as a significant predictor of development of diabetes in patients with psychotic spectrum disorders (Miller et al., 2016). Data from first episode psychosis patients has also provided valuable information regarding the inherited glucose metabolism vulnerability in SMls. Recent studies with treatmentnaïve, first episode psychosis patients have shown higher insulin resistance, $\mathrm{HbA1c}$, fasting insulin levels and impaired glucose tolerance in these patients compared to the general population (Arranz et al., 2004; Misiak et al., 2016; Ryan, Collins, \& Thakore, 2003; Spelman, Walsh, Sharifi, Collins, \& Thakore, 2007). These findings have also confirmed in three recent meta-analyses (Greenhalgh et al., 2016; Perry et al., 2016; Pillinger et al., 2017). Increased diabetes prevalence is also an emerging medical problem in other SMls, such as bipolar disorder and major depression. Limited number of studies have also indicated that other SMIs (bipolar disorder, major depression) may be carrying similar vulnerability to develop glucose metabolism disturbances (Chang et al., 2013; Clemente Garcia-Rizo et al., 2013; Guha et al., 2014). However, glucose metabolism differences in specific SMI groups are yet to be fully evaluated in future studies.

In an attempt to examine the existing body of knowledge, Chapter 2 presented findings from a systematic review and meta-analysis on glucose metabolism disturbances in treatment-naïve, first episode patients with SMIs. Overall, cumulative findings of this meta-analysis confirmed an increase in fasting glucose, insulin resistance levels and impaired oral glucose tolerance in patients with first episode psychosis (Greenhalgh et al., 2016; Perry et al., 2016; Pillinger et al., 2017). Impaired oral glucose tolerance in mood disorders also indicated an innate vulnerability to diabetes in this patient population. This meta-analysis showed no significant differences of glucose levels between patients with first episode psychosis and mood disorders. 
In general, these findings suggest an impaired glucose metabolism at the beginning of all SMls. Chapter 2 summarized various mechanisms to explain this pre-diabetic condition in first episode patients with SMI. These underlying mechanisms can be listed as: altered systemic inflammation, shared genetic make-up between SMI and diabetes, early environmental factors (i.e. prenatal and postnatal events) and acutely stressful state at the beginning of SMI. However, this meta-analysis was not designed to examine the causative relationship between diabetes and first episode SMIs in detail. Therefore, future studies on glucose metabolism outcomes in drug-naïve first episode SMIs are needed to explain the differences between the diagnostic groups and the causality of the relationship.

\section{Obesity is partly an iatrogenic problem in serious mental}

\section{illnesses}

Patients with SMI are exposed to the same obesogenic environment as the rest of us. They are also more likely to drift down to a more obesity vulnerable socioeconomic status due to functional impairments. Negative symptoms in psychotic spectrum disorders and cognitive impairments affect nutrition knowledge and motivation in patients with SMI. Moreover, they are less likely to have moderate physical activity (Ratliff et al., 2012). The single most important common factor among the diseases that constitute SMI is the necessity of continuous use of antipsychotic medications. Given the preantipsychotic era historical data that typically points to lower than population average body weight in untreated chronic schizophrenia patients (Baganz, 1943; Sharp \& Baganz, 1940), as well as metabolic profiles that are similar to those of historical cohorts (Padmavati, McCreadie, \& Tirupati, 2010), increased obesity rate in patients with schizophrenia is partly an iatrogenic problem (D. B. Allison et al., 1999). Numerous studies in chronic patients have shown the individual effects of antipsychotic medications on body weight (Lieberman et al., 2005; Newcomer \& Hennekens, 2007; Newcomer \& S., 2005). On the other hand, we have limited knowledge on individual weight gain liabilities of antipsychotic medications in first-episode patients. Since 


\section{Chapter 8. Discussion}

antipsychotic medication trials in first episode patients do not involve placebo control arms, findings from these studies do not reflect the natural course of body weight in this mostly younger and still growing population. In order to isolate the natural growth process effect and provide better estimates of antipsychotic related body weight gain, I presented a systematic review and meta-analysis of antipsychotic related body weight gain in first episode patient population in Chapter 3. In this meta-analysis, body weight change data from a prodromal patient population was used as a control group (Woods et al., 2003). Findings from this meta-analysis showed that almost all included antipsychotic medications were associated with body weight gain in the shortterm ( $<12$ weeks) and long-term ( $>12$ weeks). Among the included antipsychotic medications, olanzapine and clozapine was found to be the most body weight increasing agents. Unlike studies from chronic patients, haloperidol and aripiprazole were also associated with body weight gain in first episode patients. These findings highlight the importance of initial antipsychotic medications to prevent obesity in first episode patients.

Treatment of obesity in the general population, as well as in SMI, presents significant challenges. Behavioral interventions for antipsychotic induced weight gain are essential but not sufficient. Numerous clinical intervention trials, using a variety of behavioral methods, showed limited benefits for patients with SMI, particularly compared to antipsychotic medications induced weight gain in the long-term (Naslund et al., 2017); often, pharmacological interventions become necessary (Tek, Ratliff, Reutenauer, Ganguli, \& O'Malley, 2014). However, most of the approved treatments for obesity (i.e. topiramate, phentermine) have varying tolerability issues in patients with SMI. Therefore, it is important to evaluate alternative pharmacological options to treat obesity. For this purpose, Chapter 4 provided a systematic review and meta-analysis that evaluated the effects of alpha lipoic acid in various samples (i.e. patients with diabetes, patients with schizophrenia) as a weight-loss supplement. As an antioxidant and a free radical scavenger, alpha lipoic acid has been shown to reduce body weight 


\section{Chapter 8. Discussion}

in animal studies (Carbonelli et al., 2010; Huerta, Navas-Carretero, PrietoHontoria, Martinez, \& Moreno-Aliaga, 2015). Clinical trials with various samples yielded inconsistent results (Ansar, Mazloom, Kazemi, \& Hejazi, 2011; Carbonelli et al., 2010; Huerta et al., 2015). Cumulative results from this meta-analysis showed that alpha lipoic acid treatment provides small but significant decrease in body weight $(1.2 \mathrm{~kg})$. However, only limited number of studies with small sample sizes have evaluated alpha-lipoic acid in patients with SMI. This meta-analysis included only one small sample sized study of patients with schizophrenia, which showed no significant weight loss with alpha lipoic acid treatment (-1.34 kg vs 1.74 in placebo arm) (Kim et al., 2016). On the other hand, two open-label studies have indicated that alpha-lipoic acid may help patients with schizophrenia lose weight (Ratliff, Palmese, Reutenauer, \& Tek, 2013), and may also improve psychopathology outcomes, neurocognitive parameters and extrapyramidal symptoms (Sanders et al., 2017). Therefore, findings from this meta-analysis suggest that alpha-lipoic acid may provide a cost-effective and well tolerable supplementation for body weight management in selected individuals. Additionally, alpha-lipoic acid may also be helpful to improve clinical outcomes, through its antioxidant effects, in patient with SMI. Future clinical trials with larger sample sizes should evaluate the promising effects of alphalipoic acid in patients with SMI.

\section{Antipsychotic exposure and the risk of gestational diabetes}

Changes on glucose metabolism are a part of the natural course of pregnancy. In general, increased metabolic demand and placental hormones lead to insulin resistance in pregnancy. Naturally, insulin resistance is overcome by increased insulin levels (Buchanan, Xiang, Kjos, \& Watanabe, 2007). Various factors (i.e. maternal age, obesity, previous physical disorders) that affect this balance can cause glucose metabolism dysregulation and gestational diabetes. Consequently, antipsychotic medication exposure may cause additional challenges to regulate glucose levels in pregnant women with SMI (Kulkarni et al., 2015; Park et al., 2018). 


\section{Chapter 8. Discussion}

As discussed in Chapter 3, antipsychotic medications, particularly secondgeneration antipsychotics, have been associated with significant body weight gain and diabetes. Furthermore, patients with SMI are already vulnerable to develop glucose metabolism abnormalities at the onset of the disease (Tomasik et al., 2019). Therefore, it is expected that antipsychotic-exposure in pregnant women with SMI is at high risk of developing gestational diabetes. However, only limited number of studies have evaluated the association between pregnancy term antipsychotic exposure and gestational diabetes risk (Bellet et al., 2015; Boden et al., 2012; McKenna et al., 2005; Reis \& Kallen, 2008). Chapter 5 conducted a systematic review and meta-analysis to assess GDM risk associated with antipsychotic-exposure in pregnancy. In this meta-analysis I tested the differences of GMD risk in three groups: antipsychotic-exposed pregnant women, antipsychotic-ceased pregnant women and healthy controls. Compared to the healthy control cohorts, unadjusted and adjusted risk of GDM was found to be higher in antipsychoticexposed pregnant women. Findings of this meta-analysis also showed that withdrawing antipsychotic medication in pregnancy does not change the risk of GDM development.

These findings indicate an increased risk of GDM with antipsychoticexposure in pregnant women, who may benefit from additional care in pregnancy and pre-pregnancy term. Clinicians should carefully evaluate the benefits and drawbacks of antipsychotic medication use during pregnancy. Antipsychotic medications should be used in patients with SMI that are not manageable otherwise. If the initiation or continuation of an antipsychotic treatment in pregnancy term is decided, a medication with lower weight gain side effect should be preferred. Treatment regimen should be adjusted according to the changes in drug metabolism during pregnancy and the plasma levels (Whitworth, 2017). A careful review of individual patient related factors and shared clinical decision making on a case by case basis is crucial in managing GDM risk among antipsychotic users. Additionally, women with SMI should be monitored closely for unwanted pregnancies during the pre- 
pregnancy and pregnancy terms, and life-style modifications that target modifiable risk factors should be encouraged.

\section{A disordered eating pattern: Night Eating Syndrome}

Eating patterns are one area of focus to explain increased obesity rates in SMI (Palmese et al., 2012). Night eating syndrome (NES), a delayed type of eating pattern, has been assumed to cause obesity (Bruzas \& Allison, 2019; Kucukgoncu, Midura, \& Tek, 2015). Although research showed inconsistent findings on the relationship between NES and obesity, NES is proposed to be a contributor to later-life obesity (Marshall, Allison, O'Reardon, Birketvedt, \& Stunkard, 2004; Palmese et al., 2012; Yoshida, Eguchi, Nagaoka, Ito, \& Ogino, 2018). Moreover, a recent longitudinal study has shown that individuals with night eating habits at baseline are more prone to develop metabolic syndrome and dyslipidemia than those without NES (Yoshida et al., 2018).

Research indicates a bidirectional relationship between NES and depression (K. C. Allison et al., 2005; Calugi, Dalle Grave, \& Marchesini, 2009; O'Reardon et al., 2004). While patients with NES reported higher depression levels than individuals without NES, patients with major depression also reported increased rates of NES than the general population (Kucukgoncu \& Bestepe, 2014; Lundgren, Allison, O'Reardon, \& Stunkard, 2008). Chapter 6 presented a cross-sectional study that investigated the frequency and clinical features of NES in a sample of patients with depression, with a $21.3 \%$ prevalence of NES. In addition to supporting the relationship between depression and NES, findings from this study also showed deteriorating effects of NES on the clinical outcomes in depressed patients. Depressed patients with NES had higher depression, anxiety, BMI levels, smoking rates and lower sleep qualities than those patients without NES. Overall findings from this study suggest a complex relationship between NES and depression as determined by factors such as sleep, smoking, and body weight. 


\section{Chapter 8. Discussion}

Given the link between depression and NES, it is important to identify eating habits in patients with major depression. Patients with psychiatric disorders who also have NES may be unaware of their altered eating pattern and its consequences. Therefore, mental health professionals should be aware of the risk for NES in their patients. Screening and assessment tools for NES may help professionals identify these patients (Kucukgoncu, Tek, Bestepe, Musket, \& Guloksuz, 2014). To our knowledge, no treatment study has been conducted for the treatment of NES in major depression. Although, selective serotonin reuptake inhibitors can help to treat both conditions, relaxation exercises and life style interventions should also be employed during the treatment.

\section{Immune Activation and Cognitive Functioning in Patients with Schizophrenia}

Aberrant immune response in patients with schizophrenia has been associated with the pathoetiology, clinical outcomes and cognitive functioning (Asevedo et al., 2013; Dickerson, Stallings, Origoni, Boronow, \& Yolken, 2007; Fineberg \& Ellman, 2013; Miller, Buckley, Seabolt, Mellor, \& Kirkpatrick, 2011; Schulz \& Murray, 2016). Research in patients with schizophrenia shows that immune activation may lead to more severe cognitive impairment in individuals with CRP $\geq 5.0 \mathrm{mg} / \mu \mathrm{l}$ compared to those with $\mathrm{CRP}<5.0 \mathrm{mg} / \mu \mathrm{l}$; and that chemotactic cytokines, also known as chemokines, are correlated with cognitive domain scores, e.g. working memory, verbal fluency (Asevedo et al., 2013; Dickerson et al., 2007). Moreover, early low-grade inflammatory response was found to be related to better cognitive recovery in acute psychotic episodes (Fathian et al., 2019).

Cognitive dysfunction has detrimental effects on functional outcomes in patients with schizophrenia. However, current psychopharmacological and psychosocial treatment options have few, if any, beneficial effects on cognitive performance (Fathian et al., 2019). In light of the putative role of inflammation in cognitive functioning, a number of clinical trials have tested the effectiveness of anti-inflammatory medications in patients with 


\section{Chapter 8. Discussion}

schizophrenia (Muller, Riedel, Schwarz, \& Engel, 2005; Nitta et al., 2013; Vreeker, van Bergen, \& Kahn, 2015). Although a few of these trials have showed some improvements on cognitive functioning (Levkovitz et al., 2010; Liu et al., 2014), several others have failed to confirm these findings (Muller et al., 2005; Nitta et al., 2013; Vreeker et al., 2015). Nevertheless, modifying inflammatory response in schizophrenia provides some clinical improvements, and thus may lead to a better cognitive functioning (Muller et al., 2005; Nitta et al., 2013; Vreeker et al., 2015). In this respect, Chapter 7 provided findings from an add-on curcumin trial of inflammatory markers and cognitive functioning in patients with schizophrenia. In this randomized, double-blind, placebo-controlled study, curcumin treatment significantly improved working memory, and reduced IL-6 levels in comparison to placebo. Although the study sample was small and the study tested the short term (8 weeks) effects of curcumin, our findings suggest that curcumin treatment may have beneficial effects in cognitive functioning, likely through anti-oxidant and anti-inflammatory mechanisms, in patients with schizophrenia.

\section{Conclusion}

Findings represented in this thesis underline the importance of early identification of major risk factors for cardiovascular diseases, and also initiating early strategies to prevent cardiovascular related morbidity and mortality, in patients with SMI. First and foremost, detailed medical history and physical examination, including family history of diabetes, smoking habit, dietary and physical activity habits, sleep patterns, body mass index, fasting blood glucose and insulin levels should be obtained as a golden rule at the start of SMI. When deciding on the initial antipsychotic treatment, antipsychotic medication with a lower weight gain liability should be considered to prevent obesity and related cardiovascular risk. After the initiation of psychotropic treatment, body weight and diabetes risk should be evaluated annually. Health promising strategies like behavioral interventions, lifestyle changes and smoking cessation should be implemented as part of regular treatment modalities in patients with SMI. Finally, better 


\section{Chapter 8. Discussion}

pharmacological treatment options are needed to decrease the risk of cardiovascular disease in patients with SMI. 
References

Allison, D. B., Mentore, J. L., Heo, M., Chandler, L. P., Cappelleri, J. C., Infante, M. C., \& Weiden, P. J. (1999). Antipsychotic-induced weight gain: a comprehensive research synthesis. Am J Psychiatry, 156(11), 1686-1696.

doi:

10.1176/ajp.156.11.1686

Allison, K. C., Ahima, R. S., O'Reardon, J. P., Dinges, D. F., Sharma, V., Cummings, D. E., . . . Stunkard, A. J. (2005). Neuroendocrine profiles associated with energy intake, sleep, and stress in the night eating syndrome. J.Clin.Endocrinol.Metab, 90(11), 6214-6217. doi: jc.2005-1018 [pii];10.1210/jc.2005-1018 [doi]

Ansar, H., Mazloom, Z., Kazemi, F., \& Hejazi, N. (2011). Effect of alphalipoic acid on blood glucose, insulin resistance and glutathione peroxidase of type 2 diabetic patients. Saudi Med J, 32(6), 584588.

Arranz, B., Rosel, P., Ramirez, N., Duenas, R., Fernandez, P., Sanchez, J. M., . . . San, L. (2004). Insulin resistance and increased leptin concentrations in noncompliant schizophrenia patients but not in antipsychotic-naive firstepisode schizophrenia patients. $J$ Clin Psychiatry, 65(10), 1335-1342.

Asevedo, E., Gadelha, A., Noto, C., Mansur, R. B., Zugman, A., Belangero, S. I., . . . Brietzke, E.
(2013). Impact of peripheral levels of chemokines, BDNF and oxidative markers on cognition in individuals with schizophrenia. J Psychiatr Res, 47(10), 1376-1382. doi: 10.1016/j.jpsychires.2013.05.032

Baganz, C. N. (1943). A study of malnutrition in chronic schizophrenia. American Journal of Psychiatry, 99(4), 534-541. doi: DOI 10.1176/ajp.99.4.534

Bellet, F., Beyens, M.-N., Bernard, N., Beghin, D., Elefant, E., \& Vial, T. (2015). Exposure to aripiprazole during embryogenesis: a prospective multicenter cohort study. Pharmacoepidemiology and Drug Safety, 24(4), 368-380. doi: 10.1002/pds.3749

Boden, R., Lundgren, M., Brandt, L., Reutfors, J., Andersen, M., \& Kieler, H. (2012). Risks of adverse pregnancy and birth outcomes in women treated or not treated with mood stabilisers for bipolar disorder: population based cohort study. British Medical Journal, 345. doi: 10.1136/bmj.e7085

Bruzas, M. B., \& Allison, K. C. (2019). A Review of the Relationship between Night Eating Syndrome and Body Mass Index. Curr Obes Rep. doi: 10.1007/s13679-019-00331-7

Buchanan, T. A., Xiang, A., Kjos, S. L., \& Watanabe, R. (2007). What is gestational diabetes? Diabetes Care, 
30 Suppl 2, S105-111. doi: $10.2337 / d c 07-s 201$

Calkin, C. V., Gardner, D. M., Ransom, T., \& Alda, M. (2013). The relationship between bipolar disorder and type 2 diabetes: more than just co-morbid disorders. Ann Med, 45(2), 171-181. doi: 10.3109/07853890.2012.687835

Calugi, S., Dalle Grave, R., \& Marchesini, G. (2009). Night eating syndrome in class II-III obesity: metabolic and psychopathological features. Int J Obes (Lond), 33(8), 899-904. doi: 10.1038/ijo.2009.105

Carbonelli, M. G., Di Renzo, L., Bigioni, M., Di Daniele, N., De Lorenzo, A., \& Fusco, M. A. (2010). Alpha-lipoic acid supplementation: a tool for obesity therapy? Curr Pharm Des, 16(7), 840-846.

Chang, H. H., Chi, M. H., Lee, I. H., Tsai, H. C., Gean, P. W., Yang, Y. K., . . Chen, P. S. (2013). The change of insulin levels after six weeks antidepressant use in drug-naive major depressive patients. J Affect Disord, 150(2), 295-299. doi: 10.1016/j.jad.2013.04.008

Correll, C. U., Solmi, M., Veronese, N., Bortolato, B., Rosson, S., Santonastaso, P., . . Stubbs, B. (2017). Prevalence, incidence and mortality from cardiovascular disease in patients with pooled and specific severe mental illness: a large-scale meta-analysis of $3,211,768$ patients and $113,383,368$ controls. World Psychiatry, 16(2), 163-180. doi: 10.1002/wps.20420
Dickerson, F., Stallings, C., Origoni, A., Boronow, J., \& Yolken, R. (2007). $\mathrm{C}$-reactive protein is associated with the severity of cognitive impairment but not of psychiatric symptoms in individuals with schizophrenia. Schizophr Res, 93(1-3), 261-265. doi: 10.1016/j.schres.2007.03.022

Fathian, F., Løberg, E.-M., Gjestad, R., Steen, V. M., Kroken, R. A., Jørgensen, H. A., \& Johnsen, E. (2019). Associations between Creactive protein levels and cognition during the first 6 months after acute psychosis. Acta neuropsychiatrica, 31(1), 36-45. doi: $10.1017 /$ neu. 2018.25

Fineberg, A. M., \& Ellman, L. M. (2013). Inflammatory cytokines and neurological and neurocognitive alterations in the course of schizophrenia. Biol Psychiatry, 73(10), 951-966. doi: 10.1016/j.biopsych.2013.01.001

Garcia-Rizo, C., Fernandez-Egea, E., Miller, B. J., Oliveira, C., Justicia, A., Griffith, J. K., . . Kirkpatrick, B. (2013). Abnormal glucose tolerance, white blood cell count, and telomere length in newly diagnosed, antidepressant-naïve patients with depression. Brain, Behavior, and Immunity, 28, 49-53. doi: http://dx.doi.org/10.1016/j.bbi.2012. 11.009

Garcia-Rizo, C., Kirkpatrick, B., Fernandez-Egea, E., Oliveira, C., \& Bernardo, M. (2016). Abnormal glycemic homeostasis at the onset of serious mental illnesses: A common pathway. 
Psychoneuroendocrinology, 67, 7075. doi:

10.1016/j.psyneuen.2016.02.001

Greenhalgh, A. M., GonzalezBlanco, L., Garcia-Rizo, C., Fernandez-Egea, E., Miller, B., Arroyo, M. B., \& Kirkpatrick, B. (2016). Meta-analysis of glucose tolerance, insulin, and insulin resistance in antipsychotic-naive patients with nonaffective psychosis. Schizophr Res. doi: 10.1016/j.schres.2016.09.026

Guha, P., Bhowmick, K., Mazumder, P., Ghosal, M., Chakraborty, I., \& Burman, P. (2014). Assessment of insulin resistance and metabolic syndrome in drug naive patients of bipolar disorder. Indian journal of clinical biochemistry : IJCB, 29(1), 51-56. doi: 10.1007/s12291-0120292-x

Huerta, A. E., Navas-Carretero, S., Prieto-Hontoria, P. L., Martinez, J. A., \& Moreno-Aliaga, M. J. (2015). Effects of alpha-lipoic acid and eicosapentaenoic acid in overweight and obese women during weight loss. Obesity (Silver Spring), 23(2), 313-321. doi: 10.1002/oby.20966

Kim, N. W., Song, Y. M., Kim, E., Cho, H. S., Cheon, K. A., Kim, S. J., \& Park, J. Y. (2016). Adjunctive alpha-lipoic acid reduces weight gain compared with placebo at 12 weeks in schizophrenic patients treated with atypical antipsychotics: a doubleblind randomized placebo-controlled study. Int Clin Psychopharmacol, 31(5), 265-274. doi: 10.1097/YIC.0000000000000132
Kucukgoncu, S., \& Bestepe, E. (2014). Night Eating Syndrome in Major Depression and Anxiety Disorders. Noro Psikiyatr Ars, 51(4), 368-375.

10.5152/npa.2014.7204

Kucukgoncu, S., Midura, M., \& Tek, C. (2015). Optimal management of night eating syndrome: challenges and solutions. Neuropsychiatr Dis Treat, 11, 751-760. doi: 10.2147/NDT.S70312

Kucukgoncu, S., Tek, C., Bestepe, E., Musket, C., \& Guloksuz, S. (2014). Clinical features of night eating syndrome among depressed patients. Eur Eat Disord Rev, 22(2), 102-108. doi: 10.1002/erv.2280

Kulkarni, J., Storch, A., Baraniuk, A., Gilbert, H., Gavrilidis, E., \& Worsley, R. (2015). Antipsychotic use in pregnancy. Expert Opin Pharmacother, 16(9), 1335-1345. doi:

10.1517/14656566.2015.1041501

Levkovitz, Y., Mendlovich, S., Riwkes, S., Braw, Y., LevkovitchVerbin, H., Gal, G., . . . Kron, S. (2010). A double-blind, randomized study of minocycline for the treatment of negative and cognitive symptoms in early-phase schizophrenia. J Clin Psychiatry, 71(2), 138-149. doi: 10.4088/JCP.08m04666yel

Lieberman, J. A., Stroup, T. S., McEvoy, J. P., Swartz, M. S., Rosenheck, R. A., Perkins, D. O., . . . Hsiao, J. K. (2005). Effectiveness of antipsychotic drugs in patients with 
chronic schizophrenia. N Engl J Med, 353(12), 1209-1223. doi: 10.1056/NEJMoa051688

Liu, F., Guo, X., Wu, R., Ou, J., Zheng, Y., Zhang, B., . . Zhao, J. (2014). Minocycline supplementation for treatment of negative symptoms in early-phase schizophrenia: a double blind, randomized, controlled trial. Schizophr Res, 153(1-3), 169176. doi: 10.1016/j.schres.2014.01.011

Lundgren, J. D., Allison, K. C., O'Reardon, J. P., \& Stunkard, A. J. (2008). A descriptive study of nonobese persons with night eating syndrome and a weight-matched comparison group. Eat.Behav., 9(3), 343-351. doi: S14710153(08)00002-0

[pii];10.1016/j.eatbeh.2007.12.004 [doi]

Marshall, H. M., Allison, K. C., O'Reardon, J. P., Birketvedt, G., \& Stunkard, A. J. (2004). Night eating syndrome among nonobese persons. Int.J.Eat.Disord., 35(2), 217-222. doi: 10.1002/eat.10241 [doi]

McKenna, K., Koren, G., Tetelbaum, M., Wilton, L., Shakir, S., Diav-Citrin, O., . . . Einarson, A. (2005). Pregnancy outcome of women using atypical antipsychotic drugs: a prospective comparative study. J Clin Psychiatry, 66(4), 444-449; quiz 546.

Miller, B. J., Buckley, P., Seabolt, W., Mellor, A., \& Kirkpatrick, B. (2011). Meta-analysis of cytokine alterations in schizophrenia: clinical status and antipsychotic effects. Biol Psychiatry, 70(7), 663-671. doi: 10.1016/j.biopsych.2011.04.013

Miller, B. J., Goldsmith, D. R., Paletta, N., Wong, J., Kandhal, P., Black, C., . . Buckley, P. F. (2016). Parental type 2 diabetes in patients with non-affective psychosis. Schizophr Res, 175(1-3), 223-225. doi: 10.1016/j.schres.2016.04.035

Misiak, B., Laczmanski, L., Sloka, N. K., Szmida, E., Piotrowski, P., Loska, O., . . . Frydecka, D. (2016). Metabolic dysregulation in firstepisode schizophrenia patients with respect to genetic variation in onecarbon metabolism. Psychiatry Res, 238, 60-67. doi: 10.1016/j.psychres.2016.01.077

Mukherjee, S., Schnur, D. B., \& Reddy, R. (1989). Family history of type 2 diabetes in schizophrenic patients. Lancet, 1(8636), 495.

Muller, N., Riedel, M., Schwarz, M. J., \& Engel, R. R. (2005). Clinical effects of COX-2 inhibitors on cognition in schizophrenia. Eur Arch Psychiatry Clin Neurosci, 255(2), 149-151. doi: 10.1007/s00406-0040548-4

Naslund, J. A., Whiteman, K. L., McHugo, G. J., Aschbrenner, K. A., Marsch, L. A., \& Bartels, S. J. (2017). Lifestyle interventions for weight loss among overweight and obese adults with serious mental illness: A systematic review and metaanalysis. Gen Hosp Psychiatry, 47, 83-102. doi: 
10.1016/j.genhosppsych.2017.04.00 3

Newcomer, J. W., \& Hennekens, C. H. (2007). Severe mental illness and risk of cardiovascular disease. JAMA, 298(15), 1794-1796. doi: 10.1001/jama.298.15.1794

Newcomer, J. W., \& S., C. N. (2005). Second-generation

(atypical) antipsychotics and metabolic effects: a comprehensive I iterature review. 19 Suppl, 1 SRC - BaiduScholar, 193.

Nitta, M., Kishimoto, T., Muller, N., Weiser, M., Davidson, M., Kane, J. M., \& Correll, C. U. (2013). Adjunctive Use of Nonsteroidal Antiinflammatory Drugs for Schizophrenia: A Meta-analytic Investigation of Randomized Controlled Trials. Schizophr Bull, 39(6), 1230-1241. doi: 10.1093/schbul/sbt070

O'Reardon, J. P., Ringel, B. L., Dinges, D. F., Allison, K. C., Rogers, N. L., Martino, N. S., \& Stunkard, A. J. (2004). Circadian eating and sleeping patterns in the night eating syndrome. Obes.Res., 12(11), 17891796. doi: 12/11/1789 [pii]; 10.1038/oby.2004.222 [doi]

Padmavati, R., McCreadie, R. G., \& Tirupati, S. (2010). Low prevalence of obesity and metabolic syndrome in never-treated chronic schizophrenia. Schizophr Res, 121(1-3), 199-202. doi: 10.1016/j.schres.2010.05.010

Palmese, L. B., Ratliff, J. C., Reutenauer, E. L., Tonizzo, K. M.,
Grilo, C. M., \& Tek, C. (2012). Prevalence of night eating in obese individuals with schizophrenia and schizoaffective disorder. Compr.Psychiatry. doi: S0010440X(12)00143-5

[pii];10.1016/j.comppsych.2012.07.0 14 [doi]

Park, Y., Hernandez-Diaz, S., Bateman, B. T., Cohen, J. M., Desai, R. J., Patorno, E., . . Huybrechts, K. F. (2018). Continuation of Atypical Antipsychotic Medication During Early Pregnancy and the Risk of Gestational Diabetes. $A m \quad J$ Psychiatry, 175(6), 564-574. doi: 10.1176/appi.ajp.2018.17040393

Perry, B. I., McIntosh, G., Weich, S., Singh, S., \& Rees, K. (2016). The association between first-episode psychosis and abnormal glycaemic control: systematic review and metaanalysis. Lancet Psychiatry, 3(11), 1049-1058. doi: 10.1016/S22150366(16)30262-0

Pillinger, T., Beck, K., Gobjila, C., Donocik, J. G., Jauhar, S., \& Howes, O. D. (2017). Impaired glucose homeostasis in first-episode schizophrenia: A systematic review and meta-analysis. JAMA Psychiatry. doi: 10.1001/jamapsychiatry.2016.3803

Ratliff, J. C., Palmese, L. B., Reutenauer, E. L., Liskov, E., Grilo, C. M., \& Tek, C. (2012). The effect of dietary and physical activity pattern on metabolic profile in individuals with schizophrenia: a cross-sectional study. Compr Psychiatry, 53(7), 
1028-1033.

doi: 10.1016/j.comppsych.2012.02.003

Ratliff, J. C., Palmese, L. B., Reutenauer, E. L., \& Tek, C. (2013). An open-label pilot trial of alphalipoic acid for weight loss in patients with schizophrenia without diabetes. Clin Schizophr Relat Psychoses, 113. doi: $10.3371 /$ csrp.rapa.030113

Reis, M., \& Kallen, B. (2008). Maternal use of antipsychotics in early pregnancy and delivery outcome. J Clin Psychopharmacol, 28(3), 279-288. doi: 10.1097/JCP.0b013e318172b8d5

Ryan, M. C., Collins, P., \& Thakore, J. H. (2003). Impaired fasting glucose tolerance in first-episode, drug-naive patients with schizophrenia. Am J Psychiatry, 160(2), 284-289. doi: 10.1176/appi.ajp.160.2.284

Sanders, L. L. O., de Souza Menezes, C. E., Chaves Filho, A. J. M., de Almeida Viana, G., Fechine, F. V., Rodrigues de Queiroz, M. G., . . Freitas de Lucena, D. (2017). alpha-Lipoic Acid as Adjunctive Treatment for Schizophrenia: An Open-Label Trial. J Clin Psychopharmacol, 37(6), 697-701. doi: $10.1097 / \mathrm{jcp} .0000000000000800$

Schulz, S. C., \& Murray, A. (2016). Assessing cognitive impairment in patients with schizophrenia. J Clin Psychiatry, 77 Suppl 2, 3-7. doi: 10.4088/JCP.14074su1c.01

Sharp, H. C., \& Baganz, C. N. (1940). A study of the problem of malnutrition in institutionalized psychotic patients. American Journal of Psychiatry, 97(3), 650-658. doi: DOI 10.1176/ajp.97.3.650

Spelman, L. M., Walsh, P. I., Sharifi, N., Collins, P., \& Thakore, J. H. (2007). Impaired glucose tolerance in first-episode drug-naive patients with schizophrenia. Diabet Med, 24(5), 481-485. doi: 10.1111/j.14645491.2007.02092.x

Tek, C., Ratliff, J., Reutenauer, E., Ganguli, R., \& O'Malley, S. S. (2014). A randomized, double-blind, placebo-controlled pilot study of naltrexone to counteract antipsychotic-associated weight gain: proof of concept. J Clin Psychopharmacol, 34(5), 608-612. doi:

10.1097/JCP.0000000000000192

Tomasik, J., Lago, S. G., VazquezBourgon, J., Papiol, S., SuarezPinilla, P., Crespo-Facorro, B., \& Bahn, S. (2019). Association of Insulin Resistance With Schizophrenia Polygenic Risk Score and Response to Antipsychotic Treatment. JAMA Psychiatry. doi: 10.1001/jamapsychiatry.2019.0304

Vancampfort, D., Correll, C. U., Galling, B., Probst, M., De Hert, M., Ward, P. B., . . Stubbs, B. (2016). Diabetes mellitus in people with schizophrenia, bipolar disorder and major depressive disorder: a systematic review and large scale meta-analysis. World Psychiatry, 15(2), 166-174. doi: 10.1002/wps.20309 


\section{Chapter 8. Discussion}

Vreeker, A., van Bergen, A. H., \& Kahn, R. S. (2015). Cognitive enhancing agents in schizophrenia and bipolar disorder. Eur Neuropsychopharmacol, 25(7), 9691002. 10.1016/j.euroneuro.2015.04.014 doi:

Walker, E. R., McGee, R. E., \& Druss, B. G. (2015). Mortality in mental disorders and global disease burden implications: a systematic review and meta-analysis. JAMA Psychiatry, 72(4), 334-341. doi: 10.1001/jamapsychiatry.2014.2502

Whitworth, A. B. (2017). Psychopharmacological treatment of schizophrenia during pregnancy and lactation. Current Opinion in
Psychiatry, 30(3), 184-190. doi: 10.1097/yco.0000000000000329

Woods, S. W., Breier, A., Zipursky, R. B., Perkins, D. O., Addington, J., Miller, T. J., . . McGlashan, T. H. (2003). Randomized trial of olanzapine versus placebo in the symptomatic acute treatment of the schizophrenic prodrome. Biol Psychiatry, 54(4), 453-464.

Yoshida, J., Eguchi, E., Nagaoka, K., Ito, T., \& Ogino, K. (2018). Association of night eating habits with metabolic syndrome and its components: a longitudinal study. BMC Public Health, 18(1), 1366. doi: 10.1186/s12889-018-6262-3 


\section{SUMMARY}




\section{Summary}

People with SMI die earlier than the general population, mostly related to the premature cardiovascular disease (CVD). Contributors of the increased CVD rate in SMI is usually related to antipsychotic medication side effects, innate metabolic factors and lifestyle factors. The general aim of this thesis is to examine the factors that lead to the increased obesity rates and cardio-metabolic risk in people with SMI.

Chapter 2 sought to explore the differences of glucose metabolism outcomes between first episode psychosis and mood disorders through a systematic review and meta-analysis. In total 31 eligible studies were identified in this meta-analysis. Compared to the healthy control outcomes, insulin and insulin resistance levels were found higher in patients with first episode psychosis. Additionally, glucose tolerance test levels were found to be higher in patients with first episode psychosis and mood disorders. No significant difference was found in glucose metabolism outcomes between SMI groups. Findings presented in Chapter 2 suggest both patients with first episode psychosis and mood disorders are high risk groups for diabetes development and a subsequent increase in the risk of diabetes-related complications such as cardiovascular diseases and cognitive deterioration later in life.

In Chapter 3, individual effects of antipsychotic medications on body weight was examined in patients with first episode psychosis through a meta-analysis. This meta-analysis revealed that almost all antipsychotic medications were associated with body weight gain. Average body weight gain with antipsychotic medications was $3.2 \mathrm{~kg}$ in the short-term (<12 weeks) and $5.3 \mathrm{~kg}$ in the long-term (>12 weeks). Specifically, olanzapine and clozapine caused the greatest weight gain compared to placebo. Clinically significant weight gain risk was increased about two-fold with antipsychotic use. Weight gain was also associated with the duration of antipsychotic mediation use. These findings demonstrate the early and continuing effects of various antipsychotic medications on body weight gain. 


\section{Summary}

Chapter 4 provided outcomes from alpha-lipoic acid meta-analysis. Results of this meta-analysis revealed a significant reduction of body weight $(-1.2 \mathrm{~kg})$ and body mass index (-0.4) with alpha-lipoic acid compared to placebo treatment. Meta-regression analyses showed that shorter duration of alpha-lipoic acid treatment achieved greater body mass reduction than longer duration treatments. Incidences of side effects and all-cause discontinuation were similar between alpha-lipoic acid and placebo.

Chapter 5 examined the risk of gestational diabetes associated with antipsychotic exposure during pregnancy. Compared to healthy controls, both unadjusted (risk ratio $=1.63$ ) and adjusted cumulative risk ratio (1.30) for GDM were found to be significantly higher in antipsychoticexposed pregnant women. The adjusted RR for GDM was similar between the antipsychotic-exposed group and the antipsychotic-ceased group. No significant association was found between study quality, smoking, alcohol use, gestational age and cumulative GDM risk. Findings in Chapter 5 suggest that antipsychotic exposure may lead to the development of gestational diabetes in pregnancy.

Chapter 6 focused on a disordered eating pattern, the Night Eating Syndrome, in patients with major depression. In this crosssectional study, the prevalence of Night Eating Syndrome in depressed patients was $21.3 \%$. Additionally, findings in this chapter showed that patients with Night Eating Syndrome had higher body mass index levels, depression, anxiety levels and poorer sleep qualities compared to those without Night Eating Syndrome. These findings indicate a complex relation between Night Eating Syndrome and depression.

Chapter $\mathbf{7}$ tested the effectiveness of add-on curcumin treatment on cognitive functioning and inflammatory markers in patients with schizophrenia. In this randomized, double-blind, placebo-controlled study, we found that add-on curcumin improved working memory in patients 


\section{Summary}

with schizophrenia. Add-on curcumin also reduced IL-6 levels after 8-weeks of treatment. These findings suggest that anti-oxidant and anti-inflammatory properties of curcumin may have beneficial effects on cognitive functioning and decrease inflammatory response in patients with schizophrenia.

In general, findings represented in this thesis underline the importance of early identification of major risk factors for CVDs, and also initiating early strategies to prevent cardiovascular related morbidity and mortality, in people with SMI. 
$\underline{\text { Impact }}$

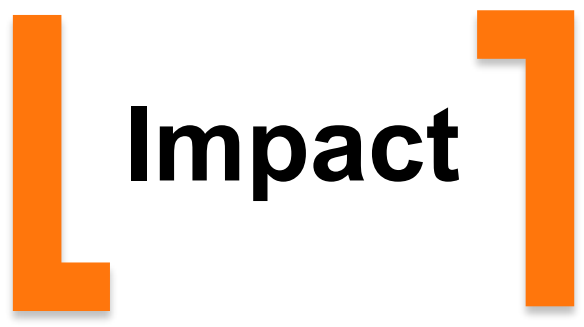


The target audience of this thesis is people with serious mental illnesses (SMI), namely schizophrenia and related disorders, bipolar disorder and depressive disorders, and their healthcare givers. The societal relevance of this thesis is to exploring the factors that leads increased cardiovascular disorder related morbidity and mortality rates in people with SMI. The outcomes of this thesis add knowledge to how people with SMI become a vulnerable population to the various medical problems, and how these problems can be prevented or improved.

Several findings of this thesis show new insights of the interaction between having an SMI and metabolic problems, which can lead innovative healthcare procedures in people with SMI. Specifically, this thesis lay out: 1. The genetic disadvantage of developing glucose metabolism abnormalities in first episode patients with SMI, 2. Specific body weight change estimations of individual antipsychotics in first episode patients with SMI by considering of natural growth in youth individuals, 3. Increased risk of gestational diabetes with antipsychotic exposure in pregnancy, and 4. Impaired psychological and physical outcomes with a disordered eating pattern in major depression. An additional meta-analytic study of body weight loss effects of Alpha-Lipoic Acid (ALA) showed that ALA may help patients with SMI to lose body weight. Finally, this thesis also showed the effectiveness of curcumin, a derivative of turmeric root, on inflammation and cognition in people with SMI.

Overall, these findings provide valuable information to help improving general health in people with SMI. The lifespan of people with SMI is shorter than to the general population. The major contributor of the shortened life span in this population is physical illnesses, particularly obesity, diabetes and cardiovascular disorders. The risk of both diseases is not just only increased, mortality rates are also higher than expected based on their incidence alone in this population. In people with SMI, the poorer physical outcomes are associated with various factors contribute to, including life style factors, genetic factors and antipsychotic medication adverse effects. Understanding 


\section{$\underline{\text { Impact }}$}

the effects of these factors in people with SMI is essential to provide better health care, and consequently improve outcomes in this vulnerable population. 


\section{Acknowledgement}

\section{Acknowledgement}

I would like to express my deep and sincere gratitude to my supervisor Prof. Dr. Bart F. Rutten for giving me the opportunity to work with him and providing invaluable guidance throughout my thesis.

My appreciation also extends to my co-supervisor Asst.Prof. Sinan Gülöksüz. Since our residency years you have always been a good friend, a colleague and a teacher. I am grateful for your conscientious guidance and encouragement to accomplish my thesis.

I would also like to thank the reading committee, Prof. Dr. D.E.J Linden (Chair), Prof. Dr. T.A.M.J. van Amelsvoort, Dr. M. Bak, Prof. Dr. J.J. van Os, Prof. Dr. L. de Haan, for sharing their valuable contributions and comments on the thesis.

I am ineffably grateful to my post-doc supervisor and my mentor Dr. Cenk Tek for his valuable guidance and support for completion of research in my thesis. Without his guidance, I would not be able to carry out most of my work.

I also acknowledge with a deep sense of reverence, my gratitude towards

my family, my wife Ceren and my friends, who has always supported me morally.

Last but not least, I would like to thank all my patients and their families who directly or indirectly helped me to carry out most research in my thesis. 


\section{Curriculum Vitae}

\section{Curriculum Vitae}

Suat Kucukgoncu was born on April 1st in Kayseri, Turkey. He graduated from Istanbul University Istanbul Faculty of Medicine and received his medical doctor degree in 2005. He completed his Psychiatry residency between 2006-2011 at Istanbul Bakırköy Research and Training Hospital for Psychiatry, Neurology and Neurosurgery. After residency training, he worked as a psychiatrist in Erzurum, Turkey. Between 2013 and 2019, he had his post-doctoral training with Dr. Cenk Tek at Yale University Department of Psychiatry. Since August 2019, Dr. Kucukgoncu is working as associate professor of psychiatry at Maltepe University School of Medicine, Department of Psychiatry. 


\section{List of Publications}

- Pollard JM, Ferrara M, Lin I, Kucukgoncu S, Wasser T, Li F, Srihari VH. Analysis of Early Intervention Services on adult Judicial Outcomes. JAMA Psychiatry. 2020; 77:871-872, doi:10.1001/ jamapsychiatry.2020.0448.

- Kucukgoncu S, Guloksuz S, Celik K, Bahtiyar MO, Luykx JJ, Rutten PF, Tek C. Antipsychotic Exposure in Pregnancy and the Risk of Gestational Diabetes: A Systematic Review and Meta-analysis. Schizophrenia Bulletin. 2020; 46:311-318, doi: 10.1093/schbul/sbz058.

- Kucukgoncu S, Guloksuz S, Tek C. Effects of Curcumin on Cognitive Functioning and Inflammatory State in Schizophrenia: A Double-Blind, Placebo-Controlled Pilot Trial. Journal of Clinical Psychopharmacology. 2019; 39:182-184.

- Budak EA, Kucukgoncu S, Bestepe E. Theory of mind abilities and its relationship with clinical features in euthymic bipolar patients. Cukurova Medical Journal. 2019; 44:176-182.

- Kucukgoncu S, Kosir U, Zhou E, Sullivan E, Srihari V, Tek C. Glucose metabolism dysregulation at the onset of mental illness is not limited to first episode psychosis: A systematic review and metaanalysis. Early Intervention in Psychiatry. 2018

- Murphy SM, Kucukgoncu S, Bao Y, Li F, Tek C, Breitborde NJK, et al. An Economic Evaluation of Coordinated Specialty Care (CSC) Services for First-Episode Psychosis in the US Public Sector. The Journal of Mental Health Policy and Economics. 2018: 21;123-130.

- Uygun E, Koseoglu A, Kucukgoncu S, Erkoc SN. Psychological Resilience and Related Factors in the Euthymic Bipolar Patients. Journal of Cognitive-Behavioral Psychotheraphy and Research. 2018; 7:120-126. 
- Karas H, Yildirim EA, Kucukgoncu S, Yakut U. The relationship of childhood trauma, dissociative experiences and depression with pain in female patients with fibromyalgia: a cross-sectional study. Dusunen Adam The Journal of Psychiatry and Neurological Sciences. 2017; 30:86-94.

- Zhou EK, Kosir U, Kucukgoncu S, Sullivan-Reutanuer EL, Tek C. How accurate are self-reported height and weight in the seriously mentally ill?Psychiatry Research. 2017; 257: 51-55.

- Kucukgoncu S, Zhou EK, Lucas KB, Tek C. Alpha-lipoic acid (ALA) as a supplementation for weight loss: Results from a meta-analysis of randomized controlled trials. Obesity Reviews. 2017; 18(5): 594-601

- Tek C, Kucukgoncu S, Guloksuz S, Woods S, Srihari V, Annamalai A. Antipsychotic Induced Weight Gain in First Episode Psychosis Patients: A Meta-Analysis of Differential Effects of Antipsychotic Medications. Early Intervention in Psychiatry. 2016; 10(3):193-202.

- Srihari V, Tek C, Kucukgoncu S, Phutane V, Pollard J, Woods S. FirstEpisode Service for Psychotic Disorders in the U.S. Public Sector: A Pragmatic Randomized Controlled Trial. Psychiatric Services. 2015;66 (7):705-712.

- Temiz M, Bestepe E, Yildiz O, Kucukgoncu S, Yazici A, Calikusu C, Erkoc $S$. The effect of Domestic Violence on the diagnosis and the course of illness among psychiatric women inpatients. Archives of Neuropsychiatry 2014; 51 (3): $1-10$.

- Ornek F, Kucukgoncu S, Bestepe E. The Relationship Between the Experience Of Abuse And Neglect In Childhood And Suicide Attempts In An Adult Unipolar Depression Sample. Archives of Neuropsychiatry 2014; 51 (2): 133-141. 
- Kucukgoncu S, Yildirim Ornek F, Cabalar M, Bestepe M, Yayla V. Childhood trauma and dissociation in tertiary care patients with migraine and tension type headache: A controlled study. Journal of Psychosomatic Research 2014; 77 (1): 40-44.

- Kucukgoncu S, Tek C, Bestepe E, Musket C, Guloksuz S. Clinical Features of Night Eating Syndrome among Depressed Patients. European Eating Disorders Review 2014; 22 (2): 102-108.

- Srihari VH, Tek C, Pollard J, Zimmet S, Keat J, Cahill JD, Kucukgoncu S, Walsh BC, Li F, Gueorguieva R, Levine N, Mesholam-Gately RI, Friedman-Yakoobian M, Seidman LJ, Keshavan MS, McGlashan TH, Woods SW. Reducing the duration of untreated psychosis and its impact in the U.S.: the STEP-ED study. BMC Psychiatry 2014; 14(1):335.

- Kucukgoncu S, Bestepe E. Night Eating Syndrome among Depression and Anxiety Disorders. Achieves of Neuropsychiatry 2014; 51 (4): 368-375.

- Calikusu C, Kucukgoncu S, Bestepe E. Skin Picking in Turkish Students. Prevalence, Characteristics, and Gender Differences. Behavior Modification 2012; 36 (1): 49-66.

- Ipekcioglu D, Cetinkaya O, Kucukparlak I, Guveli H, Bozgeyik G, Kucukgoncu S, Karamustafalioglu N, Yener F, Ilnem MC. The sociodemographic and clinical characteristics of the psychiatric emergency patients with 60 years or older. Anatolian Journal of Psychiatry 2012; 13 (1): 24-31.

- Calikusu C, Kucukgoncu S, Bestepe E. Does Antidepressant Use Increase Risk of Restless Legs Syndrome? Archives of Neuropsychiatry 2012; 49 (3): 212-217.

- Bestepe E, Cabalar M, Kucukgoncu S, Calikusu C, Ornek F, Yayla V, Erkoc $S$. Sexual dysfunction in women with migraine versus tensiontype headaches: a comparative study. International Journal of Impotence Research 2011; 23 (3):

$122-127$. 
- Kucukgoncu S, Aktar E, Erginbas E, Bestepe E, Calikusu C, Algin F, Erkoc S. Relationship between dissociative experiences, abnormal sleep experiences, and sleep quality in undergraduate students. Dusunen Adam: The Journal of Psychiatry and Neurological Sciences 2010; 23 (2): 77-84.

- Doğan S, Öncü B, Saraçoğlu GV, Kucukgoncu S. Validity and reliability of the Turkish version of the Adult ADHD Self-Report Scale (ASRS-v1.1). Anatolian Journal of Psychiatry 2009; 10 (2): 77-87.

- Doğan S, Saraçoğlu GV, Kucukgoncu S. A study on standardization of the Turkish version if the Snell-Papini Sexuality Scale. Bulletin of Clinical Psychopharmacology 2009; 19(Suppl. 1): 188-191.

- Doğan S, Öncü B, Saraçoğlu GV, Kucukgoncu S. Prevalence of ADHD Symptoms in University Students and Developmental, Academic and Psychological Factors Related to Symptom Level. Journal of Psychiatry and Related Disciplines 2008; 10 (3): 109-115.

\section{Editorials, Reviews, Book Chapters}

- Kucukgoncu S, Midura M, Tek C. Optimal Management of Night Eating Syndrome: Challenges and Solutions. Neuropsychiatric Disease and Treatment. 2015; 11:751-60.

- Şar V, Öztürk E, Islam S, Küçükgöncü S, Yumbul Ç, Ertem-Vehid H. Zwischen Selbstreflexion und Selbst-Überszeugtsein: Kognitive Einsicht bei dissoziativen und schizophrenen Störungen und das Dissoziationsparadox. Zeit heilt nicht alle Wunden: Kompendium zur Psychotraumatologie. Editors: Özkan, I., Sachsse, U., Streeck-Fischer, A. Göttingen: Vandenhoeck Ruprecht, 2012, 161-172. 
- Dogan S, Kucukgoncu S. Alcohol and Alcohol Dependence: Sexuality, Sleep, Eating Disorders. Turkiye Klinikleri Journal of Psychiatry 2010; 3 (3): 95-99

- Dogan S, Kucukgoncu S. Sexuality Research: From Past to Present. Archives of Neuropsychiatry 2009; $46 \quad$ (3): 102-109.

\section{Case Reports \& Technical Notes}

- Sezgin E, Evren C, Cınar OG, Kucukgoncu S, Bayram MK. Two cases with antiepileptic barbexoclone (maliasin $®$ ) addiction. Dusunen Adam: The Journal of Psychiatry and Neurological Sciences 2010; 23 (2): 128-132.

- Kucukgoncu S, Bestepe E, Calikusu C, Takmaz O, Tunc S, Erkoc S. Clozapine and ECT treatment for pregnant woman with schizophrenia: $A$ case report. Bulletin of Clinical Psychopharmacology 2009; 19 (Suppl. 1): $173-175$. 
